University of Nebraska - Lincoln

DigitalCommons@University of Nebraska - Lincoln

\title{
Review of soil salinity assessment for agriculture across multiple scales using proximal and/or remote sensors
}

Dennis Corwin

USDA Salinity Laboratory, dennis.corwin@ars.usda.gov

\section{E. Scudiero}

USDA Salinity Laboratory \& University of California, Riverside

Follow this and additional works at: https://digitalcommons.unl.edu/usdaarsfacpub

Corwin, Dennis and Scudiero, E., "Review of soil salinity assessment for agriculture across multiple scales using proximal and/or remote sensors" (2019). Publications from USDA-ARS / UNL Faculty. 2148. https://digitalcommons.unl.edu/usdaarsfacpub/2148

This Article is brought to you for free and open access by the U.S. Department of Agriculture: Agricultural Research Service, Lincoln, Nebraska at DigitalCommons@University of Nebraska - Lincoln. It has been accepted for inclusion in Publications from USDA-ARS / UNL Faculty by an authorized administrator of DigitalCommons@University of Nebraska - Lincoln. 


\title{
Review of soil salinity assessment for agriculture across multiple scales using proximal and/or remote sensors
}

\author{
D.L. Corwin ${ }^{a}, *$ E. Scudiero ${ }^{a, b}$
}

${ }^{a}$ USDA-ARS, U.S. Salinity Laboratory, Riverside, CA, United States

${ }^{b}$ Department of Environmental Sciences, University of California, Riverside, CA, United States

*Corresponding author: e-mail address: dennis.corwin@ars.usda.gov

\section{Contents}

1. Introduction

1.1 Background in salinity: Definition, salinization processes, categories of saltaffected soils, and impacts

1.2 Global extent of the salinity problem

$\begin{array}{ll}1.3 \text { Brief background in laboratory measurement of soil salinity } & 11\end{array}$

1.4 Electrical resistivity

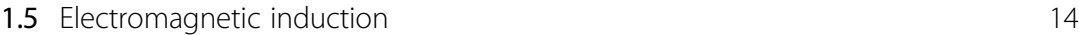

1.6 Time domain reflectometry 15

2. Geospatial apparent soil electrical conductivity $\left(E_{a}\right)$ measurements 16

$\begin{array}{ll}2.1 \text { Basis for field-scale mapping of salinity with } \mathrm{EC}_{a} & 17\end{array}$

3. Historical perspective of soil salinity assessment

4. Previous reviews of the measurement of soil salinity with proximal and/or remote sensors

5. Milestones of salinity assessment research with proximal and remote sensors

5.1 Understanding the soil properties influencing apparent soil electrical conductivity $\left(\mathrm{EC}_{\mathrm{a}}\right)$

5.2 Development of mobile electromagnetic induction and electrical resistivity equipment for field-scale use

5.3 Statistical sampling approaches from geospatial sensor data

5.4 Multi-scale salinity assessment approaches

5.5 Inverse modeling

$\begin{array}{ll}5.6 \text { Spectral indices of soil salinity from remote sensing } 61 & 63\end{array}$

5.7 Data fusion of multiple sensors 63

5.8 Applications of multi-scale soil salinity assessment 66

6. Knowledge gaps and trends in salinity assessment research 77

Acknowledgments $\quad 82$

References $\quad 82$

$\begin{array}{lr}\text { Further reading } & 130\end{array}$ 


\section{Abstract}

Mapping and monitoring soil spatial variability is particularly problematic for temporally and spatially dynamic properties such as soil salinity. The tools necessary to address this classic problem only reached maturity within the past 2 decades to enable field- to regional-scale salinity assessment of the root zone, including GPS, GIS, geophysical techniques involving proximal and remote sensors, and a greater understanding of apparent soil electrical conductivity $\left(\mathrm{EC}_{\mathrm{a}}\right)$ and multi- and hyperspectral imagery. The concurrent development and application of these tools have made it possible to map soil salinity across multiple scales, which back in the 1980s was prohibitively expensive and impractical even at field scale. The combination of $\mathrm{EC}_{\mathrm{a}}$-directed soil sampling and remote imagery has played a key role in mapping and monitoring soil salinity at large spatial extents with accuracy sufficient for applications ranging from field-scale site-specific management to statewide water allocation management to control salinity within irrigation districts. The objective of this paper is: (i) to present a review of the geophysical and remote imagery techniques used to assess soil salinity variability within the root zone from field to regional scales; (ii) to elucidate gaps in our knowledge and understanding of mapping soil salinity; and (iii) to synthesize existing knowledge to give new insight into the direction soil salinity mapping is heading to benefit policy makers, land resource managers, producers, agriculture consultants, extension specialists, and resource conservation field staff. The review covers the need and justification for mapping and monitoring salinity, basic concepts of soil salinity and its measurement, past geophysical and remote imagery research critical to salinity assessment, current approaches for mapping salinity at different scales, milestones in multi-scale salinity assessment, and future direction of field- to regional-scale salinity assessment.

\section{Highlights}

- A review of multi-scale soil salinity assessment using proximal and remote sensors is presented.

- Geophysical and remote sensing approaches to map salinity across multiple scales are discussed.

- Milestones in multi-scale salinity assessment are outlined.

- Future direction and knowledge gaps of field- to regional-scale salinity assessment are pointed out.

\section{Abbreviations}

ANOCOVA analysis of covariance

CCR

$\mathrm{EC}_{\mathrm{a}}$

common coefficient regression

$\mathrm{EC}_{\mathrm{e}}$

apparent soil electrical conductivity $\left(\mathrm{dS} \mathrm{m}^{-1}\right)$

$\mathrm{EC}_{\mathbf{e}}$ electrical conductivity of the saturation extract $\left(\mathrm{dS} \mathrm{m}^{-1}\right)$

$\mathrm{EC}_{\mathrm{a}}$ measured with electromagnetic induction in the horizontal coil configuration $\left(\mathrm{dS} \mathrm{m}^{-1}\right)$ 
$\mathbf{E M}_{\mathbf{v}}$ $\mathrm{EC}_{\mathrm{a}}$ measured with electromagnetic induction in the vertical coil configuration $\left(\mathrm{dS} \mathrm{m}^{-1}\right)$

EMI electromagnetic induction

FSR field specific regression

MSE mean square error

MSPE mean square prediction error

\section{Introduction}

Soils are notoriously heterogeneous, which is a well-documented fact since the classic paper by Nielsen et al. (1973) regarding the spatial variability of soil water properties measured within a field. The variability of soil is due to the interaction of pedogenic (i.e., soil parent material), edaphic (i.e., soil permeability, water table depth, salinity of perched groundwater, topography, and geohydrology), meteorological (i.e., amount and distribution of rainfall, temperature, relative humidity, and wind), biological (i.e., vegetation), and anthropogenic (i.e., irrigation, drainage, tillage, and cropping practices) factors (Rhoades et al., 1999a; Samake et al., 2005; Wei et al., 2008; Yemefack et al., 2005). Characterizing soil spatial variability is without question one of the most significant areas of soil research because of its broad reaching influence on field- to landscape-scale processes related to agriculture and the environment, including solute transport, within-field variation in crop yield, and soil salinity distribution, just to mention a few. No practical environmental or agricultural application involving soil at field scale or larger spatial extents can ignore spatial variability because soil is spatially variable in its physical and chemical makeup.

Soil salinity is a worldwide concern in arid and semi-arid agricultural areas. Salt-affected soils are estimated to comprise $23 \%$ of the cultivated land, approximately $3.5 \times 10^{8}$ ha (Massoud, 1981). In actuality, there are no directly measured global inventories of soil salinity. All known global inventories of soil salinity and with only a few exceptions all known regional-scale inventories are gross approximations based on qualitative and not quantitative data (Lobell, 2010; Lobell et al., 2010).

Soil salinity is a property that is particularly challenging to assess in the field because it is a dynamic property that is highly variable in space and time. The ability to map and monitor soil salinity from field to regional scale in near real time (i.e., hours or days rather than weeks or months) meets a 
fundamental soil information need of researchers, producers, agriculture consultants, farm advisors, soil and crop scientists, natural resource conservationists and managers, irrigation specialists, cooperative extension specialists, and land and water policy makers at a time in modern history when altered weather patterns are impacting agricultural lands and the environment to an unprecedented extent. Arid-zone agricultural areas, such as the west side of California's San Joaquin Valley, are experiencing salt accumulation in the root zone due to extreme drought conditions (Corwin and Scudiero, 2017). In addition, the scarcity of water is causing a shift from flood and sprinkler irrigation to micro irrigation (e.g., drip, buried drip, and micro-sprinkler irrigation), which significantly increases the spatial and temporal complexity of field-scale salinity distribution in the root zone, making the long-term management of salinity a greater challenge.

The need for field-scale mapping and monitoring of salinity in the root zone has never been greater due to limited water resources and complex spatial distributions of salinity that necessitate site-specific management using near real-time maps of salinity distributions. Concomitantly, maps of root-zone salinity are in demand at regional, state, national, and global levels. Spatial knowledge of root-zone soil salinity is needed at multiple scales for site-specific management of salinity at farm levels to optimize scarce water resources, for the development of water use and regulatory guidelines at state and national levels, and for assessing trends of climate change impact at state, national, and global levels.

It is the objective of this review to provide an overview of soil salinity assessment through a discussion of (i) a brief background of salinity including its definition, salinization processes, categories of salt-affected soils, and impacts, (ii) global extent of the salinity problem, (iii) brief background in laboratory measurement of soil salinity, (iv) geospatial apparent soil electrical conductivity $\left(\mathrm{EC}_{\mathrm{a}}\right)$ measurements for field-scale mapping of salinity, (v) historical perspective of soil salinity assessment, (vi) previous reviews of the measurement of soil properties with proximal and remote (i.e., airborne or satellite) sensors, (vii) milestones of salinity assessment research with proximal and remote sensors, and (viii) knowledge gaps and trends in salinity assessment research. This review distinguishes itself from previous reviews of proximal and/or remote sensors used to measure soil properties by focusing solely on soil salinity and on the pivotal research that has brought the scientific community to its current level of understanding of assessing soil salinity across multiple scales. 


\subsection{Background in salinity: Definition, salinization processes, categories of salt-affected soils, and impacts}

Soil salinity refers to the total salt concentration in the soil solution (i.e., aqueous liquid phase of the soil and its solutes) consisting of soluble and readily dissolvable salts including charged species (e.g., $\mathrm{Na}^{+}, \mathrm{K}^{+}, \mathrm{Mg}^{+2}, \mathrm{Ca}^{+2}$, $\mathrm{Cl}^{-}, \mathrm{HCO}_{3}{ }^{-}, \mathrm{NO}_{3}{ }^{-}, \mathrm{SO}_{4}{ }^{-2}$ and $\mathrm{CO}_{3}{ }^{-2}$ ), non-ionic solutes, and ions that combine to form ion pairs (Corwin, 2003). The origin of salts in soil can be natural or anthropogenic, where the former refers to primary salinization and the latter, secondary salinization. The primary source of salts in soil and water is the geochemical weathering of rocks from the Earth's upper strata, with atmospheric deposition, seawater intrusion, rising ground waters in low-lying topography from saline aquifers serving as other natural sources, and anthropogenic activities serving as secondary sources. Anthropogenic sources include salts present in irrigation waters, residual salts from amendments added to soil and water, animal wastes, chemical fertilizers, and applied sewage sludge and effluents (Tanji, 2002). The predominant mechanism causing the accumulation of salt in the root zone of agricultural soils is loss of water through evapotranspiration (i.e., combined processes of evaporation from the soil surface and plant transpiration), which selectively removes water, leaving salts behind. Salinization commonly occurs on arid and semi-arid zone soils where irrigation and/or rainfall are insufficient to leach salts, where poor drainage and/or shallow water tables exist, where there is an upslope recharge and downslope discharge, and where saline sub-soils formed naturally from marine deposits.

The accumulation of soil salinity is a consequence of a variety of processes. Fig. 1 illustrates some of these processes. In arid and semi-arid areas, for example, where precipitation is less than evaporation, salts can accumulate at the soil surface when the depth to the water table is $<1-1.5 \mathrm{~m}$ depending on the soil texture. The accumulation of salts at the soil surface is the consequence of the upward flow of water and subsequent transport of salts due to capillary rise driven by the evaporative process. However, the most common cause for the accumulation of salts is evapotranspiration (ET) by plants, which results in an increase in salt concentration with depth through the root zone (see graph in Fig. 1) and the accumulation of salts below the root zone. The level of salt accumulation within and below the root zone due to ET depends upon the fraction of irrigation and/or precipitation that flows beyond the root zone, referred to as the leaching fraction (LF). As the LF increases the total salts within the root zone decrease due to their removal from the root zone by leaching. A third process is the 


\section{What Causes Salt Accumulation?}

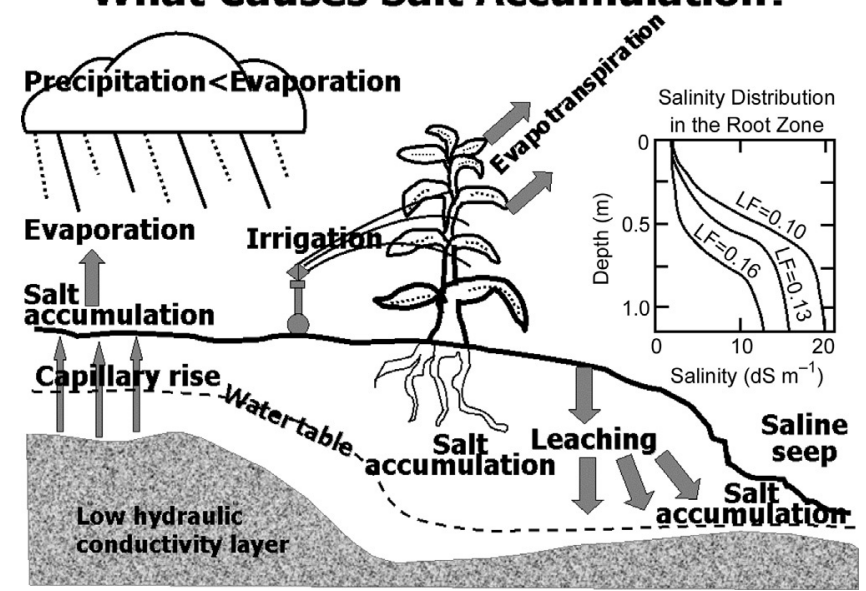

Fig. 1 Various examples of how salts accumulate in soil. Taken from Corwin, D.L., Lesch, S.M., Lobell, D.B., 2012. Chapter 10: Laboratory and field measurements. In: Wallender, W.W. and Tanji, K.K., (Eds.), Agricultural Salinity Assessment and Management, second ed., ASCE Manuals and Reports on Engineering Practice No. 71. ASCE, New York, NY, 295-341 with permission.

formation of saline seeps, which generally form from topographic variation. Saline seeps are common in the northern Great Plains of the United States. There are several forms of saline seeps differing in their means of development. In general, saline seeps form downslope of recharge areas in locations where discharge is occurring because of the presence of a low conductivity layer and shallow water table (Fig. 1). Salts leach from the upslope recharge area, which tends to be an area of higher conductivity than the downslope discharge area. Once the water and salts from upslope reach the downslope low conductivity layer, they accumulate and move to the surface by evaporation.

Soil salinity is a dynamic soil property particularly within the root zone. This is due to evaporation from the soil surface and actively transpiring plants that remove soil water through root-water extraction, which concentrate salts in the soil solution, and due to replenishment of soil water from rainfall, irrigation, or snowmelt, which dilute salts. Dissolved salts within the soil profile are mobile due to diffusion and convective-dispersive processes. Soil properties, including salinity development, are a consequence of the complex interaction of meteorological, topographic, anthropogenic, edaphic, pedogenic, and biological factors. These factors result in complex, 3-dimensional spatial patterns of salinity distribution within the root zone 
with a coefficient of variation generally over 60\% (Corwin et al., 2003a). This spatial complexity is clearly visible in the aerial images of precipitated salt patterns on the surfaces of fields shown in Fig. 2. In contrast to temporally stable soil properties such as texture or bulk density, the spatial variation of dynamic soil properties, such as salinity, is especially challenging to measure, map, and monitor due to their complex temporal and spatial nature. To assess (i.e., measure, map, and/or monitor) soil salinity from field to regional scale, reliable measurement techniques are required that can take numerous geo-referenced measurements rapidly and accurately. Geophysical techniques including proximal sensors such as electrical resistivity (ER), electromagnetic induction (EMI), and satellite sensors such as moderate resolution imaging spectroradiometer (MODIS) and Landsat 7 are those most commonly used to assess soil salinity from field to regional scale.

Traditionally, there are three types of salt-affected soils: saline, sodic, and saline-sodic. The U.S. Salinity Laboratory Staff (1954) classifies saline soils as those with an electrical conductivity of the saturated soil paste extract $\left(\mathrm{EC}_{\mathrm{e}}\right)$ of $>4 \mathrm{dSm}^{-1}$ and an exchangeable sodium percentage (ESP) of $<15 \%$. However, the salinity threshold above which deleterious effects occur to plants varies depending on the plant species, climate, soil fertility, physical condition of the soil, and soil-water regime (Maas, 1996). There is considerable uncertainty in yield-threshold salinity values because of the influence of these factors on the salinity threshold (Grieve et al., 2012). Handbook 60 (U.S. Salinity Laboratory Staff, 1954) defines various general categories of soil salinity: $0-2 \mathrm{dS} \mathrm{m}^{-1}$ (non-saline), $2-4 \mathrm{dS} \mathrm{m}^{-1}$ (slightly saline), $4-8 \mathrm{dS} \mathrm{m}^{-1}$ (moderately saline), $8-16 \mathrm{dS} \mathrm{m}^{-1}$ (strongly saline), and $>16 \mathrm{dS} \mathrm{m}^{-1}$ (extremely saline). Sodic soils have an ESP $>15$, an $\mathrm{EC}_{\mathrm{e}}<4 \mathrm{dSm}^{-1}$, and a lower limit of 13 for the saturation extract sodium adsorption ratio (SAR). Saline-sodic soils have an $\mathrm{EC}_{\mathrm{e}}>4 \mathrm{dS} \mathrm{m}^{-1}$ and an ESP $>15$.

The accumulation of salts in the root zone can have a variety of agricultural impacts. Soil salinity can reduce plant growth, reduce yields, and in severe cases, cause crop failure. Salinity impacts plant yield for several reasons. Salinity limits plant water uptake by reducing the osmotic potential making it more difficult for the plant to extract water. Salinity may also cause specific-ion toxicity or upset the nutritional balance of plants. Extensive plant salt tolerance literature documents the influence of soil salinity on crop yield (Maas, 1996). In addition, the salt composition of the soil solution influences the composition of cations on the exchange complex of soil particles, which influences soil permeability and tilth. 

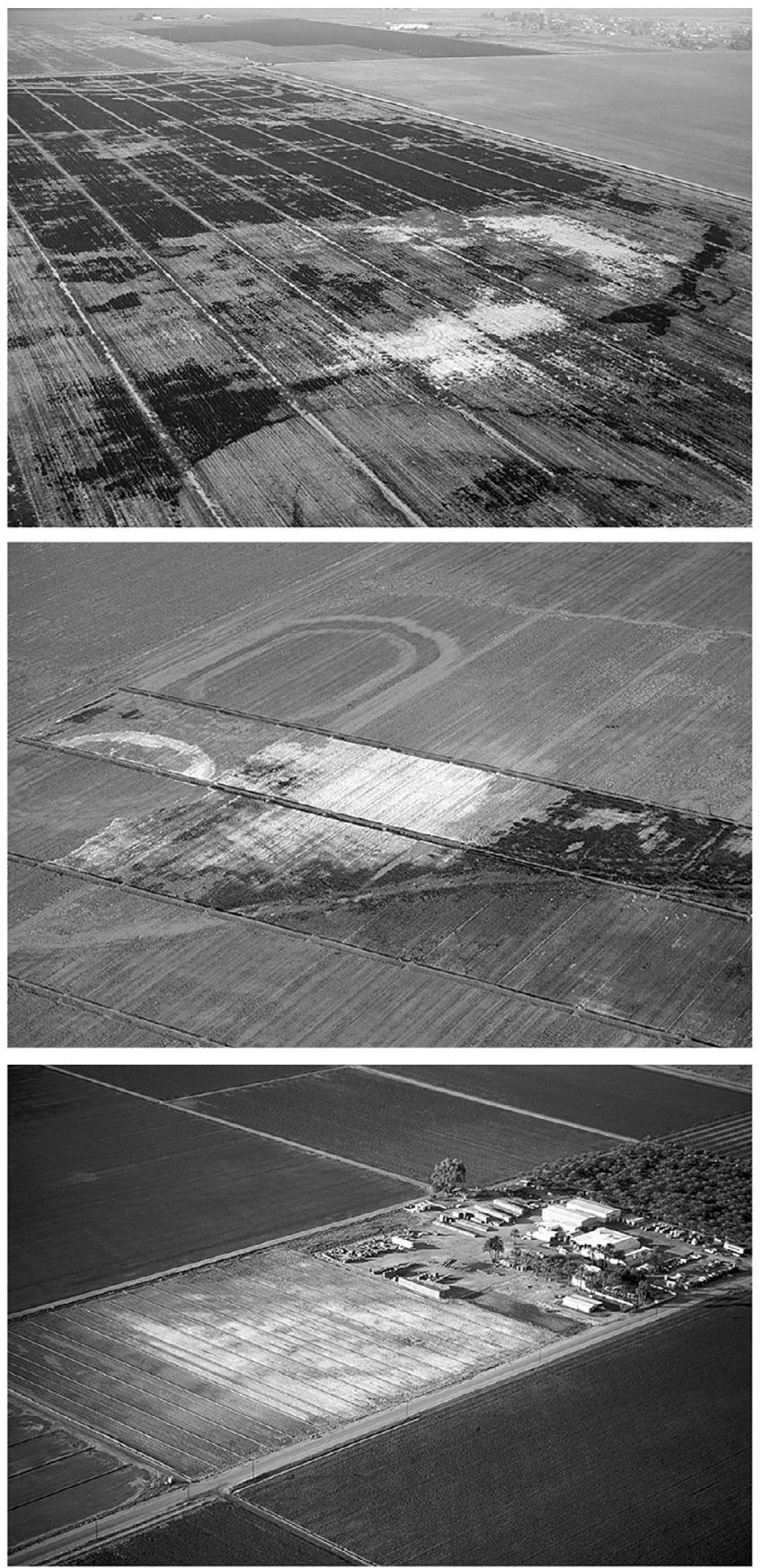

Fig. 2 Aerial views illustrating the complex spatial patterns of soil salinity distribution within various fields. 
Assessing and mapping soil salinity across multiple scales is an agronomic decision-making tool for managing salinity and water. From an agricultural perspective, two approaches customarily used to manage salinity are: (i) irrigation and drainage and/or (ii) selecting plants of sufficient salt tolerance. Field-scale maps of soil salinity assist producers and agriculture consultants in crop selection, salinity and irrigation management, soil quality and health assessment, reclamation, and assessing degraded water reuse impacts, while basin- to regional-scale maps of salinity provide resource managers and policy makers with a decision-making tool for water and land management. Field- to regional-scale maps of salinity are particularly crucial to producers and decision-makers in water scarce areas of the world that are agriculturally productive, such as California's San Joaquin Valley.

\subsection{Global extent of the salinity problem}

Secondary salinization dates back 6000 years to the degradation of agricultural lands in the Tigris-Euphrates Valleys of Mesopotamia by the Sumerians between 4000 and $2000 \mathrm{BC}$ due to irrigation practices. From a contemporary perspective, of the $13.2 \times 10^{9}$ ha of land surface on the Earth, only $1.5 \times 10^{9}$ ha is cultivated, $23 \%$ of the cultivated land is estimated to be saline and another $37 \%$ is sodic, which comprises about $10 \%$ of the total arable land (Massoud, 1981; Szabolcs, 1989). Squires and Glenn (2009) estimated the global extent of saline soils to be $412 \mathrm{Mha}$, which closely agrees with the FAO (http://www.fao.org/soils-portal/en/) estimate of 397 Mha. The estimate of Szabolcs (1989) is more conservative, at 352 Mha. Only $17 \%$ of the world's cropland is irrigated and yet irrigated agriculture accounts for $30 \%$ of the world's total agricultural production (Hillel, 2000). Worldwide, in the 1990s irrigated soils totaled about 227 million ha with 20-50\% regarded as salt affected (Flowers, 1999; Ghassemi et al., 1995; Rhoades and Loveday, 1990; Szabolcs, 1989, 1992). In 2012 irrigated lands worldwide were estimated at 324 million ha (FAO-AQUASTAT, 2013), with an estimated $20 \%$ or 62 million ha salt affected (Qadir et al., 2014). In the 1990s, a conservative estimate of the cost of salinity to agriculture was approximately $\$ 12$ billion USD per year (Ghassemi et al., 1995). More recently, an inflation-adjusted cost of salt-induced land degradation was estimated at $\$ 441 \mathrm{ha}^{-1}$, resulting in an estimated global economic loss of $\$ 27.3$ billion USD for 2013 (Qadir et al., 2014). Welle and Mauter (2017) estimate an income loss due to salinity within California alone at $\$ 3.7$ billion USD for 2014 . 
Approximately one-third of all agricultural lands are becoming saline with over 100 countries experiencing problems from salt-affected soils (Rengasamy, 2006; Squires and Glenn, 2009). Recent estimates are that over the past 20 years the world has lost an average of 2000 ha of farmland daily to salt damage (Qadir et al., 2014). Extensive salt-affected soils can be found in the Aral Sea Basin of Central Asia, Indo-Gangetic Basin of India, Indus Basin of Pakistan, Yellow River Basin of China, Euphrates Basin of Syria and Iraq, Murray-Darling Basin of Australia, and California's San Joaquin Valley in the United States as well as Mediterranean areas of Europe (e.g., Spain, Caspian Basin, the Ukraine, and the Carpathian Basin), northern and eastern Africa, and northeastern Mexico. Table 1 provides an estimation of the global distribution of all saline and sodic land areas with over 1 billion ha of land worldwide considered saline and/or sodic soils. Approximately $30 \%$ of the soil in the conterminous United States is regarded as moderate to severe potential for salinity issues (Tanji, 1996). In California alone, an estimated 1.72 Mha (29\%) of all non-federal land is either saline or sodic (Tanji, 1996).

However, the estimates of salt-affected soils in Table 1 are not based on quantitative measurements of salinity and sodicity, but rather on qualitative visual estimates of ground-truth salinity by field experts. Accurate statistics on the extent of salt-affected soils are not available. In fact, there is no worldwide inventory of salt-affect soils based on quantitative measurements of

Table 1 Global distribution of salt-affected soil.

\section{Continent}

Saline (Mha)

Sodic (Mha) Total (Mha)

\begin{tabular}{llll}
\hline Africa & 122.9 & 86.7 & 209.6 \\
\hline South Asia & 82.2 & 1.8 & 84.0 \\
\hline North and Central Asia & 91.4 & 120.1 & 211.4 \\
\hline Southeast Asia & 20.0 & - & 20.0 \\
\hline South America & 69.4 & 59.8 & 129.2 \\
\hline North America & 6.2 & 9.6 & 15.8 \\
\hline Mexico and Central America & 2.0 & - & 2.0 \\
\hline Australia & 17.6 & 340.0 & 357.6 \\
\hline Global total & 411.7 & 617.9 & 1029.5
\end{tabular}

Taken from Squires, V.R., Glenn, E.P., 2009. Salination, desertification, and soil erosion. In: Squires, V.R. (Ed.), The Role of Food, Agriculture, Forestry and Fisheries in Human Nutrition. Vol. III-Encyclopedia of Life Support Systems. EOLSS Publishers, Oxford, UK, 102-123. 
salinity and sodicity because of the tremendous scale of such an undertaking and the prohibitive cost. Recently, methodology has been developed to map salinity quantitatively at regional scale (Corwin and Scudiero, 2016; Scudiero et al., 2015). Another complicating factor in getting a worldwide inventory of salt-affected soil is the different systems of classification used by individual countries. Aside from the classification system established by the U.S. Salinity Laboratory, which was adopted by the old Soil Conservation Service (now referred to as the Natural Resource Conservation Service) for their soil surveys, the Australians traditionally define sodic soils as having an ESP between 6 and 14 and a strongly sodic soil having ESP $>15$ (Northcote and Skene, 1972).

\subsection{Brief background in laboratory measurement of soil salinity}

The most common technique for measuring soil salinity is laboratory analysis of aqueous extracts from disturbed soil samples. Because the currentcarrying capacity of soil solution is proportional to the concentration of ions in the solution, soil salinity is quantified in terms of the total concentration of the soluble salts as measured by the electrical conductivity (EC) of the soil solution in $\mathrm{dS} \mathrm{m}^{-1}$ (U.S. Salinity Laboratory Staff, 1954).

Measurement of electrical conductivity is with a cell containing two electrodes of constant geometry and distance of separation (Jurinak and Suarez, 1996). Soil solution is placed between the two electrodes. An electrical potential is imposed across the electrodes and the resistance of the solution between the electrodes is measured. The measured conductance is a consequence of the solution's salt concentration and the electrode geometry whose effects are embodied in a cell constant. At constant potential, the current is inversely proportional to the solution's resistance:

$$
E C_{t}=k / R_{t}
$$

where $E C_{t}$ in units of $\mathrm{dS} \mathrm{m}^{-1}$ is the electrical conductivity of the solution at temperature $t\left({ }^{\circ} \mathrm{C}\right), k$ is the cell constant, and $R_{t}$ is the measured resistance at temperature $t$.

The soil/water ratio of an extract influences the partitioning of solutes between the three soil phases (i.e., gas, solid, liquid); consequently, the ratio must be standardized to obtain results that can be applied and interpreted universally. Laboratory measurement of the $\mathrm{EC}$ of the saturation extract $\left(\mathrm{EC}_{\mathrm{e}}\right)$ is the customary means of measuring soil salinity because it is impractical for routine purposes to extract soil water from samples at typical field 
water contents. One widely used technique is to obtain an extract by vacuum filtration of a saturated soil paste made with distilled water (Rhoades, 1996). Other commonly used extract ratios are 1:1, 1:2, and 1:5 soil/water mixtures. However, extracts at these ratios adjust soil to unnaturally high water contents not found in the field, providing only relative salinity. Soil salinity can also be determined from the measurement of the $\mathrm{EC}$ of the soil solution at some defined field water content $\left(\mathrm{EC}_{\mathrm{w}}\right)$, such as field capacity. Field capacity represents the water content of soil 2-3 days after irrigation when free drainage is negligible. Theoretically, $\mathrm{EC}_{\mathrm{w}}$ is a more representative index of soil salinity because the plant root is exposed to salinity at field capacity. Nevertheless, $\mathrm{EC}_{\mathrm{w}}$ has not been widely used for two reasons: (i) it varies over the irrigation cycle as the soil water content changes and (ii) methods for obtaining soil solution samples at water contents less than saturation are too labor and cost intensive to be practical for field-scale applications (Rhoades et al., 1999a).

Temperature has an effect on EC. Electrolytic conductivity increases approximately $1.9 \%$ per degree centigrade over the range of $15-35^{\circ} \mathrm{C}$; consequently, $\mathrm{EC}$ is expressed at a reference temperature of $25^{\circ} \mathrm{C}$ for purposes of comparison (Corwin, 2003). To adjust the $\mathrm{EC}$ (e.g., $\mathrm{EC}_{\mathrm{e}}$ or $\mathrm{EC}_{\mathrm{w}}$ ) measured at a temperature $t\left({ }^{\circ} \mathrm{C}\right), E C_{t}\left(\mathrm{dS} \mathrm{m}^{-1}\right)$, to a reference $\mathrm{EC}$ at $25^{\circ} \mathrm{C}$, $E C_{25}$, the following equations from Sheets and Hendrickx (1995) are used:

$$
\begin{gathered}
E C_{25}=f_{t} \bullet E C_{t} \\
f_{t}=0.4470+1.4034 \exp (-t / 26.815)
\end{gathered}
$$

where $f_{t}$ is a temperature conversion factor.

Obtaining the EC of a soil solution when the water content is at or less than field capacity, which are the water contents most commonly found in the field, is considerably more difficult than extracts for water contents at or above saturation because of the pressure or suction required to remove the soil solution at field capacity and lower water contents. Even so, measuring soil salinity of $1: 1,1: 2$, or 1:5 soil/water extracts from soil samples taken to characterize salinity distributions for volumes of soil beyond $10-20 \mathrm{~m}^{3}$ is impractical due to the intensive labor requirements. Subsequently, the measurement of apparent soil electrical conductivity $\left(E C_{a}\right)$ has been used to measure the spatial variability of soil salinity in soil volumes $>10-20 \mathrm{~m}^{3}$ (i.e., the size of a small experimental plot).

Apparent soil electrical conductivity measures the conductance of the bulk soil, i.e., it measures anything conductive in the soil. It is a fast, reliable 
measurement that is easily mobilized; consequently, extensive geospatial $\mathrm{EC}_{\mathrm{a}}$ data can be collected in a short length of time. There are three primary geophysical techniques for measuring $\mathrm{EC}_{\mathrm{a}}$ in the root zone (i.e., top 1.2 or $1.5 \mathrm{~m}$ ): electrical resistivity (ER), electromagnetic induction (EMI), and time domain reflectometry (TDR). Electrical resistivity and EMI are easily mobilized and are well suited for field-scale applications because of the ease and low cost of measurement with a volume of measurement that is sufficiently large $\left(>1 \mathrm{~m}^{3}\right)$ to reduce the influence of local-scale variability. Developments in agricultural applications of ER and EMI have occurred along parallel paths with each filling a needed niche based upon inherent strengths and limitations. Even though TDR is a useful and well-studied technique for measuring $\mathrm{EC}_{\mathrm{a}}$, it has lagged behind $\mathrm{ER}$ and $\mathrm{EMI}$ as an "on-the-go" proximal sensor because it does not provide a continuous stream measurement with associated GPS positions. Rather, TDR requires the user to go from one location to the next, stopping at each location to take discrete measurements; consequently, it is less rapid and is less appealing for mapping $\mathrm{EC}_{\mathrm{a}}$ at field scales and larger spatial extents.

\subsection{Electrical resistivity}

Electrical resistivity methods introduce an electrical current into the soil through current electrodes at the soil surface. The difference in current flow potential is measured at potential electrodes that are placed in the vicinity of the current flow (Fig. 3). These methods were developed in the second decade of the 1900s by Conrad Schlumberger in France and Frank Wenner

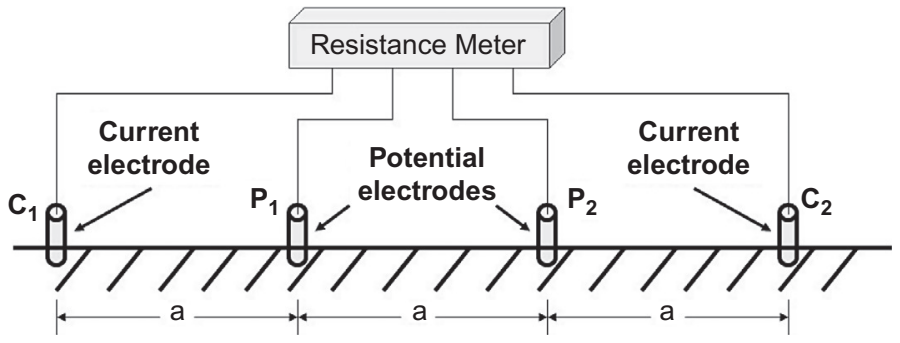

Fig. 3 Schematic showing the electrical resistivity method with an array of four electrodes: two current electrodes $\left(C_{1}\right.$ and $\left.C_{2}\right)$ and two potential electrodes $\left(P_{1}\right.$ and $\left.P_{2}\right)$. When electrodes are equally spaced at distance $a$, as shown, the electrode array is called a Wenner array. Taken from Corwin, D.L., Lesch, S.M., 2005a. Apparent soil electrical conductivity measurements in agriculture. Comput. Electron Agric. 46 (1-3), 11-43 with permission. 
in the United States for the evaluation of ground ER (Burger, 1992; Telford et al., 1990).

The electrode configuration is referred to as a Wenner array when four electrodes are equidistantly spaced in a straight line at the soil surface with the two outer electrodes serving as the current or transmission electrodes and the two inner electrodes serving as the potential or receiving electrodes (see Fig. 3; Corwin and Hendrickx, 2002). The depth of penetration of the electrical current and the volume of measurement increase as the inter-electrode spacing, $a$, increases. For a homogeneous soil, the soil volume measured is roughly $\pi a^{3}$. There are additional electrode configurations that are frequently used, as discussed by Dobrin (1960), Telford et al. (1990), and Burger (1992).

Electrical resistivity and EMI techniques are both well suited for fieldscale applications because their volumes of measurement are large, which reduces the influence of local-scale variability. However, ER is an invasive technique that requires good contact between the soil and four electrodes inserted into the soil; consequently, it produces less reliable measurements in dry or stony soils than the non-invasive EMI measurement.

\subsection{Electromagnetic induction}

A transmitter coil located at one end of the EMI instrument induces circular eddy-current loops in the soil with the magnitude of these loops directly proportional to the electrical conductivity in the vicinity of that loop. Each current loop generates a secondary electromagnetic field that is proportional to the value of the current flowing within the loop. A fraction of the secondary induced electromagnetic field from each loop is intercepted by the receiver coil of the instrument and the sum of these signals is amplified and formed into an output voltage, which is related to a depth-weighted soil electrical conductivity, $\mathrm{EC}_{\mathrm{a}}$. The amplitude and phase of the secondary field will differ from those of the primary field as a result of soil properties (e.g., clay content, water content, salinity), spacing of the coils and their orientation, frequency, and distance from the soil surface (Hendrickx and Kachanoski, 2002).

The two most commonly used EMI conductivity meters in soil science and in vadose zone hydrology are the Geonics ${ }^{\mathrm{a}}$ EM-31 and EM-38.

\footnotetext{
${ }^{a}$ Geonics Limited, Mississauga, Ontario, Canada. All references to commercial equipment and instrumentation are provided solely for the benefit of the reader and do not imply the endorsement of the USDA.
} 


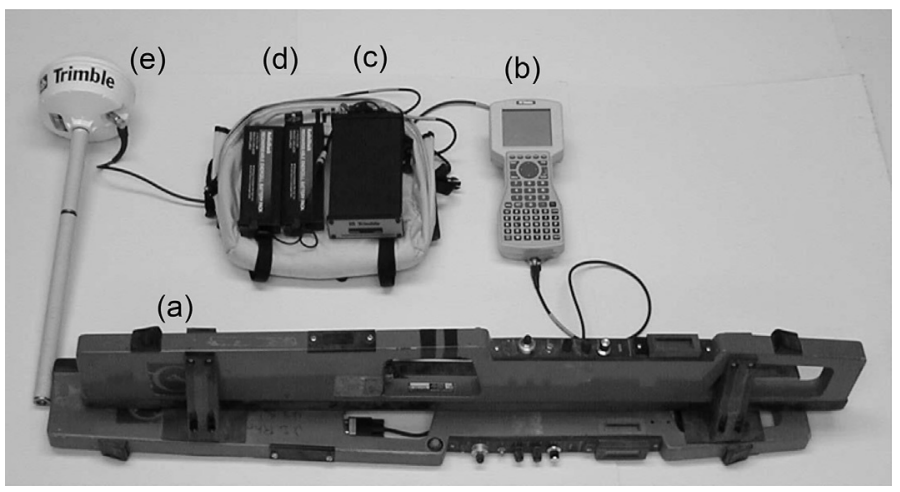

Fig. 4 Dual-dipole EM38 conductivity meter showing the connection between (A) EM-38m and Trimble MC-V Pro-XL system consisting of (B) MC-V data logger, (C) TANS receiver, (D) battery pack, and (E) dome antenna. Source: Corwin, D.L., Lesch, S.M., 2005b. Characterizing soil spatial variability with apparent soil electrical conductivity: I. Survey protocols. Comput. Electron Agric. 46 (1-3), 103-133.

The EM-38 (Fig. 4) has had greater application for agricultural purposes because the depth of measurement corresponds roughly to the root zone (i.e., $1.5 \mathrm{~m}$ ), when the instrument is placed in the vertical coil configuration. In the horizontal coil configuration, the depth of the measurement is 0.75-1.0 m. McNeill $(1980,1986)$ and Hendrickx and Kachanoski (2002) discuss the operation of the EM-38 equipment. The depth of measurement of the EM-31 is approximately $6 \mathrm{~m}$.

\subsection{Time domain reflectometry}

Noborio (2001) provides a review of time domain reflectometry (TDR) with a thorough discussion of the theory for the measurement of soil water content and $\mathrm{EC}_{\mathrm{a}}$; probe configuration, construction, and installation; and strengths and limitations. In addition, Wraith (2002) provides an excellent overview of the principles, equipment, procedures, range and precision of measurement, and calibration of TDR.

Time domain reflectometry was initially adapted for use in measuring soil water content (Topp et al., 1980, 1982; Topp and Davis, 1981). The TDR technique is based on the time for a voltage pulse to travel down a soil probe and back, which is a function of the dielectric constant $(\gamma)$ of the porous media being measured. Later, Dalton et al. (1984) demonstrated the utility of TDR to measure $\mathrm{EC}_{\mathrm{a}}$, based on the attenuation of the applied signal voltage as it traverses through soil. 
Advantages of TDR for measuring $\mathrm{EC}_{\mathrm{a}}$ include (i) a relatively noninvasive nature, (ii) an ability to measure both soil water content and $\mathrm{EC}_{\mathrm{a}}$, (iii) an ability to detect small changes in $\mathrm{EC}_{\mathrm{a}}$ under representative soil conditions, (iv) the capability of obtaining continuous unattended measurements at a single location, and (v) a lack of a calibration requirement for soil water content measurements in many cases (Wraith, 2002). However, because TDR is a stationary instrument where measurements are taken from point-to-point thereby preventing it from mapping at the spatial resolution of ER and EMI approaches, it is currently impractical for developing detailed geo-referenced $\mathrm{EC}_{\mathrm{a}}$ maps for large areas.

Although TDR has been demonstrated to compare closely with other accepted methods of $\mathrm{EC}_{\mathrm{a}}$ measurement (Heimovaara et al., 1995; Mallants et al., 1996; Reece, 1998; Spaans and Baker, 1993), it is still not sufficiently simple, robust, and fast enough for the general needs of fieldscale soil salinity assessment (Rhoades et al., 1999b). Currently, the use of TDR for field-scale spatial characterization of soil water content and $\mathrm{EC}_{\mathrm{a}}$ distributions is largely limited. Only ER and EMI have been widely adapted for detailed spatial surveys consisting of intensive geo-referenced measurements of $\mathrm{EC}_{\mathrm{a}}$ at field scales and larger (Rhoades et al., 1999a, b).

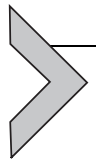

\section{Geospatial apparent soil electrical conductivity $\left(E C_{a}\right)$ measurements}

Geospatial $\mathrm{EC}_{\mathrm{a}}$ measurements are particularly well suited for establishing within-field spatial variability of soil properties because they are quick and dependable measurements that integrate the influence of several soil properties contributing to the electrical conductance of the bulk soil. At present, no other measurement provides a greater level of spatial soil information than that of geospatial measurements of $\mathrm{EC}_{\mathrm{a}}$ when used to direct soil sampling (Corwin and Lesch, 2005a). However, EC $_{\mathrm{a}}$ is a complex soil property that is influenced by a complex interaction of a variety of edaphic properties, including soil salinity (most commonly measured as the electrical conductivity of the saturated soil paste extract or $\mathrm{EC}_{\mathrm{e}}$ ), texture (quantitatively approximated by saturation percentage or SP), water content $\left(\theta_{\mathrm{w}}\right)$, bulk density $\left(\rho_{\mathrm{b}}\right)$, organic matter $(\mathrm{OM})$, clay minerology, cation exchange capacity (CEC), and temperature (T). Measurements of $\mathrm{EC}_{\mathrm{a}}$ must be interpreted with these influencing edaphic factors in mind. Geospatial $\mathrm{EC}_{\mathrm{a}}$ measurements serve as a means of defining spatial patterns that indicate 
differences in electrical conductance due to the combined conductance influences of $\mathrm{EC}_{\mathrm{e}}, \mathrm{SP}, \theta_{\mathrm{w}}, \rho_{\mathrm{b}}$, OM, CEC, and T.

\subsection{Basis for field-scale mapping of salinity with $\mathrm{EC}_{\mathrm{a}}$}

The characterization of the spatial variability of soil salinity at field scale using geospatial $\mathrm{EC}_{\mathrm{a}}$ measurements is based on the hypothesis that spatial $\mathrm{EC}_{\mathrm{a}}$ information can be used to develop a directed soil sampling plan, which identifies sites that adequately reflect the range and variability of soil salinity correlated with $\mathrm{EC}_{\mathrm{a}}$ at the site of interest. This hypothesis has repeatedly held true for a variety of agricultural applications (Corwin and Lesch, 2005a). Because $\mathrm{EC}_{\mathrm{a}}$ is influenced by a variety of edaphic properties, an understanding and interpretation of geospatial $\mathrm{EC}_{\mathrm{a}}$ data can only be obtained from ground-truth measures of soil properties that correlate with $\mathrm{EC}_{\mathrm{a}}$, which results from either a direct influence or indirect association at the particular study site of interest. For this reason, geospatial $\mathrm{EC}_{\mathrm{a}}$ measurements are used as a surrogate of soil spatial variability to direct soil sampling when mapping soil salinity (or any soil property correlated to $\mathrm{EC}_{\mathrm{a}}$ ) at field scales and larger spatial extents (i.e., up to $10 \mathrm{~km}^{2}$ ) and are not generally used as a direct measure of soil salinity except in instances where salinity is dominating the $\mathrm{EC}_{\mathrm{a}}$ measurement.

\section{Historical perspective of soil salinity assessment}

Historically, there have been six methods commonly used to determine soil salinity at field scale and larger spatial extents (Corwin, 2008): (i) visual crop observations, (ii) EC of soil solution extracts or extracts at higher than normal water contents, (iii) ER, (iv) EMI, (v) TDR, and (vi) multi- and hyper-spectral imagery. Visual crop observation is the oldest and least quantitative means of determining the presence of soil salinity. It is a rapid method, but has the distinct disadvantage that salinity is detected after crop damage has occurred and it provides very little information about low and moderate levels of salinity that do not influence a crop's yield. For obvious reasons, visual observation is the least desirable method because crop yields are reduced to obtain spatial information on soil salinity. Multi- and hyper-spectral imagery represent a quantitative approach to the antiquated method of visual observation that offers tremendous potential for the detection of a full range of salinities from field to regional scales. Even though the measurement of EC of soil solution extracts or extracts at higher than normal water contents has at times been used for field-scale studies, it is an 
impractical application because of the intensive time, effort, and cost demands. Its greatest utility is as a means of obtaining ground-truth salinity measurements that can be used to calibrate $\mathrm{EC}_{\mathrm{a}}$ measurements taken with ER, EMI, or TDR. For research purposes, the three geophysical techniques of ER, EMI, and TDR are not used equally to map soil salinity. Both ER and TDR are invasive methods, which puts them at a disadvantage. TDR requires the insertion of a probe, which necessitates point-to-point measurements across a field instead of the steady stream of data that can be obtained from EMI and ER. Electrical resistivity requires good contact between the four electrodes and the surface soil. This necessitates adequate soil moisture at the soil surface to maintain the liquid conductance pathway, which often times makes it difficult to obtain $\mathrm{EC}_{\mathrm{a}}$ measurements with $\mathrm{ER}$ when the soil surface is dry, crusted, or filled with coarse material such as sand, gravel, and rocks. Furthermore, ER can only be used on fallow fields with a flat surface since the electrodes would damage a crop or any beds and furrows. The geophysical tool of choice for mapping soil salinity has been and will continue to be EMI. Subsequently, the discussion of the major pivotal research and research trends will principally focus on the use of EMI and multi- and hyper-spectral imagery to assess salinity from field to regional scales.

In the 1960s through the early 1970s soil solution extractors and porous matric salinity sensors were commonly used in the field. The measurement of EC to determine soil salinity shifted away from soil extractions to the measurement of $\mathrm{EC}_{\mathrm{a}}$ because the time and cost of obtaining soil solution extracts prohibited their practical use at field scales, and the high local-scale variability of soil rendered salinity sensors and small volume soil core samples of limited quantitative value. Rhoades and colleagues at the U.S. Salinity Laboratory led the shift in the early 1970s to the use of $\mathrm{EC}_{\mathrm{a}}$ measured with ER as the measure of soil salinity (Rhoades and Ingvalson, 1971; Rhoades and van Schilfgaarde, 1976). The use of $\mathrm{EC}_{\mathrm{a}}$ to measure salinity has the advantage of increased volume of measurement and quickness of measurement, but suffers from the complexity of measuring $\mathrm{EC}$ for the bulk soil rather than restricted to the solution phase. Furthermore, $\mathrm{EC}_{\mathrm{a}}$ measurement techniques, such as ER and EMI, are easily mobilized and are well suited for field-scale applications because of the ease and low cost of measurement with a volume of measurement that is sufficiently large $\left(>1 \mathrm{~m}^{3}\right)$ to reduce the influence of local-scale variability.

In the late 1970s and early 1980s, de Jong et al. (1979), Rhoades and Corwin (1981), and Williams and Baker (1982) began investigating the use of EMI to measure soil salinity. de Jong et al. (1979) published the first 
use of EMI for measuring soil salinity. The early studies with EMI by Rhoades and Corwin were efforts to profile soil salinity through the root zone (Corwin and Rhoades, 1982, 1984; Rhoades and Corwin, 1981). Unlike ER, vertical profiling with EMI is not a trivial task because a relatively simple linear model can be used for low conductivity media, but for higher conductivity values, a nonlinear model is required. Williams and Baker (1982) sought to use EMI as a means of surveying soil salinity at landscape scales and larger with the first use of aerial EMI to map geologic sources of salinity having agricultural impacts.

The field-scale mapping of soil salinity (and other soil properties correlating with $\mathrm{EC}_{\mathrm{a}}$ at a specific field, sometimes referred to as "target" properties) began in the 1990s. The first map of salinity using geospatial $\mathrm{EC}_{\mathrm{a}}$ measurements was by Lesch et al. (1995a, b). The pivotal point for the field-scale mapping of soil salinity came when GPS, mobile EMI equipment, sample design software (Lesch et al., 2000; Lesch, 2005), and protocols for soil sampling based on the spatial variation in geospatial $\mathrm{EC}_{\mathrm{a}}$ measurements (Corwin and Lesch, 2003, 2005b) came together to become what is now referred to as $E C_{a}$-directed soil sampling. Conceptually speaking, $\mathrm{EC}_{\mathrm{a}}$-directed soil sampling consists of geospatial measurements of $\mathrm{EC}_{\mathrm{a}}$ that are used as a surrogate of soil spatial variability to direct soil sampling when mapping soil salinity or other target soil properties (e.g., texture, water content, organic matter) correlated to $\mathrm{EC}_{\mathrm{a}}$ at a field (Corwin and Scudiero, 2016). The directed soil samples reflect the range and variability in salinity or other target property or properties (Corwin and Scudiero, 2016).

Geospatial measurements of $\mathrm{EC}_{\mathrm{a}}$ have been used to measure and map a variety of soil properties in the field. Table 2 is a comprehensive compilation of the research conducted broken down into the predominate property or properties measured in the $\mathrm{EC}_{\mathrm{a}}$ study. Table 2 not only provides a thorough listing of the field-scale $\mathrm{EC}_{\mathrm{a}}$ research conducted, but also reveals the tremendous amount of redundancy regarding $\mathrm{EC}_{\mathrm{a}}$ measurement of soil spatial variability, especially for measuring salinity.

Rhoades et al. (1999a) and Hendrickx et al. (2002b) provide a detailed discussion of the theory, operation, and construction of EMI instrumentation used to measure $\mathrm{EC}_{\mathrm{a}}$ in the root zone (i.e., top $1.5 \mathrm{~m}$ of soil). There are various types of mobilized $\mathrm{EC}_{\mathrm{a}}$-measurement equipment using EMI instrumentation. These range from simple ATVs with hand-built PVC or wood sleds carrying the EMI and GPS equipment to modified herbicide spray rigs with enclosed cabs and retractable sleds housing EMI equipment that can create $\mathrm{EC}_{\mathrm{a}}$ maps in real time instead of post-processing the data after the 
Table 2 Compilation of literature measuring $\mathrm{EC}_{\mathrm{a}}$ with geophysical techniques (ER or EMI) that have been categorized according to edaphic properties that were either directly or indirectly measured by $\mathrm{EC}_{\mathrm{a}}$.

\section{Directly measured soil properties}

Salinity (including total dissolved solids, sodicity, inorganic $\mathrm{C}, \mathrm{CaCO}$, and nutrients)

Halvorson and Rhoades (1976), Rhoades et al. (1976, 1989a, 1990a, b, 1997, 1999a, b), Rhoades and Halvorson (1977), de Jong et al. (1979), Cameron et al. (1981), Rhoades and Corwin (1981, 1990), Corwin and Rhoades (1982, 1984, 1990), Williams and Baker (1982), Greenhouse and Slaine (1983), van der Lelij (1983), Williams and Fidler (1983), Williams and Braunach (1984), Wollenhaupt et al. (1986), Williams and Hoey (1987), Boivin et al. (1989), Dixon (1989), McKenzie et al. (1989, 1993, 1997), Norman (1989), Slavich (1990), Slavich and Petterson (1990), Diaz and Herrero (1992), Hendrickx et al. (1992), Lesch et al. (1992, 1993, 1995a, b, 1998, 2005), McNeill (1992), Rhoades (1992, 1993), Cannon et al. (1994), Dunn et al. (1994), Nettleton et al. (1994), Salama et al. (1994), Sheets et al. (1994), Whiteley (1994), Bennett and George (1995), Drommerhausen et al. (1995), Jaynes et al. (1995a, b), Ranjan et al. (1995), SriRanjan and Karthigesu (1995), Vaughan et al. (1995), López-Bruna and Herrero (1996), Bourgault et al. (1997), Ceuppens et al. (1997), Hanson and Kaita (1997), Johnston et al. (1997), Mankin et al. (1997), Eigenberg et al. (1998, 2002, 2006), Eigenberg and Nienaber (1998, 1999, 2001, 2003), Odeh et al. (1998), Ceuppens and Wopereis (1999), Hopkins and Richardson (1999), Bennett et al. (2000), Chaudhry (2000), McKenzie (2000), Triantafilis et al. (2000, 2001a, 2002, 2003, 2004), Barbiéro et al. (2001, 2008), Clay et al. (2001), Doolittle et al. (2001), Johnson et al. (2001, 2005a, b), Broadfoot et al. (2002), Mankin and Karthikeyan (2002), Barnes et al. (2003), Corwin and Lesch (2003, 2005a, b, c, 2013, 2014, 2017), Corwin et al. (2003a, b, 2006b, 2008a, b, 2010), Edwards and Webb (2003), Fitzpatrick et al. (2003), Heiniger et al. (2003), Herrero et al. (2003), Lesch and Corwin (2003, 2008), Paine (2003), Gill and Yee (2004), Soliman et al. (2004), Bekele et al. (2005), Bronson et al. (2005), Cockx et al. (2005), Corwin (2005a, b, 2012), Douaik et al. (2005), Friedman (2005), Horney et al. (2005), Kaffka et al. (2005), Korsaeth (2005), Lesch (2005), Amezketa (2006, 2007a, b), Grigera et al. (2006), Kinal et al. (2006), Nogués et al. (2006), Wittler et al. (2006), Aimrun et al. (2007), Brunner et al. (2007), ${ }^{\mathrm{a}}$ Dent (2007), Yao et al. (2007, 2012, 2014, 2015, 2016a, b), Amezketa and del Valle de Lersundi (2008), Akramkhanov et al. (2008, 2011, 2014), Urdanoz et al. (2008), Arriola-Morales et al. (2009), Goes et al. (2009), Thomas et al. (2009), Triantafilis and Buchanan (2009, 2010), Zheng et al. (2009), Aragüés et al. (2010, 2011), Bakker et al. (2010), Dixit and Chen (2010), López-Lozano et al. (2010), McLeod et al. (2010), Moffett et al. (2010), Rongjiang and Jingsong (2010), Viezzoli et al. (2010), Yao and Yang (2010), Cordeiro et al. (2011a, b), Dang et al. (2011), Feikema and Baker (2011), Ganjegunte and Braun (2011), Gholizadeh et al. (2011), Heilig et al. (2011), Herrero et al. (2011), Jayawickreme et al. (2011), Kaman et al. (2011), Krum et al. (2011), Rahimian and Hasheminejhad (2011), Scudiero et al. (2011, 2013, ${ }^{\mathrm{a}} 2014 \mathrm{a},{ }^{\mathrm{a}}$ 2015 $)$, Urdanoz and Aragüés (2011, 2012), 
Table 2 Compilation of literature measuring $\mathrm{EC}_{\mathrm{a}}$ with geophysical techniques (ER or EMI) that have been categorized according to edaphic properties that were either directly or indirectly measured by $\mathrm{EC}_{\mathrm{a}}$. - cont'd Directly measured soil properties

Wu and Margulis (2011), Adam et al. (2012), Amakor et al. (2013), Bouksila et al. (2012), Cetin et al. (2012), Goldshleger et al. (2012), ' Li et al. (2012, 2013a, b), Mahmood et al. (2012), ${ }^{a}$ Morway and Gates (2012), Rekha et al. (2012), ${ }^{a}$ Atwell et al. (2013), Casa et al. (2013), 'Ganjegunte et al. (2013, 2014, 2017), Guo et al. (2013a, 2016), ${ }^{a}$ Peralta and Costa (2013), Berkal et al. (2014), Ding and Yu (2014), ${ }^{\text {a }}$ Herrero and Hudnall (2014), Huang et al. (2014a, b, c, 2015a, b, c, e, f, 2017a, b), Taghizadeh-

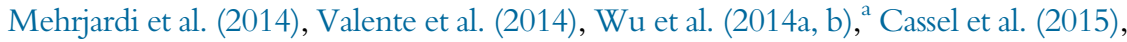
Chaali et al. (2015), Corwin and Ahmad (2015), Davies et al. (2015), Jadoon et al. (2015, 2017), Peralta et al. (2015), Ezrin et al. (2016), Liu et al. (2016), Moghadas et al. (2016), Tycholiz et al. (2016), Aboelsoud and AbdelRahman (2017), Dakak et al. (2017), Moral and Rebollo (2017), Narjary et al. (2017), Watson et al. (2017), Nouri et al. (2018), ${ }^{a}$ Uribeetxebarria et al. (2018), and Walter et al. (2018)

Water content (including macropore porosity, water table depth, and irrigation canal seepage)

Rhoades et al. (1976), Fitterman and Stewart (1986), Kean et al. (1987), Kachanoski et al. (1988, 1990), Sheets and Hendrickx (1995), Vaughan et al. (1995), Hanson and Kaita (1997), Khakural et al. (1998), Fritz et al. (1999), Doolittle et al. (2000), Malo et al. (2000), Morgan et al. (2000), Bobert et al. (2001), Clay et al. (2001), Freeland et al. (2001), Brevik and Fenton (2002), Wilson et al. (2002, 2003), Corwin and Lesch (2003), Corwin et al. (2003b, 2008a), Lesch and Corwin (2003), Reedy and Scanlon (2003), Schumann and Zaman (2003), Sherlock and McDonnell (2003), Hall et al. (2004), Akbar et al. (2005), Carroll and Oliver (2005), Erindi-kati (2005), Kaffka et al. (2005), Sudduth et al. (2005), Brevik et al. (2006), McCutcheon et al. (2006), Vitharana et al. (2006), Wong and Asseng (2006), Hezarjaribi and Sourell (2007), Huth and Poulton (2007), Jiang et al. (2007a, b), Abdu et al. (2008), Jayawickreme et al. (2008, 2011), Buchanan and Triantafilis (2009), Hedley and Yule (2009), Lück et al. (2009), Robinson et al. (2009, 2012), Tromp-van Meerveld and McDonnell (2009), Chaplot et al. (2010), Houssain et al. (2010), Martínez et al. (2010, 2018), Zhu et al. (2010a), Dadfar et al. (2011), Ekwue and Bartholomew (2011), Hadzick et al. (2011), Padhi and Misra (2011), Rodríguez-Pérez et al. (2011), Sun et al. (2011a, 2013), Heil and Schmidhalter (2012), Lardo et al. (2012), Moysey and Liu (2012), Serrano et al. (2012, 2013, 2014), De Benedetto et al. (2013), Guo et al. (2013a, 2016), ${ }^{a}$ Hedley et al. (2013), Pognant et al. (2013), Wunderlich et al. (2013), Chrétien et al. (2014), Costa et al. (2014), Gooley et al. (2014), ${ }^{\text {a }}$ Liao et al. (2014), Misra and Padhi (2014), Fortes et al. (2015), Haghverdi et al. (2015), Huang et al. (2015d, 2016, 2017c, d), Landrum et al. (2015), 'Shanahan et al. (2015), Stadler et al. (2015), Segundo et al. (2015), Walter et al. (2015), Cho et al. (2016), Neely et al. (2016), Pedrera-Parrilla et al. (2016, 2017), Altdorff et al. (2017, 2018), Filho et al. (2017), Lu et al. (2017), Martini et al. (2017), Moghadas et al. (2017), Watson et al. (2017), Al Rashid et al. (2018), Mallet et al. (2018), Rallo et al. (2018), Robinet et al. (2018), and Nocco et al. (2019)

Texture-related (including sand, clay, depth to claypans or sand layers, soil layers, topsoil thickness, depth to bedrock, saturation percentage, soil type, and map units) 
Table 2 Compilation of literature measuring $\mathrm{EC}_{\mathrm{a}}$ with geophysical techniques (ER or EMI) that have been categorized according to edaphic properties that were either directly or indirectly measured by $\mathrm{EC}_{\mathrm{a}}$. - cont'd

\section{Directly measured soil properties}

Zalasiewicz et al. (1985), Williams and Hoey (1987), Krabbenborg and Biewinga (1988), Ammons et al. (1989), Biewinga et al. (1990), Brus et al. (1992), Jaynes et al. (1993), Sudduth and Kitchen (1993), Doolittle et al. (1994, 2002a, b), Knotters et al. (1995), Kitchen et al. (1996, 1999), Banton et al. (1997), Boettinger et al. (1997), Bork et al. (1998), Doolittle and Collins (1998), Fenton and Lauterbach (1999), Rhoades et al. (1999b), Scanlon et al. (1999), Waine et al. (2000), Bobert et al. (2001), Dalgaard et al. (2001), Inman et al. (2001, 2002), Kimble et al. (2001), Nehmdahl and Greve (2001), Schmidhalter et al. (2001), Stroh et al. (2001), Triantafilis et al. (2001a, b, 2003, 2004, 2009), Anderson-Cook et al. (2002), Brevik and Fenton (2002), Delin and Söderström (2002), Corwin and Lesch (2003, 2005c), Corwin et al. (2003b), Dampney et al. (2003), James et al. (2003), Lesch and Corwin (2003), Sommer et al. (2003), Sudduth et al. (2003, 2005), Domsch and Giebel (2004), Hedley et al. (2004), Rampant and Abuzar (2004), Allred et al. (2005), Bronson et al. (2005), Carroll and Oliver (2005), Johnson et al. (2001, 2005b), Jung et al. (2005), Korsaeth (2005), McBratney et al. (2005), Triantafilis and Lesch (2005), Grigera et al. (2006), Jung et al. (2006), McCutcheon et al. (2006), SiriPrieto et al. (2006), Vervoort and Annen (2006), Cockx et al. (2007, 2009), Weller et al. (2007), Mertens et al. (2008), Robinson et al. (2008, 2010), Shaner et al. (2008a), Vitharana et al. (2006, 2008), Harvey and Morgan (2009), Kühn et al. (2009), Lukas et al. (2009), Martínez et al. (2009), Morari et al. (2009), Saey et al. (2009a, b, 2011, 2012a, b), Cai et al. (2010), Chaplot et al. (2010), De Benedetto et al. (2010, 2012), Triantafilis and Monteiro Santos (2010b), Zhu et al. (2010b, 2013), Bréchet et al. (2012), Fulton et al. (2011), Hbirkou et al. (2011), Lück et al. (2011), Nelson et al. (2011), Rodríguez-Pérez et al. (2011), Sun et al. (2011b), Terrón et al. (2011), Brevik et al. (2012), Castrignanò et al. (2012), ${ }^{a}$ Gholizadeh et al. (2012), Heil and Schmidhalter (2012), Islam et al. (2012), Mahmood et al. (2012), , Casa et al. (2013), ${ }^{a}$ Grellier et al. (2013), Koszinski et al. (2013), Nearing et al. (2013), Piikki et al. (2013), ${ }^{\text {a }}$ Rossi et al. (2013), Huang et al. (2014d), ${ }^{a}$ Klassen et al. (2014), Pan et al. (2014), Ciampalini et al. (2015), ${ }^{a}$ Pedrera-Parrilla et al. (2015, 2016), Pozdnyakov et al. (2015), Rodríguez et al. (2015), Rodrigues Jr. et al. (2015), , Rudolph et al. (2015), Stadler et al. (2015), Stepień et al. (2015), 'Afshar et al. (2016), ${ }^{a}$ Cho et al. (2016), Khan et al. (2016), Moghadas et al. (2016), Filho et al. (2017), Ganjegunte et al. (2017), García-Tomillo et al. (2017), Kelley et al. (2017), de Lima et al. (2017), Tucker-Kulesza et al. (2017), Grubbs et al. (2019), Brogi et al. (2019), and Nocco et al. (2019)

Bulk density related (including compaction, and rock content)

Rhoades et al. (1999b), Malo et al. (2000), Gorucu et al. (2001), Johnson et al. (2001), Brevik and Fenton (2004), Carroll and Oliver (2005), Chaplot et al. (2010), Ekwue and Bartholomew (2011), André et al. (2012), ${ }^{a}$ Naderi-Boldaji et al. (2013, 2014), Rossi et al. (2013), Al-Asadi and Mouazen (2014), ${ }^{a}$ Islam et al. (2014a, b), Cho et al. (2016), Filho et al. (2017), and Al Rashid et al. (2018) 
Table 2 Compilation of literature measuring $\mathrm{EC}_{\mathrm{a}}$ with geophysical techniques (ER or EMI) that have been categorized according to edaphic properties that were either directly or indirectly measured by $\mathrm{EC}_{\mathrm{a}}$. - cont'd Directly measured soil properties

Organic matter related (including soil organic carbon, total carbon, and organic chemical plumes)

Greenhouse and Slaine (1983, 1986), Brune and Doolittle, 1990, Nyquist and Blair (1991), Jaynes (1996), Benson et al. (1997), Bowling et al. (1997), Brune et al. (1999), Nobes et al. (2000), Bekele et al. (2005), Grigera et al. (2006), Shaner et al. (2008a), Martínez et al. (2009), Werban et al. (2009), Ekwue and Bartholomew (2011), Kweon et al. (2013), , Koszinski et al. (2015), ${ }^{a}$ Peralta et al. (2015), Pozdnyakov et al. (2015), Altdorff et al. (2016), ${ }^{a}$ Huang et al. (2017e), Grubbs et al. (2019), Uribeetxebarria et al. (2018), and Nocco et al. (2019)

Cation exchange capacity

McBride et al. (1990), Triantafilis et al. (2002, 2009), Sudduth et al. (2003, 2005), Bronson et al. (2005), Gholizadeh et al. (2011), Terrón et al. (2011), Kweon et al. (2013), ${ }^{\text {a }}$ Peralta and Costa (2013), Pozdnyakov et al. (2015), Rodrigues Jr. et al. (2015), and Walter et al. (2015)

Soil temperature

Brevik et al. (2004) and Giordano et al. (2017)

Soil mineralogy

Nagra et al. (2017)

\section{Indirectly measured soil properties}

Groundwater recharge

Cook and Kilty (1992), Cook et al. (1989, 1992), Cook and Williams (1998), Salama et al. (1994), and Massuel et al. (2006)

Heavy metals

Corwin and Ahmad (2015)

Herbicide partition coefficients

Jaynes et al. (1995b) and Shaner et al. (2008b)

Leaching (including leaching fraction)

Rhoades (1981), Slavich and Yang (1990), Corwin et al. (1999, 2003b), and Rhoades et al. (1999b)

$p H$ (soil acidity)

Clay et al. (2001), Bekele et al. (2005), Aimrun et al. (2007), Dunn and Beecher (2007), Wong et al. (2008), Serrano et al. (2010), Gholizadeh et al. (2011), Terrón et al. (2011), Mahmood et al. (2012), ${ }^{\text {a }}$ Peralta and Costa (2013), Huang et al. (2014c, d), ${ }^{a}$ Peralta et al. (2015), Tycholiz et al. (2016), and Grubbs et al. (2019) 
Table 2 Compilation of literature measuring $\mathrm{EC}_{\mathrm{a}}$ with geophysical techniques (ER or $\mathrm{EMI}$ ) that have been categorized according to edaphic properties that were either directly or indirectly measured by $\mathrm{EC}_{\mathrm{a}}$. - cont'd Indirectly measured soil properties

Soil drainage and drainage classes (including hydraulic conductivity)

Rhoades et al. (1997), Kravchenko et al. (2002), Triantafilis et al. (2004), Vervoort

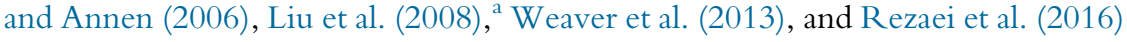

Soil resistance to penetration

Siqueira et al. (2014)

${ }^{\mathrm{a}}$ Data fusion: use of $\mathrm{EC}_{\mathrm{a}}$ (either ER or EMI) and 1 or more other proximal or satellite sensors (e.g., gamma-ray spectrometry, hyperspectral reflectance, synthetic aperture radar, LiDAR) or aerial photos. Definitions: $\mathrm{EC}_{\mathrm{a}}=$ apparent soil electrical conductivity; $\mathrm{ER}=$ electrical resistivity; $\mathrm{EMI}=$ electromagnetic induction.

Modified from Corwin, D.L., Lesch, S.M., 2005a. Apparent soil electrical conductivity measurements in agriculture. Comput. Electron Agric. 46 (1-3), 11-43; Corwin, D.L., Lesch, S.M., 2013. Protocols and guidelines for field-scale measurement of soil salinity distribution with ECa-directed soil sampling. J.Environ. Eng. Geophys. 18 (1), 1-25.

geospatial $\mathrm{EC}_{\mathrm{a}}$ measurements. Examples are found in Rhoades (1992,1993), Carter et al. (1993), Cannon et al. (1994), and Freeland et al. (2002).

The sampling strategy is crucial to the $\mathrm{EC}_{\mathrm{a}}$-directed soil sampling approach. The sample design software used to select soil sample sites from the geospatial $\mathrm{EC}_{\mathrm{a}}$ measurements is covered in detail in Corwin and Scudiero (2016). Either design-based (i.e., probability based) or modelbased (i.e., prediction-based) sampling schemes are used to establish the locations of where soil cores are taken based on the range and variability of the georeferenced $\mathrm{EC}_{\mathrm{a}}$ measurements taken in a field. Design-based sampling relies on randomization principles for drawing statistical inference (Lesch, 2012) and includes random sampling, stratified random sampling, and supervised classification, to mention a few. Designed-based sampling methods are particularly useful whenever the reason for sampling does not involve spatial modeling, such as when comparing soil properties over different fields. In contrast, model-based sampling, such as a response surface sampling design, supports the use of parametric modeling (Lesch, 2012) by focusing on the requirements of the model one intends to use. Lesch (2005), Lesch and Corwin (2008), and Corwin et al. (2010) compared the design-based and model-based sampling strategies and found that model-based sampling resulted in more precise parameter estimates and smaller prediction variances 
than design-based sampling strategies. More specifically, the use of a response surface sampling design resulted in a substantial reduction in the number of samples required to characterize variation in the target soil property. For this reason, the work of Lesch and colleagues in the development of the ESAP software (Lesch et al., 2000), which uses the response surface sampling design approach, is regarded as a significant contribution to $\mathrm{EC}_{\mathrm{a}}$-directed soil sampling.

The protocols for $\mathrm{EC}_{\mathrm{a}}$-directed soil sampling have evolved (Corwin and Lesch, 2003, 2005b, 2013; Corwin and Scudiero, 2016). However, the goal of the protocols has remained unchanged. The protocols are intended to mitigate the influence of primary and secondary factors influencing an $\mathrm{EC}_{\mathrm{a}}$ survey targeted at measuring soil salinity (or other target property) to optimize the collection of reliable $\mathrm{EC}_{\mathrm{a}}$ survey data that will render spatially accurate maps of soil salinity (or other target property). Fig. 5 is a conceptual path diagram showing the primary and secondary factors influencing an $\mathrm{EC}_{\mathrm{a}}$ survey that can cause unreliable $\mathrm{EC}_{\mathrm{a}}$ data. The failure to follow $\mathrm{EC}_{\mathrm{a}}$-directed soil sampling protocols will likely result in unreliable data that causes an inaccurate calibration of $\mathrm{EC}_{\mathrm{a}}$ to the target property causing spurious maps of the target property.

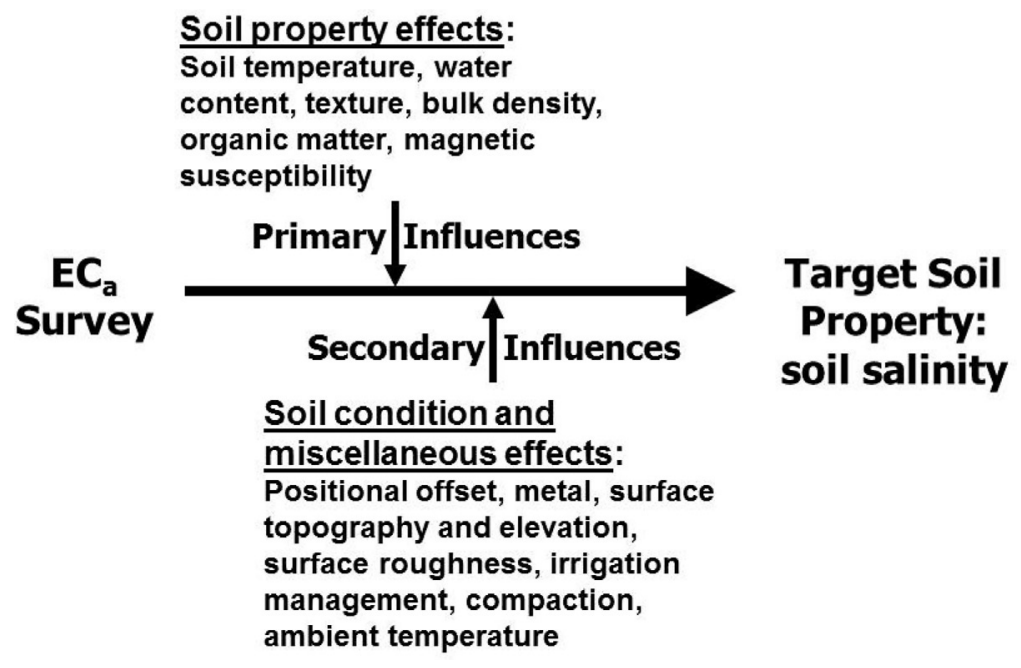

Fig. 5 Conceptual path diagram of the primary and secondary factors influencing an apparent soil electrical conductivity $\left(\mathrm{EC}_{\mathrm{a}}\right)$ survey targeted at measuring soil salinity. Taken from Corwin, D.L., Lesch, S.M., 2013. Protocols and guidelines for field-scale measurement of soil salinity distribution with $E C_{a}$-directed soil sampling. J. Environ. Eng. Geophys. 18 (1), 1-25 with permission. 
To manage the threat posed by soil salinity, producers, land and water resource managers, and policy makers need reliable, up-to-date, high resolution assessments of soil salinity across multiple scales (i.e., field to regional scales). The development of field-scale $\mathrm{EC}_{\mathrm{a}}$-directed soil sampling opened the door for salinity assessment at larger spatial extents than field scale (i.e., $>3 \mathrm{~km}^{2}$ ). Two quantitative salinity assessment approaches have evolved and are in current use for application at scales ranging from landscape-scale $\left(3-10 \mathrm{~km}^{2}\right)$ to regional-scale $\left(10-10^{6} \mathrm{~km}^{2}\right)$, both relying on field-scale $\mathrm{EC}_{\mathrm{a}}$-directed soil sampling. One approach uses analysis of covariance (ANOCOVA) to calibrate $\mathrm{EC}_{\mathrm{a}}$ to salinity over large spatial extents (i.e., 100,000 ha or more). The second approach uses satellite imagery and $\mathrm{EC}_{\mathrm{a}}$-directed soil sampling to calibrate categories of pixels with a vegetation index or VI (i.e., spectral transformation of two or more wavelengths, which allows spatial and temporal comparisons of vegetation cover condition such as photosynthesis and canopy structure) by itself or VI in combination with other environmental co-variates.

The earliest efforts to map soil properties, including soil salinity, at landscape scale and larger spatial extents were qualitative approaches taken by such federal agencies as the soil conservation service (SCS), which later became the current natural resources conservation service (NRCS). NRCS is charged with the mission of mapping soils throughout the United States. Mapping soils and their associated soil properties were based on the premise that soil formation was a process involving the interplay of five main factors: time, parent material, climate, relief, and organisms. Ultimately, spatial soils databases at three scales were developed in the United States: the national level called NATSGO (National Soil Geographic database at a scale of $1: 7,500,000)$, the state level called STATSGO (State Soil Geographic database with scales ranging from 1:250,000 to 1:1,000,000), and the county level called SSURGO (Soil Survey Geographic database with scales ranging from 1:12,000 to 1:63,360). Soil properties in SSURGO were qualitatively established by associating a representative soil profile to a soil series, which consists of pedons grouped together because of similar soil chemistry, physical properties, and pedogenesis. Subsequently, the first regional-scale maps of soil salinity were from SSUR GO. However, representative soil profiles in SSURGO were representative of natural conditions and not conditions reflecting anthropogenic impacts from irrigation and crop management. Subsequently, mapping transient soil chemical properties within the root zone, such as soil salinity, from SSURGO with any likelihood of accuracy 
is dubious. Corwin et al. (2017) confirmed this in a validation study comparing SSURGO data to ground-truth measurements of soil salinity. The validation study revealed that only 5 out of 22 fields assessed the mean salinity accurately, suggesting that the transient salinity levels influenced by anthropogenic activity are not captured by the one-time measurements of NRCS soil surveys. However, SSURGO was able to assess 15 out of 22 fields accurately for salinity below the root zone, indicating that the salt levels below the root zone remained relatively unchanged and unaffected by anthropogenic influences.

The earliest effort to map root-zone soil salinity quantitatively at regional scale did not rely on proximal or remote sensors, but rather approached the problem from a modeling perspective. Corwin et al. (1989) developed a phenomenological model for salinization of the root zone from edaphic, anthropogenic, and hydrological factors influencing salinity development. These salinization factors included soil permeability, leaching fraction, and groundwater quality. Corwin et al. (1989) mapped root-zone soil salinity for the entire Wellton-Mohawk Irrigation District $\left(440 \mathrm{~km}^{2}\right)$ near Yuma, AZ. Comparison of the salinity predictions from the model to ground-truth salinity from soil samples indicated that $86 \%$ of the categories of salinity (i.e., low salinity of $<2 \mathrm{dS} \mathrm{m}^{-1}$; medium salinity of $2-4 \mathrm{dS} \mathrm{m}^{-1}$; high salinity of $>4 \mathrm{dS} \mathrm{m}^{-1}$ ) were correctly predicted. The biggest drawback to this modeling approach is that considerable spatial data (i.e., leaching fraction, soil permeability, and groundwater quality) is needed that is seldom available.

These early landscape- and regional-scale approaches were either too qualitative and unreliable as shown by SSURGO or too site-specific and data intensive as shown by the phenomenological model of Corwin et al. (1989). Subsequently, Harvey and Morgan (2009) and Corwin and Lesch (2014) showed that a calibration of $\mathrm{EC}_{\mathrm{a}}$ to salinity over multiple fields, landscape scale $\left(3-10 \mathrm{~km}^{2}\right)$, and larger spatial extents is possible using ANOCOVA regression models. Corwin and Lesch (2014) observed that abrupt changes in the magnitude of $\mathrm{EC}_{\mathrm{a}}$ occurred across field boundaries in multi-field surveys. This presents a challenge to the conversion of $\mathrm{EC}_{\mathrm{a}}$ to salinity when mapping across thousands to tens of thousands of hectares. The ANOCOVA calibration models adjust out any abrupt change (Corwin and Lesch, 2014). An extensive multi-field validation of the ANOCOVA approach, consisting of 77 fields, has been conducted by Corwin and Lesch (2017), which established the viability and reliability of this approach. The ANOCOVA approach represents a compromise between calibrating a 
regression model for each field and calibrating a model across all fields in the survey area (Corwin and Lesch, 2014). An alternative approach of calibrating $\mathrm{EC}_{\mathrm{a}}$ to salinity across multiple fields was taken by Amakor et al. (2013) using quantile regression. However, their approach appears less accurate and was not validated as extensively as the ANOCOVA approach. Nocco et al. (2019) followed the approach of Amakor et al. (2013) on coarse non-saline soil and found strong significant $(P<0.05)$ correlative and predictive relationships between $\mathrm{EC}_{\mathrm{a}}$ and topsoil $(0-0.3 \mathrm{~m})$ particle size fraction, OM content, and field capacity within and across multiple fields. Additional multifield studies by Kelley et al. (2017), Robinet et al. (2018), and Brogi et al. (2019) using $\mathrm{EC}_{\mathrm{a}}$ to characterize the spatial variability of soil water content or texture show similar inadequacies that could be addressed by the use of the ANOCOVA approach. A comparison between the approaches of Harvey and Morgan (2009), Corwin and Lesch (2014), Amakor et al. (2013), Kelley et al. (2017), Robinet et al. (2018), and Brogi et al. (2019) would be of value to the scientific community; specifically, a comparison between the quantile regression (Amakor et al., 2013) and ANOCOVA (Corwin and Lesch, 2014) approaches is needed for salinity assessment.

For obvious reasons remote sensing has been a stalwart tool for mapping attributes such as soil properties across multiple scales, particularly regional scale, since the first Landsat satellites of the 1970s. As pointed out by Lobell (2010), there is no other instrument platform that offers the spatially exhaustive, objective, and repeated measurements at an effective cost comparable to satellite remote sensing. Remote-sensor measurements of soil attributes fall into two categories: direct and indirect measurements. Direct methods are those that identify wavelengths or combinations of wavelengths that directly reflect changes in soil properties. On the other hand, indirect methods infer soil attributes from some aspect of the vegetation that influences combinations of wavelength formulations. Both methods have inherent weaknesses. The direct method suffers from the difficulty of separating out the "signal" of the desired target soil property from the "noise" created by variations in other soil properties or factors influencing the sensor measurement. Whereas, the indirect method can successfully measure the vegetation condition by means of a VI but translating attribute changes in vegetation to specific soil properties is problematic, particularly when considering climatic variations and anthropogenic influences. Consequently, three types of methodologies are used for estimating soil properties with remote sensing: (i) physical models based on spectra relating remote sensing 
signals to soil parameters, (ii) empirical models based on satellite and ground databases, and (iii) semi-empirical models based on a mixture of physical modeling and empirical data.

Numerous researchers have found that various soil constituents including mineral composition, organic matter, soil texture, soil moisture, and surface roughness, and several others influence soil reflectance (Goetz, 1992; Jensen, 2000; Lillesand et al., 2004). For salt-affected soils the presence of salt evaporates influences the soil spectral reflectance. Researchers have found five spectral bands that appear to be significant for salinity assessment, including visible $(550-770 \mathrm{~nm})$, near-infrared $(900-1030,1270-1520 \mathrm{~nm})$, and middle infrared (1940-2150, 2150-2310, 2330-2400 nm) spectral bands at spectral resolution varying from 3 to $80 \mathrm{~nm}$ (Csillag et al., 1993; Farifteh et al., 2007a, 2008; Metternicht and Zinck, 1997; Nawar et al., 2014; Shrestha et al., 2005; Sidike et al., 2014; Wang et al., 2012). However, two of these ranges (i.e., 1270-1520 and 1940-2150 nm) cannot be used because of water vapor absorption in the atmosphere. Most of the spectral features seen in saline minerals from 400 to $2500 \mathrm{~nm}$ are attributed to internal vibrational modes of borate, carbonate, neutral water molecules, and hydroxyl groups (Crowley, 1991; Hunt, 1980). Farifteh et al. (2006) point out that there are surface features found in salt-affected soils that also cause soil reflectance variation, which can be categorized as soil-related indicators (e.g., white salt crusts on the soil surface, puffy soil surface, dark greasy surface of pure alkali soils, dehydration carcks 1-2 cm wide, and coarse topsoil texture) and performance oriented indicators (e.g., spotty growth of crops, presence of dead trees, a blue-green tinge, and moisture stress condition). Taylor et al. (1994) were the first to demonstrate the mapping of salinity in soils using airborne imaging spectroscopy (now referred to as hyperspectral imagery).

A variety of techniques and statistical approaches have been used to establish the relationship between surface soil salinity and diagnostic spectral features. These include spectral derivative analysis (Wang et al., 2014), continuum-removed methods (Wang et al., 2014), optimum index factor (Dwivedi and Rao, 1992; Goossens and Van Ranst, 1998), multiple regression analysis (Ben-Dor et al., 2002; Dehaan and Taylor, 2002; Ekercin and Ormeci, 2008; Shrestha, 2006), partial least square regression (Fan et al., 2015; Farifteh et al., 2007a; Goldshleger et al., 2012; Nawar et al., 2014, 2015; Wang et al., 2014; Weng et al., 2008a), multivariate adaptive regression splines (Nawar et al., 2014, 2015), principal component regression 
(Moreira et al., 2015), and artificial neural networks (Farifteh et al., 2007a). In addition, several interpretation strategies of hyperspectral imagery have been utilized including linear unmixing (Adams et al., 1986; Gillespie et al., 1990), matched filtering (Boardman, 1993), mixture-tuned matched filtering (Better Solutions Consulting, 1997), and spectral feature fitting (Clark et al., 1990). Wang et al. (2014) used first-order derivative analysis and continuum-removed reflectance to detect subtle changes in spectral adsorption features due to changes in soil salinity and then used partial least square regression to model the relationship between soil spectra and soil salinity. Continuum-removal analysis was first suggested by Clark and Roush (1984) to isolate absorption features of interest. Partial least square regression is particularly well suited for hyperspectral data because it is effective in dealing with strong collinearity between independent variables and noisy predictor variables (Nawar et al., 2015; Wold et al., 2001). Optimun index factor was used by Dwivedi and Rao (1992) to identify the most appropriate three-band combination of Landsat thematic mapper reflectance bands for delineating salt-affected soils for a $78 \mathrm{~km}^{2}$ area in the IndoGangetic alluvial plain. Multivariate adaptive regression splines are a powerful nonparametric modeling method for establishing complex nonlinear relationships.

Direct and indirect remote sensing methods are applied to soil surface and subsurface mapping of salinity, respectively. Both radar and optical remote sensing have been used to map salinity. Radar, photographic, multi-spectral, and hyper-spectral sensors have been used for mapping surface soil salinity. The use of radar, specifically microwaves, is based on the dielectric properties of soil, where the dielectric constant is a complex number consisting of a real part related to water content and an imaginary part related to salinity (Sreenivas et al., 1995). The imaginary part is calculated and calibrated with salinity using inverse modeling (Bell et al., 2001a; Shao et al., 2003; Taylor et al., 1996). Lasne et al. (2008) studied the influence of polarized radar backscattering and found greater sensitivity of backscattering to salinity for vertical polarization. Barbouchi et al. (2014) used interferometric coherence of synthetic aperture radar for detecting soil surface changes that were correlated with variation in soil salinity. Highresolution aerial photographic sensors provide color information regarding brightness, Munsel color, and pseudo-color infrared that can identify salinized soil surfaces (Metternicht and Zinck, 2003). The spectral response patterns from saline soils are a function of the mineralogy and quantity of salts 
present. For instance, saline soils have spectral features related to water in hydrated evaporate minerals in the VNIR region of the spectrum. Hydrated evaporate minerals show adsorption at 505, 920, 1415, 195, and $2205 \mathrm{~nm}$. However, salt-affected soils do not show all the adsorption features found in pure minerals and highly saline soils show additional adsorption at 680, 1180, and $1780 \mathrm{~nm}$. Additionally, Taylor and Dehaan (2000) found that the overall slope of the reflection curve from 800 to $1300 \mathrm{~nm}$ decreased with increased salinity. Hyper-spectral remote sensing has tremendous potential to quantify soil salinity because the hydrogen bond with soil water and soil salt results in subtle spectral changes detectable with hyper-spectral data (Hirschfield, 1985). The ample spectral information from hyper-spectral measurements provides the capability for the identification of target characteristics based on their established absorption features (Goetz et al., 1985). As examples, Ben-Dor et al. (2002) determined field soil moisture and salinity separately with the DAIS-7915 hyper-spectral airborne sensor using visible and near infrared analysis (VNIRA). Howari et al. (2002) found that under certain conditions spectroscopy could identify the presence of primary diagnostic features of salt crusts. Weng et al. (2008b) found a strong correlation $(r=0.91)$ between a soil salinity index constructed using a continuum removed reflectance at 2052 and $2203 \mathrm{~nm}$ bands of the ASD spectrometer and soil salinity content. Other hyper-spectral research was conducted by Dehaan and Taylor (2002, 2003), Howari (2003), Lu et al. (2005), Shrestha et al. (2005), Naumann et al. (2008), Weng et al. (2008a), Qu et al. (2009), Bilgili et al. (2011), Kobayashi et al. (2013), Wang et al. (2014), and Xu et al. (2016).

A variety of spectral indices have been proposed for monitoring and mapping surface and subsurface soil salinity from multi- and hyper-spectral data (Table 3). These indices include simple ratio indices of reflectance, intensity indices, soil indices, and vegetation indices. Simple ratio, intensity, and soil indices are confined to the top $0.05-0.1 \mathrm{~m}$, while vegetation indices reflect stresses on the plant root system throughout the root zone. Table 3 provides a list of the categories of spectral indices, the indices associated with each category, their equation, and the original citation for the index and where needed an associated reference on the use of the index to monitor and/or map surface or subsurface soil salinity.

Salinity at or near the soil surface has been identified with remote imagery over large spatial extents (Allbed and Kumar, 2013; Metternicht and Zinck, 2003, 2009; Mougenot et al., 1993), but measuring and monitoring 
Table 3 Spectral indices used in studies to monitor and/or map surface and/or subsurface soil salinity.

\section{Index}

Simple ratio $\quad \mathrm{SR}_{680}=\mathrm{R}_{800} / \mathrm{R}_{680}$

indices

\begin{tabular}{|c|c|c|}
\hline & $\mathrm{SR}_{705}=\mathrm{R}_{750} / \mathrm{R}_{705}$ & $\begin{array}{l}\text { Gitelson and Merzlyak } \\
\text { (1994) and Zhang et al. } \\
\text { (2011) }\end{array}$ \\
\hline & $\mathrm{RVI}=N I R / R$ & $\begin{array}{l}\text { Major et al. (1990) and } \\
\text { Allbed and Kumar } \\
(2013)\end{array}$ \\
\hline & WSRR $=\mathrm{R}_{990} / \mathrm{R}_{933}$ & Tilley et al. (2007) \\
\hline \multirow[t]{3}{*}{ Intensity indices } & $\operatorname{Int} 1=(G+R) / 2$ & Douaoui et al. (2006) \\
\hline & $\operatorname{Int} 2=(G+R+N I R) / 2$ & Douaoui et al. (2006) \\
\hline & $\mathrm{BI}=\left(R^{2}+N I R^{2}\right)^{1 / 2}$ & Khan et al. $(2001,2005)$ \\
\hline \multirow[t]{14}{*}{ Soil indices } & $\begin{array}{l}\text { NDRGI }=(\text { Band } 5-\text { Band } 7) /(\text { Band } 5 \\
+ \text { Band } 7)\end{array}$ & $\begin{array}{l}\text { Nield et al. (2007) and } \\
\text { Yu et al. (2010) }\end{array}$ \\
\hline & $\begin{array}{l}\text { NDRNI }=(\text { Band } 5-\text { Band } 4) /(\text { Band } 5 \\
+ \text { Band } 4)\end{array}$ & Nield et al. (2007) \\
\hline & $\mathrm{NDSI}=(R-N I R) /(R+N I R)$ & Khan et al. $(2001,2005)$ \\
\hline & OLI_SI $=\left(C B^{2} \cdot 50\right)-(B+G+R)$ & El Harti et al. (2016) \\
\hline & $\mathrm{SI}=(B \cdot R)^{1 / 2}$ & $\begin{array}{l}\text { Khan et al. (2001, 2005) } \\
\text { and Gorji et al. (2017) }\end{array}$ \\
\hline & $\mathrm{SI} 1=(G \bullet R)^{1 / 2}$ & $\begin{array}{l}\text { Douaoui et al. (2006) } \\
\text { and Gorji et al. (2017) }\end{array}$ \\
\hline & $\mathrm{SI} 2=\left(G^{2}+R^{2}+N I R^{2}\right)^{1 / 2}$ & $\begin{array}{l}\text { Douaoui et al. (2006) } \\
\text { and Gorji et al. (2017) }\end{array}$ \\
\hline & $\mathrm{SI} 3=\left(G^{2}+R^{2}\right)^{1 / 2}$ & $\begin{array}{l}\text { Douaoui et al. (2006), } \\
\text { Gorji et al. (2017) }\end{array}$ \\
\hline & $\mathrm{SI} 4=\left(R^{2}+N I R^{2}\right)^{1 / 2}$ & $\begin{array}{l}\text { Khan et al. (2005) and } \\
\text { Gorji et al. (2017) }\end{array}$ \\
\hline & $\begin{array}{l}\text { ASTER-SI }=(S W I R 1-S W I R 2) / \\
(S W I R 1+S W I R 2)\end{array}$ & $\begin{array}{l}\text { Al-Khaier (2003) and } \\
\text { Bouaziz et al. (2010) }\end{array}$ \\
\hline & SI-1 = ALI9/ALI10 & Bannari et al. (2008) \\
\hline & SI-2 = (ALI6 - ALI9)/(ALI6 + ALI9) & Bannari et al. (2008) \\
\hline & $\begin{array}{l}\text { SI-3 }=(\text { ALI9 }- \text { ALI10) } /(\text { ALI } 9 \\
+ \text { ALI10 })\end{array}$ & Bannari et al. (2008) \\
\hline & $\mathrm{SI}-\mathrm{T}=(R / N I R) \bullet 100$ & Tripatthi et al. (1997) \\
\hline
\end{tabular}

\section{References $^{\mathrm{a}}$}

Blackburn (1998) and Zhang et al. (2011)

Gitelson and Merzlyak (1994) and Zhang et al

Allbed and Kumar 
Table 3 Spectral indices used in studies to monitor and/or map surface and/or subsurface soil salinity.- - cont'd

Index

Equation

References $^{\mathrm{a}}$

\begin{tabular}{|c|c|}
\hline $\mathrm{S}_{1}=B / R$ & Abbas and Khan (2007) \\
\hline $\mathrm{S}_{2}=(B-R) /(B+R)$ & Abbas and Khan (2007) \\
\hline $\mathrm{S}_{3}=(G \bullet R) / B$ & Abbas and Khan (2007) \\
\hline $\mathrm{S}_{4}=(B \cdot R)^{1 / 2}$ & Abbas and Khan (2007) \\
\hline $\mathrm{S}_{5}=(B \bullet R) / G$ & Abbas and Khan (2007) \\
\hline $\mathrm{S}_{6}=(R \bullet N I R) / G$ & Abbas and Khan (2007) \\
\hline $\mathrm{SSI}=\left(\mathrm{B}_{2}-\mathrm{B}_{1}\right) /\left(\mathrm{B}_{2}+\mathrm{B}_{1}\right)$ & $\begin{array}{l}\text { Weng et al. (2010) and } \\
\text { Oskoee (2017) }\end{array}$ \\
\hline SSSI-1 = ALI9 - ALI10 & Bannari et al. (2008) \\
\hline $\begin{array}{l}\text { SSSI-2 }= \\
((\text { ALI9 } \bullet \text { ALI10 })-(\text { ALI10 } \bullet \text { ALI10 })) / \\
\text { ALI9 }\end{array}$ & Bannari et al. (2008) \\
\hline $\begin{array}{l}\mathrm{ISK}=\left(((R-G) \cdot(R+G))^{1 / 2}\right) / \\
\left(R^{2}+G^{2}\right)^{1 / 2}\end{array}$ & $\begin{array}{l}\text { Noureddine et al. (2014) } \\
\text { and Nouri et al. (2018) }\end{array}$ \\
\hline $\begin{array}{l}\mathrm{EC}_{\mathrm{EO}}=\alpha_{1}+\left[\left(\alpha_{2} \bullet \mathrm{TM}_{1}+\alpha_{3} \bullet \mathrm{TM}_{2}+\right.\right. \\
\left.\alpha_{4} \bullet \mathrm{TM}_{3}+\alpha_{5} \bullet \mathrm{TM}_{4}\right) /\left(\alpha_{6} \bullet \mathrm{TM}_{4}+\right. \\
\left.\left.\alpha_{7} \bullet \mathrm{TM}_{7}\right)\right]\end{array}$ & $\begin{array}{l}\text { Ekercin and Ormeci } \\
(2008) \text { and Nouri et al. } \\
(2018)\end{array}$ \\
\hline
\end{tabular}

\begin{tabular}{lll}
\hline Vegetation & CRSI $=[((N I R \bullet R)-(G \bullet B)) /$ & Scudiero et al. (2014a, \\
indices & $((N I R \bullet R)+(G \bullet B))]^{1 / 2}$ & $2015)$ \\
\hline
\end{tabular}

indices

$\mathrm{GDVI}^{\wedge} n=\left(N I R^{n}-R^{n}\right) /\left(N I R^{n}+R^{n}\right) \quad \mathrm{Wu}(2014)$ and

Mhaimeed et al. (2013)

$\mathrm{NDVI}=(N I R-R) /(N I R+R) \quad$ Rouse et al. (1973,

1974) and Wiegand et al. (1994)

\begin{tabular}{|c|c|}
\hline $\begin{array}{l}\text { NDVI no. } 3=\left(N I R_{1}-Y\right) / \\
\left(N I R_{1}+Y\right)\end{array}$ & Abood et al. (2011) \\
\hline $\begin{array}{l}\text { Modified NDVI }{ }_{1}=\left(\mathrm{R}_{774}-\mathrm{R}_{681}\right) / \\
\left(\mathrm{R}_{774}+\mathrm{R}_{681}\right)\end{array}$ & $\begin{array}{l}\text { Tucker (1979) and } \\
\text { Tilley et al. (2007) }\end{array}$ \\
\hline $\begin{array}{l}\text { Modified } \mathrm{NDVI}_{2}=\left(\mathrm{R}_{750}-\mathrm{R}_{680}\right) / \\
\left(\mathrm{R}_{750}+\mathrm{R}_{680}\right)\end{array}$ & $\begin{array}{l}\text { Gitelson and Merzlyak } \\
\text { (1994) }\end{array}$ \\
\hline $\begin{array}{l}\text { Modified } \mathrm{NDVI}_{3}=\left(\mathrm{R}_{830}-\mathrm{R}_{660}\right) / \\
\left(\mathrm{R}_{830}+\mathrm{R}_{660}\right)\end{array}$ & Wang et al. (2002) \\
\hline $\begin{array}{l}\mathrm{AFRI}_{1600}=\left(N I R-0.66 \mathrm{R}_{1600}\right) / \\
\left(N I R+0.66 \mathrm{R}_{1600}\right)\end{array}$ & $\begin{array}{l}\text { Karnieli et al. (2001) and } \\
\text { Nouri et al. (2018) }\end{array}$ \\
\hline $\begin{array}{l}\mathrm{AFRI}_{2100}=\left(N I R-0.5 \mathrm{R}_{2100}\right) / \\
\left(N I R+0.5 \mathrm{R}_{2100}\right)\end{array}$ & $\begin{array}{l}\text { Karnieli et al. (2001) and } \\
\text { Nouri et al. (2018) }\end{array}$ \\
\hline
\end{tabular}


Table 3 Spectral indices used in studies to monitor and/or map surface and/or subsurface soil salinity.-Cont'd

Index

Equation

References $^{\mathrm{a}}$

$\mathrm{DVI}=N I R-R$

Clevers (1988) and

Douaoui et al. (2006)

$\mathrm{EVI}=2.5(\mathrm{NIR}-\mathrm{R}) /$

Liu and Huete (1995)

$(N I R+6 R-7.5 B+1)$

and Allbed and Kumar

(2013)

$\mathrm{fWBI}=\mathrm{R}_{900} / \min \left(\mathrm{R}_{930}-\mathrm{R}_{980}\right)$

Strachan et al. (2002)

and Tilley et al. (2007)

\begin{tabular}{|c|c|}
\hline $\mathrm{WDVI}=N I R-a \cdot R$ & $\begin{array}{l}\text { Clevers (1989) and } \\
\text { Douaoui et al. (2006) }\end{array}$ \\
\hline $\begin{array}{l}\text { Chl NDI }=\left(\mathrm{R}_{750}-\mathrm{R}_{705}\right) / \\
\left(\mathrm{R}_{750}+\mathrm{R}_{705}\right)\end{array}$ & Thorhaug et al. (2006) \\
\hline $\mathrm{PRI}=\left(\mathrm{R}_{531}-\mathrm{R}_{570}\right) /\left(\mathrm{R}_{531}+\mathrm{R}_{570}\right)$ & $\begin{array}{l}\text { Gamon et al. (1997) and } \\
\text { Tilley et al. (2007) }\end{array}$ \\
\hline $\mathrm{PSRI}=\left(\mathrm{R}_{678}-\mathrm{R}_{500}\right) / \mathrm{R}_{750}$ & $\begin{array}{l}\text { Merzlyak et al. (1999) } \\
\text { and Zhang et al. (2011) }\end{array}$ \\
\hline $\mathrm{PVI}=(N I R-(a \bullet R+b)) /\left(1+a^{2}\right)^{1 / 2}$ & $\begin{array}{l}\text { Richardson and } \\
\text { Wiegand (1977) }\end{array}$ \\
\hline $\mathrm{REP}=\lambda_{\text {re }}$ & $\begin{array}{l}\text { Horler et al. (1983) and } \\
\text { Zhang et al. (2011) }\end{array}$ \\
\hline $\mathrm{VOG} 1=\mathrm{R}_{740} / \mathrm{R}_{720}$ & $\begin{array}{l}\text { Vogelmann et al. (1993) } \\
\text { and Hamzeh et al. (2013) }\end{array}$ \\
\hline $\begin{array}{l}\mathrm{SARVI}=\left((1+L) \cdot\left(N I R-\rho_{R B}\right)\right) / \\
\left(N I R+\rho_{R B}+L\right)\end{array}$ & $\begin{array}{l}\text { Kaufman and Tanré } \\
\text { (1992) and Mhaimeed } \\
\text { et al. (2013) }\end{array}$ \\
\hline $\begin{array}{l}\mathrm{SASI}=\left((1+L) \cdot\left(\lambda_{2}-\lambda_{1}\right)\right) / \\
\left(\lambda_{2}+\lambda_{1}+L\right)\end{array}$ & Zhang et al. (2011) \\
\hline $\begin{array}{l}\mathrm{SAVI}=((N I R-R) /(N I R+R+L)) \bullet \\
(1+L)\end{array}$ & $\begin{array}{l}\text { Huete (1988) and Zhang } \\
\text { et al. (2011) }\end{array}$ \\
\hline $\begin{array}{l}\text { SAVI no. } 2=1.5 \cdot\left(\left(N I R_{1}-Y\right) /\right. \\
\left.\left(N I R_{1}+Y+0.5\right)\right)\end{array}$ & Abood et al. (2011) \\
\hline $\mathrm{SIPI}=\left(\mathrm{R}_{800}-\mathrm{R}_{445}\right) /\left(\mathrm{R}_{800}-\mathrm{R}_{680}\right)$ & $\begin{array}{l}\text { Penuelas et al. (1995) } \\
\text { and Zhang et al. (2011) }\end{array}$ \\
\hline $\begin{array}{l}\text { SWSI1 }=\left(\mathrm{R}_{803}-\mathrm{R}_{681}\right) / \\
\left(\mathrm{R}_{905}+\mathrm{R}_{972}\right)^{1 / 2}\end{array}$ & Hamzeh et al. (2013) \\
\hline $\begin{array}{l}\mathrm{SWSI} 2=\left(\mathrm{R}_{803}-\mathrm{R}_{681}\right) / \\
\left(\mathrm{R}_{1326}+\mathrm{R}_{11507}\right)^{1 / 2}\end{array}$ & Hamzeh et al. (2013) \\
\hline
\end{tabular}


Table 3 Spectral indices used in studies to monitor and/or map surface and/or subsurface soil salinity.-Cont'd

Index Equation References $^{\mathrm{a}}$

$\mathrm{SWSI3}=\left(\mathrm{R}_{803}-\mathrm{R}_{681}\right) /$

$\left(\mathrm{R}_{972}+\mathrm{R}_{1174}\right)^{1 / 2}$

Hamzeh et al. (2013)

TSAVI $=(a \cdot(N I R-(a \bullet R+b))) /$

$\left(R+a \bullet(N I R-b)+0.08\left(1+a^{2}\right)\right)$

Baret and Guyot (1991)

and Douaoui et al.

(2006)

Combined soil COSRI $=\left[\left(\right.\right.$ band $_{1}+$ band $\left._{2}\right) /$

and vegetation $\quad\left(\right.$ band $_{3}+$ band $\left.\left._{4}\right)\right] \cdot \mathrm{NDVI}$

Fernández-Buces et al.

index

(2006)

${ }^{a}$ Earliest known reference of the index and where needed an associated reference on the use of the index to monitor and/or map surface or subsurface soil salinity.

Definitions: $\lambda_{1}$ and $\lambda_{2}$ are band pair combinations (e.g., SASI ${ }_{1}: \lambda_{1}=$ average $(546-575 \mathrm{~nm}), \lambda_{2}=$ average $(560-590 \mathrm{~nm}) ; \lambda_{\text {re }}=$ wavelength of the red edge defined as the wavelength of maximum change in reflectance with change in wavelength $(d \mathrm{R} / d \lambda) ; \rho_{R B}=R-\gamma(B-R)$ where $\gamma$ is a weighting function dependent on the aerosol type and defaults to $1 ; a, b=$ soil line coefficients; band ${ }_{1}=430-525 \mathrm{~nm}$; band $_{2}=510-600 \mathrm{~nm}$; band $_{3}=600-700 \mathrm{~nm} ;$ band $_{4}=780-1100 \mathrm{~nm} ; \mathrm{B}_{1}$ and $\mathrm{B}_{2}=$ the continuum-removed reflectance of available pairs of spectral bands (e.g., 2052 and $2203 \mathrm{~nm}$, respectively, in Weng et al. (2010) and 742-772 and 2335-2345 nm, respectively, in Oskoee (2017); B, CB, G, R, NIR= reflectance in the blue, coastal blue, green, red, and near-infrared spectral bands, respectively; $L=$ soil adjustment factor ranging from 0 to 1 ; $N I R_{1}=$ reflectance of the WorldView 2s first near-infrared band $(770-895 \mathrm{~nm})$ and $Y=$ reflectance of $\mathrm{t}$ he WorldView 2s yellow band (585-625 nm); SWIR1 and SWIR2=short wave infrared ASTER band $4(1600-1700 \mathrm{~nm})$ and band $5(2145-2185 \mathrm{~nm})$, respectively; AFRI $_{1600}=$ aerosol free vegetation index at the $1600 \mathrm{~nm}$ band where $\mathrm{R}_{1600}$ is the reflectance at $1600 \mathrm{~nm} ; \mathrm{AFRI}_{2100}=$ aerosol free vegetation index at the $2100 \mathrm{~nm}$ band where $\mathrm{R}_{2100}$ is the reflectance at $2100 \mathrm{~nm}$; ALI-6 = EO-1 advanced land imaging sensor band 6 (775-805 nm); ALI-9=EO-1 advanced land imaging sensor band 9 (1550-1750 nm); ALI$10=$ EO-1 advanced land imaging sensor band $10(2080-2350 \mathrm{~nm})$; ASTER-SI = ASTER salinity index; Band4, Band5, and Band7 = 775-900, 1550-1750, and 2090-2350 nm, respectively; BI = brightness index; Chl NDI = chlorophyll normalized difference index; CRSI $=$ canopy response salinity index; DVI $=$ difference vegetation index; $\mathrm{EC}_{\mathrm{EO}}=$ electrical conductivity in $\mathrm{dSm}^{-1}$ for the Ekercin and Ormeci (2008) salinity index where $\alpha_{1}, \alpha_{2}, \alpha_{3}, \alpha_{4}, \alpha_{5}, \alpha_{6}$, and $\alpha_{7}$ are the model coefficients and $\mathrm{TM}_{1}, \mathrm{TM}_{2}, \mathrm{TM}_{3}, \mathrm{~T}$ $\mathrm{M}_{4}$, and $\mathrm{TM}_{7}$ represent the Landsat 5 Thematic Mapper spectral bands of 450-520, 520-600, 630-690, 760-900, and 2080-2350 nm, respectively; EVI = enhanced vegetation index; $\mathrm{fWBI}=$ floating-position water band index; GDVI $n=$ generalized difference vegetation index where $n$ is a power; Int $1=$ intensity within the visible spectral range; Int $2=$ intensity within the VIS-NIR spectral range; NDRGI = normalized difference ratio gypsic index; NDRI = normalized difference ratio natric index; NDVI = normalized difference vegetation index; NDSI = normalized difference salinity index; OLI_SI=Operational Land Imager salinity index; PRI = photochemical reflectance index; PSRI = plant senescence reflectance index; $\mathrm{PVI}=$ perpendicular vegetation index; $\mathrm{R}_{445}, \mathrm{R}_{680}$, and $\mathrm{R}_{800}=$ reflectance at 445,680 , and $800 \mathrm{~nm}$, respectively; $\mathrm{R}_{500}, \mathrm{R}_{678}, \mathrm{R}_{705}$, and $\mathrm{R}_{750}=$ reflectance at $500,678,705$, and $750 \mathrm{~nm}$, respectively; $\mathrm{R}_{660}$ and $\mathrm{R}_{830}=$ reflectance at 660 and $830 \mathrm{~nm}$, respectively; $\mathrm{R}_{900}, \mathrm{R}_{930}$, and $\mathrm{R}_{980}=$ reflectance at 900,930 , and $980 \mathrm{~nm}$, respectively; $R_{531}$ and $R_{570}=$ reflectance at $531 \mathrm{~nm}$ (the waveband of the xanthophyll signal) and reflectance at $570 \mathrm{~nm}$ (a reference wave band, respectively; $\mathrm{REP}=$ red edge position index; $\mathrm{RVI}=$ ratio vegetation index; SARVI = soil adjusted and atmospherically resistant vegetation index; SASI $=$ soil adjusted salinity index; SAVI = soil adjusted vegetation index; SI1 = salinity index 1 ; SI2 = salinity index 2; SI3 = salinity index 3; SI-1 = salinity index 4; SI-2=salinity index 5; SI-3=salinity index 6; $\mathrm{SI}-\mathrm{T}=$ salinity index $7 ; \mathrm{S}_{1}=$ salinity index $8 ; \mathrm{S}_{2}=$ salinity index $9 ; \mathrm{S}_{3}=$ salinity index $10 ; \mathrm{S}_{4}=$ salinity index 11; $\mathrm{S}_{5}=$ salinity index $12 ; \mathrm{S}_{6}=$ salinity index 13 ; SIPI = structure-insensitive pigment index; $\mathrm{SR}=$ simple ratio index; SSI = soil salinity spectral index; SSSI-1 = soil salinity and sodicity index $1 ;$ SSSI-2 = soil salinity and sodicity index 2; ISK = soil salinity index Koulla; SWSI1 = salinity and water stress index 1, where $\mathrm{R}_{681}, \mathrm{R}_{803}, \mathrm{R}_{905}$, and $\mathrm{R}_{972}$ are reflectances at 681,803 , 905 , and $972 \mathrm{~nm}$, respectively; SWSI2= salinity and water stress index 2 , where $\mathrm{R}_{681}, \mathrm{R}_{803}, \mathrm{R}_{1326}$, and $\mathrm{R}_{11507}$ are reflectances at $681,803,1326$, and $11,507 \mathrm{~nm}$, respectively; SWSI3 = salinity and water stress index 3 , where $\mathrm{R}_{681}, \mathrm{R}_{803}, \mathrm{R}_{972}$, and $\mathrm{R}_{1174}$ are reflectances at $681,803,972$, and $1174 \mathrm{~nm}$, respectively; TSAVI $=$ transformed soil-adapted vegetation index; VOG1 = Vogelmann red edge index, where $R_{720}$ and $R_{740}$ are reflectance at 720 and $740 \mathrm{~nm}$, respectively; WDVI $=$ weighted difference vegetation index. WSRR $=$ wetlands salinity reflectance ratio. 
salinity within the top $0.05-0.1 \mathrm{~m}$ is of limited value from an agricultural perspective, especially for irrigated agriculture. Aside from germination, the top $0.1 \mathrm{~m}$ of soil has no significant impact on crop yield. Rather, crops are influenced by soil properties throughout the root zone, which extends generally to a depth of $0.5-1.5 \mathrm{~m}$ depending on the crop. Even though surface salts are readily detected by satellite data they are often obstructed by overlying vegetation or are plowed into the ground in the off-season. Furthermore, surface salts are not always associated with subsurface salts. Farifteh et al. (2008) pointed out three major problems associated with the detection of salt-affected soils using spectral analysis of remote sensing: (i) soil salinity often goes undetected particularly when salts have not yet severely affected the soil, (ii) the boundaries separating different levels of salt are vague and often difficult to delineate, and (iii) the salinization process is not restricted to the soil surface but extends through the soil profile, which is undetectable by spectral analysis of the soil surface with optical sensors. Furthermore, most relationships between soil salinity and reflectance are optimal for severely salt-affected soils but become weaker for low and moderately salt-affected soils (Wang et al., 2012), reflectance measurements are influenced by soil texture Yao et al. (2010), and both salinity and moisture can result in similar soil reflectance or albedo data, making salinity measurement difficult in wet or waterlogged soils (Xu et al., 2016). For these reasons, using indirect methods of remote sensing to determine soil salinity within the root zone is implicit. Visible, near infrared, and thermal reflectance have been used to indicate salt stress in plants. Subsequently, a variety of vegetation indices (VI) have been used to estimate salinity in the root zone (Table 3): normalized difference vegetation index or NDVI (Rouse et al., 1973), enhanced vegetation index or EVI (Huete et al., 2002), soil adjusted salinity index or SASI (Zhang et al., 2011), and canopy response salinity index or CRSI (Scudiero et al., 2014a, 2015), to mention a few. However, other plant stressors such as pests, disease, and water and nutrient deficiency can trigger similar responses in canopy reflectance thereby confounding the relationship between reflectance and salinity. Table 4 provides a comprehensive compilation of papers that have used spectral analysis, soil indices, vegetation indices, and combinations of these as well as synthetic aperture radar to map soil salinity.

Up until the beginning of the new millennium accurate ground-truth measurements of soil properties at the pixel scale of remote imagery, which were primarily of low resolution (e.g., MODIS with $250 \mathrm{~m} \times 250 \mathrm{~m}$ pixel resolution), were non-existent and relied on qualitative judgments by field 
Table 4 Compilation of literature using spectral analysis, soil indices, vegetation indices, and combinations of these to map soil salinity.

Spectral analysis

Hirschfield (1985), Toth et al. (1991), Dwivedi and Rao (1992), Csillag et al. (1993), Metternicht and Zinck (1997), Dwivedi and Sreenivas (1998), Goossens and Van Ranst (1998), Taylor and Dehaan (2000), Ben-Dor et al. (2002, 2009), Dehaan and Taylor (2002, 2003), Howari et al. (2002), Howari (2003), Verma et al. (1994), Huang et al. (2005a, b), Lu et al. (2005), Shrestha et al. (2005), Farifteh et al. (2006, 2007a, b, 2008), Shrestha (2006), Ekercin and Ormeci (2008), Weng et al. (2008a, b), Qu et al. (2009), Elnaggar and Noller (2010), Yu et al. (2010), Bilgili et al. (2011), Goldshleger et al. (2012, 2013), Rekha et al. (2012), Kobayashi et al. (2013), Moreira et al. (2014), Nawar et al. (2014, 2015), Wang et al. (2014), Fan et al. (2015), and Xu et al. (2016)

\section{Soil indices}

Tripatthi et al. (1997), Khan et al. (2001, 2005), Al-Khaier (2003), Madani (2005), Douaoui et al. (2006), Abbas and Khan (2007), Nield et al. (2007), Bannari et al. (2008, 2017, 2018), Odeh and Onus (2008), Bouaziz et al. (2010, 2011), Elnaggar and Noller (2010), Melendez-Pastor et al. (2010), Weng et al. (2010), Yu et al. (2010), Dehni and Lounis (2012), Mashimbye et al. (2012), Teggi et al. (2012), Abbas et al. (2013), Li et al. (2015), Shamsi et al. (2013), Allbed et al. (2014a, b, $2018^{\mathrm{my}}$ ), Masoud (2014), Moreira et al. (2015), Azabdaftari and Sunar (2016), ${ }^{\text {my }}$ Elhag (2016), El Harti et al. (2016), Morshed et al. (2016), Gorji et al. (2017), Oskoee (2017), Zewdu et al. (2017), Asfaw et al. (2018), Babiker et al. (2018), and Ennaji et al. (2018)

\section{Vegetation indices}

Wiegand et al. (1992, 1994, 1996), Gitelson and Merzlyak (1994), Metternicht $\left(2001,2003^{\mathrm{fm}}\right)$, Huete et al. (2002), Wang et al. (2002), Douaoui et al. (2006), Malins and Metternicht (2006), ${ }^{\text {m }}$ Thorhaug et al. (2006), Lobell et al. (2007), ${ }^{\text {my }}$ Tilley et al. (2007), Odeh and Onus (2008), Eldeiry and Garcia (2010), Elnaggar and Noller (2010), Naumann et al. (2008), Wu et al. (2008), Aldakheel (2011), Abood et al. (2011), Bouaziz et al. (2011), Dehni and Lounis (2012), Platonov et al. (2012), ${ }^{\text {my }}$ Allbed and Kumar (2013), Hamzeh et al. (2013), Ivits et al. (2013), ${ }^{\text {ts }} \mathrm{Li}$ et al. (2015), Mandal and Sharma (2011), Zhang et al., 2011, 2015 ${ }^{\text {ts }}$ ), Jin et al. (2012), Sivanpillai et al. (2012), Guo et al. (2013b), ${ }^{\mathrm{fm}}$ Mhaimeed et al. (2013), Shamsi et al. (2013), Allbed et al. (2014a, 2018 ${ }^{\mathrm{my}}$ ), Scudiero et al. (2014a), ${ }^{\mathrm{my}} \mathrm{Wu}$ (2014), Moreira et al. (2015), Azabdaftari and Sunar (2016), ${ }^{\text {my }}$ El Harti et al. (2016), Mandal (2016), Morshed et al. (2016), Elhag and Bahrawi (2017), Ivushkin et al. (2017), Alexakis et al. (2018), Asfaw et al. (2018), Babiker et al. (2018), Casterad et al. (2018), Nouri et al. (2018), and Whitney et al. (2018) $)^{\mathrm{ts}, \mathrm{my}}$ 
Table 4 Compilation of literature using spectral analysis, soil indices, vegetation indices, and combinations of these to map soil salinity.-_cont'd

Combination of spectral analysis, soil indices, and/or vegetation indices

Fernández-Buces et al. (2006), ${ }^{a}$ Brunner et al. (2007), ${ }^{a}$ Eldeiry and Garcia (2008), Judkins and Myint (2012), ${ }^{\mathrm{a}}$ Ding and Yu (2014), ${ }^{\mathrm{b}}$ Chuangye et al. (2016), ${ }^{\mathrm{a}}$ and Peng et al. $(2019)^{\mathrm{b}}$

Spectral analysis/indices and/or other co-variates (e.g., terrain attributes, geomorphology, edaphic attributes, DEM)

Caccetta et al. (2010), ${ }^{\text {DEM1 }}$ Furby et al. (2010), ${ }^{\text {DEM1,my }}$ Lobell et al. (2010), ${ }^{\text {my }}$ Taghizadeh-Mehrjardi et al. (2014), Wu et al. (2014a, $b^{\text {my }}$ ), Yahiaoui et al.

(2015), ${ }^{\text {DEM2 }}$ Yang et al. (2015), Scudiero et al. (2015, 2016b, 2017), ${ }^{\text {my }}$ and Peng et al. (2019) $)^{\text {DEM2 }}$

Synthetic aperture radar

Sreenivas et al. (1995), Taylor et al. (1995, 1996), Metternicht (1997, 1998), Bell et al. (2001a, b), Shao et al. (2003), Aly et al. (2004), Lasne et al. (2008), Grissa et al. (2011), and Barbouchi et al. (2014)

${ }^{\mathrm{a}}$ Combination of spectral analysis and vegetation index.

${ }^{\mathrm{b}}$ Combination of soil and vegetation indices.

Definitions: DEM, digital elevation model. DEM1, spectral analysis and DEMs; DEM2, soil and vegetation indices, and DEMs; $f m$, fuzzy modeling; $t s$, time-series analysis; $m \gamma$, multi-year remote sensing.

experts. Accurate ground-truth data are essential to calibrate the remote imagery derived VI to a soil property. Available regional-scale maps of salinity from remote sensing were qualitative and unreliable (Lal et al., 2004, Lobell et al., 2010). Furthermore, most if not all of the early remote sensing salinity assessment studies covered ranges of salinity (e.g., $0-100 \mathrm{dS} \mathrm{m}^{-1}$ ) well outside the range applicable for agricultural applications (i.e., $0-20 \mathrm{dS} \mathrm{m}^{-1}$ ), serving more as inventories of degraded soils than as management information for agriculture. Prior to 2010, available regional-scale soil salinity information was unreliable and irrelevant to agricultural needs. It was unreliable because it lacked rigorous and robust quantitative foundation in measured ground-truth salinity and the inability to distinguish the influence of salinity from other stress factors on remote imagery. It was irrelevant because nearly all previous regional-scale salinity studies covered ranges well outside the salinity ranges relevant to agriculture thereby serving more as an inventory of degraded soil than as an agricultural management tool.

Three developments occurred over the past 2 decades with respect to regional-scale salinity assessment within the root zone to overcome many 
of the inherent weaknesses of remote sensing: (i) the accurate ground-truth measurement of soil salinity at pixel scales using $\mathrm{EC}_{\mathrm{a}}$-directed soil sampling, (ii) expanded use and development of vegetation indices for assessing soil salinity, and (iii) multi-temporal remote sensing data to isolate the influence of soil salinity on a VI from the influence of other soil properties (e.g., water content) or factors (e.g., disease). The $\mathrm{EC}_{\mathrm{a}}$-directed soil sampling protocols and guidelines of Corwin and Lesch $(2003,2005 b)$ provided the means for establishing the ground-truth soil salinity at pixel scale whether the pixel size was $30 \times 30 \mathrm{~m}^{2}$ for Landsat 7 imagery or $250 \times 250 \mathrm{~m}^{2}$ for MODIS imagery. Monitoring vegetative condition with VI provides a proxy for subsurface salinity. Recent success in regional-scale salinity assessment has come from the use of VI such as the EVI from MODIS imagery (Lobell et al., 2010), canopy response salinity index (CRSI) from Landsat 7 imagery (Scudiero et al., 2014a, 2015), and others. However, monitoring salinity at low to moderate levels across a multitude of fields within large regions is a challenge because variations in pests, disease, climate, edaphic properties, management, and topography can have a significantly greater influence on vegetation than salinity. Lobell et al. $(2007,2010)$ observed that when average root zone salinity remains stable over a period of 5-7 years then multi-temporal analysis of canopy reflectance could reduce some of the error caused by dynamic factors other than soil salinity because these factors tend to fluctuate more over time than salinity. Multi-temporal analysis of canopy reflectance isolates the effects of soil salinity from these other factors. Over the past decade, several studies have used multi-temporal analysis of canopy reflectance to detect soil salinity with considerable success in isolating the influence of salinity (Gorji et al., 2017; Lobell et al., 2007, 2010; Platonov et al., 2012; Scudiero et al., 2014a, 2015; Wu et al., 2014a, b; Zhang et al., 2015).

A comparison by Corwin and Lesch (2017) of the ANOCOVA approach to the remote imagery approach of Scudiero et al. (2015) showed that the ANOCOVA approach provided greater accuracy and higher resolution, but at the expense of higher cost and greater labor requirements. Even though the ANOCOVA approach could be used at regional scale (i.e., $10-10^{6} \mathrm{~km}^{2}$ ), its greater demand on resources and greater accuracy and resolution makes it more appropriate for landscape scale $\left(3-10 \mathrm{~km}^{2}\right)$ application, whereas the satellite imagery approach of Lobell et al. (2010), Scudiero et al. (2015), and Zhang et al. (2015) is clearly best for regionalscale application. 


\section{Previous reviews of the measurement of soil salinity with proximal and/or remote sensors}

Several reviews have been written pertaining to the use of $\mathrm{EC}_{\mathrm{a}}$ to characterize the spatial heterogeneity of soil properties relevant to agricultural productivity, including soil salinity. The first was by Corwin and Lesch (2005a), which provided a review of the development and use of georeferenced $\mathrm{EC}_{\mathrm{a}}$ measurements for precision agriculture applications. Details were presented to provide (i) an understanding of the basic theories and principles of the $\mathrm{EC}_{\mathrm{a}}$ measurement, (ii) an overview of $\mathrm{EC}_{\mathrm{a}}$ measurement techniques, (iii) applications specific to site-specific crop management, (iv) $\mathrm{EC}_{\mathrm{a}}$ survey guidelines for characterizing soil spatial variability, and (v) current and future research trends. Doolittle and Brevik (2014) reviewed the expanded use of EMI from its initial use for soil salinity assessment to include mapping soil types; characterizing soil water content and flow patterns; assessing variations in soil texture, compaction, organic matter content, and $\mathrm{pH}$; and determining the depth to subsurface horizons, stratigraphic layers or bedrock. Subsequently, Heil and Schmidhalter (2017) provided an overview of soil sampling designs and a comprehensive compilation of field-scale characterization studies of salinity, soil texture, water content and soil water turnover, soil types and boundaries, nutrients and N-turnover using EMI. The rationale for the literature compilation was to provide users with an understanding of the soil parameters that are detectable with EMI to make realistic objectives when using EMI. Cursory overviews specific to field-scale soil salinity assessment using $\mathrm{EC}_{\mathrm{a}}$ include Rhoades et al. (1999a), Corwin and Lesch (2013), and Visconti and Miguel de Paz (2016).

Several reviews of remote sensing of general soil properties (Anderson and Croft, 2009; Ben-Dor, 2002; Ben-Dor et al., 2008, 2009; Ge et al., 2011; Kuang et al., 2012; Mulder et al., 2011; Mulla, 2013; Shoshany et al., 2013; Viscarra Rossel et al., 2011; Viscarra Rossel and Lobsey, 2016) and remote sensing specifically of soil salinity (Allbed and Kumar, 2013; Metternicht and Zinck, 2003, 2009; Mougenot et al., 1993; Singh et al., 2010) are present in the literature. The earliest review of remote sensing of salt-affected soils is by Mougenot et al. (1993), which focuses on reflectance properties of sunlight and touches on thermal infrared information to detect hygroscopic characteristics of salt and microwaves indirect information on salts. Spectral properties of different salts and calcite and direct detection of salt-affected soil from spectral responses of salts in visible 
to middle infrared are presented. The frequently cited review paper by Metternicht and Zinck (2003) sums up all the remote sensing strategies tried up to 2003 reporting limited success, especially on agricultural soils where surface soil crust is not visible. The paper reviews various sensors including aerial photography, satellite and airborne multi-spectral sensors, microwave sensors, video imagery, airborne geophysics, hyper-spectral sensors, and EMI meters. Constraints on the application of these sensors for mapping salt-affected areas are discussed with respect to spectral confusions from terrain surface features, vegetation interferences, changes in salinity with time, spectral behavior of different types of salts, and spatial patterns of salts at the soil surface. The review also briefly discusses image processing (i.e., selection of best band combinations, image transformations, intensity-hue-saturation transformations, unmixing of surface features, fuzzy classifications, decision trees and neural networks, and radar backscatter inversion techniques), assessing temporal and spatial changes of salinity, and data fusion and data integration.

The reference book by Metternicht and Zinck (2009) covers three major sections including an introduction, trends in mapping and monitoring soil salinity with proximal and remote sensors, and the diversity of spatio-temporal approaches to modeling soil salinity. The introduction includes the global extent of the salinity problem and approaches for monitoring soil salinity, spectral behavior of various salt types, and review of remote sensing based methods for assessing soil salinity. The section on mapping trends with proximal and remote sensors includes mapping salinity with ground-based EMI, combined active and passive remote sensing methods, multi-sensor radar, satellite and airborne hyper-spectral imagery, IKONOS-II multispectral data, and Landsat multi-spectral imagery. The final section on salinization modeling approaches covers the identification of salt hazard for bare-soil areas from the combined use of evapotranspiration, geopedological, and remote sensing models; a comparison of two interpolation methods, i.e., kriging and Bayesian maximum entropy, for space-time mapping of soil salinity; use of a combined spectral response index that takes into account the reflectance of bare soil and vegetation cover; model-based integration of hyper-spectral remote sensing to quantify salinity of bare soils; and data mining from machine-learning algorithms using mixed remotely sensed and GIS data to map secondary salinization. All of the studies in Metternicht and Zinck (2009) fell outside the relevant range of soil salinity for agricultural purposes and were based on qualitative rather than quantitative ground-truth measurements of soil salinity in the root zone, which makes this work more relevant to inventorying degraded soils than to agricultural applications. 
Singh et al. (2010) review the use of remote sensing in India for mapping salt-affected soils. Their review provides an overview of the development, identification, characterization, and delineation of salt-affected soils from conventional and remote sensing approaches and discusses issues of mapping salt-affected soils. Detecting salt-affected soils with remote sensing by direct methods from salt-encrusted surfaces of varying salt mineralogy and indirectly from crop and vegetation condition are discussed with the preponderance of work focused on measuring surface soil salinity directly. Even though extensive work has been done in India to map salt-affected soils, it focused on surface soil salinity, primarily measured salinities well outside the range of tolerance by crops, lacked quantitative measurements of ground-truth salinity with proximal sensors, and lacked the ability to map salinity within the root zone; consequently, it does not serve agricultural needs but rather serves only as an inventory of degraded soils.

Allbed and Kumar (2013) review the use of remote sensing technology for mapping and monitoring soil salinity in arid and semi-arid regions. A discussion is given of (1) direct (i.e., spectral measurement of salt features visible at the soil surface) and indirect (i.e., presence of halophytic plants and assessing the performance level of salt-tolerant plants) indicators, (2) satellite sensors for detecting and mapping soil salinity, (3) spectral vegetation and salinity indices, and (4) the issues limiting the use of remote sensing for salinity mapping in arid and semi-arid regions. The salient contributions of the review include a compilation of vegetation and salinity indices and list of issues in mapping salinity with remote sensing, many of which are still pertinent. The most significant issues limiting the assessment of salinity in the root zone from remote sensing include the spatio-temporal variability of salinity and the difficulty of isolating the influence of salinity on plant reflectance from other stressors (e.g., matric stress, pests, disease, microclimate).

\section{Milestones of salinity assessment research with proximal and remote sensors}

Eight milestones of salinity assessment research from proximal and remote sensors have been identified by the authors: (i) an understanding of the soil properties influencing $\mathrm{EC}_{\mathrm{a}}$, (ii) development of mobile electromagnetic induction and electrical resistivity equipment for field-scale use, (iii) statistical sampling approaches from geospatial sensor data, (iv) multi-scale salinity assessment approaches, (v) inverse modeling of geospatial $\mathrm{EC}_{\mathrm{a}}$ measurements, (vi) spectral indices of soil salinity from remote sensing, (vii) data fusion of multiple sensors, and (viii) applications of multi-scale soil salinity assessment. 


\subsection{Understanding the soil properties influencing apparent soil electrical conductivity $\left(\mathrm{EC}_{\mathrm{a}}\right)$}

Numerous studies have examined the relationships between $\mathrm{EC}_{\mathrm{a}}$ and soil properties, including Archie (1942), Gupta and Hanks (1972), Rhoades et al. (1976), Kalinski and Kelly (1993), Abu-Hassanein et al. (1996), McCarter and Desmazes (1997), Revil et al. (1998), Seladji et al. (2010), Beck et al. (2011), and Kibria and Hossain (2012), just to mention a few. Measurements of $\mathrm{EC}_{\mathrm{a}}$ properties of soil began at the end of the 19th century with work by Briggs (1899), Wenner (1915), and Smith-Rose (1933). The relationship between $\mathrm{EC}_{\mathrm{a}}$ and electrical conductivity of the soil water $\left(\mathrm{EC}_{\mathrm{w}}\right)$ has been investigated since the 1940s with the development of Archie's empirical law for sand soils and saturated rock (Archie, 1942), which is still used to evaluate porosity or solution conductivity of water-saturated soils and rocks:

$$
E C_{a}=a E C_{w} \phi^{m}
$$

where $a$ is an empirical constant, $\phi$ is the porosity, and $m$ is the materialdependent cementation exponent $(m=1.3$ for unconsolidated sands and $m=1.8-2.0$ for consolidated sandstones). Archie's law was found to hold for various porous media and ranged in value from 1.2 to 4.0.

It was observed by Klein and Sill (1982), De Lima and Sharma (1990), and Keller (1994) that the linear relationship of Eq. (4) was not applicable to soils containing clay minerals due to the large number of ions adsorbed to the surfaces of clay minerals. As a soil wets up, these adsorbed ions become available for ion conductivity. The large CEC of clay results in a considerable increase in electrical conductivity of the soil solution for clayey soils. Rhoades et al. (1976) developed a theoretical model that accounted for the contribution of clay minerals to $\mathrm{EC}_{\mathrm{a}}$. The model of Rhoades et al. (1976) was formulated on the concept of two parallel conductance pathways: (i) conductance through the soil liquid phase $\left(\mathrm{EC}_{\mathrm{w}}, \mathrm{dS} \mathrm{m}^{-1}\right)$, which depends on solute concentration and soil water content and (ii) surface conductance $\left(\mathrm{EC}_{\mathrm{s}}, \mathrm{dS} \mathrm{m}^{-1}\right)$, which occurs through or along the surfaces of the soil solid phase. The surface conductance is regarded as constant and is independent of the soil solution (Rhoades et al., 1976; Shainberg et al., 1980); consequently, the model becomes:

$$
E C_{a}=k_{T}\left(\theta_{w}\right) E C_{w}+E C_{s}
$$

where $k_{T}\left(\theta_{w}\right)$ is the transmission coefficient $(\leq 1)$, which accounts for the tortuosity of the electrical current flow path as a linear function of soil water content $(\theta)$, i.e., $k_{T}\left(\theta_{w}\right)=a \theta_{w}+b$, with $a$ and $b$ constant for a given soil. 
Pathways of Electrical Conductance

Soil Cross Section

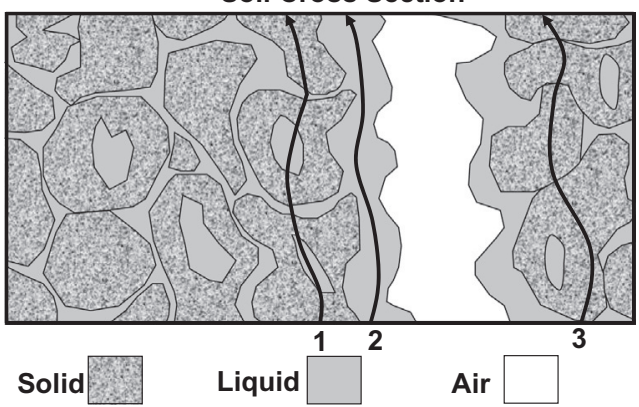

Fig. 6 Schematic illustrating the three conductance pathways of the DPPC model of apparent soil electrical conductivity or $\mathrm{EC}_{\mathrm{a}}$. The three conductance pathways are: (i) solid-liquid conductance pathway (Pathway \#1), (ii) liquid conductance pathway (Pathway \#2), and (iii) solid conductance pathway (Pathway \#3). Modified from Rhoades, J.D., Manteghi, N.A., Shouse, P.J., Alves, W.J., 1989b. Soil electrical conductivity and soil salinity: new formulations and calibrations. Soil Sci. Soc. Am. J. 53 (2), 433-439.

However, the pivotal research came from Rhoades et al. (1989b) with the development of a complete physical model explaining the relationship between $\mathrm{EC}_{\mathrm{a}}, \mathrm{EC}_{\mathrm{w}}$, and $\theta_{\mathrm{w}}$ under all soil conditions that eliminated the need for an empirical transmission coefficient, $k_{T}\left(\theta_{w}\right)$. This model was based on multi-pathway parallel electrical conductance (Fig. 6). The model is often referred to as the dual-pathway parallel conductance (DPPC) model. The DPPC model has been shown to be applicable to a wide range of typical agricultural situations (Corwin and Lesch, 2003). The three conductance pathways in soil of the DPPC model are: (i) solid-liquid, (ii) liquid, and (iii) solid conductance pathways. Because of these conductance pathways, $\mathrm{EC}_{\mathrm{a}}$ is influenced by a complex interaction of edaphic properties, including salinity, water content, texture, bulk density, cation exchange capacity, clay mineralogy, organic matter, and temperature. These interactions make $\mathrm{EC}_{\mathrm{a}}$ a complex measurement that can be interpreted only by keeping these influencing factors in mind.

The DPPC model demonstrates that $\mathrm{EC}_{\mathrm{a}}$ can be reduced to a nonlinear function of five soil properties: salinity as measured by $\mathrm{EC}_{\mathrm{e}}$, SP, soil water content, $\rho_{\mathrm{b}}$, and soil temperature. The DPPC model of Rhoades et al. $(1989 b)$ is shown in Eq. (6):

$$
E C_{a}=\left(\frac{\left(\theta_{s s}+\theta_{w s}\right)^{2} \cdot E C_{w s} \cdot E C_{s}}{\left(\theta_{s s} \cdot E C_{w s}\right)+\left(\theta_{w s} \cdot E C_{s}\right)}\right)+\left(\theta_{w}-\theta_{w s}\right) \cdot E C_{w c}
$$


where $\theta_{w}=\theta_{w s}+\theta_{w c}$ is the total volumetric water content $\left(\mathrm{cm}^{3} \mathrm{~cm}^{-3}\right) ; \theta_{w s}$ and $\theta_{w c}$ are the volumetric soil water content in the soil-water pathway $\left(\mathrm{cm}^{3} \mathrm{~cm}^{-3}\right)$ and in the continuous liquid pathway $\left(\mathrm{cm}^{3} \mathrm{~cm}^{-3}\right)$, respectively; $\theta_{s s}$ is the volumetric water content of the surface-conductance $\left(\mathrm{cm}^{3} \mathrm{~cm}^{-3}\right)$; $E C_{w s}$ and $E C_{w c}$ are the specific electrical conductivities of the soil-water pathway $\left(\mathrm{dS} \mathrm{m}^{-1}\right)$ and continuous liquid pathway $\left(\mathrm{dS} \mathrm{m}^{-1}\right)$, respectively; and $E C_{s}$ is the electrical conductivity of the surface conductance $\left(\mathrm{dS} \mathrm{m}^{-1}\right)$.

Eq. (6) is not easily parameterized. To overcome this difficulty, Rhoades et al. (1989b, 1990a) established empirical relationships. Using the following empirical relationships, Eqs. (7)-(11), Rhoades et al. (1989b, 1990a) showed that the five parameters from Eq. (6) (i.e., $\theta_{w}, \theta_{w s}, \theta_{s s}, E C_{s}$, and $E C_{w}$ ) are related to easily measured soil properties:

$$
\begin{gathered}
\theta_{w}=\frac{P W \cdot \rho_{b}}{100} \\
\theta_{w s}=0.639 \theta_{w}+0.011 \\
\theta_{s s}=\frac{\rho_{b}}{2.65} \\
E C_{s}=0.019(S P)-0.434 \\
E C_{w}=\left[\frac{E C_{e} \cdot \rho_{b} \cdot S P}{100 \cdot \theta_{w}}\right]=E C_{e}\left[\frac{S P}{100 \cdot \theta_{g}}\right]
\end{gathered}
$$

where $P W$ is the percent water on a gravimetric basis, $\rho_{b}$ is the bulk density $\left(\mathrm{Mg} \mathrm{m}^{-3}\right), S P$ is the saturation percentage, $E C_{w}$ is the average electrical conductivity of the soil water assuming equilibrium (i.e., $E C_{w}=E C_{w s}=E C_{w c}$ ), $\theta_{g}$ is the gravimetric water content $\left(\mathrm{kg} \mathrm{kg}^{-1}\right)$, and $E C_{e}$ is the electrical conductivity of the saturation extract $\left(\mathrm{dS} \mathrm{m}^{-1}\right)$. The DPPC model is a module in the ESAP software by Lesch et al. (2000), which can be downloaded from http://www.ars.usda.gov/Services/docs.htm?docid=15992. Lesch and Corwin (2003) evaluated the reliability of Eqs. (6)-(11) and found that the equations are reliable except under extremely dry soil conditions. Lesch and Corwin (2003) developed a means of extending these equations for extremely dry conditions by dynamically adjusting the assumed water content function.

Eqs. (2) and (6)-(11) indicate that $\mathrm{EC}_{\mathrm{a}}$ is directly influenced by $E C_{e}, S P$, $\theta_{g}, \rho_{b}$, and temperature. Several of these properties are also influenced by other properties. For instance, SP and $\rho_{b}$ are influenced by clay content and organic matter $(\mathrm{OM})$. The exchange surfaces on clays and $\mathrm{OM}$ provide a solid-liquid phase pathway primarily through exchangeable cations; as a 
result, CEC, OM, clay content, and clay mineralogy are additional properties influencing the $\mathrm{EC}_{\mathrm{a}}$ measurement.

The liquid pathway is the only conductance pathway needed to measure soil salinity. The fact that two other conductance pathways are measured with $\mathrm{EC}_{\mathrm{a}}$ complicates the ability to determine what soil property or properties are measured. Numerous studies conducted since 1980 reveal the site specificity and complexity of the $\mathrm{EC}_{\mathrm{a}}$ measurement. Table 2 provides an up-to-date compilation of $\mathrm{EC}_{\mathrm{a}}$ studies and the associated dominant soil property or properties measured by $\mathrm{EC}_{\mathrm{a}}$ for that study.

The $\mathrm{EC}_{\mathrm{a}}$ measurement is a consequence of the complex interaction of a variety of soil properties that vary from one location to the next and some vary over time; consequently, the $\mathrm{EC}_{\mathrm{a}}$ measurement is time and site specific, making interpretation difficult. Interpretation of an $\mathrm{EC}_{\mathrm{a}}$ measurement requires an associated soil sample to establish the ground truth and to establish those soil properties that are influencing the $\mathrm{EC}_{\mathrm{a}}$ measurement at that time and location. The basic research that led to an understanding of the properties influencing the $\mathrm{EC}_{\mathrm{a}}$ measurement provided the knowledge necessary to enable the interpretation of the meaning of an $\mathrm{EC}_{\mathrm{a}}$ measurement and to guide the development of protocols and guidelines that would enable the mapping and monitoring of a target soil property influencing the $\mathrm{EC}_{\mathrm{a}}$ measurement. For an $\mathrm{EC}_{\mathrm{a}}$ measurement to have meaning it must be interpreted through an understanding of the properties influencing $\mathrm{EC}_{\mathrm{a}}$ and the extent of the influence of those properties at a given location and time. Eqs. (6)-(11) provide a quantitative understanding of the interaction of soil properties on $\mathrm{EC}_{\mathrm{a}}$.

\subsection{Development of mobile electromagnetic induction and electrical resistivity equipment for field-scale use}

The $\mathrm{EC}_{\mathrm{a}}$ measurement is a quick, reliable, easy-to-take measurement for establishing within-field spatial variability of soil properties that either directly or indirectly influence the reading. Geo-referenced $\mathrm{EC}_{\mathrm{a}}$ measurements serve to define spatial patterns of variation in $\mathrm{EC}_{\mathrm{a}}$ that reflect the variation in soil properties influencing the $\mathrm{EC}_{\mathrm{a}}$ measurement. Geo-referenced $\mathrm{EC}_{\mathrm{a}}$ measurements from ER and EMI are well suited for mobilization since they can be taken in a steady data stream, unlike TDR where the $\mathrm{EC}_{\mathrm{a}}$ measurement is taken at a discreet point since a TDR probe must be inserted into the ground to the desired depth. During the 1980s, maps of $\mathrm{EC}_{\mathrm{a}}$ were laboriously created using tape measures, distance wheels, or surveying equipment (e.g., Theodolite) to establish position. It was not until the early 1990 s with the commercial availability of meter to sub-meter accuracy GPS 
data that mobilization of EMI and ER equipment came to fruition. The development of mobile $\mathrm{EC}_{\mathrm{a}}$ equipment by a variety of researchers (Cannon et al., 1994; Carter et al., 1993; Freeland et al., 2002; Jaynes et al., 1993; Kitchen et al., 1996; McNeill, 1992; Rhoades, 1993) made it possible to produce $\mathrm{EC}_{\mathrm{a}}$ maps with measurements taken every few meters. Maps of $\mathrm{EC}_{\mathrm{a}}$ could be obtained with tens of thousands of $\mathrm{EC}_{\mathrm{a}}$ measurements covering $35 \mathrm{ha}$ in $20 \mathrm{~h}$ or less.

As pointed out by Corwin and Scudiero (2016), there are four basic components to a mobilized $\mathrm{EC}_{\mathrm{a}}$ measurement system: (i) $\mathrm{EC}_{\mathrm{a}}$ measurement sensor, (ii) global positioning system (GPS), (iii) hardware interfacing, and (iv) transport platform.

Mobile $\mathrm{EC}_{\mathrm{a}}$ measurement equipment has been developed for both $\mathrm{ER}$ and EMI sensors. In the case of ER, considerable time for a measurement is saved by mounting the electrodes to "fix" their spacing. A tractor-mounted version of the "fixed-electrode array" has been developed that geo-references the $\mathrm{EC}_{\mathrm{a}}$ measurement with a GPS (see Fig. 7A; Carter et al., 1993; Rhoades, 1992, 1993). Veris Technologies ${ }^{b}$ has developed a commercial mobile system

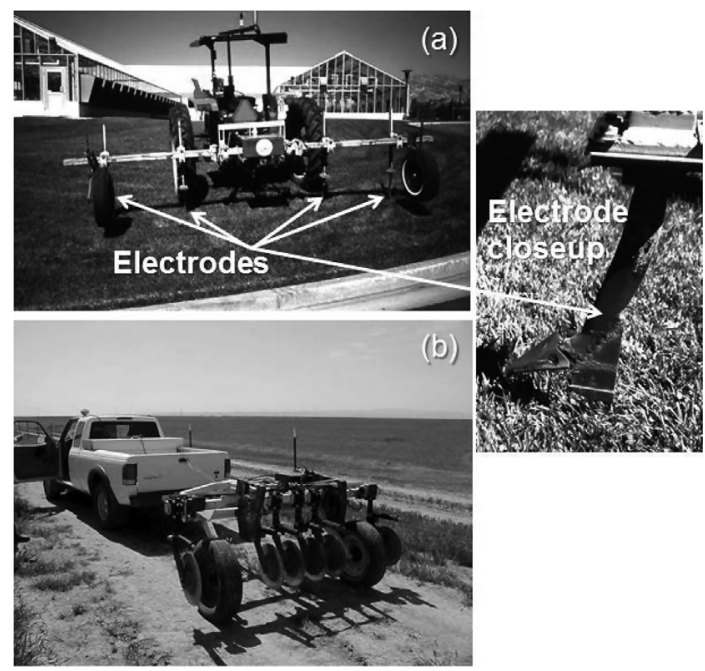

Fig. 7 Non-commercial and commercial mobile electrical resistivity (ER) equipment, respectively: (A) mobile ER rig by Rhoades $(1992,1993)$ and Carter et al. (1993) and (B) Veris $3100^{2}$.

\footnotetext{
${ }^{\mathrm{b}}$ Veris Technologies, Salinas, Kansas, USA (www.veristech.com). All references to commercial equipment and instrumentation are provided solely for the benefit of the reader and do not imply the endorsement of the USDA.
} 


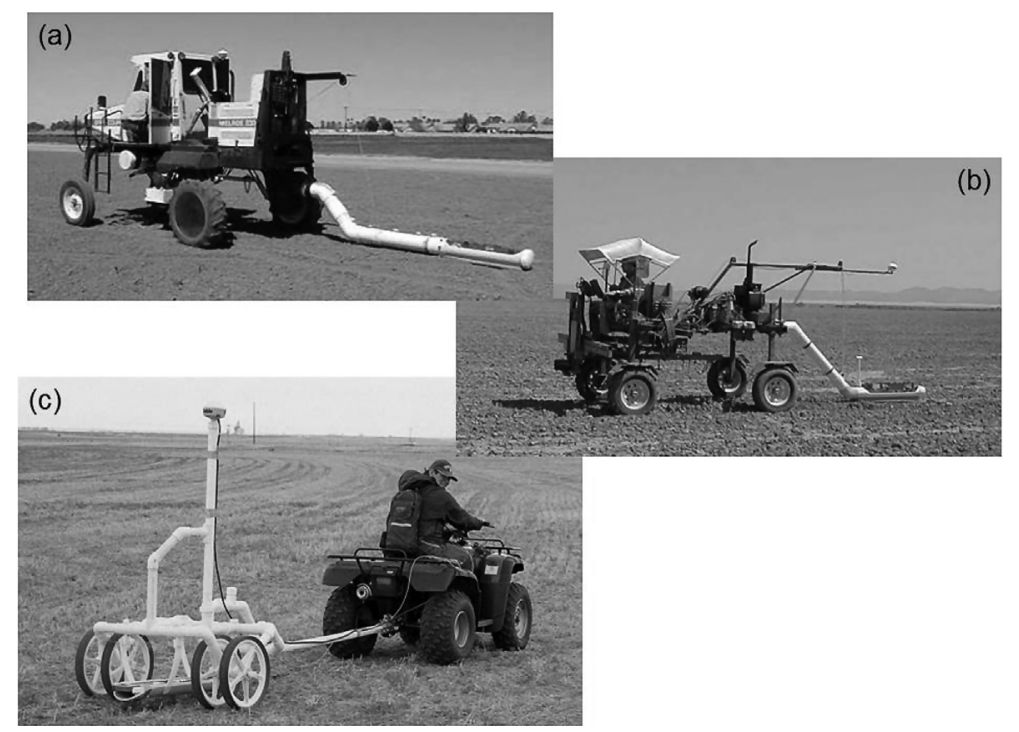

Fig. 8 Mobile electromagnetic induction (EMI) equipment varying in cost: (A) Imperial Irrigation District EMI rig, (B) U.S. Salinity Laboratory EMI rig (Carter et al., 1993; Rhoades, 1992, 1993), and (c) NRCS EMI rig.

for measuring $\mathrm{EC}_{\mathrm{a}}$ using the principles of ER (Fig. 7B). In the case of EMI, a Geonics $^{\mathrm{a}}$ EM-38 unit and other EMI units such as EM-31, DUALEM-2, DUALEM-21, DUALEM-421, and GF CMD-1 soil conductivity meters (Geonics Ltd., Dualem, GF Instruments) have been mounted behind herbicide spray rigs or ATVs (Fig. 8). The first mobile EMI salinity assessment rig was developed by the U.S. Salinity Laboratory (Carter et al., 1993; Rhoades, 1992, 1993). It consisted of an EM-38 mounted inside a cylindrical nonmetallic housing in the front of a mobile spray rig that has adequate clearance to traverse fields with a crop cover. The housing could be raised and lowered to take measurements at the soil surface or at various heights above the soil, or to lock into a travel position to go from one measurement site to the next. The housing could also be rotated $90^{\circ}$ to take $\mathrm{EM}_{\mathrm{h}}$ and $\mathrm{EM}_{\mathrm{v}}$ readings at each measurement site. Subsequently, the mobile EMI equipment developed at the Salinity Laboratory was modified by the addition of a dual-dipole EM-38 unit (Fig. 8B) in place of the single EM-38 unit and the EMI conductivity meter was housed in a PVC tube pulled behind the spray rig. The dual-dipole EM-38 unit permits continuous, simultaneous $\mathrm{EC}_{\mathrm{a}}$ measurements in both the horizontal $\left(E M_{h}\right)$ and vertical $\left(E M_{v}\right)$ dipole configurations at time intervals of just a few seconds between readings. Other less costly mobile EMI equipment (Fig. 8C) 
has been developed that carry the EM-38 unit on a non-metallic cart or sled pulled by an ATV or tractor (Cannon et al., 1994; Freeland et al., 2002; Jaynes et al., 1993; Kitchen et al., 1996). These sleds or carts allow continuous $E_{a}$ measurements, but in only one dipole position. No commercial mobile system has been developed with EMI. The mobile EMI and "fixed-electrode array" equipment are well suited for collecting detailed maps of the spatial variability of average root zone soil electrical conductivity at field scales and larger spatial extents $\left(<10 \mathrm{~km}^{2}\right)$. Comparisons between commercial EMI and ER equipment (Gebbers et al., 2009; Serrano et al., 2014; Sudduth et al., 2003) and between various commercial EMI sensors (Heil and Schmidhalter, 2015; Saey et al., 2009b; Urdanoz and Aragüés, 2012) are available in the literature.

Two GPS systems commonly used with mobile $\mathrm{EC}_{\mathrm{a}}$-measurement equipment are: (i) self-contained systems and (ii) stand-alone GPS receivers with external data logging. They differ in their interfacing. Self-contained GPS systems consist of data loggers and software that record, modify, and/or store GPS data independent of the attached proximal sensor or hardware interfacing. Whereas, stand-alone GPS receivers must be connected to a microprocessor to store and/or process GPS data.

Hardware interfacing links the $\mathrm{EC}_{\mathrm{a}}$-measurement sensor to the GPS and controls the timing of the acquisition of the GPS coordinates and $\mathrm{EC}_{\mathrm{a}}$ measurement. The sophistication of the hardware interface, and therefore its cost, depends on the number of proximal sensors and the extent of the real-time processing. In the simplest mobile $\mathrm{EC}_{\mathrm{a}}$-measurement system, such as a single EM-38 conductivity meter, the hardware interface is eliminated by direct output of the real-time sensor data through an RS-232 serial connection with the internal data capture of the GPS.

The transport platform can be as simple as hand-carried by an individual to a range of transportation vehicles, such as pickups, all-terrain vehicles (ATVs), tractors, or modified herbicide-insecticide spray rigs (Fig. 8). The fixed-array four electrode (Rhoades, 1992, 1993) and Veris 3100 (Lund et al., 1999; Sudduth et al., 1999) are examples of ER sensor platforms that are towed. Simple non-metallic platforms to tow EMI instrumentation have been developed by Jaynes et al. (1993), Cannon et al. (1994), Kitchen et al. (1996), and Freeland et al. (2002).

The mobilization of ER and EMI was one of the most impactful milestones in field-scale salinity assessment because it made mapping salinity and other soil properties a practical task. Even though the cost of all the GPS, ER or EMI, and computer equipment was substantial, ranging from $\$ 20 \mathrm{~K}$ to over $\$ 100 \mathrm{~K}$ USD, the ability to create detailed maps of $\mathrm{EC}_{\mathrm{a}}$ measurements 
every 3-5 $\mathrm{m}$ was no longer a technical barrier. The outcome was the rapid increase in field-scale research related to $\mathrm{EC}_{\mathrm{a}}$ mapping.

\subsection{Statistical sampling approaches from geospatial sensor data}

Once $\mathrm{EC}_{\mathrm{a}}$ maps became available to researchers, the next challenge was how to use the georeferenced $\mathrm{EC}_{\mathrm{a}}$ data to characterize the spatial variability of soil salinity (or any other target soil property that was significantly correlated with $\mathrm{EC}_{\mathrm{a}}$ at the site of interest). The spatial variation in georeferenced $\mathrm{EC}_{\mathrm{a}}$ data is used to direct a soil-sampling scheme that provides the necessary ground-truth information to characterize the spatial distribution of any soil property correlated with $\mathrm{EC}_{\mathrm{a}}$ within a field, which is referred to as $E C_{a^{-}}$ directed soil sampling (Corwin and Scudiero, 2016).

Two distinct sampling strategies have been used to identify the location of soil sample sites that reflected the range and variation of spatial $\mathrm{EC}_{\mathrm{a}}$ data within a field: (i) designed-based (or probability-based) and (ii) model-based (prediction-based) sampling strategies. Designed-based sampling strategies include simple random sampling, stratified random sampling, unsupervised classification, and cluster sampling, to mention a few. Designed-based sampling is useful whenever there is not a need for spatial modeling, such as when comparing salinity content between two different fields. Designedbased sampling is not ideal when the goal is to build a spatial model, such as maps, pedotransfer functions, and plant-soil models. In contrast, model-based sampling strategies support the use of parametric modeling by focusing on the requirements of a particular model, such as minimizing kriging variance (Van Groenigen et al., 1999) and avoiding the autocorrelation of residuals in linear regression modeling (Hengl et al., 2003; Lesch, 2005). A comparison of design-based and model-based sampling strategies by Corwin et al. (2010) highlighted some of the strengths of model-based sampling, including better model discrimination, more precise parameter estimates, and smaller prediction variances. Corwin et al. (2010) concluded that the model-based sampling strategy of the response surface sampling design provided an increased level of assurance of spatial characterization of soil sampling with $\mathrm{EC}_{\mathrm{a}}$-directed soil sampling over the design-based sampling strategy of a stratified random sampling design.

Numerous sampling strategies have been presented in the literature, including, but not limited to: (i) Lesch et al.'s (2000) response surface sampling design (Fitzgerald et al., 2006; Guo et al., 2016; Lesch, 2005), (ii) Van Groenigen et al.'s (2000) minimization of a weighted means of the shortest 
distance (Barca et al., 2015; Brus and Heuvelink, 2007; Debba et al., 2005; Scudiero et al., 2011, 2016a), (iii) Minasny et al.'s (2007) variance Quad-Tree algorithm (Yan et al., 2007; Yao et al., 2012), (iv) stratified random sampling (Corwin et al., 2010), balanced sampling (Brus, 2015), and (v) a special case of the latter known as Minasny and McBratney's (2006) conditioned Latin hypercube (Clifford et al., 2014; Kidd et al., 2015; Ließ, 2015). Currently, the most widely used sampling strategy for the characterization of soil spatial variability with $\mathrm{EC}_{\mathrm{a}}$-directed soil sampling is the response surface sampling design in the ESAP software developed by Lesch et al. (2000). The reason for ESAP's widespread use is that there is a substantial reduction in the number of samples required to characterize the variation in the target soil property as compared to other approaches and ESAP is public-domain software that is easily obtained online with support documentation for its use and operation.

\subsection{Multi-scale salinity assessment approaches}

Since 1980 the USDA-ARS U.S. Salinity Laboratory (USSL) has been the center of research related to mapping and monitoring soil salinity at field scale and larger spatial extents using electromagnetic induction (EMI) and electrical resistivity (ER) (Corwin, 2008). Over that time, USDA-ARS scientists and scientists visiting USSL have developed three approaches for mapping soil salinity at three distinct spatial scales: field $\left(<3 \mathrm{~km}^{2}\right)$, landscape $\left(3-10 \mathrm{~km}^{2}\right)$, and regional $\left(10-10^{6} \mathrm{~km}^{2}\right)$ scales. Each approach is based on the measurement of apparent soil electrical conductivity $\left(\mathrm{EC}_{\mathrm{a}}\right)$, which is the bulk conductivity of the soil and is a complex measurement influenced by a variety of soil properties, including salinity, texture, water content, bulk density, clay minerology, and organic matter. The three approaches are: (i) $\mathrm{EC}_{\mathrm{a}}$-directed soil sampling (field scale), (ii) ANOCOVA approach (landscape scale), and (iii) remote-sensor imagery combined with $\mathrm{EC}_{\mathrm{a}}$-directed soil sampling (regional scale). A detailed discussion of the protocols for mapping soil salinity at field, landscape, and regional is in Corwin and Scudiero (2016).

\subsubsection{Field-scale approach: $E C_{a}$-directed soil sampling}

Scientists at the U.S. Salinity Laboratory developed an integrated system for the measurement of field-scale spatial variability, particularly salinity, consisting of (i) guidelines and protocols for the characterization of soil spatial variability using $\mathrm{EC}_{\mathrm{a}}$-directed soil sampling presented by Corwin and Lesch (2003, 2005b) and Corwin and Scudiero (2016) and protocols specific to soil salinity assessment presented by Corwin and Lesch (2013), (ii) mobile 


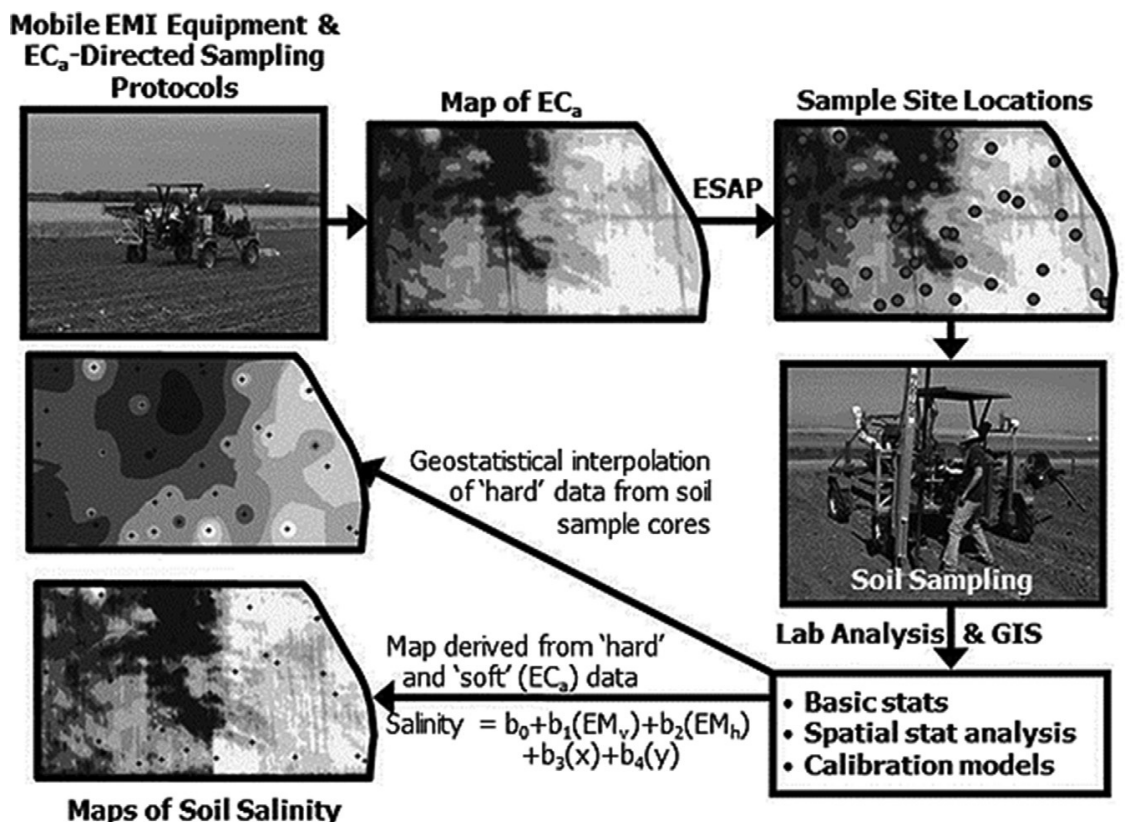

Fig. 9 Schematic illustrating the integrated system and procedure for assessing soil salinity at field scale using apparent soil electrical conductivity $\left(E C_{a}\right)$ directed soil sampling protocols, a mobile electromagnetic induction (EMI) rig, ESAP software, and geographic information system (GIS). $\mathrm{EM}_{v}$ refers to the measurement of $E C_{a}$ by $E M I$ in the vertical coil configuration and $\mathrm{EM}_{\mathrm{h}}$ refers to the measurement of $\mathrm{EC}_{\mathrm{a}}$ by $\mathrm{EMI}$ in the horizontal coil configuration. Taken from Corwin, D.L., 2015. Use of advanced information technologies for water conservation on salt-affected soils. In: Mueller, T.G. and Sassenrath, G.F., (Eds.), GIS Applications in Agriculture, vol. 4: Conservation Planning. Taylor and Francis Group, Boca Raton, FL, Chapter 8, 119-150 with permission.

$\mathrm{EC}_{\mathrm{a}}$ measurement equipment (Rhoades, 1993), and (iii) sample design software (Lesch et al., 2000; Lesch, 2005). The integrated system and procedure for mapping soil salinity at field scale is schematically illustrated in Fig. 9.

The protocols for an $\mathrm{EC}_{\mathrm{a}}$-directed soil sampling survey to measure soil salinity at field scale include eight steps (Corwin and Scudiero, 2016): (i) EC $_{a}$ survey design, (ii) geo-referenced $\mathrm{EC}_{\mathrm{a}}$ data collection, (iii) soil sample design based on geo-referenced $\mathrm{EC}_{\mathrm{a}}$ data, (iv) soil sample collection, (v) physical and chemical analysis of pertinent soil properties, (vi) spatial statistical analysis, (vii) determination of the dominant soil properties influencing the $\mathrm{EC}_{\mathrm{a}}$ measurements at the study site, and (viii) GIS development.

As indicated in Fig. 8, maps of soil salinity can be created by interpolating the salinity from soil samples (i.e., "hard" salinity data alone) or from a 
calibration equation, such as Eq. (12). Eq. (12) relates soil salinity to EMI measurements of $\mathrm{EC}_{\mathrm{a}}$ in the vertical $\left(\mathrm{EM}_{\mathrm{v}}\right)$ and horizontal coil configurations $\left(\mathrm{EM}_{\mathrm{h}}\right)$ and $x-y$ location (i.e., easting and northing) in the field to account for any spatial trend across the field due to anthropogenic or pedogenic influences (i.e., using "hard" salinity and "soft" $\mathrm{EC}_{\mathrm{a}}$ data in combination):

$$
\ln \left(E C_{e}\right)=\beta_{0}+\beta_{1} \ln \left(E M_{v}\right)+\beta_{2} \ln \left(E M_{h}\right)+\beta_{3}(x)+\beta_{4}(\gamma)+\varepsilon
$$

where $E C_{e}$ is the soil salinity or electrical conductivity of the saturation extract $\left(\mathrm{dS} \mathrm{m}^{-1}\right) ; \beta_{0}, \beta_{1}, \beta_{2}, \beta_{3}$, and $\beta_{4}$ represent the empirical regression model coefficients; $x$ and $y$ are the easting and northing UTM coordinates $(\mathrm{m})$, and $\varepsilon$ is the error term. Fig. 10 shows a typical map of an $\mathrm{EC}_{\mathrm{a}}$ survey (i.e., geospatial $\mathrm{EM}_{\mathrm{h}}$ and $\mathrm{EM}_{\mathrm{v}} \mathrm{EC}_{\mathrm{a}}$ measurements) for a 32.4-ha saline-sodic field with sample site locations (circle symbol) directed by geospatial $\mathrm{EC}_{\mathrm{a}}$ measurements and a map of the soil salinity $\left(\mathrm{EC}_{\mathrm{e}}\right)$ estimated from a calibration equation, i.e., Eq. (12).

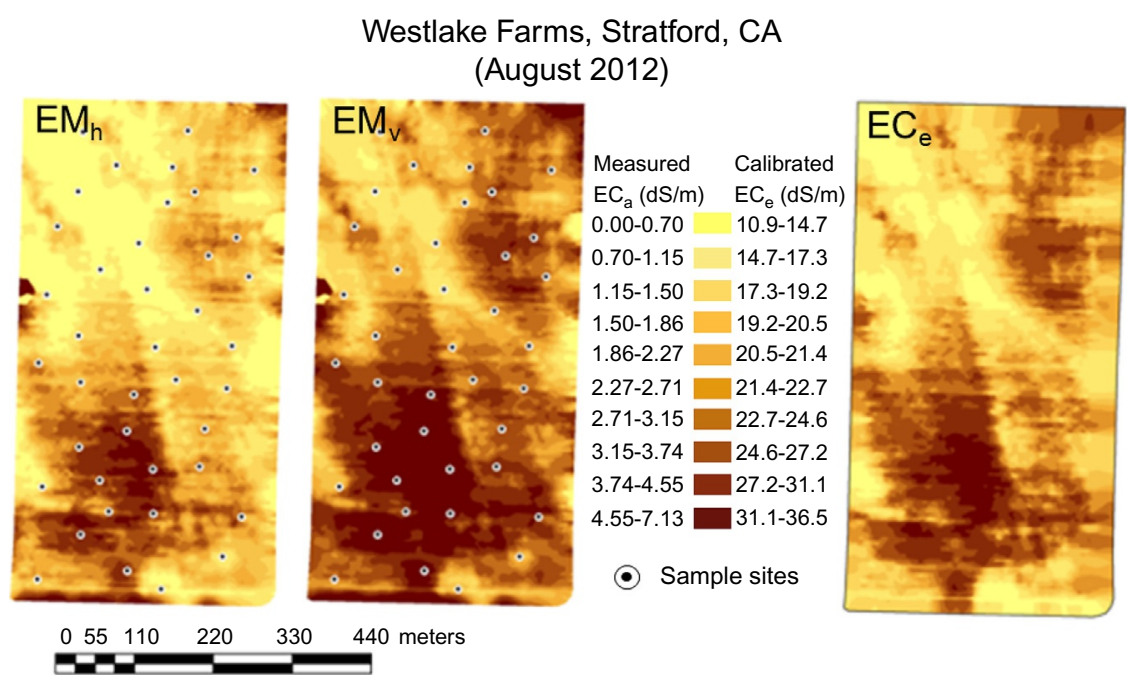

Fig. 10 Maps of an apparent soil electrical conductivity $\left(E C_{a}\right)$ survey for a 32.4-ha salinesodic field near Stratford, CA, consisting of maps of $E C_{a}$ in the vertical $\left(E M_{v}\right)$ and horizontal $\left(E M_{h}\right)$ coil configurations using electromagnetic induction, and a map of soil salinity (i.e., $\mathrm{EC}_{\mathrm{e}}$ or electrical conductivity of the saturation extract in $\mathrm{dSm}^{-1}$ ) based on a calibration equation of the form shown in Eq. (12). 


\subsubsection{Landscape-scale approach: Analysis of co-variance (ANOCOVA)}

Multiple-field $\mathrm{EC}_{\mathrm{a}}$ survey data often exhibit an abrupt change in magnitude across field boundaries, generally a consequence of anthropogenic influences, such as crop and irrigation management, and often times pedogenic influences. This presents a challenge to the conversion of $\mathrm{EC}_{\mathrm{a}}$ to $\mathrm{EC}_{\mathrm{e}}$ at spatial extents of thousands to tens of thousands of hectares (i.e., landscape scale). The abrupt change is caused by various reasons: (i) between-field variation in field average water content due to irrigation method, frequency, and timing; (ii) between-field variation in soil texture; (iii) condition of the soil surface (e.g., till vs no-till) due to management practices that effect soil compaction; (iv) surface geometry (i.e., presence or absence of beds and furrows); (v) temperature differences (i.e., $\mathrm{EC}_{\mathrm{a}}$ surveys conducted at different times of the year); and (vi) between-field spatial variation in salinity (Corwin and Lesch, 2014).

Calibration models are often used to adjust out an abrupt change. Consider the case of surface geometry, i.e., presence and absence of beds and furrows in a field, where an $\mathrm{EC}_{\mathrm{a}}$ survey has been conducted. In the absence of any surface geometry, a simple power model describes the deterministic component of the $\mathrm{EC}_{\mathrm{e}}-\mathrm{EC}_{\mathrm{a}}$ calibration relationship, i.e., $E C_{e, i} \approx \beta \cdot E C_{a, i}^{\alpha}$ where $\beta$ is a coefficient and $i=1,2,3, \ldots, n$. To account for the surface geometry effect an additional dummy variable $(x)$ and associated scaling parameter $(\theta)$ are used, i.e., $E C_{e, i} \approx \theta^{x_{i}} \cdot \beta \cdot E C_{a, i}^{\alpha}$ where $x_{i}=1$ if there is a surface geometry effect and $x_{i}=0$ otherwise. Under a log transformation, this multiplicative parameter becomes additive as shown in Eq. (13):

$$
\begin{aligned}
\ln \left(E C_{e, i}\right) & \approx x_{i} \ln (\theta)+\ln (\beta)+\alpha \ln \left(E C_{a, i}\right) \\
& =\beta_{01}+\beta_{02}\left(x_{i}\right)+\alpha \ln \left(E C_{a, i}\right)
\end{aligned}
$$

On a log-log scale, a simple linear regression model with an additional blocking (shift) parameter can adjust an abrupt change in any multiplicative $\mathrm{EC}_{\mathrm{a}}$ effect within a field. Eq. (13) is a type of analysis of co-variance (ANOCOVA) model. In principle, this type of ANOCOVA modeling approach could be used to calibrate multiple-field $\mathrm{EC}_{\mathrm{a}}$ surveys to $\mathrm{EC}_{\mathrm{e}}$ provided the assumptions in Eq. (13) are reasonable.

If geo-referenced $\mathrm{EC}_{\mathrm{a}}$ survey data are acquired across multiple fields and the number of soil sampling locations collected in any given field is minimal (i.e., $n \leq 10$ ), then in the absence of any useful spatial or geostatistical modeling approach under these conditions, basic regression modeling techniques 
are used, such as ANOCOVA. An ANOCOVA model for $\mathrm{EC}_{\mathrm{a}}-\mathrm{EC}_{\mathrm{e}}$ calibration is defined by Eq. (14):

$$
\ln \left(E C_{e, i j k}\right)=\beta_{0, j k}+\beta_{1, j} \ln \left(E M_{v, i k}\right)+\beta_{2, j} \ln \left(E M_{h, i k}\right)+\varepsilon_{i j k}
$$

where $i$ refers to the soil sample site within a field $\left(i=1,2,3, \ldots, n_{k}\right), j$ is the sample depth $(j=1,2,3, \ldots, p), k$ is the field $(k=1,2,3, \ldots, M), E M_{v}$ is the $\mathrm{EC}_{\mathrm{a}}$ measured with EMI in the vertical coil configuration $\left(\mathrm{dS} \mathrm{m}^{-1}\right)$, and $E M_{h}$ is the $\mathrm{EC}_{\mathrm{a}}$ measured with EMI in the horizontal coil configuration $\left(\mathrm{dS} \mathrm{m}^{-1}\right)$. In the ANOCOVA model, the intercept parameter is uniquely estimated for each sampling depth and field, but the slope coefficients are only assumed to change across sampling depths (not across fields).

The ANOCOVA approach for $\mathrm{EC}_{\mathrm{a}}-\mathrm{EC}_{\mathrm{e}}$ calibration has been validated at regional-scale (Corwin and Lesch, 2017). However, the practical application of the ANOCOVA approach is best used at landscape scale, i.e., 3-10 km² (Corwin and Lesch, 2017; Scudiero et al., 2016b).

\subsubsection{Regional-scale approach: Remote imagery}

At the regional-scale, spatial patterns of soil salinity are influenced by several factors, including: pedogenic, meteorological, hydrological, topographical, agronomic, anthropogenic and edaphic factors. In general, agronomic management influences local-scale salinity, whereas anthropogenic and pedogenic factors influence landscape-scale salinity. To model such multi-scale variations, covariates offering continuous spatial coverage, such as remote sensing data, are ideal. In the past 3 decades, two remote sensing approaches have been developed for mapping soil salinity. The most popular approach includes a variety of spatial analyses of surface (bare-) soil reflectance. The other consists of the indirect assessment of root-zone soil salinity through the study of plant canopy reflectance.

Salt accumulation at the soil surface often results in the formation of white salt crusts. Such crusts are easily identifiable with remote sensing as their reflectance properties are different from those of soils not affected by soil salinity (Mougenot et al., 1993). One way to identify crusts is through image classification (e.g., Metternicht, 1998). Often, salt efflorescence is partial, making the identification of salt-affected bare-land more problematic. This is because of confounding effects from different soil types (e.g., texture, color), soil roughness, presence of vegetation, and surface soil water content. However, most of these confounding effects can be accounted for (e.g., Xu et al., 2016). Unfortunately, this approach has limited relevance in 
agricultural applications because crop growth and yield are influenced by the salinity in the root-zone. In agriculture, information of surface soil salinity is often only relevant for evaluation of plant germination. Indeed, several studies show that there is no direct correlation between root-zone and surface soil salinity (e.g., Zare et al., 2015).

Spectral reflectance properties of salt-affected vegetation are different from those of non-stressed plants. Differences can be seen in the spectral signature of crops, especially in the visible (e.g., $450-700 \mathrm{~nm}$ ) and near-infrared (e.g., $770-900 \mathrm{~nm}$ ) spectra. Plants stressed by soil salinity are characterized by higher visible and lower near-infrared range reflectance than non-stressed plants. Unfortunately, the use of surface reflectance (i.e., multi- and hyper-spectral) from a single airborne or satellite scene to model soil salinity is site-specific, for reasons including: (i) the spectral signature of a crop changes with phenological stages; (ii) different crops are characterized by different spectral signatures; (iii) other stress sources, such as nutrient deficiency or water stress, trigger similar responses in plants reflectance properties; and (iv) surface reflectance is influenced by different soil backgrounds. Due to these confounding effects, regional-scale mapping of soil salinity with remote sensing has often yielded unsatisfactory and inconsistent results in the past.

Salinity stress can be isolated from other types of within-season and season-wide transient stressors by analyzing multi-year canopy reflectance data (e.g., Lobell et al., 2007, 2010; Scudiero et al., 2015). Lobell et al. (2010) used 7 years of MODIS (NASA) reflectance data $\left(250 \times 250 \mathrm{~m}^{2}\right.$ spatial resolution) to map salinity in the agriculturally relevant $0-20 \mathrm{dS} \mathrm{m}^{-1}$ range in Minnesota's Red River Valley. Zhang et al. (2015) used the same satellite sensor to map salinity in the $0-30 \mathrm{dS} \mathrm{m}^{-1}$ range for the Yellow River Delta, China. Unfortunately, the resolution of MODIS imagery is generally insufficient to map the spatial variability of salinity that usually exists within agricultural landscapes (Eldeiry and Garcia, 2008; Scudiero et al., 2014a). Subsequently, Scudiero et al. (2015) used Landsat 7 ETM+canopy reflectance imagery (i.e., Canopy Response Salinity Index or CRSI) and $\mathrm{EC}_{\mathrm{a}}$-directed soil sampling to map soil salinity in 2013 for the entire west side of California's San Joaquin Valley. Scudiero et al. (2015) considered annual average values of Landsat 7 (USGS and NASA, USA) vegetation indices from 7 years, and used the year with highest VI value (i.e., year with maximum average plant performance) to build a regression model from ground-truth fields located in California's western San Joaquin Valley (WSJV). The regional-scale salinity model included co-variate information 


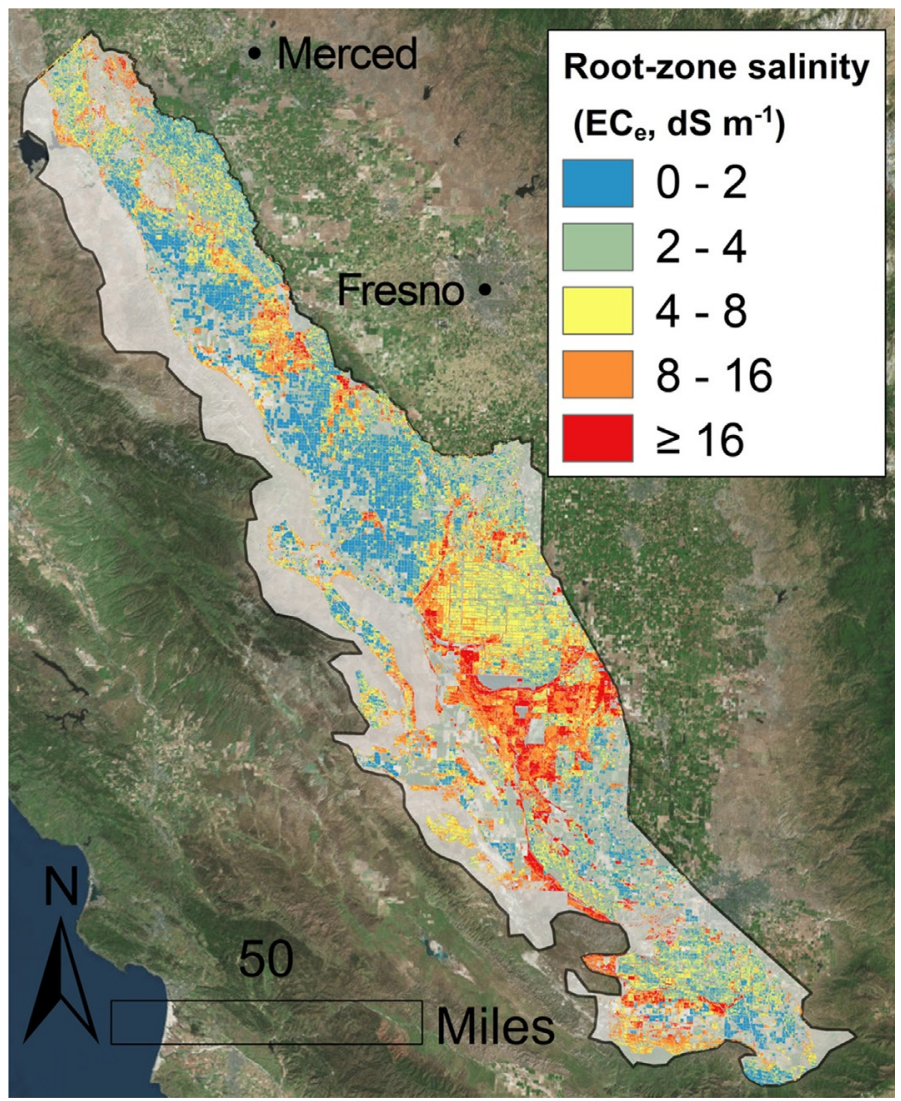

Fig. 11 Map of soil salinity within the root zone $(0-1.2 \mathrm{~m})$ for the west side of the San Joaquin Valley for 2013. Taken from Scudiero, E., Corwin, D.L., Anderson, R.G., Yemoto, K., Clafry, W., Wang, Z.L., Skaggs, T.H., 2017. Remote sensing is a valuable tool for mapping soil salinity in agricultural lands. Calif. Agric. 71 (2), 1-8. doi: 10.3733/ca.2017a0009 with permission.

on land use (i.e., cropping system) and meteorology. Fig. 11 shows the map of soil salinity for WSJV using the regional-scale salinity model. The regional-scale salinity models of Lobell et al. (2010) and Scudiero et al. (2015) related salinity to a VI determined from multi-year data and other co-variates, including rainfall and texture in the case of Scudiero et al. (2015) and whether or not the location was classified as environmentally sensitive, high erodible land qualified for the Conservation Reserve Program in the case of Lobell et al. (2010).

Zhang et al. (2015) made an additional advancement by proposing the use of the one-year integral of temporally interpolated MODIS EVI time 
series data as an explanatory variable for agricultural soil salinity modeling. Whitney et al. (2018) combined the Zhang et al. (2015) methodology with the multi-year maximum approach of Scudiero et al. (2015) rendering an even more robust regional-scale salinity model for the WSJV.

\subsection{Inverse modeling}

Through the 1980s and early 1990s, the focus of EMI work in agriculture was on vertical profiling (Corwin and Rhoades, 1982, 1984, 1990; Cook and Walker, 1992; Rhoades and Corwin, 1981; Slavich, 1990; Wollenhaupt et al., 1986). Prior to the development of multi-coil offset EMI equipment vertical profiling of soil salinity with EMI involved raising the EMI conductivity meter to various heights at or above the soil surface (e.g., $0,30,60,90,120$, and $150 \mathrm{~cm}$ ) to measure the $\mathrm{EC}_{\mathrm{a}}$ corresponding to incremental depths below the soil surface (i.e., 0-150, 0-120, 0-90, 0-60, and 0-30, respectively). Rhoades and Corwin (1981) and Slavich (1990) used multiple linear regression to correlate aboveground EMI measurements to measured $\mathrm{EC}_{\mathrm{a}}$ soil profiles. These site-specific empirical relationships were not widely used because they could not be applied to other sites without calibration. McNeill (1980) developed a linear model of the response of the EM-38 conductivity meter with depth. Using this response function, Corwin and Rhoades $(1982,1984)$ and Cook and Walker (1992) selected linear combinations of measurements that maximized the response to conductivity for the depth range of interest.

It was not until the work of Borchers and colleagues that inverse procedures for linear (Borchers et al., 1997) and nonlinear models (Hendrickx et al., 2002a) were developed to profile soil salinity with aboveground EMI measurements. Vertical profiling of $\mathrm{EC}_{\mathrm{a}}$ with EMI is mathematically complex and a difficult quantitative undertaking (Borchers et al., 1997). The pivotal papers of vertical $\mathrm{EC}_{\mathrm{a}}$ profiling are those by Borchers et al. (1997), McBratney et al. (2000), and Hendrickx et al. (2002a) introducing the use of second order Tikhonov regularization, which is an inverse procedure. Further strides have been made in vertical EC profiling and threedimensional EC imaging with EMI, not only for soil salinity but other soil properties (e.g., water content, clay content, and bulk density), as a result of the inverse modeling research of Gebbers et al. (2007), Saey et al. (2008, 2009b, 2015), Monteiro Santos et al. (2010), Triantafilis and Monteiro Santos (2010a, 2013), Sudduth et al. (2010, 2013), Mester et al. (2011), and von Hebel et al. (2014). These strides are largely the consequence of 
developments in multi-coil offset EMI equipment, such as the DUALEM421 and CMD Mini-Explorer, and improvements in inversion algorithms, e.g., DUALEM-2D algorithm (Monteiro Santos, 2004; Monteiro Santos et al., 2010), IX2D (Interpex, Golden, CO, USA) and EM4Soil software (EMTOMO, 2014). Table 5 provides a comprehensive compilation of literature using inversion techniques to profile vertically apparent soil electrical conductivity $\left(\mathrm{EC}_{\mathrm{a}}\right)$ or other properties with $\mathrm{EMI}$ and electrical resistivity tomography (ERT).

Numerous inversion approaches have been developed to profile variations of electrical conductivity using electromagnetic induction, including Borchers et al. (1997), Monteiro Santos (2004), Jardani et al. (2007), Mester et al. (2011), Saey et al. (2015), and Jadoon et al. (2017), to mention a few. As pointed out by Sudduth et al. (2013), three approaches for vertical $\mathrm{EC}$ profiling have been used. The oldest approach used $\mathrm{EC}_{\mathrm{a}}$ sensor data taken at multiple heights above the ground and at two different coil configurations (i.e., $\mathrm{EM}_{\mathrm{h}}$ and $\mathrm{EM}_{\mathrm{v}}$, horizontal and vertical coil configurations, respectively) at each sampling point (Borchers et al., 1997; Corwin and Rhoades, 1982; Hendrickx et al., 2002a; Rhoades and Corwin, 1981). This approach is impractical for mobilized mapping purposes. The next two approaches are the consequence of developments in EMI instrumentation. The second approach is the use of multiple EMI frequencies. However, theoretical issues (McNeill, 1996) and the reported high collinearity of readings at different frequencies (Tromp-van Meerveld and McDonnell, 2009) make this approach infeasible. The third approach, which is currently receiving the greatest interest, is the use of different coil configurations and/or coil spacings to obtain multiple readings of $\mathrm{EC}_{\mathrm{a}}$ (Monteiro Santos et al., 2010). A combination of the second and third approaches using a two-layer inversion of calibrated data from two coil orientations, offsets, and frequencies has been reported by Mester et al. (2011).

Of particular interest is recent work by Jadoon et al. (2017), which uses an adaptive Bayesian Markov chain Monte Carlo algorithm (Oh and Kwon, 2001) to assess multi-orientation and multi-offset EMI measurements to infer soil salinity in drip irrigation. As water scarcity becomes a critical problem in irrigated agricultural areas, such as California's San Joaquin Valley, the expanded use of drip irrigation and greater need for site-specific management of irrigation water to control salinity will create greater need for the mapping of salinity and water within drip-irrigated systems. The research of Jadoon et al. (2017) is a step in the right direction to make this possible. However, predicted salinity and water content profiles from $\mathrm{EC}_{\mathrm{a}}$ inversion methods needs rigorous validation 
Table 5 Compilation of literature using inversion techniques to profile vertically apparent soil electrical conductivity $\left(E C_{a}\right)$ or other soil properties with electromagnetic induction (EMI) and electrical resistivity tomography (ERT).

\section{Soil properties}

Apparent soil electrical conductivity

Borchers et al. (1997), McBratney et al. (2000), Hendrickx et al. (2002a), Gebbers et al. (2007), Monteiro Santos et al. (2010), Mester et al. (2011), Saey et al. (2015), Lueck and Ruehlmann (2013), Sudduth et al. (2013), Triantafilis and Monteiro Santos (2013), Huang et al. (2014a, 2015a), von Hebel et al. (2014), and Dragonetti et al. (2018)

Salinity (including exchangeable sodium percentage)

McBratney et al. (2000), Cresswell et al. (2004), Koestel et al. (2008), Triantafilis and Monteiro Santos (2013), Huang et al. (2014a, b, c, 2015b, c, e, 2017a, b), Jadoon et al. (2015, 2017), Zare et al. (2015), Moghadas et al. (2016), and Walter et al. (2018)

\section{Water content (including water infiltration)}

al Hagrey (2007), Schwartz et al. (2008), Brasso et al. (2010), Brunet et al. (2010), Nijland et al. (2010), Celano et al. (2011), Kelly et al. (2011), Travelletti et al. (2012), Chrétien et al. (2014), Huang et al. (2015d, 2016, 2017c, d), Ain-Lhout et al. (2016), Alamry et al. (2017), Moghadas et al. (2017), and Martínez et al. (2018)

Texture (including clay content, topsoil thickness, and soil type)

Amato et al. (2009), Saey et al. (2012a, b), Grellier et al. (2013), Rossi et al. (2013), Sudduth et al. (2013), Buvat et al. (2014a, b ${ }^{a}$ ), Huang et al. (2014d), Pan et al. (2014), Rudolph et al. (2015), and Moghadas et al. (2016)

Bulk density (including tillage layers, compaction, archeological/pedological prospecting, rock content)

Besson et al. (2004), Séger et al. (2009), Brasso et al. (2010), Thiessen et al. (2011), and Rossi et al. (2013)

Organic matter related (including soil organic carbon)

Altdorff et al. (2016) and Huang et al. (2017e)

Hydraulic conductivity (including percolation)

Brosten et al. (2011) and Greve et al. (2011)

Leachate plume (including groundwater contamination)

Triantafilis et al. (2011) and Rao et al. (2014)

Electrical anisotropy

Greve et al. (2010)

${ }^{\mathrm{a}}$ Use of electrical resistivity $\mathrm{EC}_{\mathrm{a}}$ for composite depths of $0-0.5,0-1.0$, and $0-1.7 \mathrm{~m}$ with no inversion necessary, obtained with an automated resistivity-profiling device (ARP ${ }^{\circledR}$, GEOCARTA, Paris, France). Definitions: $\mathrm{EC}_{\mathrm{a}}$, apparent soil electrical conductivity; ERT, electrical resistivity tomography; EMI, electromagnetic induction. 
with separate data sets to gain the credibility and knowledge of uncertainty needed for future site-specific management of drip irrigation. Validation with separate data sets has been limited. Only von Hebel et al. (2014) has validated using a separate data set, which compared predicted $\mathrm{EC}_{\mathrm{a}}$ from inverted $\mathrm{EMI}$ measurements of $\mathrm{EC}_{\mathrm{a}}$ to $\mathrm{EC}_{\mathrm{a}}$ profile measurements from electrical resistivity tomography (ERT). Even though considerable research has been conducted over the past decade involving the inversion of EMI measurements to profile soil properties such as salinity, water content, texture, and organic matter, very little significant knowledge has been gained beyond that provided from the early works of Borchers et al. (1997), McBratney et al. (2000), and Hendrickx et al. (2002a) and what was already understood in the papers by Corwin and Lesch (2003, 2005a, b). However, the recent work by von Hebel et al. (2014) and Jadoon et al. (2017) indicate a potential shift away from the numerous repetitive observational inversion studies found in the literature over the past decade to research of greater practical relevance and impact.

Direct-current resistivity imaging or ERT to profile soil properties has been studied more thoroughly than EMI inversion. Mobile electrical resistivity systems have been developed and tested, including cylindrical steel electrodes with an in-line array geometry (Sørenson, 1996) and spiked wheels for continuous galvanic soil contact (Dabas, 2009; Panissod et al., 1998). Electrical resistivity imaging (ERI) has been successfully applied to characterize soil moisture profiles (Ain-Lhout et al., 2016; Alamry et al., 2017; Brunet et al., 2010; Celano et al., 2011; Nijland et al., 2010; Schwartz et al., 2008), plant water uptake (Ain-Lhout et al., 2016; Celano et al., 2011; Nijland et al., 2010), the tillage layer (Basso et al., 2010; Besson et al., 2004; Séger etal., 2009), to map and quantify root biomass (al Hagrey, 2007; Amato et al., 2009; Rossi et al., 2010), to monitor water percolation and optimize irrigation patterns (Greve et al., 2011; Kelly et al., 2011), to investigate soil weathering profiles (Beauvais et al., 2004), to characterize soil contamination and monitor remediation (West et al., 1999), to define site-specific management units (Morari et al., 2009), and to develop 3D soil-geology models (Tye et al., 2011). Revil et al. (2012) and Loke et al. (2013) provide reviews of direct-current geoelectrical imaging methods for 2D, 3D, and 4D surveys.

\subsection{Spectral indices of soil salinity from remote sensing}

As indicated in Table 3 spectral indices of soil salinity are categorized into simple ratio, intensity, soil, and vegetation indices. Simple ratio, intensity, and soil indices reflect salinity that is present in the top $0.1 \mathrm{~m}$ or less, which 
is not relevant for agriculture since the root zone of crops is generally associated with the top $1.5 \mathrm{~m}$ of soil. For this reason, simple ratio, intensity, and soil indices are best used to inventory degraded soils due to salt accumulation; consequently, vegetation indices are of most relevance and impact to agriculture since they can reflect the influence of a soil property for the entire root zone, such as soil salinity, upon plant condition.

Aside from advances in remote sensing equipment development, which will not be discussed in this paper, vegetation indices are arguably the most significant development in remote sensing for agricultural uses. This is particularly true for its application in mapping soil salinity at regional scale and will potentially hold true for field and landscape scales once affordable high-resolution $(<5 \mathrm{~m})$ multi- and hyper-spectral images are available at regular and frequent time intervals. Xue and Su (2017) provide a succinct review of the development and application of remote sensing vegetation indices.

The advantage of vegetation indices is that they reflect the influence of a soil property, such as salinity, upon plant condition for the entire root zone, but a major disadvantage is the inability to distinguish between other soil properties also influencing plant condition. Plant condition is influenced by a number of stressors (e.g., osmotic, matric, nutrient, pests, and disease stresses) causing near-infrared reflectance to drop and visible reflectance (red, blue, green) to increase. Vegetation indices, such as NDVI and CRSI, do not distinguish between stressors; subsequently, a decrease in NDVI or CRSI, which indicates plant stress, does not indicate whether the stress is due to salinity, water deficiency, nutrient deficiency, pests, and/or disease. The current means of overcoming this problem and isolating the target property of soil salinity is to combine the yearly integral of temporally interpolated VI time series data over multi-years to reduce the influence of stressors aside from salinity (Whitney et al., 2018). The yearly integral of temporally interpolated VI time series data diminishes seasonal influences, while the multi-year analysis isolates the effects of soil salinity from other confounding factors (e.g., water deficiency, nutrient deficiency, pests, and/or disease) that tend to be more transient and vary intra-annually (Lobell et al., 2007, 2010; Scudiero et al., 2014b). Therefore, a single-year perturbation to plant condition, such as disease, which in turn influences the visible and near-infrared reflectance, is smoothed out over multiple years as long as the average root zone salinity remains stable over those years. Another means of isolating salinity from other stressors is data fusion and the combined use of multiple sensors. 
No single VI has worked best at every agricultural location for salinity assessment. Vegetation index application is region specific (Whitney et al., 2018; Zhang et al., 2015); consequently, preliminary testing to identify the VI that performs best at each region of interest is necessary (Whitney et al., 2018).

\subsection{Data fusion of multiple sensors}

Table 6 shows five categories of proximal sensors commonly used in agriculture and the associated soil properties influencing their measurement as developed by Adamchuk et al. (2004). More than one agronomic property affects each sensor. For this reason, multiple proximal sensors are used in combination to better separate out the multiple properties influencing the different proximal sensors. The intent of the fusion of sensor data is to render novel soil property models characterizing soil spatial variability to produce maps of soil properties of greater accuracy and reliability. Most of the need to characterize and map field-scale spatial variation in soil properties accurately stems from site-specific management. The ease with which multiple sensors can be mounted on vehicles (e.g., ATV, tractor, modified pesticide spray rig) adds further impetus for their use. Grunwald et al. (2015) provides a comprehensive review of the fusion of soil and remote sensing data to model and map soil properties. The detailed review provides an overview of the integration pathways utilizing proximal and satellite sensors to model soil properties based on classic disciplinary (e.g., soil measurement techniques and proximal and remote sensing) and inter- and transdisciplinary approaches (e.g., digital soil mapping and pedometrics).

As categorized by Grunwald et al. (2015) the fusion of sensor data falls into three groups: (i) proximal sensor fusion, (ii) proximal and remote sensor fusion, and (iii) remote sensor fusion. Further sub-classification of sensor data fusion studies reviewed by Grunwald et al. (2015) met the following criteria or purposes: (i) sensor data was used as covariates to predict or classify a soil property, (ii) sensor data was used as the target variable, (iii) multitemporal and/or multi-location sensing, (iv) spectral indices derived from proximal and remote sensing data, (v) sensor comparison, and (vi) sensor fusion where data from multiple sensors are integrated. Grunwald et al. (2015) identified three studies related to sensor data fusion for soil salinity, each falling within a different category, including work by Metternicht and Zinck (2003), Nield et al. (2007), and Melendez-Pastor et al. (2010). Metternicht and Zinck (2003) reviewed the integration of proximal and 
Table 6 Soil properties influencing proximal sensors.

\section{Agronomic soil property}

\begin{tabular}{|c|c|c|c|c|c|c|c|c|c|c|}
\hline $\begin{array}{l}\text { Category of } \\
\text { proximal sensor }\end{array}$ & $\begin{array}{l}\text { Texture (sand, silt, } \\
\text { clay content) }\end{array}$ & OM & $\theta$ & $\begin{array}{l}\mathrm{EC} \text { or } \\
\mathrm{Na}\end{array}$ & $\begin{array}{l}\text { Cp or } \\
\rho_{b}\end{array}$ & $\begin{array}{l}\text { Depth of topsoil or } \\
\text { hard pan }\end{array}$ & $\mathrm{pH}$ & $\begin{array}{l}\text { Residual } \mathrm{NO}_{3} \text { or } \\
\text { total } \mathrm{N}\end{array}$ & $\begin{array}{l}\text { Other macro- } \\
\text { nutrients }\end{array}$ & $\overline{\mathrm{CEC}}$ \\
\hline Electrical and EMI & $\mathrm{X}$ & $\mathrm{X}$ & $\mathrm{X}$ & $\mathrm{X}$ & $\mathrm{X}$ & $\mathrm{X}$ & & $\mathrm{X}$ & & $\mathrm{X}$ \\
\hline $\begin{array}{l}\text { Optical and } \\
\text { radiometric }\end{array}$ & $\mathrm{X}$ & $\mathrm{X}$ & $\mathrm{X}$ & & & & $\mathrm{X}$ & $\mathrm{X}$ & & $\mathrm{X}$ \\
\hline Mechanical & & & & & $\mathrm{X}$ & $\mathrm{X}$ & & & & \\
\hline $\begin{array}{l}\text { Acoustic and } \\
\text { pneumatic }\end{array}$ & $\mathrm{X}$ & & & & $\mathrm{X}$ & $\mathrm{X}$ & & & & \\
\hline Electrochemical & & & & $\mathrm{X}$ & & & $\mathrm{X}$ & $\mathrm{X}$ & $\mathrm{X}$ & \\
\hline
\end{tabular}

EMI, electromagnetic induction, OM, soil organic matter, $\theta$, water content, EC, electrical conductivity (salinity), Na, sodium content, Cp, compaction, $\rho_{\mathrm{b}}$, bulk density, CEC, cation exchange capacity.

Modified from Adamchuk, V.I., Hummel, J.W., Morgan, M.T., Upadhyaya, S.K., 2004. On-the-go soil sensors for precision agriculture. Comput. Electron. Agric. 44, 71-91 
remote sensors, including aerial photographs, satellite and airborne multispectral sensors, microwave sensors, video imagery, airborne geophysics, hyper-spectral sensors, and electromagnetic induction sensors using various techniques such as spectral unmixing, maximum likelihood classification, fuzzy classification, band ratioing, principal components analysis, and correlation equations. Limited success was found especially on agricultural soils where surface soil crust was not visible. The work by Nield et al. (2007) fell into the category of remote sensing (i.e., Landsat ETM +) used as a covariate resulting in the correct prediction of $87 \%$ of the field-observed gypsic soil areas. Melendez-Pastor et al. (2010) was a multi-temporal remote sensing study using imaging spectroscopy techniques (i.e., matched filtering and mixture tuned matched filtering) to map saline soils with ASTER images from two approaches: (i) using image based spectra of saline and non-saline training areas and (ii) using the spectrum of the halite mineral as a proxy to the spectra of saline soils. The image-based mapping approaches were discovered to be more robust with respect to mapping performance and accuracy compared to the halite spectrum-based approaches.

Aside from the studies presented in Metternicht and Zinck (2003) several additional proximal-remote sensor fusion studies have improved the estimation of soil salinity, including Farifteh et al. (2006), Brunner et al. (2007), Goldshleger et al. (2012), Mahmood et al. (2012), Guo et al. (2013a), Scudiero et al. (2013, 2014a, 2015), Ding and Yu (2014), and Aldabaa et al. (2015). Farifteh et al. (2006) outlined a conceptual framework that integrated remote sensing, solute modeling, and geophysical $\mathrm{EC}_{\mathrm{a}}$ surveys to assess saltaffected soils. Goldshleger et al. (2012) evaluated the combined use of active and passive proximal and remote sensors to assess soil salinity, which consisted of (i) in situ and airborne sensor spectral measurements, (ii) frequency domain electromagnetic measurements, and (iii) ground penetration radar measurements. They concluded that merging the passive and active sensors yielded a better understanding of the underlying processes than any single sensor alone. Brunner et al. (2007) combined geospatial $\mathrm{EC}_{\mathrm{a}}$ measurements with spectral correlation mapping and NDVI to produce a regional-scale salinity map for the Yanqi Basin, China. Mahmood et al. (2012) used vis-NIR spectrometry and $\mathrm{EMI} \mathrm{EC}_{\mathrm{a}}$ for multiple soil properties aside from soil salinity, including texture, $\mathrm{pH}$, total organic carbon, total nitrogen, and carbon-to-nitrogen ratio. Mahmood et al. (2012) concluded that soil property models based on data fusion significantly improved the prediction accuracy for salinity, texture (i.e., clay, silt, and sand), and $\mathrm{pH}$ from those based on either of the individual 
sensors. Guo et al. (2013a) fused ALOS/PALSAR (Advanced Land Observing Satellite/Phased Array type L-band Synthetic Aperture Radar) radar remote sensing imagery and $\mathrm{EMI} \mathrm{EC}_{\mathrm{a}}$ sensor data to map soil moisture and salinity variability in reclaimed coastal areas of Zhejiang Province in China, concluding that integrating active remote sensing and proximal sensors are effective for rapidly and accurately detecting these soil properties. Scudiero et al. (2013) combined the use of intensive geospatial $\mathrm{EC}_{\mathrm{a}}$ measurements and bare-soil NDVI data to characterize the spatial variability of salinity, texture, organic carbon content, and bulk density to divide a field cropped in maize into five sitespecific management units (SSMUs) using fuzzy c-means clustering. Scudiero et al. (2014a, 2015) used ground-truth measurements of soil salinity obtained from ECa-directed soil sampling following the protocols of Corwin and Lesch (2005b, 2013) and canopy response salinity index (CRSI) from Landsat 7 reflectance data to facilitate salinity mapping. Their results indicated that a fusion of multi-year Landsat 7 reflectance data with meteorological information, crop type, and soil texture would improve salinity assessment of the western San Joaquin Valley. Ding and Yu (2014) integrated spectral information from Landsat TM images from the dry and wet seasons of 2011 and then applied universal kriging, spectral index regression, and regression-kriging approaches to define salinity patterns. Their results indicated that regressionkriging with a nest spherical model produced the closest fit to observed $\mathrm{EC}_{\mathrm{a}}$ data. Aldabaa et al. (2015) evaluated the use of visible near infrared diffuse reflectance spectroscopy, portable X-ray fluorescence spectrometry, and remote sensing to quantify soil salinity rapidly, concluding that the fusion of all three techniques produced the highest predictability.

\subsection{Applications of multi-scale soil salinity assessment}

The applications of multi-scale salinity assessment obtained from proximal and remote sensors are diverse, including field-scale mapping of soil quality, landscape-scale modeling of salt loads to tile drain systems, delineation of SSMUs for irrigation and salinity control, spatio-temporal monitoring of degraded water reuse, plant salt tolerance determination, assessing biofuel production feasibility on salt-affected soils, and monitoring the impact of climate change on soil salinization. Scientists at the USDA-ARS U.S. Salinity Laboratory spearheaded applied research in this area and contributed the greatest concentration of research to demonstrate the application of multi-scale salinity assessment derived from proximal and satellite sensors. 


\subsubsection{Mapping soil salinity and soil quality}

An inventory of salinity is an obvious product of maps generated from salinity assessments using proximal and satellite sensors irrespective of the scale. Corwin et al. (2003a) went beyond mapping the spatial variability of only soil salinity and extended the use of $\mathrm{EC}_{\mathrm{a}}$-directed soil sampling to mapping soil quality, comprised of 31 soil chemical and physical properties. Corwin et al. (2003a) mapped the soil quality of a 32.4-ha saline-sodic field in California's San Joaquin Valley following the $\mathrm{EC}_{\mathrm{a}}$-directed soil sampling guidelines of Corwin and Lesch (2003). A range of soil quality properties were mapped pertaining to the intended use of the soil, which was to grow Bermuda grass (C. dactylon (L.) Pers.) as forage for livestock.

Soil quality was established both by soil sample analyses at sites determined from $\mathrm{EC}_{\mathrm{a}}$-directed soil sampling and by yield and chemical analyses of the forage crop at the same site locations. The soil quality properties of interest were those that potentially influenced the yield and quality of the livestock forage crop, including $\mathrm{EC}_{\mathrm{e}} ; \mathrm{pH}_{\mathrm{e}}$, anions $\left(\mathrm{HCO}_{3}{ }^{-}, \mathrm{Cl}^{-}, \mathrm{NO}_{3}{ }^{-}\right.$, $\left.\mathrm{SO}_{4}{ }^{-2}\right)$ and cations $\left(\mathrm{Na}^{+}, \mathrm{K}^{+}, \mathrm{Ca}^{+2}, \mathrm{Mg}^{+2}\right)$ in the saturation extract, trace elements $(\mathrm{B}, \mathrm{Se}, \mathrm{As}, \mathrm{Mo})$ in the saturation extract; $\mathrm{CaCO}_{3}$; gypsum, cation exchange capacity (CEC); exchangeable $\mathrm{Na}^{+}, \mathrm{K}^{+}, \mathrm{Mg}^{+2}$, and $\mathrm{Ca}^{+2}$; exchangeable sodium percentage (ESP); sodium adsorption ratio (SAR); inorganic and organic $\mathrm{C}$; total $\mathrm{N}$; saturation percentage $(\mathrm{SP})$; volumetric water content $\left(\theta_{\mathrm{v}}\right)$; bulk density $\left(\rho_{\mathrm{b}}\right)$; clay content; and saturated hydraulic conductivity $\left(\mathrm{K}_{\mathrm{s}}\right)$.

The study demonstrated the field-scale application of $\mathrm{EC}_{\mathrm{a}}$-directed soil sampling to characterize the spatial variability of soil quality properties. As long as the properties are significantly correlated to $\mathrm{EC}_{\mathrm{a}}$, whether by direct influence on the $\mathrm{EC}_{\mathrm{a}}$ measurement or indirectly by correlation with a property that directly influences the $\mathrm{EC}_{\mathrm{a}}$ measurement, they can be accurately mapped. The soil quality maps provide producers with information regarding where and how to reclaim the soil to increase crop yield or crop quality.

\subsubsection{Modeling landscape-scale salt loads to tile drains}

Corwin et al. (1999) modeled salt loading to tile drains in a unique landscape-scale solute transport study. The uniqueness of this study was the use of a proximal sensor (i.e., geospatial measurements of $\mathrm{EC}_{\mathrm{a}}$ with EMI) to define and delineate stream tubes (i.e., spatial domains of soil where the variability of properties influencing solute transport is minimized) that characterize the spatial variability of edaphic properties influencing solute 
transport. The study used $\mathrm{EC}_{\mathrm{a}}$-directed soil sampling to identify stream tubes for a 2396-ha study area in the former Broadview Water District of California's San Joaquin Valley. Corwin et al. (1999) linked the functional-deterministic solute transport model TETrans (Corwin et al., 1991) to a GIS where the map units were the stream tubes delineated from the $\mathrm{EC}_{\mathrm{a}}$ survey. Physical, chemical, and biological properties influencing salt transport associated with each stream tube served as inputs and parameters for the TETrans model. TETrans is a one-dimensional, functional, deterministic model often referred to as a "tipping bucket" layer-equilibrium solute transport model. TETrans was specifically developed for field-scale application using capacity parameters (e.g., field capacity) that are less spatially variable than the rate parameters (e.g., hydraulic conductivity) used in mechanistic-deterministic solute transport models. In addition, the inputs and parameters for TETrans are more readily available and more commonly measured by irrigation and drainage districts in the southwestern USA than other deterministic models of solute transport.

A map of salt loading across the 2396-ha study area was obtained by applying TETrans to each stream tube. Model simulations were performed from May 1991 to May 1996. Simulations of salt loads were compared to measured salt loads in tile drain sumps connected to tile drains that drained various combinations of quarter sections of land in the Broadview Water District. Table 7 compares the measured and simulated salt load amounts. In all but one instance, the simulated salt loads were within $29 \%$ of the measured salt load and in the majority of instances $<20 \%$. These simulation results exceed the prediction capabilities of other more complex solute transport models under landscape-scale applications (Oster et al., 2012) and serve as a landscape-scale validation of TETrans when used with stream tubes.

The intended goal of the study was to demonstrate the practicality, utility, and reliability of a functional solute transport model coupled to a GIS to predict landscape-scale salt loads to tile drains and groundwater, thereby providing a useful salinity management tool for irrigation and drainage district managers. Corwin et al. (1999) concluded that "aside from serving as a partial [model] validation, the results indicate the practicality and utility of applying a one-dimensional GIS-linked solute transport model of the vadose zone to predict and visually display salt loading to groundwater over hundreds or thousands of hectares." The implication of this work is that the level of sophistication of a solute transport model is of no greater importance than the spatial characterization of the model inputs and parameters. Furthermore, scale dictates the general type of model in accordance with the organizational hierarchy of spatial scales (Corwin et al., 2006a). 
Table 7 Comparison of measured and predicted salt load amounts for Broadview Water District from May 1991 to May 1996.

\begin{tabular}{|c|c|c|}
\hline Quarter sections draining into a drainage sump & $\begin{array}{l}\text { Measured }^{\mathrm{a}} \\
\left(\mathrm{kg} \times 10^{3} / \mathrm{ha}\right)\end{array}$ & $\begin{array}{l}\text { Predicted } \\
\left(\mathrm{kg} \times 10^{3} / \mathrm{ha}\right)\end{array}$ \\
\hline $3-1,3-2,3-3$, and $3-4$ & 14.33 & 16.97 \\
\hline 4-1 and 4-3 & 39.22 & 31.84 \\
\hline $4-2$ and $4-4$ & 46.23 & 33.00 \\
\hline $9-1$ and $9-2$ & 11.48 & 13.22 \\
\hline $9-3$ and $9-4$ & 2.1 & 10.45 \\
\hline $10-1$ and $10-2$ & 16.53 & 16.56 \\
\hline $10-3$ and $10-4$ & 16.05 & 15.91 \\
\hline
\end{tabular}

${ }^{a}$ Measured at drainage sump.

${ }^{\mathrm{b}}$ Area-weighted average of between 8 and 16 stream tubes within each quarter section.

Source from Corwin, D.L., Carrillo, M.L.K., Vaughan, P.J., Rhoades, J.D., Cone, D.G., 1999.

Evaluation of GIS-linked model of salt loading to groundwater. J. Environ. Qual. 28, 471-480.

\subsubsection{Delineating site-specific management units (SSMUs) for irrigation and salinity management}

Conventional farming manages resource inputs (i.e., fertilizer, irrigation water, amendments, pesticides) uniformly, ignoring the naturally inherent spatial heterogeneity of soil and crop conditions between and within fields. The uniform application of inputs results in over and under applications of resources. In most instances producers over apply inputs in an effort to maximize crop yield across the entire field. The over application of inputs results in reduced profitability and detrimental environmental impacts to soil, surface water, and groundwater resources, and to drainage water. Site-specific crop management applies inputs when, where, and in the amounts needed. Site-specific crop management accounts for local variability by managing at a spatial scale smaller than the whole field with the aim of cost effectively optimizing crop production and profitability while making efficient use of finite resource inputs to minimize detrimental environmental impacts.

Mulla (2013) reviewed the key advances in remote sensing for precision agriculture and Corwin and Plant (2005) reviewed the application of $\mathrm{EC}_{\mathrm{a}}$ in precision agriculture. Multispectral imagery has been used in precision agriculture for mapping crop growth and yield variability (Inman et al., 2008; Varvel et al., 1999; Yang and Everitt, 2002), characterizing soil spatial variability (Barnes et al., 2003), mapping water status (Cohen et al., 2017), and identifying crop pest infestations (Backoulou et al., 2015) and disease (Yang et al., 2016). Hyperspectral imagery has also mapped crop yield variability 
(Goel et al., 2003; Yang et al., 2007; Zarco-Tejada et al., 2005) and crop pests (Fitzgerald et al., 2004; Kumar et al., 2012; Li et al., 2014; MacDonald et al., 2016) as well as soil fertility (Bajwa and Tian, 2005). Many of the earliest applications of proximal sensors were for site-specific crop management (Corwin, 2008; Corwin and Lesch, 2005a). Most of these applications related maps of productivity zones to maps of $\mathrm{EC}_{\mathrm{a}}$ or $\gamma$-ray measurements without any associated site-specific management recommendations. Corwin et al. (2003b) departed from this early approach. Corwin et al. (2003b) hypothesized that in instances where $\mathrm{EC}_{\mathrm{a}}$ correlates with crop yield, then $\mathrm{EC}_{\mathrm{a}}$ must be measuring some edaphic property or properties influencing yield. Spatial $\mathrm{EC}_{\mathrm{a}}$ information was used to direct a soil and crop-yield sampling plan that identified sites reflecting the range and variability of soil properties influencing crop yield. Subsequently, a crop-yield response model relating crop yield to various edaphic properties influencing the crop yield was formulated. From the crop-yield response model, site-specific management units (SSMUs) were delineated and site-specific management recommendations were developed for the SSMUs.

Corwin et al. (2003b) used a 32.4-ha field of Panoche silty clay soil (thermic Xerorthents) growing cotton located in the former Broadview Water District in California's San Joaquin Valley. Exploratory statistical analysis consisting of simple correlation coefficients and scatter plots identified six edaphic properties that potentially influenced cotton yield: $\mathrm{EC}_{\mathrm{e}}$, leaching fraction $(\mathrm{LF})$, clay content $(\%), \mathrm{pH}_{\mathrm{e}}$, gravimentric water content $\left(\theta_{\mathrm{g}}\right)$, and bulk density $\left(\rho_{\mathrm{b}}\right)$. From scatter plots of the soil properties and cotton yield, there was found to be a quadratic relationship between $\mathrm{EC}_{\mathrm{e}}$ and yield, curvilinear relationship between $\mathrm{LF}$ and yield, and linear relationships between yield and the remaining four properties (clay $\%, \mathrm{pH}_{\mathrm{e}}, \theta_{\mathrm{g}}$, and $\rho_{\mathrm{b}}$ ). Using ordinary least squares and adjusting for spatial autocorrelation with a restricted maximum likelihood approach the most robust and parsimonious cotton yield response model was Eq. (15):

$$
\begin{aligned}
Y= & 19.28+0.22\left(\mathrm{EC}_{\mathrm{e}}\right)-0.02\left(\mathrm{EC}_{\mathrm{e}}\right)^{2}-4.42(\mathrm{LF})^{2} \\
& -1.99\left(\mathrm{pH}_{\mathrm{e}}\right)+6.93\left(\theta_{\mathrm{g}}\right)+\varepsilon
\end{aligned}
$$

where $Y$ is the cotton yield $\left(\mathrm{Mgha}^{-1}\right), \mathrm{EC}_{\mathrm{e}}\left(\mathrm{dS} \mathrm{m}^{-1}\right)$, and $\theta_{\mathrm{g}}\left(\mathrm{kg} \mathrm{kg}^{-1}\right)$. LF and $\mathrm{pH}_{\mathrm{e}}$ are unitless. Details regarding the delineation of the SSMUs and development of the recommendations are found in the paper by Corwin and Lesch (2010). 
Scudiero et al. (2013) advanced this an additional step by combining soil reflectance and $\mathrm{EC}_{\mathrm{a}}$-directed soil sampling. Approximately 53\% of the spatial variation in maize yield was attributable to the variation of four soil properties: $\mathrm{EC}_{\mathrm{e}}$, texture, organic carbon content, and $\rho_{\mathrm{b}}$. The spatial variability of these properties was characterized by combining $\mathrm{EC}_{\mathrm{a}}$-directed soil sampling based on a simulated spatial annealing sampling strategy and bare-soil NDVI, which resulted in five SSMUs using fuzzy c-means clustering. This research pointed out the utility of the combined use of proximal and satellite sensors to delineate SSMUs.

Though not pertaining specifically to soil salinity, Miao et al. (2018) used a combination of soil and yield information as done by Corwin and Lesch (2010) and Scudiero et al. (2013) to develop an integrated approach. Miao et al. (2018) developed an integrated approach for delineating SSMUs using relative elevation, organic matter, slope, electrical conductivity, yield spatial trend map, and yield temporal stability map (ROSE-YSTTS). Their ROSE-YSTTS approach was able to account reasonably effectively for three sources of variability for soil and landscape, nutrient level, and $\mathrm{pH}$.

\subsubsection{Monitoring degraded water reuse}

Water resources are finite and yet demand for water continues to increase to meet domestic agricultural, industrial, and recreational needs. The increase in water demands comes at a time in history when erratic weather patterns from climate change have caused a greater occurrence of extended droughts. Globally, projections for the 2090s show a net overall global drying trend with the proportion of land surface in extreme drought predicted to increase by a factor of 10 to 30, increasing from 1-3\% currently to 30\% by the 2090 s (World Meteorological Organization, 1997). Global water consumption rose sixfold from 1900 to 1995, which was double the population growth rate (World Meteorological Organization, 1997). Today degraded water is increasingly viewed as an alternative water resource rather than as wastewater to be disposed. Corwin and Bradford (2008) point out that the "increased reuse of degraded water is an inevitable consequence of current trends in demand for and supply of water resources, and of the need to dispose of increased volumes of degraded water" and "to prepare for the expected shift to degraded water reuse an understanding and assessment of the potential detrimental environmental impacts and short- and longterm sustainability is needed." Corwin et al. (2006b, 2008b) and Corwin (2012) addressed the concern of Corwin and Bradford (2008) by investigating the spatio-temporal impacts on soil of reusing drainage water using 
$\mathrm{EC}_{\mathrm{a}}$-directed soil sampling to monitor at field scale the changes in soil quality impacted by degraded water reuse.

Corwin et al. (2008b) and Corwin (2012) used $\mathrm{EC}_{\mathrm{a}}$-directed soil sampling to look at the short- (5 years) and long-term (10 years) sustainability, respectively, of applying $1.8-16.3 \mathrm{dSm}^{-1}$ drainage water to a 32.4-ha saline-sodic soil field of marginal crop productivity located in the San Joaquin Valley. The objective of the drainage water reuse studies was to evaluate the sustainability of drainage water reuse on saline-sodic soil in the WSJV from the perspective of the impact on soil chemical properties in the root zone (i.e., top $1.2 \mathrm{~m}$ of the soil profile) crucial to the soil's intended use of producing Bermuda grass for forage by livestock. Spatiotemporal changes in four soil properties were identified as having the greatest impact on the intended use of growing a forage crop (i.e., Bermuda grass): $\mathrm{EC}_{\mathrm{e}}$, SAR, B, and Mo. The soil properties of $\mathrm{EC}_{\mathrm{e}}, \mathrm{SAR}$, and $\mathrm{B}$ influenced the yield of Bermuda grass while Mo influenced the quality. Plants absorb amounts of Mo harmful to ruminant animals from soils containing as little as $1.5-5.0 \mathrm{mg} \mathrm{kg}^{-1}$ of total Mo (Barshad, 1948). After 5 years (i.e., 1999-2004) salinity decreased by $11 \%$ on a mass basis, SAR decreased 11\%, B decreased 21\%, and Mo decreased 56\%. By 2009 salinity had decreased 21\%, SAR decreased 19\%, B decreased 32\%, and Mo decreased $67 \%$. Even though general soil quality improved, the extent of the improvement was spatially dependent both by depth and by position in the field. Fig. 12 shows the complex spatio-temporal patterns of soil salinity for 1999, 2002, and 2004. Considerable leaching of salts occurred at the north end of the field, while salts accumulated in the south particularly below $0.6 \mathrm{~m}$ (Fig. 12D). This continued through 2009 and was attributed to the accumulation of $\mathrm{Na}$ at the southern end of the field below $0.6 \mathrm{~m}$, which caused the soil to disperse making the soil below $0.6 \mathrm{~m}$ less permeable (Corwin, 2012).

Corwin et al. (2008b) and Corwin (2012) concluded that (i) $\mathbf{E C}_{\mathbf{a}^{-}}$ directed sampling was a viable and reliable means of spatio-temporally monitoring degrade water reuse impacts on soil, (ii) applying drainage water to saline-sodic soils in the WSJV was a means of reducing drainage volumes, improving soil quality, and and using an alternative water resource (i.e., drainage water) to bring marginally productive soils back into production, and (iii) the reuse of drainage water in the WSJV was sustainable at least for 10 years with steady improvements in soil quality.

Since the closure of the Kesterson reservoir in the mid 1980s, drainage water in the WSJV has been a disposal problem. Evaporation ponds were largely used to deal with the problem. For every 10 ha of artificially drained 


\section{Soil Salinity $\left(E_{\mathrm{e}}\right)$ from 1999 to 2004}

(a)

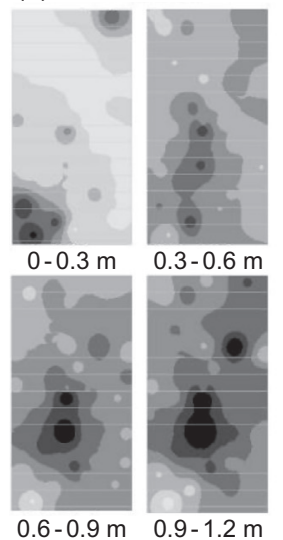

(b) $\quad 2002$
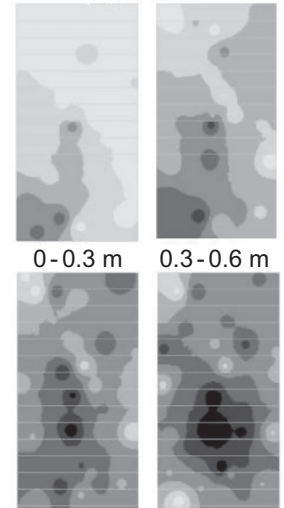

$0.6-0.9 \mathrm{~m}$ (a-c) $\mathrm{EC}_{\mathrm{e}}\left(\mathrm{dS} \mathrm{m}^{-1}\right)$ :

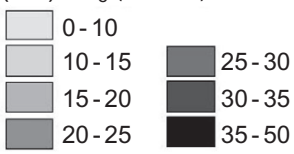

(c) $\quad 2004$

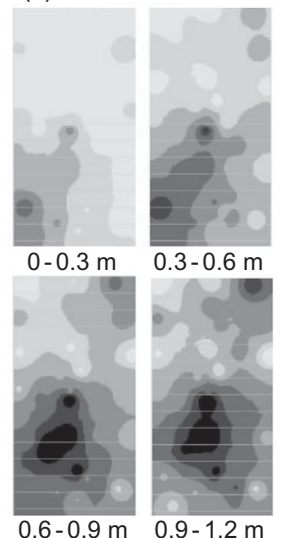

(d) $1999-2004$

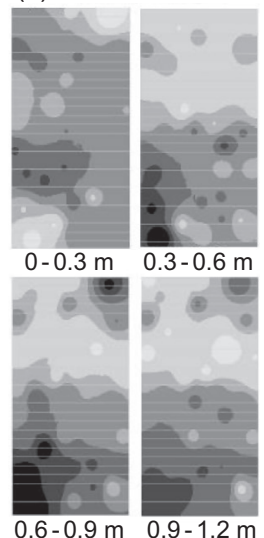

(d) $\mathrm{EC}_{\mathrm{e}}\left(\mathrm{dS} \mathrm{m}^{-1}\right)$ change:

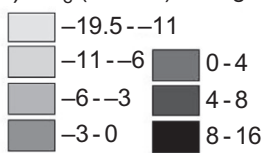

Fig. 12 Maps of a 32.4-ha saline-sodic field near Stratford, CA, showing the spatiotemporal change in spatial patterns of salinity (electrical conductivity of the saturation extract in $\mathrm{dS} \mathrm{m}^{-1}, \mathrm{EC}_{\mathrm{e}}$ ) due to the application of drainage water with maps are arranged by depth increment $(0-0.3,0.3-0.6,0.6-0.9$, and $0.9-1.2 \mathrm{~m})$ for the sampling times of (A) 1999, (B) 2002, and (C) 2004. (D) Maps showing the spatial patterns of net change in $\mathrm{EC}_{\mathrm{e}}$ from 1999 to 2004 by depth. Taken from Corwin, D.L., Lesch, S.M., Oster, J.D., Kaffka, S.R., 2008b. Short-term sustainability of drainage water reuse: spatio-temporal impacts on soil chemical properties. J. Environ. Qual. 37, S-8-S-24 with permission.

land, 1 ha of evaporation pond was needed, which took 34,000 ha of land out of production to serve as land used for evaporation ponds. Furthermore, Scudiero et al. (2017) estimated that strongly and extremely salt-affected soils (i.e., 8-16 and $>16 \mathrm{dSm}^{-1}$, respectively) in the WSJV covered over 210,000 ha. The research of Corwin et al. (2008b) and Corwin (2012) provides WSJV producers with a tool to reclaim strongly and extremely saltaffected soils, bringing non-productive land back into production, while reducing drainage water volumes, thereby reducing the land taken out of production for use as evaporation ponds.

\subsubsection{Assessing the feasibility of biofuel production on marginally productive salt-affected soil}

Biofuel is more costly than petroleum-based fuels and is a minor component of overall military fuel sources. Even so, biofuel serves a strategically valuable 
role to the U.S. military because of the intentional reliance on multiple, reliable, secure fuel sources. Significant reduction in oilseed biofuel cost occurs when salt-tolerant Ida Gold mustard oilseed (Sinapis alba L.) is grown on marginally productive saline-sodic soils plentiful in California's San Joaquin Valley (SJV) where degraded water can be applied without negatively affecting soil quality. Recent research by Corwin et al. (2017) uses proximal and remote sensors in a variety of integrated roles to evaluate oilseed biofuel production feasibility in SJV. These roles included establishing salt and $\mathrm{B}$ tolerance of mustard oilseed, mapping root-zone soil for the entire SJV, and developing a mustard oilseed yield response model. The objective of the study was to evaluate the feasibility of mustard oilseed production on marginal soils in the SJV to support a 115 ML per year biofuel conversion facility. In other words, can Ida Gold mustard oilseed grow with sufficient yields on marginally productive salt-affected soils (i.e., $\mathrm{EC}_{\mathrm{e}}>4 \mathrm{dS} \mathrm{m}^{-1}$ ) in the SJV to support a $115 \mathrm{ML}$ per year conversion facility?

The feasibility study involved (i) development of an Ida Gold mustard oilseed yield model from marginal soils following the $\mathrm{EC}_{\mathrm{a}}$-directed sampling approach of Corwin et al. (2003b), (ii) identification of marginally productive salt-affected soils as outlined in the combined proximal and remote sensor work of Scudiero et al. (2014a, 2015, 2017), (iii) development of a spatial database of probability density functions for edaphic factors influencing oilseed yield, which served as input into the crop yield model, and (iv) performance of Monte Carlo simulations showing potential biofuel production on salt-affeected SJV soils.

Eq. (16) represents the most parsimonious and robust Ida Gold oilseed yield model, indicating that oilseed yield is related to boron, salinity, leaching fraction, and water content at field capacity:

$$
\begin{aligned}
Y= & 146.4(B)-18.3(B)^{2}+83.0\left(E C_{e}\right) \\
& -6.1\left(E C_{e}\right)^{2}+1301.0(L F)+319.8\left(\theta_{g}\right)+30.1
\end{aligned}
$$

where $Y$ is the Ida Gold mustard oilseed yield $\left(\mathrm{kgha}^{-1}\right), B$ is boron concentration $\left(\mathrm{mgL}^{-1}\right), E C_{e}$ is electrical conductivity of the saturation extract $\left(\mathrm{dS} \mathrm{m}^{-1}\right), L F$ is leaching fraction; and $\theta_{g}$ is the gravimentric water content $\left(\mathrm{kg} \mathrm{kg}^{-1}\right)$. Monte Carlo simulations for the entire SJV fit the shifted gamma probability density function shown in Eq. (17):

$$
Q=68.986+\operatorname{gamma}(6.134,5.285)
$$


where $Q$ is the biofuel production in ML per year. Eq. (17) indicates a 0.15-0.17 probability of meeting the target oilseed production level of 115 ML per year, which of course is infeasible.

This study exemplifies the combined use of proximal and satellite sensors to address a salinity-related issue of national strategic significance for aviation fuel needs of the U.S. military. Even though the conclusion was not positive, it clearly revealed the low probability of meeting the minimum production level, eliminating any further need for the consideration of growing mustard oilseed as a biofuel in the SJV.

\subsubsection{Establishing plant salt tolerance with $E C_{a}$-directed soil sampling} Traditional plant salt tolerance studies are conducted under highly controlled conditions, where only soil salinity is allowed to vary in order to establish the salinity threshold and yield decrement slope for the two-piece salt tolerance model of Maas and Hoffman (1977) presented in Eq. (18):

$$
Y_{r}=100-b\left(E C_{e}-a\right)
$$

where $Y_{r}$ is the relative crop yield, $a$ is the salinity threshold $\left(\mathrm{dSm}^{-1}\right), b$ is the slope expressed in yield decrement percentage per $\mathrm{dSm}^{-1}$, and $E C_{e}$ is the mean electrical conductivity of the saturation extract for the root zone $\left(\mathrm{dS} \mathrm{m}{ }^{-1}\right)$. A compilation of plant salt tolerance work with the salinity thresholds and yield decrement slope for various crops and plants has been presented by Maas and Hoffman (1977), Maas (1996), and Grieve et al. (2012).

In traditional plant salt tolerance studies the influences on plant yield of all other soil properties aside from salinity (e.g., matric stress, soil permeability, infiltration, $\mathrm{pH}$ ) are removed by making them optimal for the soil used in the study. The salinity threshold and yield decrement slope are highly optimized in traditional salt tolerance studies; consequently, they are often not found to be what actually occurs in the field where a different soil than that used in the salt tolerance study is present (Corwin et al., 2003b, 2017), making their relevance questionable. Even though the properties are controlled to be optimal, their optimal state will still differ from one soil to the next. Even so, traditional plant salt tolerance studies appear to have been the best means of establishing salinity effects on crop yield and certainly the most widely used until an approach is found that provides better information for real-world application.

Recently, an alternative to traditional plant salt tolerance studies has been presented by Corwin et al. (2017), which uses EC $_{\mathrm{a}}$-directed soil sampling 
and boundary line analysis to develop a salt tolerance curve from which a salinity threshold and yield decrement slope are determined. The extent to which these salt tolerance parameters (i.e., salinity threshold and yield decrement slope) can be generalized is unknown pending future research, but it is reasonable to assume the parameters are scale dependent and valid within a localized area of similar soil type. The advantage of this alternative approach is that the salt tolerance parameters are tailored for the site of interest and are thereby more relevant and are established under real-world conditions. Furthermore, the cost is less compared to traditional salt tolerance experiments.

Corwin et al. (2017) conducted salt tolerance studies using EC $_{\mathrm{a}}$-directed soil sampling and boundary line analysis. The salt tolerance data were collected from 40 soil cores taken within a 16.2-ha field west of Los Banos in California's Merced County and from 10 supplemental sites. The 40 soil cores were identified from $\mathrm{EC}_{\mathrm{a}}$-directed soil sampling. The 10 supplemental sites were from a transect covering a range of mustard oilseed yields. Salt tolerance data were only from those sites varying in oilseed yield where all soil properties were optimal except salinity, which were identified from boundary line analysis. Boundary line analysis places the focus on the upper edge of a scatter-plot data cloud. The upper edge boundary represents the maximum yield response to the independent variable (i.e., salinity or $\mathrm{EC}_{\mathrm{e}}$ ), so the upper edge boundary line is where all conditions are optimal except for the independent variable. Any points below the upper edge boundary line represent conditions where some other influencing property or properties have limited the yield. Corwin et al. (2017) determined the salinity threshold, i.e., $a$ in Eq. (18), and the yield decrement slope, i.e., $b$ in Eq. (18), to be $8.3 \mathrm{dS} \mathrm{m}^{-1}$ and $17 \%$, respectively, for Ida Gold mustard oilseed. However, the two-piece linear salt tolerance model (i.e., Eq. 18) of Maas and Hoffman (1977) was not the best model to fit the data, but rather a quadratic fit proved best:

$$
Y=74.0+254.6 E C_{e}-18.8 \mathrm{EC}_{\mathrm{e}}^{2}\left(R^{2}=0.87\right)
$$

where $Y$ is the Ida Gold mustard oilseed yield $\left(\mathrm{kgha}^{-1}\right)$. Greater discussion of boundary line analysis can be found in Webb (1972), Kitchen et al. (1999, 2003), and Shatar and McBratney (2004).

\subsubsection{Monitoring the impact of climate change on soil salinity}

As climate change alters weather patterns drought cycles are predicted to become longer and more intense, particularly in already water-scarce 
regions of the world; consequently, an ability to monitor climate change impacts on soil salinity over multiple scales is essential for management of soil salinity. Corwin and Scudiero (2017) assessed at multiple scales the impact of a recent 6-year drought (i.e., 2011-15) on soil salinity for the west side of California's San Joaquin Valley. At field scale, a 32.4-ha reclaimed field returned to its original saline-sodic condition within 18 months of the onset of the drought. At landscape scale, 2400 ha of the former Broadview Water District increased in field-average soil salinity of the root zone by $43 \%$. At regional scale, the estimate of salt-affected soil (i.e., $\mathrm{EC}_{\mathrm{e}}>4 \mathrm{dS} \mathrm{m}^{-1}$ ) increased from $4.5 \times 10^{5}$ ha in 1984 to $5.5 \times 10^{5}$ ha in 2013. Corwin and Scudiero (2017) concluded that "As a consequence of changes in climate patterns, salt accumulation will most likely occur in irrigated agricultural areas around the world subjected to extended drought conditions where shallow water tables and fine textured soils exist ..."

Corwin and Scudiero (2017) also assessed the impact on soil salinity due to a change in weather patterns for Minnesota's Red River Valley (RRV) resulting in rainfall exceeding the average rainfall in 17 of the last years prior to 2007. The increased rainfall and a shift from deeper-rooted higher-ET crops to more shallow-rooted lower ET crops resulted in rising water tables. Because of the high clay content of soil in areas of the RRV (e.g., Kittson County), capillary rise from shallow water tables resulted in the accumulation of salts in the root zone. For roughly 150,000 ha of western Kittson County there was a $30 \%$ increase in agricultural land with soil salinity $>2 \mathrm{dS} \mathrm{m}^{-1}$. Corwin and Scudiero (2017) concluded that agricultural areas around the world subjected to extensive rainfall on fine-textured soils where shallow water tables result will likely accumulate salt like the RRV's Kittson County.

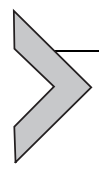

\section{Knowledge gaps and trends in salinity assessment research}

As previously mentioned, Table 2 indicates that extensive field-scale research has been conducted in the use of geospatial measurements of $\mathrm{EC}_{\mathrm{a}}$ to characterize soil spatial variability, especially for soil salinity. However, much of this research is redundant and in the majority of cases does not follow the protocols for $\mathrm{EC}_{\mathrm{a}}$-directeded soil sampling that first occurred in Corwin and Lesch (2003). A certain level of redundancy in research is needed, but not to the extend it has been conducted for $\mathrm{EC}_{\mathrm{a}}$. Conducting $\mathrm{EC}_{\mathrm{a}}$ research at different geographical locations does not constitute original 
reseach and it is not sufficient for research to be just technically correct to be worthy of publication. Research should add to the current base of scientific knowledge and understanding. The failure of most researchers to adhere to $\mathrm{EC}_{\mathrm{a}}$-directed soil sampling protocols of Corwin and Lesch (2003, 2005b, 2013) and Corwin and Scudiero (2016) casts a shadow of doubt on much of the past research. Researchers need to strive to follow accepted procedures and to build upon past research rather than repeat it. For example, field-scale $\mathrm{EC}_{\mathrm{a}}$-directed soil sampling protocols are designed to minimize soil sampling by using the spatial variation in $\mathrm{EC}_{\mathrm{a}}$ measurements to select soil sample sites that will reflect the variation and range in $\mathrm{EC}_{\mathrm{a}}$ without clustering the sample sites. This approach works well under conventional sprinkler and flood irrigation systems, but breaks down under micro-irrigation systems due to the high level of local-scale variation in salinity and water content that is found within distances of $1-2 \mathrm{~m}$ and less; consequently, the $\mathrm{EC}_{\mathrm{a}}-\mathrm{EC}_{\mathrm{e}}$ calibration is seldom reliable. Additional research is needed to develop reliable protocols for fields under drip and micro-sprinkler irrigation systems.

The current trend in the use of inverse modeling to profile soil salinity in two and three dimensions will continue. The impetus for continued research in inverse modeling comes from micro-irrigation. The application of this area of research is needed for characterizing the complex 2D and 3D distributions of salinity within the root zone associated with well-established micro-irrigation systems. The increase in the use of micro-irrigation systems on high cash crops (e.g., pistachios, almonds, grapes) in arid zone agricultural areas such as the SJV where water scarcity is a recurring problem will substantially increase the need for detailed meter and sub-meter knowledge of salinity distributions to provide producers with the level of information needed to manage water application for each tree or vine. In the past, water has been applied in copious amounts even with micro-irrigation systems. With longer and harsher droughts forecasted for arid agricultural areas due to altered climate patterns, water management for salinity control will be the key to sustainability in these water-scarce agricultural areas since salinity and water go hand-in-hand in irrigated agriculture. Before this can happen the validation of salinity distributions generated from inverse modeling with separate data sets is needed and the validation needs to be comprehensive, like the validation of the ANOCOVA approach by Corwin and Lesch (2017). Cross validation methods have been used in the past (Huang et al., 2017a, b), but no validation has been presented using a separate data set that is sufficiently comprehensive to provide confidence in the reliability of 
profile salinity predictions from inverse modeling and to establish inverse modeling as reliable for practical application.

Not many multi-field or landscape-scale salinity assessment studies with proximal and satellite sensors have occurred in the past. However, increased awareness of the ANOCOVA $\mathrm{EC}_{\mathrm{a}}$-directed soil sampling approach and increased availability of higher resolution satellite imagery should create greater opportunity and provide greater incentive for researchers to conduct multi-field salinity assessment studies. The spatial extent of the application of the ANOCOVA approach is largely set by economic and human resource constraints. Currently, the ANOCOVA approach is most efficiently used from 3 to $10 \mathrm{~km}^{2}$. It has been shown by Scudiero et al. (2016b) that the ANOCOVA $\mathrm{EC}_{\mathrm{a}}$-directed soil sampling approach is more accurate for regional-scale salinity assessment than the use of remote imagery, but this could change with higher resolution (i.e., $1 \mathrm{~m} \times 1 \mathrm{~m}$ pixels) remote imagery and advanced data analysis (e.g., machine learning).

Regional-scale salinity assessment research needs greater focus and attention given to seasonal and yearly influences on remote imagery to dampen the non-target property influences on the measurement of soil salinity with remote imagery. Multi-year spectral data helps to smooth out the short-term influences of non-target property influences, but there are many unanswered questions: How many years of spectral data are needed to develop a regional-scale salinity model? Do the number of years vary from crop to crop or from one geographic location to another? Are the regional-scale models developed by researchers temporally stable or are they only pertinent within the range of multi-year data from which they were developed? Do the models have a shelf life and what is that shelf life?

In addition, guidelines and protocols for regional-scale salinity assessment similar to those developed for $\mathrm{EC}_{\mathrm{a}}$-directed soil sampling are needed. There is a fundamental similarity between regional-scale salinity assessment with remote sensing and field-scale $\mathrm{EC}_{\mathrm{a}}$-directed soil sampling. Similar to the $\mathrm{EC}_{\mathrm{a}}$ measurement, VIs determined from multi- and hyper-spectral imagery are influenced by a variety of factors. These factors include salinity, water deficiency, nutrient deficiency, disease, and pests, which affect the plant reflectance and in turn affect the VI. For this reason the influence of non-target properties (e.g., water deficiency, nutrient deficiency, disease, and pests), which influence the plant reflectance and thereby influence the VI, must be minimized, while the conditions that influence the target property (e.g., salinity) must be optimized. This conceptual approach, which is the basis of $\mathrm{EC}_{\mathrm{a}}$-directed soil sampling, will minimize the influence of 
non-target properties on the VI. A primary consideration in the development of these protocols is the measurement of ground-truth for the target property (i.e., salinity) at the pixel scale to calibrate the VI; therefore, protocols must also be developed for measuring the target property at pixel scale, presumably with a proximal sensor or sensors. Once regional-scale salinity assessment protocols are developed, then other target property (e.g., disease, pests, soil texture) protocols should be developed.

The application of $\mathrm{EC}_{\mathrm{a}}$-directed soil sampling as a replacement for traditional plant salt tolerance methodology needs more extensive study. The preliminary work of Corwin et al. (2017) suggests that EC $_{\mathrm{a}}$-directed soil sampling has great potential for providing salt tolerance data that is specific and more relevant to an agricultural region. Another application that would benefit agriculture tremendously is the use of regional-scale salinity assessment to estimate lost crop revenues due to salinity within an agricultural region, an entire state, as well as at national and global levels. The recent work by Lobell et al. (2007, 2010), Scudiero et al. (2014a, 2015), Zhang et al. (2015), and Whitney et al. (2018) showed that accurate inventories of root-zone soil salinity can be obtained at regional scale. Prior to this research the inventories of soil salinity within the root zone were qualitative and any estimates of revenue lost due to yield decrements from salinity were educated guesses (e.g., Qadir et al., 2014; University of California-Davis, 2009). The paper by Welle and Mauter (2017), which used the San Joaquin Valley salinity map of Scudiero et al. (2015) to help determine the lost revenue due to salinity for California, is a good example of the use of current regional-scale salinity assessment technology to establish credible financial loss estimates. Knowing the financial loss due to salinity at regional, state, national, and global levels not only provides researchers with justification for addressing salinity-related research issues, but also makes the general public aware of the monetary impact of salinity and provides decision makers with the information needed to justify the allocation of future research funds for salinity.

Greater research is needed to establish more robust VIs of root-zone soil salinity. Currently, the CRSI has great potential as a VI to identify soil salinity in the root zone. Continued investigation of the application of the CRSI to various geographical locations is needed as well as the use of hyperspectral data to identify other VIs that may be of boarder geographical use. Performance evaluations between newly developed VIs and the previously developed VIs in Table 3 are needed to establish a single or group of VIs that can be used at state, national, and global levels. Continued basic research into the 
impact of salinity on plant reflectance from a mechanistic perspective is needed. What is biologically and biochemically taking place within plants to manifest itself in an altered reflectance? Is there a particular wavelength or VI from hyperspectral data that can distinguish different plant stressors from each other?

Data fusion from the combined use of multiple proximal and remote sensors is a research trend that will continue. This stems from the fact that proximal and remote sensors do not measure one property, but are influenced by multiple properties as shown in Table 6; consequently, multiple sensors help to separate out individual properties. A means of distinguishing between various stressors (i.e., salinity, pests, disease, nutrient deficiency, soil water content) influencing remote imagery is needed. Separating out individual stressors that influence vegetation indices is crucial to mapping salinity, water deficiency, nutrient deficiency, disease, and pests from remote imagery. Arguably, the greatest need from an agricultural perspective in arid and semi-arid regions is to differentiate osmotic and matric stresses spatially, which will provide site-specific irrigation management information for salinity control. The ability to distinguish between matric stress (i.e., soil water content) and osmotic stress is important to determine leaching requirements, i.e., the water in excess of consumptive water use that is needed to leach salts. The combined use of geospatial $\mathrm{EC}_{\mathrm{a}}$ and $\gamma$-ray data with multi- or hyper-spectral imagery to better delineate matric and osmotic stress patterns at field scale is a potential means of accomplishing this. The combined use of soil, landscape, and yield information obtained most easily from proximal and remote sensors to delineate SSMUs is a research trend that will undoubtedly also continue with the integration of more groundbased, aerial (i.e., sensors on drones or airplanes), and satellite sensors to measure the meteorological, topographic, anthropogenic, edaphic, and biological properties that influence crop yield.

Even though significant advances have been made in the past few years, regional-scale salinity assessment is still in its infancy. A comprehensive validation of current regional-scale salinity assessment models using separate data sets rather than cross validation is needed to support the credibility and reliability of the methodology. Additional fine-tuning of regional-scale salinity models through the inclusion of co-variates, higher resolution spatial data for the co-variates, and special considerations such as micro-irrigation systems is needed.

Even though the multi-scale use of proximal and remote sensors for mapping salinity has been shown to be robust for a variety of applications, 
there are still specific knowledge gaps to be filled. These specific knowledge gaps include: (1) combining geospatial $\mathrm{EC}_{\mathrm{a}}$ and $\gamma$-ray data with multi- or hyper-spectral imagery to better delineate matric and osmotic stress patterns at field scale; (2) comparing the quantile regression (Amakor et al., 2013) and ANOCOVA (Corwin and Lesch, 2014) approaches for landscape-scale $\mathrm{EC}_{\mathrm{a}}$ to soil property calibration, (3) enhancing the robustness and reliability of regional-scale salinity assessment modeling through (a) incorporation of co-variates (e.g., texture, temperature, rainfall), (b) development and evaluation of hybrid regional-scale salinity models such as combining the approaches of Zhang et al. (2015) with the multi-year imagery approach of Lobell et al. (2010), (c) validation of regional-scale salinity models with independent data sets, (d) establishing the temporal stability and site specificity of current regional-scale salinity models, and (e) developing more robust VIs with broader geographic relevance; (4) developing regional-scale salinity assessment guidelines and protocols; (5) refining field-scale $\mathrm{EC}_{\mathrm{a}}$ directed soil sampling protocols under conditions of drip and microsprinkler irrigation; (6) applying inverse modeling to obtain 2D soil salinity profiles and 3D salinity maps for micro-irrigation systems; (7) applying $\mathrm{EC}_{\mathrm{a}}-$ directed soil sampling to field-scale salt tolerance studies; and (8) applying salinity assessment from proximal and satellite sensors to accurately, and subsequently more compellingly, determine the economic impact of salinity on agriculture from field to farm to community to state to national to global levels as a means of focusing attention on the severity of the salinity issue.

\section{Acknowledgments}

The authors acknowledge the assistance of several colleagues, technicians, and field personnel whose hard work and technical capabilities resulted in development of the salinity assessment methodologies described in this chapter and applied in numerous previous scientific publications. Particular acknowledgement is given to the senior author's collaborators including Jim Rhoades for his development of mobile EMI equipment, Scott Lesch for his development of the ESAP software, and David Lobell for his work in regional-scale salinity assessment with satellite imagery. In addition, the senior author wishes to acknowledge the technical laboratory and field support provided by Kevin Yemoto, Wes Clary, Clay Wilkinson, Nahid Vishteh, Harry Forster, Jack Jobes, and Jim Wood.

\section{References}

Abbas, A., Khan, S., 2007. Using remote sensing techniques for appraisal of irrigated soil salinity. In: Oxley, L., Kulasiri, D. (Eds.), International Congress on Modelling and Simulation (MODSIM): Land, Water and Environmental Management Integrated Systems for Sustainability. Modeling and Simulation Society of Australia and New Zealand, Christchurch, New Zealand, pp. 2632-2638. 
Abbas, A., Khan, S., Hussain, N., Hanjra, M.A., Akbar, S., 2013. Characterizing soil salinity in irrigated agriculture using a remote sensing approach. Phys. Chem. Earth 55-57, 43-52. https://doi.org/10.1016/j.pce.2010.12.004.

Abdu, H., Robinson, D.A., Seyfried, M., Jones, S.B., 2008. Geophysical imaging of watershed subsurface patterns and predictions of soil texture and water holding capacity. Water Resour. Res. 44, W00D18. https://doi.org/10.1029/2008WR007043.

Aboelsoud, H.M., AbdelRahman, M.A.E., 2017. Rapid field technique for soil salinity appraisal in North Nile Delta using EM38 through some empirical relations. Int. J. Plant Soil Sci. 14 (5), 1-9. https://doi.org/10.9734/IJPSS/2017/30858.

Abood, S., Maclean, A., Falkowski, M., 2011. Soil salinity detection in the mesopotamian agricultural plain utilizing worldview-2 imagery. In: Digital Corporation 8-Band Research Challenge. Maxar Technologies Inc., Westminster, CO.

Abu-Hassanein, Z., Benson, C., Blotz, L., 1996. Electrical resistivity of compacted clays. J. Geotech. Eng. 122, 397-406.

Adam, I., Michot, D., Guero, Y., Soubega, B., Moussa, I., Dutin, G., Walter, C., 2012. Detecting soil salinity changes in irrigated vertisols by electrical resistivity prospection during a desalinisation experiment. Agric. Water Manag. 109, 1-10.

Adamchuk, V.I., Hummel, J.W., Morgan, M.T., Upadhyaya, S.K., 2004. On-the-go soil sensors for precision agriculture. Comput. Electron. Agric. 44, 71-91.

Adams, J.B., Smith, M.O., Johnson, P.E., 1986. Special mixture modelling: a new analysis of rock and soil types at the Viking Lander 1 site. J. Geophys. Res. 91, 8098-8112.

Afshar, F.A., Ayoubi, S., Besalatpour, A.A., Khademi, H., Castrignano, A., 2016. Integrating auxillary data and geophysical techniques for the estimation of soil clay content using CHAID algorithm. J.Appl. Geophys. 126, 87-97. https://doi.org/10.1016/j. jappgeo.2016.01.015.

Aimrun, W., Amin, M.S.M., Ahmad, D., Hanafi, M.M., Chan, C.S., 2007. Spatial variability of bulk soil electrical conductivity in a Malaysian paddy field: key to soil management. Paddy Water Environ. 5, 113-121.

Ain-Lhout, F., Boutaleb, S., Diaz-Barradas, M.C., Jauregui, J., Zunzunegui, M., 2016. Monitoring the evolution of soil moisture in root zone system of Argania spinosa using electrical resistivity imaging. Agric. Water Manag. 164, 158-166.

Akbar, M.A., Kenimer, A.L., Searcy, S.W., Torbert, H.A., 2005. Soil water estimation using electromagnetic induction. Trans. ASAE 48, 129-135.

Akramkhanov, A., Sommer, R., Martius, C., Hendrickx, J.M.H., Vlek, P.L.G., 2008. Comparison and sensitivity of measurement techniques for spatial distribution of soil salinity. Irrig. Drain. Syst. 22, 115-126.

Akramkhanov, A., Martius, C., Park, S.J., Hendrickx, J.M.H., 2011. Environmental factors of spatial distribution of soil salinity on flat irrigated terrain. Geoderma 163, 55-62.

Akramkhanov, A., Brus, D.J., Walvoort, D.J.J., 2014. Geostatistical monitoring of soil salinity in Uzbekistan by repeated EMI surveys. Geoderma 213, 600-607.

al Hagrey, S.A., 2007. Geophysical imagiing of root-zone, trunk, and moisture heterogeneity. J. Exp. Bot. 58 (4), 839-854.

Al Rashid, Q.A., Abuel-Naga, H.M., Leong, E.-C., Al Abadi, H., 2018. Experimentalarticial intelligence approach for characterizing electrical resistivity of partially saturated clay liners. Appl. Clay Sci. 156, 1-10.

Alamry, A.S., van der Meijde, M., Noomen, M., Addink, E.A., van Benthem, R., de Jong, S.M., 2017. Spatial and temporal monitoring of soil mpoisture using surface electrical resistivity tomography in Mediterraanean soils. Catena 157, 388-396.

Al-Asadi, R.A., Mouazen, A.M., 2014. Combining frequency domain reflectometry and visible and near infrared spectroscopy for assessment of soil bulk density. Soil Tillage Res. $135,60-70$. 
Aldabaa, A.A.A., Weindorf, D.C., Chakraborty, S., Sharma, A., Li, B., 2015. Combination of proximal and remote sensing methods for rapid soil salinity quantification. Geoderma 239, 34-46. https://doi.org/10.1016/j.geoderma.2014.09.011.

Aldakheel, Y.Y., 2011. Assessing NDVI spatial pattern as related to irrigation and soil salinity management in Al-Hassa Oasis, Saudi Arabia. J. Indian Soc. Remote Sens. 39 (2), 171-180.

Alexakis, D.D., Daliakopoulos, N., Panagea, I.S., Tsanis, I.K., 2018. Assessing soil salinity using WorldView-2 multispectral images in Timpaki, Crete, Greece. Geocarto Int. 33 (4), 321-338. https://doi.org/10.1080/10106049.2016.1250826.

Al-Khaier, F., 2003. Soil salinity detection using satellite remote sensing. MS thesis. Geoinformation Science and Earth Observation, Internation Institute for Geo-information Science and Earth Observation. $61 \mathrm{pp}$.

Allbed, A., Kumar, L., 2013. Soil salinity mapping and monitoring in arid and semi-arid regions using remote sensing technology: a review. Adv. Remote Sens. 2, 373-385.

Allbed, A., Kumar, L., Aldakheel, Y.Y., 2014a. Assessing soil salinity using soil salinity and vegetation indices derived from IKONOS high-spatial resolution imageries: applications in a date palm dominated region. Geoderma 230-231, 1-8. https://doi.org/10.1016/j. geoderma.2014.03.025.

Allbed, A., Kumar, L., Sinha, P., 2014b. Mapping and modelling spatial variation in soil salinity in the Al Hassa Oasis based on remote sensing indicators and regression techniques. Remote Sens. (Basel) 6, 1137-1157. https://doi.org/10.3390/rs6021137.

Allbed, A., Kumar, L., Sinha, P., 2018. Soil salinity and vegetation cover change detection from multi-temporal remotely sensed imagery in Al Hassa Oasis in Saudi Arabia. Geocarto Int. 33 (8), 830-846. https://doi.org/10.1080/10106049.2017.1303090.

Allred, B.J., Redman, J.D., McCoy, E.L., Taylor, R.S., 2005. Golf course applications of near-surface geophysical metthods: a case study. J. Environ. Eng. Geophys. 10, 1-19.

Altdorff, D., Bechtold, M., van der Kruk, J., Vereecken, H., Huisman, J.A., 2016. Mapping peat layer properties with multi-coil offset electromagnetic induction and laser scanning elevation data. Geoderma 261, 178-189. https://doi.org/10.1016/j.geoderma. 2015.07.015.

Altdorff, D., von Hebel, C., Borchard, N., van der Kruk, J., Bobena, H.R., Vereecken, H., Huisman, J.A., 2017. Potential of catchment-wide soil water content prediction using electromagnetic induction in a forest ecosystem. Environ. Earth Sci. 76, 111. https:// doi.org/10.1007/s12665-016-6361-3.

Altdorff, D., Galagedara, L., Nadeem, M., Cheema, M., 2018. Effecct of agronomic treatments on the accuracy of soil moisture mapping by electromagnetic induction. Catena 164, 96-106.

Aly, Z., Bonn, F., Magagi, R., 2004. Modeling the backscattering coefficient of salt affected soils: applications to Wadi el Nattrum Bottom. In: eProc. 3rd Workshop EARSeL, pp. 372-381.

Amakor, X.N., Cardon, G.E., Symanzik, J., Jacobson, A.R., 2013. A new electromagnetic induction calibration model for estimating low range salinity in calcareous soils. Soil Sci. Soc. Am. J. 77, 985-1000. https://doi.org/10.2136/sssaj2012.0320.

Amato, M., Bitella, G., Rossi, R., Gómez, J.A., Lovelli, S., Gomes, J.J.F., 2009. Multielectrode 3D resistivity imaging of alfalfa root zone. Eur. J. Agron. 31, 213-222.

Amezketa, E., 2006. An integrated methodology for assessing soil salinization, a precondition for land desertification. J. Arid Environ. 67, 594-606.

Amezketa, E., 2007a. Soil salinity assessment using directed soil sampling from a geophysical survey with electromagnetic technology: a case study. Spanish J. Agric. Res. 5 (1), 91-101.

Amezketa, E., 2007b. Use of an electromagnetic technique to determine sodicity in salinesodic soils. Soil Use Manage. 23, 278-285. 
Amezketa, E., del Valle de Lersundi, J., 2008. Soil classification and salinity mapping for determining restoration potential of cropped riparian areas. Land Degrad. Dev. 19, 153-164.

Ammons, J.T., Timpson, M.E., Newton, D.L., 1989. Application of aboveground electromagnetic conductivity meter to separate Natraqualfs and Ochraqualfs in Gibson County, Tennessee. Soil Surv. Horiz. 30, 66-70.

Anderson, K., Croft, H., 2009. Remote sensing of soil surface properties. Prog. Phys. Geogr. 33 (4), 457-473. https://doi.org/10.1177/0309133309346644.

Anderson-Cook, C.M., Alley, M.M., Roygard, J.K.F., Khosia, R., Noble, R.B., Doolittle, J.A., 2002. Differentiating soil types using electromagnetic conductivity and crop yield maps. Soil Sci. Soc. Am. J. 66, 1562-1570.

André, F., van Leeuwen, C., Saussez, S., Van Durmen, R., Bogaert, P., Moghadas, D., de Rességuier, L., Delvaux, B., Vereecken, H., Lambot, S., 2012. High-resolution imaging of a vineyard in south of France using ground-penetrating radar, electromagnetic induction and electrical resistivity tomography. J. Appl. Geophys. 78, 113-122. https://doi. org/10.1016/j.jappgeo.2011.08.002.

Aragüés, R., Guillén, M., Royo, A., 2010. Five-year growth and yield response of two young olive cultivars (Olea europaea L., cvs. Arbequina and Empeltre) to soil salinity. Plant Soil 334, 423-432.

Aragüés, R., Urdanoz, V., Cetin, M., Kirda, C., Daghari, H., Ltifi, W., Lahlou, M., Douaik, A., 2011. Soil salinity related to physical soil characteristics and irrigation management in four Mediterranean irrigation districts. Agric. Water Manag. 98, 959-966.

Archie, G.E., 1942. The electrical resistivity $\log$ as an aid in determining some reservoirs characteristics. Trans. Am. Inst. Min. Metall. Pet. Eng. 146 (1), 54-62.

Arriola-Morales, J., Batlle-Sales, J., Valera, M.A., Linares, G., Acevedo, O., 2009. Spatial variability analysis of soil salinity and alkalinity in an endorreic volcanic watershed. Int. J. Ecol. Dev. 14 (F09), 1-17.

Asfaw, E., Suryabhagavan, K.V., Argaw, M., 2018. Soil salinity modeling and mapping using remote sensing and GIS: the case of Wonji sugar cane irrigation farm, Ethiopia. J. Saudi Soc. Agric. Sci. 17, 250-258. https://doi.org/10.1016/j.jssas.2016.05.003.

Atwell, M., Wuddivira, M., Gobin, J., Robinson, D., 2013. Edaphic controls on sedge invasion in a tropical wetland assessed with electromagnetic induction. Soil Sci. Soc. Am. J. 77, 1865-1874.

Azabdaftari, A., Sunar, F., 2016. Soil salinity mapping using multitemporal Landsat data. International Archives of the Photogrammetry, Remote Sensing and Spatial Information Sciences, pp. 3-9, XLI-B7. https://doi.org/10.5194/isprs-archives-XLI-B7-3-2016.

Babiker, S., Abulgasim, E., Hamid, H.S., 2018. Enhancing the spatial variability of soil salinity indicators by remote sensing indices and geo-statistical approach. J. Earth Sci. Clim. Change 9 (4), 462-468. https://doi.org/10.4172/2157-7617.1000462.

Backoulou, G.F., Elliott, N.C., Giles, K.L., Mink, M., 2015. Processed multispectral imagery differentiaqtes wheat crop stress caused by greenbug from other causes. Comput. Electron. Agric. 115, 34-39.

Bajwa, S.G., Tian, L.F., 2005. Soil fertility characterization in agricultural fields using hyperspectral remote sensing. Trans. ASAE 48 (6), 2399-2406.

Bakker, D.M., Hamilton, G.J., Hetherington, R., Spann, C., 2010. Productivity of waterlogged and salt-affected land in a Mediterranean climate using bed-furrow systems. Field Crop Res. 117, 24-37.

Bannari, A., Guedona, A.M., El-Hartib, A., Cherkaouic, F.Z., El-Ghmari, A., 2008. Characterization of slightly and moderately saline and sodic soils in irrigated agricultural land using simulated data of advanced land imaging (EO-1) sensor. Commun. Soil Sci. Plant Anal. 39 (19-20), 2795-2811. https://doi.org/10.1080/00103620802432717. 
Bannari, A., El-Battay, A., Hameid, N., Tashtoush, F., 2017. Salt-affected soil mapping in an arid environment using semi-empirical model and Landsat-OLI data. Adv. Remote Sens. 6, 260-291. https://doi.org/10.4236/ars.2017.64019.

Bannari, A., El-Battay, A., Bannari, R., Rhinane, H., 2018. Sentinel-MSI VNIR and SWIR bands sensitivity analysis for soil salinity discrimination in an araid landscape. Remote Sens. (Basel) 10, 855. https://doi.org/10.3390/rs10060855.

Banton, O., Seguin, M.K., Cimon, M.A., 1997. Mapping field-scale physical properties of soil with electrical resistivity. Soil Sci. Soc. Am. J. 61 (4), 1010-1017.

Barbiéro, L., Cunnac, S., Mané, L., Laperrousaz, C., Hammecker, C., Maeght, J.L., 2001. Salt distributionin the Senegal middle valey analysis of a saline structure on planned irrigation schemes from N'Galenka creek. Agric. Water Manag. 46, 201-213.

Barbiéro, L., Rrezende Filho, A., Furquim, S.A.C., Furian, S., Sakamoto, A.Y., Valles, V., Graham, R.C., Fort, M., Ferreira, R.P.D., Queiroz Neto, J.P., 2008. Soil morphological control on saline and freshwater lake hydrogeochemistry in the Pantanal of Nhecolândia, Brazil. Geoderma 148, 91-106.

Barbouchi, M., Abdelfattah, R., Chokmani, K., Aissa, N.B., Lhissou, R., Eh Harti, A., 2014. Soil salinity characterization using polarimetric InSAR coherence: case studies in Tunisia and Morocco. IEEE J. Sel. Top. Appl. Obs. Remote Sens. 8 (18), 1-10.

Barca, E., Castrignanò, A., Buttafuoco, G., De Benedetto, D., Passarella, G., 2015. Integration of electromagnetic induction sensor data in soil sampling scheme optimization using simulated annealing. Environ. Monit. Assess. 187, 1-12.

Baret, F., Guyot, G., 1991. Potentials and limits of vegetation indices for LAI and APAR assessment. Remote Sens. Environ. 535, 161-173.

Barnes, E.M., Sudduth, K.A., Hummel, J.W., Lesch, S.M., Corwin, D.L., Yang, C., Daughtry, C.S.T., Bausch, W.C., 2003. Remote- and ground-based sensor techniques to map soil properties. J. Photogramm. Remote Sens. 69 (6), 619-630.

Barshad, I., 1948. Molybdenum content of pasture plants: I. Nature of soil molybdenum, growth of plants, and soil pH. Soil Sci. 71, 297-313.

Basso, B., Amato, M., Bitella, G., Rossi, R., Kravchenko, A., Sartori, L., Carvahlo, L.M., Gomes, J., 2010. Two dimensional spatial and temporal variation of soil physical properties in tillage systems using electrical resistivity tomography. Agon. J. 102, 440-449. https:// doi.org/10.2134/agronj2009.0298.

Beauvais, A., Ritz, M., Parisot, J.-C., Bantsimba, C., Dukhan, M., 2004. Combined ERT and GPR methods for investigating two-stepped latertic weathering systems. Geoderma 119, 121-132. https://doi.org/10.1016/j.geoderma.2003.06.001.

Beck, Y.L., Lopes, S.P., Ferber, V., Côte, P., 2011. Microestructural interpretation of water content and dry density influence on the DC-electrical resistivity of a fine-grained soil. Soil Geotech. Test. J. 34 (6), 1-14.

Bekele, A., Hudnall, W.H., Daigle, J.J., Prudente, J.A., Wolcott, M., 2005. Scale dependent variability of soil electrical conductivity by indirect measures of soil properties. J. Terrramech. 42, 339-351.

Bell, D., Menges, C., Ahmad, W., van Zyl, J.J., 2001a. The application of dielectric retrieval algorithms for mapping soil salinity in a tropical coastal environment using airborne polarimetric SAR. Remote Sens. Environ. 75 (3), 375-384.

Bell, D., Menges, C.H., Bartolo, R.E., Ahmad, W., van Zyl, J.J., 2001b. A multistaged approach to mapping soil salinity in a tropical coastal environment using airborne SAR and Landsat TM data. IGARSS '01. In: Proceedings of the International Geoscience and Remote Sensing Symposium. Sydney, Australia, July 9-13, 2001. IEEE, Piscataway, NJ, pp. 1309-1311. https://doi.org/10.1109/IGARSS.2001.976828.

Ben-Dor, E., 2002. Quantitative remote sensing of soil properties. Adv. Agron. 75, 173-243. 
Ben-Dor, E., Patkin, K., Banin, A., Karnieli, A., 2002. Mapping of several soil properties using DAIS-7915 hyperspectral scanner data-a case study over clayey soils in Israel. Int. J. Remote Sens. 23, 1043-1062. https://doi.org/10.1080/01431160010006962.

Ben-Dor, E., Taylor, R.G., Hill, J., Demattê, M., Whiting, M.L., Chabrillat, S., Sommer, S., 2008. Imaging spectrometry for soil appliications. Adv. Agron. 97, 321-392. https://doi. org/10.1016/S0065-2113(07)00008-9.

Ben-Dor, E., Chabrillat, S., Demattê, J.A.M., Taylor, G.R., Hill, J., Whiting, M.L., Sommer, S., 2009. Using imaging spectroscopy to study soil properties. Remote Sens. Environ. 113, S38-S55. https://doi.org/10.1016/j.rse.2008.09.019.

Bennett, D.L., George, R.J., 1995. Using the EM38 to measure the effect of soil salinity on Eucalyptus globulus in south-western Australia. Agric. Water Manag. 27, 69-86.

Bennett, D.L., George, R.J., Whitfield, B., 2000. The use of ground EM systems to accurately assess salt store and help define land management options, for salinity management. Explor. Geophys. 31, 249-254.

Benson, A.K., Payne, K.L., Stubben, M.A., 1997. Mapping groundwater contamination using DC resistivity and VLF geophysical methods-a case study. Geophysics 62 (1), 80-86.

Berkal, I., Walter, C., Michot, D., Djili, K., 2014. Seasonal monitoring of soil salinity by electromagnetic conductivity in irrigated sandy soils from a Saharan oasis. Soil Res. 52, 769-780. https://doi.org/10.1071/SR13305.

Besson, A., Cousin, I., Samouëlian, A., Boizard, H., Richard, G., 2004. Structural heterogeneity of the soil tilled layer as characterized by $2 \mathrm{D}$ electrical resisitivity surveying. Soil Tillage Res. 79, 239-249.

Better Solutions Consulting, 1997. Environment for Visualizing Images (ENVI). User guide, version 3.0, Lafayette, CO, 1993-1999, p. 614.

Biewinga, D.T., Pruissers, A.P., Seijmonsbergen, A.C., 1990. Het Mondingsgebied Van de Oude Rijn Geofysisch Ontsloten. $\mathrm{H}_{2} \mathrm{O}$ 11, 304-307.

Bilgili, A.V., Cullu, M.A., van Es, H., Aydemir, A., Aydemir, S., 2011. The use of hyperspectral visible and near infrared reflectance spectroscopy for the characterization of saltaffected soils in the Harran Plain, Turkey. Arid Land Res. Manag. 25, 19-37.

Blackburn, G.A., 1998. Quanttifying chlorophylls and carotenoids at leaf and canopy scales: an evaluation of some hyperspectral approaches. Remote Sens. Environ. $66,273-285$.

Boardman, J.W., 1993. Automating spectral unmixing of AVIRIS data using convex geometry concepts. In: Summaries of the Fourth Annual JPL Airborne Geosciences Workshop, Oct. 25-29, 1993. vol. 93-26. Jet Propulsion Laboratory, Pasadena, CA, pp. 11-14.

Bobert, J., Schmidt, F., Gebbers, R., Selige, T., Schmidhalter, U., 2001. Estimating soil moisture distribution forcrop management with capacitance probes, EM-38 and digital terrain analysis. In: Proceedings of the 3rd European Conference on Precision Agriculture, Montpellier, France, 16-20 June 2001, pp. 349-359.

Boettinger, J.L., Doolittle, J.A., West, N.E., Bork, E.W., Schupp, E.W., 1997. Nondestructive assessment of rangeland soil depth to petrocalcic horizon using electromagnetic induction. Arid Soil Res. Rehabil. 11 (4), 375-390.

Boivin, P., Hachicha, M., Job, J.O., Loyer, J.Y., 1989. Electromagnetic conductivity and kriging: a tool for cartography of soils salinity. Science du Sol 27, 69-72.

Borchers, B., Uram, T., Hendrickx, J.M.H., 1997. Tikhonov regularization of electrical conductivity depth profiles in field soils. Soil Sci. Soc. Am. J. 61, 1004-1009.

Bork, E.W., West, N.E., Doolittle, J.A., Boettinger, J.L., 1998. Soil depth assessment of sagebrush grazing treatments using electromagnetic induction. J. Range Manage. 51, 469-474. 
Bouaziz, M., Matschullat, J., Gloaguen, R., 2010. Remote sensing indicators to identify low and moderately salt-affected soils based on MODIS terra and geochemical data. In: Neale, C.M.U., Maltese, A. (Eds.), Remote Sensing for Agriculture, Ecosystems, and Hydrology XII. In: Proc. of SPIE, vol. 7824. The International Society of Optical Engineering, pp. 78241I-1-78241I-11. https://doi.org/10.1117/12.865201.

Bouaziz, M., Matschullat, J., Gloaguen, R., 2011. Improved remote sensing detection of saoil salinity from a semi-arid climate in Northeast Brazil. C. R. Geosci. 343, 795-803. https://doi.org/10.1016/j.crte.2011.09.003.

Bouksila, F., Persson, M., Bahri, A., Berndtsson, R., 2012. Electromagnetic induction prediction of soil salinity and groundwater properties in a Tunisian Saharan oasis. Hyrdrological Sci. J. 57 (7), 1473-1486.

Bourgault, G., Journel, A.G., Rhoades, J.D., Corwin, D.L., Lesch, S.M., 1997. Geostatistical analysis of a soil salinity data set. Adv. Agron. 58, 241-292.

Bowling, S.D., Schulte, D.D., Woldt, W.E., 1997. A geophysical and geostatistical methodology for evaluating potential subsurface contamination from feedlot runoff retention ponds. In: ASAE Paper No. 972087. 1997 ASAE Winter Meetings, Dec. 1997, Chicago, IL. ASAE, St. Joseph, MI.

Brasso, B., Amato, M., Bitella, G., Rossi, R., Kravchenko, A., Sartori, L., Carvahlo, L.M., Gomes, J., 2010. Two-dimensional spatial and temporal variation of soil physical properties in tillage systems using electrical resistivity tomography. Agron. J. 102 (2), 440-449.

Bréchet, L., Oatham, M., Wuddivira, M., Robinson, D.A., 2012. Determining spatial variation in soil properties in teak and native tropical forest plots using electromagnetic induction. Vadose Zone J. 11 (4), vzj2011.0102. https://doi.org/10.2136/vzj2011.0102.

Brevik, E.C., Fenton, T.E., 2002. The relative influence of soil water, clay, temperature, and carbonate minerals on soil electrical conductivity readings taken with an EM-38 along a Mollisol catena in central Iowa. Soil Surv. Horiz. 43, 9-13.

Brevik, E.C., Fenton, T.E., 2004. The effect of changes in bulk density on soil electrical conductivity as measured with the geonics EM-38. Soil Surv. Horiz. 45, 96-102.

Brevik, E.C., Fenton, T.E., Horton, R., 2004. Effect of daily soil temperature fluctuations on soil electrical conductivity as measured with the Geonics ${ }^{\circledR}$ EM-38. Precis. Agric. 5 (2), 145-152. https://doi.org/10.1023/B:PRAG.0000022359.79184.92.

Brevik, E.C., Fenton, T.E., Lazari, A., 2006. Soil electrical conductivity as a function of soil water content and implications for soil mapping. Precis. Agric. 7, 393-404.

Brevik, E.C., Fenton, T.E., Jaynes, D.B., 2012. The use of soil electrical conductivity to investigate soil heterogeneity in Story County, Iowa, USA. Soil Surv. Horiz. 53, 50-54.

Briggs, L.J., 1899. Electrical instruments for ddetermining the moisture, temperature, and soluble salt content of soils. In: USDA Division of Soils Bulletin 10. U.S. Gov. Print. Office, Washington, DC.

Broadfoot, K., Morris, M., Stevens, D., Heuperman, A., 2002. The role of EM38 in land and water management planning on the Tragowei Plains in Northern Victoria. Explor. Geophys. 33, 90-94.

Brogi, C., Huisman, J.A., Pätzold, S., von Hebel, C., Weihermüller, L., Kaufmann, M.S., van der Kruk, J., Vereecken, H., 2019. Large-scale soil mapping using multiconfiguration EMI and supervised image claissification. Geoderma 335, 133-148. https://doi.org/10.1016/j.geoderma.2018.08.001.

Bronson, K.F., Booker, J.D., Officer, S.J., Lascano, R.J., Maas, S.J., Searcy, S. W., Booker, J., 2005. Apparent electrical conductivity, soil properties and spatial covariance in the U.S. Southern High Plains. Precis. Agric. 6, 297-311.

Brosten, T.R., Day-Lewis, F.D., Schultz, G.M., Curtis, G.P., Lane Jr., J.W., 2011. Inversion of multi-frequency electromagnetic induction data for 3D characterization of hydraulic conductivity. J. Appl. Geophys. 73, 323-335. 
Brune, D.E., Doolittle, J., 1990. Locating lagoon seepage with radar and electromagnetic survey. Environ. Geol. Water Sci. 16, 195-207.

Brune, D.E., Drapcho, C.M., Radcliff, D.E., Harter, T., Zhang, R., 1999. Electromagnetic survey to rapidly assess water quality in agricultural watersheds. ASAE Paper No. 992176. ASAE, St. Joseph, MI.

Brunet, P., Clément, R., Bouvier, C., 2010. Monitoring soil water content and deficit using electrical resistivity tomography (ERT) - a case study in the Cevennes area, France. J. Hydrol. 380, 146-153.

Brunner, P., Li, H.T., Kinzelbach, W., Li, W.P., 2007. Generating soil electrical conductivity maps at regional level by integrating measurements on the ground and remote sensing data. Int. J. Remote Sens. 28 (15), 3341-3361. https://doi.org/10.1080/01431160600928641.

Brus, D., 2015. Balanced sampling: a versatile sampling approach for statistical soil surveys. Geoderma 253, 111-121.

Brus, D.J., Heuvelink, G.B., 2007. Optimization of sample patterns for universal kriging of environmental variables. Geoderma 138, 86-95.

Brus, D.J., Knotters, M., van Dooremolen, W.A., van Kernebeek, P., van Seeters, R.J.M., 1992. The use of electromagnetic measurements of apparent soil electrical conductivity to predict the boulder clay depth. Geoderma 55, 79-93.

Buchanan, S., Triantafilis, J., 2009. Mapping water table depth using geophysical and environmental variables. Ground Water 47 (1), 80-96.

Burger, H.R., 1992. Exploration Geophysics of the Shallow Subsurface. Prentice Hall, PTR, Upper Saddle River, NJ.

Buvat, S., Thiesson, J., Micheln, J., Nicoullaud, B., Bourennane, H., Coquet, Y., Tabbagh, A., 2014a. Multi-depth electrical resistivity survey for mapping soil units within two 3 ha plots. Geoderma 232-234, 317-327.

Buvat, S., Coquet, Y., Thiesson, J., Tabbagh, A., Micheln, J., Nicoullaud, B., 2014b. Electrical multi-depth survey to assess soil cover spatial organization. In: Arrouays, D., McKenzie, N., Hempel, J., de Forges, A.R., McBratney, A.B. (Eds.), Global Soil Map. Taylor \& Francis Group, London, UK, pp. 465-470.

Caccetta, P., Dunne, R., George, R., McFarlane, D., 2010. A methodology to estimate the future extent of dryland salinity in the southwest of Western Australia. J. Environ. Qual. 39, 26-34. https://doi.org/10.2134/jeq2009.0037.

Cai, C., Lin, J., Meng, F., Sun, Y., Li, D., 2010. Estimation of topsoil thickness in reclaimed field using EM38. Trans. Chin. Soc. Agric. Eng. 26, 319-323.

Cameron, D.R., de Jong, E., Read, D.W.L., Oosterveld, M., 1981. Mapping salinity using resistivity and electromagnetic inductive techniques. Can. J. Soil Sci. 61, 67-78,

Cannon, M.E., McKenzie, R.C., Lachapelle, G., 1994. Soil-salinity mapping with electromagnetic induction and satellite-based navigation methods. Can. J. Soil Sci. 74 (3), 335-343.

Carroll, Z.L., Oliver, M.A., 2005. Exploring the spatial relations between soil physical properties and apparent electrical conductivity. Geoderma 128, 354-374.

Carter, L.M., Rhoades, J.D., Chesson, J.H., 1993. Mechanization of soil salinity assessment for mapping. In: ASAE Paper No. 931557, 1993 ASAE Winter Meetings, 12-17 Dec 1993, Chicago, IL. ASAE, St. Joseph, MI.

Casa, R., Castaldi, F., Pascucci, S., Basso, B., Pignatti, S., 2013. Geophysical and hyperspectral data fusion techniques for in-field estimation of soil properties. Vadose Zone J. 12https://doi.org/10.2136/vzj2012.0201.

Cassel, F., Goorahoo, D., Sharmasarkar, S., 2015. Salinization and yield potential of a saltladen Californian soil: an in situ geophysical analysis. Water Air Soil Pollut. 226, 422. https://doi.org/10.1007/s11270-015-2682-1.

Casterad, M.A., Herrero, J., Betrán, J.A., Ritchie, G., 2018. Sensor-based assessment of soil salinity during the first years of transition from flood to sprinkler irrigation. Sensors 18, 616. https://doi.org/10.3390/s18020616. 
Castrignanò, A., Wong, M.T.F., Stelluti, M., De Benedetto, D., Sollitto, D., 2012. Use of EMI, gamma-ray emission and GPS height as multi-sensor data for soil characterization. Geoderma 175-176, 78-89. https://doi.org/10.1016/j.geoderma.2012.01.013.

Celano, G., Palese, A.M., Ciucci, A., Martorella, E., Vignozzi, N., Xiloyannis, C., 2011. Evaluation of soil water content in tilled and cover-cropped olive orchards by the geoelectrical technique. Geoderma 163, 163-170.

Cetin, M., Ibrikci, H., Kirda, C., Kaman, H., Karnez, E., Ryan, J., Topcu, S., Oztekin, E., Mahmut, D., Sesveren, S., 2012. Using an electromagnetic sensor combined with geographic information systems to monitor soil salinity in an area of southern Turkey irrigated with drainage water. Fresen. Environ. Bull. 21, 1133-1145.

Ceuppens, J., Wopereis, M.C.S., 1999. Impact of non-drained irrigated rice cropping on soil salinization in the Senegal River Delta. Geoderma 92 (1-2), 125-140.

Ceuppens, J., Wopereis, M.C.S., Miézan, K.M., 1997. Soil salinization processes in rice irrigation schemes in the Senegal River Delta. Soil Sci. Soc. Am. J. 61, 1122-1130.

Chaali, N., Coppola, A., Comegna, A., Dragonetti, G., 2015. Assessment of soil electromagnetic parameters and their variation with soil water, salts: a comparison among EMI and TDR measuring methods. In: Proceedings of the EGU General Assembly Conference Abstracts, Vienna, Austria, 12-17 April 2015.

Chaplot, V., Lorentz, S., Podwojewski, P., Jewitt, G., 2010. Digital mapping of A-horizon thickness using the correlation between various soil properties and soil apparent electrical conductivity. Geoderma 157, 154-164.

Chaudhry, M.R.B.A., 4 Feb. 2000. Electromagnetic induction device (EM38) calibration and monitoring soil salinity/environment (Pakistan). In: Vlotman, W.F. (Ed.), EM38 Workshop Proceedings, New Delhi, India. ILRI, The Netherlands, pp. 37-48.

Cho, Y., Sudduth, K.A., Chung, S.O., 2016. Soil physical property estimation from soil strength and apparent electrical conductivity sensor data. Biosyst. Eng. 152, 68-78.

Chrétien, M., Lataste, J.F., Fabre, R., Denis, A., 2014. Electrical resistivity tomography to understand clay behavior during seasonal water content variations. Eng. Geol. $169,112-123$.

Chuangye, S., Hongxu, R., Chong, H., 2016. Estimating soil salinity in the Yellow River Delta, Eastern China - an integrated approach using spectral and terrain indices with the generalized additive model. Pedosphere 26 (5), 626-635.

Ciampalini, A., André, F., Garfagnoli, F., Grandjean, G., Lambot, S., Chiarantini, L., Moretti, S., 2015. Improved estimation of soil clay content by the fusion of remote hyperspectral and proximal geophysical sensing. J. Appl. Geophys. 116, 135-145. https://doi.org/10.1016/j.jappgeo.2015.03.009.

Clark, R.N., Roush, L., 1984. Reflectance spectroscopy quantitative analysis techniques for remote sensing applications. J. Geophys. Res. 89, 6329-6340. https://doi.org/10.1029/ JB089iB07p06329.

Clark, R.N., Gallagher, A.J., Swayze, G.A., 1990. Material absorption band depth mapping of imaging spectrometer data using the complete band shape leastr squares algorithm simultaneously fit to multiple spectral features from multiple materials. In: Proceedings of the Third Airborne Visible/Infrared Imaging Spectrometer (AVIRIS) Workshop, 90-54, June 4-5, 1990. Jet Propulsion Laboratory, Pasadena, CA, pp. 176-186.

Clay, D.E., Chang, J., Malo, D.D., Carlson, C.G., Reese, C., Clay, S.A., Ellsbury, M., Berg, B., 2001. Factors influencing spatial variability of soil apparent electrical conductivity. Commun. Soil Sci. Plant Anal. 32, 2993-3008. https://doi.org/10.1081/CSS120001102.

Clevers, J.G.P.W., 1988. The derivation of a simplified reflectance model for the estimation of leaf area index. Remote Sens. Environ. 25 (1), 53-70.

Clevers, J.G.P.W., 1989. The application of a weighted infrared vegetation index for estimating leaf area index by correcting soil moisture. Remote Sens. Environ. 29, 23-37. 
Clifford, D., Payne, J.E., Pringle, M., Searle, R., Butler, N., 2014. Pragmatic soil survey design using flexible latin hypercube sampling. Comput. Geosci. 67, 62-68.

Cockx, L., Van Meirvenne, M., Hofman, G., 2005. Characterization of nitrogen dynamics in a pasture soil by electromagnetic induction. Biol. Fertil. Soils 42, 24-30.

Cockx, L., Van Meirvenne, M., De Vos, B., 2007. Using the EM38DD soil sensor to delineate clay lenses in a sandy forest soil. Soil Sci. Soc. Am. J. 71 (4), 1314-1322. https://doi. org/10.2136/sssaj2006.0323.

Cockx, L., Van Meirvenne, M., Vitharana, U.W.A., Verbeke, L.P.C., Simpson, D., Saey, T., Van Coillie, F.M.B., 2009. Extracting topsoil information from EM38DD sensor data using a neural network approach. Soil Sci. Soc. Am. J. 73, 2051-2058.

Cohen, Y., Alchanatis, V., Saranga, Y., Rosenberg, O., Sela, E., Bosak, A., 2017. Mapping water status based on aerial thermal imagery: comparison of methodologies for upscaling from a single leaf to commercial fields. Prec. Agric. 18 (5), 801-822.

Cook, P.G., Kilty, S., 1992. A helicopter-borne electromagnetic survey to delineate groundwater recharge rates. Water Resour. Res. 28 (11), 2953-2961.

Cook, P.G., Walker, G.R., 1992. Depth profiles of electrical conductivity from linear combinations of electromagnetic induction measurements. Soil Sci. Soc. Am. J. 56 (4), 1015-1022.

Cook, P.G., Williams, B.G., 1998. Electromagnetic induction techniques. In: Zhang, L., Walker, G. (Eds.), Studies in Catchment Hydrology. The Basics of Recharge and Discharge. CSIRO Publishing, Melbourne, Australia. Part 8.

Cook, P.G., Hughes, M.W., Walker, G.R., Allison, G.B., 1989. The calibration of frequency-domain electromagnetic induction meters and their possible use in recharge studies. J. Hydrol. 107, 251-265.

Cook, P.G., Walker, G.R., Buselli, G., Potts, I., Dodds, A.R., 1992. The application of electromagnetic techniques to groundwater recharge investigations. J. Hydrol. 130, 201-229.

Cordeiro, M.R., Ranjan, R.S., Cicek, N., 2011a. Assessment of potential nutrient build-up around beef cattle production areas using electromagnetic induction. Environ. Technol. 33 (15-16), 1825-1833.

Cordeiro, M.R., Ranjan, R.S., Ferguson, I.J., 2011b. Calibration models for electromagnetic induction methods to assess nutrient accumulation beneath confined livestock areas. Environ. Technol. 32 (1-2), 103-117. https://doi.org/10.1080/09593330. 2010.487921.

Corwin, D.L., 2003. Soil salinity measurement. In: Stewart, B.A., Howell, T.A. (Eds.), Encyclopedia of Water Science. Marcel Dekker, New York, pp. 852-860.

Corwin, D.L., 2005a. Delineating site-specific crop management units: precision agriculture application in GIS. In: Proceedings of the 2005 ESRI International Users Conference, San Diego, CA, USA, 25-29 July 2005.

Corwin, D.L., 2005b. Geospatial measurements of apparent soil electrical conductivity for characterizing soil spatial variability. In: Alvarez-Benedi, J., Munoz-Carpena, R. (Eds.), Soil-Water-Solute Process Characterization: An Integrated Approach. CRC Press, Boca Raton, FL, pp. 639-672.

Corwin, D.L., 2008. Past, present, and future trends of soil electrical conductivity measurement using geophysical methods. In: Allred, B.J., Daniels, J.J., Ehsani, M.R. (Eds.), Handbook of Agricultural Geophysics. CRC Press, Boca Raton, FL, pp. 17-44.

Corwin, D.L., 2012. Field-scale monitoring of the long-term impact and sustainability of drainage water reuse on the west side of California's San Joaquin Valley. J. Environ. Monit. 14 (6), 1576-1596.

Corwin, D.L., Ahmad, H.R., 2015. Spatio-temporal impacts of dairy lagoon water reuse on soil: heavy metals and salinity. Environ. Sci.: Processes Impacts 17, 1731-1748. https:// doi.org/10.1039/C5EM00196J. 
Corwin, D.L., Bradford, S.A., 2008. Environmental impacts and sustainability of degraded water reuse. J. Environ. Qual. 37 (5), S1-S7. https://doi.org/10.2134/jeq2008.0210.

Corwin, D.L., Hendrickx, J.M.H., 2002. Solute content and concentration-Indirect measurement of solute concentration-electrical resistivity: Wenner array. In: Dane, J.H., Topp, G.C. (Eds.), Methods of Soil Analysis. In: Part 4-Physical Methods. Soil Sci. Soc. Am. Book Series 5, Soil Science Society of America, Madison, WI, pp. 1282-1287.

Corwin, D.L., Lesch, S.M., 2003. Application of soil electrical conductivity to precision agriculture: theory, principles, and guidelines. Agron. J. 95, 455-471.

Corwin, D.L., Lesch, S.M., 2005a. Apparent soil electrical conductivity measurements in agriculture. Comput. Electron Agric. 46 (1-3), 11-43.

Corwin, D.L., Lesch, S.M., 2005b. Characterizing soil spatial variability with apparent soil electrical conductivity: I. Survey protocols. Comput. Electron Agric. 46 (1-3), 103-133.

Corwin, D.L., Lesch, S.M., 2005c. Characterizing soil spatial variability with apparent soil electrical conductivity: II. Case study. Comput. Electron Agric. 46 (1-3), 135-152.

Corwin, D.L., Lesch, S.M., 2010. Delineating site-specific management units with proximal sensors. In: Oliver, M. (Ed.), Geostatistical Applications in Precision Agriculture. Springer, New York, NY, pp. 139-166. https://doi.org/10.1007/978-90-481-9133-8_6.

Corwin, D.L., Lesch, S.M., 2013. Protocols and guidelines for field-scale measurement of soil salinity distribution with $\mathrm{EC}_{\mathrm{a}}$-directed soil sampling. J. Environ. Eng. Geophys. 18 (1), 1-25.

Corwin, D.L., Lesch, S.M., 2014. A simplified regional-scale electromagnetic inductionsalinity calibration model using ANOCOVA modeling techniques. Geoderma 230-231, 288-295. https://doi.org/10.1016/j.geoderma.2014.03.019.

Corwin, D.L., Lesch, S.M., 2017. Validation of the ANOCOVA model for regional-scale $\mathrm{EC}_{\mathrm{a}}-\mathrm{EC}_{\mathrm{e}}$ calibration. Soil Use Manage. 33 (2), 178-190. https://doi.org/10.1111/ sum.12262.

Corwin, D.L., Plant, R.E., 2005. Applications of apparent soil electrical conductivity in precision agriculture. Comput. Electron Agric. 46 (1-3), 1-10.

Corwin, D.L., Rhoades, J.D., 1982. An improved technique for determining soil electrical conductivity - depth relations from above-ground electromagnetic measurements. Soil Sci. Soc. Am. J. 46 (3), 517-520.

Corwin, D.L., Rhoades, J.D., 1984. Measurement of inverted electrical conductivity profiles using electromagnetic induction. Soil Sci. Soc. Am. J. 48 (2), 288-291.

Corwin, D.L., Rhoades, J.D., 1990. Establishing soil electrical conductivity-depth relations from electromagnetic induction measurements. Commun. Soil Sci. Plant Anal. 21 (11 and 12), 861-901.

Corwin, D.L., Scudiero, E., 2016. Field-scale apparent soil electrical conductivity. In: Logsdon, S. (Ed.), Methods of Soil Analysis Online. In: vol. 1. Soil Science Society of America, Madison, WI. https://doi.org/10.2136/methods-soil.2015.0038.

Corwin, D.L., Scudiero, E., 2017. Asseessing climate change impacts on soil salinity development with proximal and satellite sensors. EEGS FastTIMES 22 (4), 36-41.

Corwin, D.L., Sorensen, M., Rhoades, J.D., 1989. Field testing of models which identify soils susceptible to salinity development. Geoderma 45, 31-64.

Corwin, D.L., Waggoner, B.L., Rhoades, J.D., 1991. A functional model of solute transport that accounts for bypass. J. Environ. Qual. 20, 647-658.

Corwin, D.L., Carrillo, M.L.K., Vaughan, P.J., Rhoades, J.D., Cone, D.G., 1999. Evaluation of GIS-linked model of salt loading to groundwater. J. Environ. Qual. 28, 471-480.

Corwin, D.L., Kaffka, S.R., Hopmans, J.W., Mori, Y., Lesch, S.M., Oster, J.D., 2003a. Assessment and field-scale mapping of soil quality properties of a saline-sodic soil. Geoderma 114 (3-4), 231-259. 
Corwin, D.L., Lesch, S.M., Shouse, P.J., Soppe, R., Ayars, J.E., 2003b. Identifying soil properties that influence cotton yield using soil sampling directed by apparent soil electrical conductivity. Agron. J. 95 (2), 352-364.

Corwin, D.L., Hopmans, J., de Rooij, G.H., 2006a. From field- to landscape-scale vadose zone processes: scale issues, modeling, and monitoring. Vadose Zone J. 5, 129-139.

Corwin, D.L., Lesch, S.M., Oster, J.D., Kaffka, S.R., 2006b. Monitoring managementinduced spatio-temporal changes in soil quality with soil sampling directed by apparent soil electrical conductivity. Geoderma 131, 369-387.

Corwin, D.L., Lesch, S.M., Farahani, H.J., 2008a. Theoretical insight on the measurement of soil electrical conductivity. In: Allred, B.J., Daniels, J.J., Ehsani, M.R. (Eds.), Handbook of Agriculotural Geophysics. CRC Press, Boca Raton, FL, pp. 59-83.

Corwin, D.L., Lesch, S.M., Oster, J.D., Kaffka, S.R., 2008b. Short-term sustainability of drainage water reuse: spatio-temporal impacts on soil chemical properties. J. Environ. Qual. 37, S-8-S-24.

Corwin, D.L., Lesch, S.M., Segal, E., Skaggs, T.H., Bradford, S.A., 2010. Comparison of sampling strategies for characterizing spatial variability with apparent soil electrical conductivity directed soil sampling. J. Environ. Eng. Geophys. 15 (3), 147-162. https://doi. org/10.2113/JEEG15.3.147.

Corwin, D.L., Yemoto, K., Clary, W., Banuelos, G., Skaggs, T.H., Lesch, S.M., Scudiero, E., 2017. Evaluating oilseed biofuel production feasibility in California's San Joaquin Valley using geophysical and remote sensing techniques. Sensors 17, 2343-2367. https://doi.org/10.3390/s17102343.

Costa, M.M., de Queiroz, D.M., Pinto, F.A.C., dos Reis, E.F., Santos, N.T., 2014. Moisture content effect in the relationship between apparent electrical conductivity and soil attributes. Acta Sci. Agron. 36 (4), 395-401. https://doi.org/10.4025/actasciagron. v36i4.18342.

Cresswell, R.G., Dent, D.L., Jones, G.L., Galloway, D.S., 2004. Three-dimensional mapping of salt stores in the southeast Murray-Darling Basin, Australia. 1. Steps in calibration of airborne electromagnetic surveys. Soil Use Manage. 20, 133-143.

Crowley, J.K., 1991. Visible and near-infrared $(0.4-2.5 \mu \mathrm{m})$ reflectance spectra of playa evaporite minerals. J. Geochem. Res. 96 (B10), 16231-16240.

Csillag, F., Pásztor, L., Biehl, L., 1993. Spectral band selectionfor the characterization of salinity status of soils. Remote Sens. Environ. 43, 231-242.

Dabas, M., 2009. Theory and practice of the new fast electrical imaging system ARP. In: Campana, S., Piro, S. (Eds.), Seeing the Unseen, Geophysics and Landscape Archaeology. CRC Press, London, pp. 105-126.

Dadfar, H., Heck, R.J., Parkin, G.W., Barfoot-Kinsie, K., 2011. Evaluation of a Geonics EM31-3RT probe to delineate hydrologic regimes in a tile-drained field. Precis. Agric. $12,623-638$.

Dakak, H., Huang, J., Zouahri, A., Douaik, A., Triantafilis, J., 2017. Mapping soil salinity in 3-dimensions using an EM38 and EM4Soil inversion modelling at the reconnaissance scale in central Morocco. Soil Use Manage. 33, 553-567.

Dalgaard, M., Have, H., Nehmdahl, H., 2001. Soil clay mapping by measurement of electromagnetic conductivity. In: Proceedings of the 3rd European Conference on Precision Agriculture, Montpellier, France, 18-20 June 2001, pp. 367-372.

Dalton, F.N., Herkelrath, W.N., Rawlins, D.S., Rhoades, J.D., 1984. Time-domain reflectometry: simultaneous measurement of soil water content and electrical conductivity with a single probe. Science 224, 989-990.

Dampney, P., King, J., Lark, R., Wheeler, H., Bradley, R., Mayr, T., 2003. Automated methods for mapping patterns of soil physical properties as a basis for variable management. In: Stafford, J., Werner, A. (Eds.), Precision Agriculture. Wageningen Academic Publishers, The Netherlands, pp. 135-140. 
Dang, Y.P., Dalal, R.C., Pringle, M.J., Biggs, A.J.W., Darr, S., Sauer, B., Moss, J., Payne, J., Orange, D., 2011. Electromagnetic induction sensing of soil identifies constraints to the crop yields of north-eastern Australia. Soil Res. 49, 559-571.

Davies, G., Huang, J., Monteiro Santos, F.A., Triantafilis, J., 2015. Modeling coastal salinity in quasi 2D and 3D using a DUALEM-421 and inversion software. Groundwater 53 (3), 424-431.

De Benedetto, D., Castrignanò, A., Sollitto, D., Modugno, F., 2010. Spatial relationship between clay content and geophysical data. Clay Miner. 45, 197-207.

De Benedetto, D., Castrignanò, A., Sollitto, D., Modugno, F., Buttafuoco, G., lo Papa, G., 2012. Integrating geophysical and geostatistical techniques to map the spatial variation of clay. Geoderma 171-172, 53-63.

De Benedetto, D., Castrignano, A., Rinaldi, M., Santoro, F., Figorito, B., Gualano, S., Diacono, M., Tamborrino, R., 2013. An approach for delineating homogeneous zones by using multi-sensor data. Geoderma 199, 117-127. https://doi.org/10.1016/ geoderma.2012.08.028.

de Jong, E., Ballantyne, A.K., Caneron, D.R., Read, D.W., 1979. Measurement of apparent electrical conductivity of soils by an electromagnetic induction probe to aid salinity surveys. Soil Sci. Soc. Am. J. 43, 810-812.

De Lima, O.A.L., Sharma, M.M., 1990. A grain conductivity approach to shaly sandstones. Geophysics 55 (10), 1347-1356.

de Lima, E.S., Lovera, L.H., Montanari, R., de Souza, Z.M., Torres, J.L.R., 2017. Spatial variability of apparent electrical conductivity and physicochemical attributes of the soil. Cultura Agronômica 26 (3), 469-482.

Debba, P., Van Ruitenbeek, F., Van Der Meer, F., Carranza, E., Stein, A., 2005. Optimal field sampling for targeting minerals using hyperspectral data. Remote Sens. Environ. 99, 373-386.

Dehaan, R.L., Taylor, G.R., 2002. Field-derived spectra of salinized soils and vegetation as indicators of irrigation-induced soil salinization. Remote Sens. Environ. 80, 406-417.

Dehaan, R.L., Taylor, G.R., 2003. Image-derived spectral endmembers as indicators of salinization. Int. J. Remote Sens. 24, 775-794.

Dehni, A., Lounis, M., 2012. Remote sensing techniques of salt affected soil mapping: application to the Oran Region of Algeria. Procedia Eng. 33, 188-198. https://doi.org/ 10.1016/j.proeng.2012.01.1193.

Delin, S., Söderström, M., 2002. Performance of soil electrical conductivity and different methods for mapping soil data from a small dataset. Acta Agric. Scand. Sect. B Soil Plant Sci. 52, 127-135. https://doi.org/10.1080/090647103100004816.

Dent, D., 2007. Environmental geophysics mapping salinity and water resources. Int. J. Appl. Earth Obs. Geoinf. 9, 130-136.

Diaz, L., Herrero, J., 1992. Salinity estimates in irrigated soils using electromagnetic induction. Soil Sci. 154, 151-157.

Ding, J., Yu, D., 2014. Monitoring and evaluating spatial variability of soil salinity in dry and wet seasons in the Werigan-Kuqa Oasis, China, using remote sensing and electromagnetic induction instruments. Geoderma 235-236, 316-322. https://doi.org/10.1016/j. geoderma.2014.07.028.

Dixit, P.N., Chen, D., 2010. Modification of a spatially referenced crop model to simulate the effect of spatial pattern of subsoil salinity. Comput. Electron. Agric. 74, 313-320.

Dixon, P., 1989. Dryland salinity in a subcatchment at Glenthompson, Victoria. Aust. Geogr. 20 (2), 144-152.

Dobrin, M.B., 1960. Introduction to Geophysical Prospecting. McGraw-Hill Book Company, New York, NY.

Domsch, H., Giebel, A., 2004. Estimation of soil textural features from soil electrical conductivity recorded using the EM38. Precis. Agric. 5, 389-409. 
Doolittle, J.A., Brevik, E.C., 2014. The use of electromagnetic induction techniques in soils studies. Geoderma 223-224, 33-45. https://doi.org/10.1016/j.geroderma.2014.01.027.

Doolittle, J.A., Collins, M.E., 1998. A comparison of EM induction and GPR methods in areas of karst. Geoderma 85, 83-102.

Doolittle, J.A., Sudduth, K.A., Kitchen, N.R., Indorante, S.J., 1994. Estimating depths to claypans using electromagnetic induction methods. J. Soil Water Conserv. 49 (6), 572-575.

Doolittle, J.A., Noble, C., Leinard, B., 2000. An electromagnetic induction survey of a riparian area in southwest Montana. Soil Surv. Horiz. 41, 27-36.

Doolittle, J.A., Petersen, M., Wheeler, T., 2001. Comparison of two electromagnetic induction tools in salinity appraisals. J. Soil Water Conserv. 56, 257-262.

Doolittle, J.A., Indorante, S.J., Potter, D.K., Hefner, S.G., McCauley, W.M., 2002a. Comparing three geophysical tools for locating sand blows in alluvial soils of southeast Missouri. J. Soil Water Conserv. 57, 175-182.

Doolittle, J., Stuebe, A., Price, A., Kelly, E., 2002b. Mappiing bedrock depths with electromagnetic induction in Costille County, Colorado. Soil Surv. Horiz. 43, 14-21.

Douaik, A., Van Meirvenne, M., Tóth, T., 2005. Soil salinity mapping using spatio-temporal kriging and Bayesian maximum entropy with interval soft data. Geoderma 128, 2248-2324.

Douaoui, A.E.K., Nicolas, H., Walter, C., 2006. Detecting salinity hazards within a semiarid context by means of combining soil and remote-sensing data. Geoderma 134, 217-230. https://doi.org/10.1016/j.geoderma.2005.10.009.

Dragonetti, G., Comegna, A., Ajeel, A., Deidda, G.P., Lamaddalena, N., Rodriguez, G., Vignoli, G., Coppola, A., 2018. Calibrating electromagnetic induction conductivities with time-domain reflectometry measurements. Hydrol. Earth Syst. Sci. 22, 1509-1523. https://doi.org/10.5194/hess-22-1509-2018.

Drommerhausen, D.J., Radcliffe, D.E., Brune, D.E., Gunter, H.D., 1995. Electromagnetic conductivity surveys of dairies for groundwater nitrate. J. Environ. Qual. 24, 1083-1091.

Dunn, B.W., Beecher, H.G., 2007. Using electro-magnetic induction technology to identify sampling sites for soil acidity assessment and to determine spatial variability of soil acidity in rice fields. Aust. J. Exp. Agric. 47, 208-214.

Dunn, G., Taylor, D., Nester, M., Beetson, T., 1994. Performance of twelve selected Australian tree species on a saline site in southeast Queensland. For. Ecol. Manage. 70, 255-264.

Dwivedi, R.S., Rao, B.R.M., 1992. The selection of the best possible Landsat TM band combination for delineating salt-affected soils. Int. J. Remote Sens. 13 (11), 2051-2058. https://doi.org/10.1080/01431169208904252.

Dwivedi, R.S., Sreenivas, K., 1998. Delineation of salt-affected soils and waterlogged areas in the Indo-Gangetic plains using IRS-1C LISS-III data. Int. J. Remote Sens. 19 (14), 2739-2751. https://doi.org/10.1080/014311698214488.

Edwards, M.D., Webb, J.A., 2003. Ground-truthing of a TEMPEST airborne electromagnetic survey in the salinized Kamarooka Catchment, near Bendigo in Central Victoria. In: Roac, I.C. (Ed.), Advances in Regolith. CRC LEME, Canberra, Australia, pp. 110-114.

Eigenberg, R.A., Nienaber, J.A., 1998. Electromagnetic survey of cornfield with repeated manure applications. J. Environ. Qual. 27, 1511-1515.

Eigenberg, R.A., Nienaber, J.A., 1999. Soil conductivity map differences for monitoring temporal changes in an agronomic field. ASAE Paper No. 992176. ASAE, St. Joseph, MI.

Eigenberg, R.A., Nienaber, J.A., 2001. Identification of nutrient distribution at abandoned livestock manure handling site using electromagnetic induction. In: ASAE Paper No. 012193, 2001 ASAE Annual International Meeting, 30 July-1 Aug 2001, Sacramento, CA. ASAE, St. Joseph, MI.

Eigenberg, R.A., Nienaber, J.A., 2003. Electromagnetic induction methods applied to an abandoned manure handling site to determine nutrient buildup. J. Environ. Qual. 32, 1837-1843. 
Eigenberg, R.A., Korthals, R.L., Neinaber, J.A., 1998. Geophysical electromagnetic survey methods applied to agricultural waste sites. J. Environ. Qual. 27, 215-219.

Eigenberg, R.A., Doran, J.W., Nienaber, J.A., Ferguson, R.B., Woodbury, B.L., 2002. Electrical conductivity monitoring of soil condition and available $\mathrm{N}$ with animal manure and a cover crop. Agric. Ecosyst. Environ. 88, 183-193.

Eigenberg, R.A., Nienaber, J.A., Woodbury, B.L., Ferguson, R.B., 2006. Soil conductivity as a measure of soil and crop status - a four-year summary. Soil Sci. Soc. Am. J. 70, 1600-1611.

Ekercin, S., Ormeci, C., 2008. Estimating soil salinity using satellite remote sensing data and real-time field sampling. Environ. Eng. Sci. 25 (7), 981-988. https://doi.org/10.1089/ ees.2007.0061.

Ekwue, E.I., Bartholomew, J., 2011. Electrical conductivity of some soils in Trinidad as affected by density, water and peat content. Biosyst. Eng. 108, 95-103.

El Harti, A., Lhissou, R., Chokmani, K., Ouzemou, J., Hassouna, M., Bachaoui, E., El Ghmari, A., 2016. Spatiotemporal monitoring of soil salinization in irrigated Tadla Plain (Morocco) using satellite spectral indices. Int. J. Appl. Earth Obs. Geoinf. 50, 64-73. https://doi.org/10.1016/j.jag.2016.03.008.

Eldeiry, A.A., Garcia, L.A., 2008. Detecting soil salinity in alfalfa fields using spatial modeling and remote sensing. Soil Sci. Soc. Am. J. 72 (1), 201-211. https://doi.org/10.2136/ sssaj2007.0013.

Eldeiry, A.A., Garcia, L.A., 2010. Comparison of ordinary kriging, regression kriging, and cokriging techniques to estimate soil salinity using Landsat images. J. Irrig. Drain. Eng. 136 (6), 355-364. https://doi.org/10.1061/(ASCE)IR.1943-4774.0000208.

Elhag, M., 2016. Evaluaation of different soil salinity mapping using remote sensing techniques in arid ecosystems, Saudi Arabia. J. Sensors 2016 7596175https://doi.org/ 10.1155/2016/7596175.

Elhag, M., Bahrawi, J.A., 2017. Soil salinity mapping and hydrological drought indices assessment in arid environments based on remote sensing techniques. Geosci. Instrum. Method. Data Syst. 6, 149-158. https://doi.org/10.5194/gi-6-149-2017.

Elnaggar, A.A., Noller, J.S., 2010. Application of remote-sensing data and decision-tree analysis to mapping salt-affected soils over large areas. Remote Sens. (Basel) 2, 151-165. https://doi.org/10.3390/rs2010151.

EMTOMO, 2014. EMTOMO Manual for EM4Soil: A Program for 1-D Laterally Constrained Inversion of EM Data. EMTOMO, Lisbon, Portugal.

Ennaji, W., Barakaat, A., Karaoui, I., El Baghdadi, M., Arioua, A., 2018. Remote sensing approach to assess salt-affected soils in the north-east part of Tadla plain, Morocco. Geol. Ecol. Landscapes 2 (1), 22-28. https://doi.org/10.1080/24749508.2018.1438744.

Erindi-kati, A., 2005. Remote sensing and root zone soil moisture. MS thesis, Department of Bioresource Engineering, McGill University, Montreal, QC.

Ezrin, M.H., Aimrun, W., Amin, M.S.M., Bejo, S.K., 2016. Development of real time soil nutrient mapping system in paddy field. Jurnal Teknologi 78 (1-2), 125-131.

Fan, X., Liu, Y., Tao, J., Weng, Y., 2015. Soil salinity retrieval from advanced multi-spectral sensor with partial least square regression. Remote Sens. (Basel) 7, 488-511. https://doi. org $/ 10.3390 / \mathrm{rs} 70100488$.

FAO-AQUASTAT, 2013. FAO's Infofrmation System on Water and Agriculture. Food and Agriculture Organization of the United Nations (FAO). Available at http://www.fao. $\mathrm{org} / \mathrm{nr} /$ water/aquastat/didyouknow/index3.stm. Accessed 22 January 2018.

Farifteh, J., Farshad, A., George, R.J., 2006. Assessing salt-affected soils using remote sensing, solute modelling, and geophysics. Geoderma 130, 191-206. https://doi.org/10.1016/j. geoderma.2005.02.003. 
Farifteh, J., van der Meer, F., Atzberger, C., Carranza, E.J.M., 2007a. Quantitative analysis of salt-affected soil reflectance spectra: a comparison of two adaptive methods (PLSR and ANN). Remote Sens. Environ. 110, 59-78. https://doi.org/10.1016/j.rse.2007.02.005.

Farifteh, J., van der Meer, F., Carranza, E.J.M., 2007b. Similarity measures for spectral discrimination of salt-affected soils. Int. J. Remote Sens. 28 (23), 5273-5293. https://doi. org/10.1080/01431160701227604.

Farifteh, J., van der Meer, van der Meijde, M., Atzberger, C., 2008. Spectral characteristics of salt-affected soils: a laboratory experiment. Geoderma 145 (3-4), 196-206. https://doi. org/10.1016/j.geoderma.2008.03.011.

Feikema, P.M., Baker, T.G., 2011. Effect of soil salinity on growth of irrigated planation eucalyptus in southeastern Australia. Agric. Water Manag. 98, 1180-1188.

Fenton, T.E., Lauterbach, M.A., 1999. Soil map unit composition and scale of mapping related to interpretations for precision soil and crop management in Iowa. In: Robert, P.C., Rust, R.H., Larson, W.E. (Eds.), Proceedings of the 4th International Conference on Precision Agriculture, St. Paul, MN, 19-22 July 1998. ASA-CSSA-SSSA, Madison, WI, pp. 239-251.

Fernández-Buces, N., Sieber, C., Cram, S., Palacio, J.L., 2006. Mapping ssoil salinity using combined spectral response index for bare soil and vegetation: a case study in the former lake Texcoco, Mexico. J. Arid Environ. 65, 644-667. https://doi.org/10.1016/j. jaridenv.2005.08.005.

Filho, A.M.S., Silva, C.L.B., Oliveira, M.A.A., Pires, T.G., Alves, A.J., Calixto, W.P., Narciso, M.G., 2017. Geoelectric method applied in correlation between physical characteristics and electrical properties. Trans. Environ. Electrical Eng. 2 (2), 36. https://doi. org/10.22149/teee.v2i2.85.

Fitterman, D.V., Stewart, M.T., 1986. Transient electromagnetic sounding for groundwater. Geophysics 51, 995-1005.

Fitzgerald, G.J., Maas, S.J., Detar, W.R., 2004. Spidermite detection in cotton using hyperspectral imagery and spectral mixture analysis. Prec. Agric. 5, 275-289.

Fitzgerald, G.J., Lesch, S.M., Barnes, E.M., Luckett, W.E., 2006. Directed sampling using remote sensing with a response surface sampling design for site-specific agriculture. Comput. Electron. Agric. 53, 98-112.

Fitzpatrick, R.W., Thomas, M., Davies, P.J., Williams, B.G., 2003. Dry saline land: an investigation using ground-based geophysics, soil survey and spatial methods near Jamestown, South Australia. Technical Report 55/03, CSIRO Land and Water, Glen Osmond, Australia.

Flowers, T.J., 1999. Salinization and horticultural production. Sci. Hortic. 78, 1-4.

Fortes, R., Millán, S., Prieto, M.H., Campillo, C., 2015. A methodology based on apparent electrical conductivity and guided soil samples to improve irrigation zoning. Precis. Agric. 16, 441-454. https://doi.org/10.1007/s11119-015-9388-7.

Freeland, R.S., Branson, J.L., Ammons, J.T., Leonard, L.L., 2001. Surveying perched water on anthropogenic soils using non-intrusive imagery. Trans. ASAE 44, 1955-1963.

Freeland, R.S., Yoder, R.E., Ammons, J.T., Leonard, L.L., 2002. Mobilized surveying of soil conductivity using electromagnetic induction. Appl. Eng. Agric. 18 (1), 121-126.

Friedman, S.P., 2005. Soil properties influencing apparent electrical conductivity: a review. Comput. Electron. Agric. 46 (1-3), 45-70.

Fritz, R., Malo, D., Schumacher, T., Clay, D., Carlson, C., Ellsbury, M., Dalsted, K., 1999. Field comparison of two soil electrical conductivity measurement systems. In: Robert, P.C., Rust, R.H., Larson, W.E. (Eds.), Proceedings of the Fourth International Conference on Precision Agriculture, St. Paul, MN, 19-22 July 1998, pp. 1211-1217. 
Fulton, A., Schwanki, L., Lynn, K., Lampinen, B., Edstrom, J., Prichard, T., 2011. Using EM and Veris technology to assess land suitability for orchard and vineyard development. Irrig. Sci. 29, 497-512.

Furby, S., Caccetta, P., Wallace, J., 2010. Salinity monitoring in Western Austrralia using remotely sensed and other spatial data. J. Environ. Qual. 39, 16-25.

Gamon, J.A., Serraano, L., Surfus, J.S., 1997. The photochemical reflectance index: an optical indicator of photosynthetic radiation use efficiency across species, functional types, and nutrient levels. Oecologia 112, 492-501.

Ganjegunte, G.K., Braun, R.J., 2011. Delineating salinity and sodicity distribution in major soil map units of El Paso, Texas, using electromagnetic induction technique. Soil Sci. 176 (8), 441-447.

Ganjegunte, G.K., Leinauer, B., Schiavon, M., Serena, M., 2013. Using electro-magnetic induction to determine soil salinity and sodicity in turf root zones. Agron. J. 105, 836-844.

Ganjegunte, G.K., Sheng, Z., Clark, J.A., 2014. Soil salinity and sodicity appraisal by electromagnetic induction in soils irrigated to grow cotton. Land Degrad. Dev. 25, 228-235. https://doi.org/10.1002/ldr.1162.

Ganjegunte, G.K., Clark, J.A., Sallenave, R., Sevostianova, E., Serena, M., Alvarez, G., Leinauer, B., 2017. Soil salinity of an urban park after long-term irrigation with saline ground water. Agron. J. 109, 3011-3018. https://doi.org/10.2134/agronj2017.06.0369.

García-Tomillo, A., Mirás-Avalos, J.M., Dafonte-Dafonte, J., Paz-Gonzalez, A., 2017. Mapping soil texture using geostatistical interpolation combined with electromagnetic induction measurements. Soil Sci. 182, 278-284. https://doi.org/10.1097/ SS.0000000000000213.

Ge, Y., Thomasson, J.A., Sui, R., 2011. Remote sensing of soil properties in precision agriculture: a review. Front. Earth Sci. 5, 229-238. https://doi.org/10.1007/s11707-011-0175-0.

Gebbers, R., Lück, E., Heil, K., 2007. Depth sounding with the EM38-detection of soil layering by inversion of apparent electrical conductivity measurements. In: Precision Agricuture '07 (Ed., J.V. Stafford), 6th European Conferencer on Precision Agrriculture, Skiathos, Greece, 3-6 June 2007. Wageningen Academic Publishers, Wageningen, the Netherlands, pp. 95-102.

Gebbers, R., Lück, E., Dabas, M., Domsch, H., 2009. Comparison of instruments for geoelectrical soil mapping at the field scale. Near Surf. Geophys. 7 (3), 179-190.

Ghassemi, F., Jakeman, A.J., Nix, H.A., 1995. Salinisation of Land and Water Resources. University of New South Wales Press, Canberra, Australia.

Gholizadeh, A., Amin, M.S.M., Anuar, A.R., Aimrun, W., 2011. Apparent electrical conductivity in correspondence to soil chemical properties and plant nutrients in soil. Commun. Soil Sci. Plant Anal. 42, 1447-1461.

Gholizadeh, A., Soom, M.A.M., Anuar, A.R., Aimrun, W., 2012. Relationship between apparent electrical conductivity and soil physical properties in a Malaysian paddy field. Arch. Agron. Soil Sci. 58 (2), 155-168.

Gill, H.S., Yee, M., 2004. Em-38 for assessing surface and sub-soil salinity and its relationship to establishment and growth of selected perennial pasture species. In: Proceedings of the SuperSoil 2004-3rd Australian New Zealand Soils Conference, Sydney, Australia, 5-9 Dec. 2004.

Gillespie, A.R., Smith, M.O., Adams, J.B., Willis, S.C., Fischer, A.F., Sabol, D.E., 1990. Interpretation of residual images: spectral mixing analysis of AVIRIS images, Owens Valley, California. In: Proc. 2nd AVIRIS Workshop. 90-54, JPL Publication, Jet Propulsion Laboratory, Pasadena, CA, pp. 243-270.

Giordano, N., Arato, A., Comina, C., Mandrone, G., 2017. Time-lapse electrical resisitivity imaging of the thermally affected zone of a borehole thermal energy storage system near 
Torino (Northern Italy). J. Appl. Geophys. 140, 123-134. https://doi.org/10.1016/j. jappgeo.2017.03.015.

Gitelson, A., Merzlyak, M.N., 1994. Spectral reflectance changes associated with autumn senescence of Aesculus hippocastanum L. and Acer platanoides L. leaves: spectral features and relation to chlorophyll estimation. J. Plant Physiol. 148, 494-500.

Goel, P.K., Prasher, S.O., Landry, J.A., Patel, R.M., Viau, A.A., Millerr, J.R., 2003. Estimation of crop biophysical parameters through airborne and field hyperspectral remote sensing. Trans. ASAE 46 (4), 1235-1246.

Goes, B.J.M., Oude Essink, G.H.P., Vernes, R.W., Seregi, F., 2009. Estimating the depth of fresh and brackish groundwater in a predominantly saline region using geophysical and hydrological methods, Zeeland, the Netherlands. Near Surf. Geophys. 7, 401-412.

Goetz, A.F., 1992. Imaginig spectrometry for Earth remote sensing. In: Toselli, F., Bodechtel, J. (Eds.), Imaging Spectrometry. Basic Principles and Prospective Applications. ECSC, EEC, EAEC, Brussels and Luxemburg, pp. 1-19.

Goetz, A.F.H., Vane, G., Solomon, J.E., Rock, B.N., 1985. Imaging spectroscopy for Earth remote sensing. Science 228 (4704), 1147-1153. https://doi.org/10.1126/ science.228.4704.1147.

Goldshleger, N., Livne, I., Chudnovsky, A., Ben-Dor, E., 2012. New results in integrating passive and active remote sensing methods to assess soil salinity: a case study from Jezre'el Valley, Israel. Soil Sci. 177 (6), 392-401. https://doi.org/10.1097/SS0b013e31824f167e.

Goldshleger, N., Chudnovsaky, A., Ben-Binyamin, R., 2013. Predicting salinity in tomato using soil reflectance spectra. Int. J. Remote Sens. 34 (17), 6079-6093. https://doi.org/ 10.1080/01431161.2013.793859.

Gooley, L., Huang, J., Page, D., Triantafilis, J., 2014. Digital soil mapping available water content using proximal and remotely sensed data. Soil Use Manage. 30, 139-151.

Goossens, R., Van Ranst, E., 1998. The use of remote sensing to map gypsiferous soils in the Ismailia Province (Egypt). Geoderma 87, 47-56.

Gorji, T., Sertel, E., Tanik, A., 2017. Monitoring soil salinity via remote sensing technology under data scarce conditions: a case study from Turkey. Ecol. Indic. 74, 384-391. https:// doi.org/10.1016/j.ecolind.2016.11.043.

Gorucu, S., Khalilian, A., Han, Y.J., Dodd, R.B., Wolak, F.J., Keskin, M., 2001. Variable depth tillage based on geo-referenced soil compaction data in coastal plain region of South Carolina. In: ASAE Paper No. 011016. 2001, ASAE Annual International Meeting, 30 July-1 Aug. 2001, Sacramento, CA. ASAE, St. Joseph, MI.

Greenhouse, J.P., Slaine, D.D., 1983. The use of reconnaissance electromagnetic methods to map contaminant migration. Ground Water Monit. Rev. 3 (2), 47-59.

Greenhouse, J.P., Slaine, D.D., 1986. Geophysical modelling and mapping of contaminated groundwater around three waste disposal sites in southern Ontario. Can. Geotech. J. $23,372-384$.

Grellier, S., Florsch, N., Camerlynck, C., Janeau, J.L., Podwojewski, P., Lorentz, S., 2013. The use of Slingram EM38 data for topsoil and subsoil geoelectrical characterization with a Bayesian inversion. Geoderma 200-201, 140-155.

Greve, A.K., Acworth, R.I., Kelly, B.F.J., 2010. Detection of subsurface soil cracks by vertical anisotropy profiles of apparent electrical resistivity. Geophysics 75 (4), WA85-WA93.

Greve, A.K., Acworth, R.I., Kelly, B.F.J., 2011. 3D cross-hole resistivity tomography to monitor water percolation during irrigation on cracking soil. Soil Res. 49, 661-669.

Grieve, C.M., Grattan, S.R., Maas, E.V., 2012. Plant salt tolerance. In: Wallender, W.W., Tanji, K.K. (Eds.), Agricultural Salinity Assessment and Management, second ed. ASCE, Reston, VA, pp. 405-459. 
Grigera, M.S., Drijber, R.A., Eskridge, K.M., Wienhold, B.J., 2006. Soil microbial biomass relationships with organic matter fractions in a Nebraska corn field mapped using apparent electrical conductivity. Soil Sci. Soc. Am. J. 70, 1480-1488.

Grissa, M., Abdelfattah, R., Mercier, G., Zribi, M., Chahbi, A., Lili-Chabaane, Z., 2011. Empirical model for soil salinity mapping from SAR data. In: Proceeding of IEEE International Geoscience and Remote Sensing Symposium. Vancouver, BC, Canada, July 24-29, 2011. IEEE, Piscataway, NJ, pp. 1099-1102. https://doi.org/10.1109/ IGARSS.2011.6049388.

Grubbs, R.A., Straw, C.M., Bowling, W.J., Radcliffe, D.E., Taylor, Z., Henry, G.M., 2019. Predicitng spatial structure of soil physical and chemical properties of golf course fairways using an apparent electrical conductivity sensor. Prec. Agric. 20, 496-519. https://doi. org/10.1007/s11119-018-9593-2.

Grunwald, S., Vasques, G.M., Rivero, R.G., 2015. Fusion of soil and remote sensing data to model soil properties. In: Sparks, D.L. (Ed.), Advances in Agronomy. In: vol. 131. Academic Press, San Diego, CA, pp. 1-109. https://doi.org/10.1016/bs.agron.2014.12.004.

Guo, Y., Shi, Z., Zhou, L.Q., Jin, X., Tian, Y.F., Teng, H.F., 2013a. Integrating remote sensing and proximal sensors for the detection of soil moisture and salinity variability in coastal areas. J. Integr. Agric. 12, 723-731.

Guo, Y., Shi, Z., Li, H.Y., Triantafilis, J., 2013b. Application of digital soil mapping metthods for identifying salinity management classes based on a study on coastal central China. Soil Use Manage. 29, 445-456.

Guo, Y., Shi, Z., Huang, J., Zhou, L., Zhou, Y., Wang, L., 2016. Characterization of field scale soil variability using remotely and proximally sensed data and response surface method. Stoch. Env. Res. Risk A 30 (3), 859-869. https://doi.org/10.1007/s00477-015-1135-0.

Gupta, S.C., Hanks, R.J., 1972. Influence of water content on electrical conductivity of the soil. Soil Sci. Soc. Am. Proc. 36, 855-857.

Hadzick, Z.Z., Guber, A.K., Pachepsky, Y., Hill, R.L., 2011. Pedotransfer functions in soil electrical resistivity estimation. Geoderma 164, 195-202.

Haghverdi, A., Leib, B.G., Washington-Allen, R.A., Ayers, P.D., 2015. High-resolution prediction of soil available water content with the crop root zone. J. Hydrol. 530, 167-179.

Hall, L.M., Brainard, J.R., Bowman, R.S., Hendrickx, J.M.H., 2004. Determination of solute distributions in the vadose zone using downhole electromagnetic induction. Vadose Zone J. 3, 1207-1214. https://doi.org/10.2136/vzj2004.1207.

Halvorson, A.D., Rhoades, J.D., 1976. Field mapping soil conductivity to delineate dryland seeps with four-electrode techniques. Soil Sci. Soc. Am. J. 44, 571-575.

Hamzeh, S., Naseri, A.A., AlaviPanah, S.K., Mojaradi, B., Bartholomeus, H.M., 2013. Estimating salinity stress in sugarcane fields with spaceborne hyperspectral vegetation indices. Int. J. Appl. Earth Obs. Geoinf. 21, 282-290. https://doi.org/10.1016/ j.jag.2012.07.002.

Hanson, B.R., Kaita, K., 1997. Response of electromagnetic conductivity meter to soil salinity and soil-water content. J. Irrig. Drain. Eng. 123, 141-143.

Harvey, O.R., Morgan, C.L.S., 2009. Predicting regional-scale soil variability using a single calibrated apparent soil electrical conductivity model. Soil Sci. Soc. Am. J. 73 (1), 164-169. https://doi.org/10.2136/sssaj2008.0074.

Hbirkou, C., Welp, G., Rehbein, K., Hillnhütter, C., Daub, M., Oliver, M.A., Pätzold, S., 2011. The effect of soil heterogeneity on the spatial distribution of Heterodera schachtii within sugar beet fields. Appl. Soil Ecol. 51, 25-34.

Hedley, C.B., Yule, I., 2009. Soil water status mapping and two variable rate irrigation scenarios. Precis. Agric. 10, 342-355.

Hedley, C.B., Yule, I.Y., Eastwood, C.R., Shepherd, T.G., Arnold, G., 2004. Rapid identification of soil textural and management zones using elevctromagnetic induction sensing of soils. Aust. J. Soil. Res. 42, 389-400. https://doi.org/10.1071/sr03149. 
Hedley, C.B., Roudier, P., Yule, I.J., Ekanayake, J., Bradbury, S., 2013. Soil water status and water table depth modelling using electromagnetic surveys for precision irrigation scheduling. Geoderma 199, 22-29.

Heil, K., Schmidhalter, U., 2012. Characterization of soil texture variability using apparent soil electrical conductivity at a highly variable site. Comput. Geosci. 39, 98-110.

Heil, K., Schmidhalter, U., 2015. Comparison of the EM38 and EM38-MK2 electromagnetic induction-based sensors for spataial soil analysis at field scale. Comput. Electron. Agric. 110, 267-280.

Heil, K., Schmidhalter, U., 2017. The application of EM38: determination of soil parameters, selection of soil sampling points and use in agriculture and archaeology. Sensors 17, 2540. https://doi.org/10.3390/s17112540.

Heilig, J., Kempenich, J., Doolittle, J., Brevik, E.C., Ulmer, M., 2011. Evaluation of electromagnetic induction to characterize and map sodium-affected soils in the Northern Great Plains. Soil Surv. Horiz. 52 (3), 77-88.

Heimovaara, T.J., Focke, A.G., Bouten, W., Verstraten, J.M., 1995. Assessing temporal variations in soil water composition with time domain reflectometry. Soil Sci. Soc. Am. J. 59, 689-698.

Heiniger, R.W., McBride, R.G., Clay, D.E., 2003. Using soil electrical conductivity to improve nutrient management. Agron. J. 95, 508-519.

Hendrickx, J.M.H., Kachanoski, R.G., 2002. Solute content and concentration-indirect measurement of solute concentration-nonintrusive electromagnetic induction. In: Dane, J.H., Topp, G.C. (Eds.), Methods of Soil Analysis. In: Part 4-Physical Methods. Soil Science Society of America Book Series 5, Soil Science Society of America, Madison, WI, pp. 1297-1306.

Hendrickx, J.M.H., Baerends, B., Raza, Z.I., Sadig, M., Chaudhry, M.A., 1992. Soil salinity assessment by electromagnetic induction of irrigated land. Soil Sci. Soc. Am. J. 56, 1933-1941.

Hendrickx, J.M.H., Borchers, B., Corwin, D.L., Lesch, S.M., Hilgendorf, A.C., Schlue, J., 2002a. Inversion of soil conductivity profiles from electromagnetic induction measurements: theory and experimental verification. Soil Sci. Soc. Am. J. 66, 673-685.

Hendrickx, J.M.H., Das, B., Corwin, D.L., Wraith, J.M., Kachanoski, R.G., 2002b. Indirect measurement of solute concentration. In: Dane, J.H., Topp, G.C. (Eds.), Methods of Soil Analysis, Part 4. Physical Methods. In: Soil Science Society of America Book Series 5, Soil Science Society of America, Madison, WI, pp. 1274-1306.

Hengl, T., Rossiter, D.G., Stein, A., 2003. Soil sampling strategies for spatial prediction by correlation with auxiliary maps. Aust. J. Soil. Res. 41, 1403-1422.

Herrero, J., Hudnall, W.H., 2014. Measurement of soil salinity using electromagnetic induction in a paddy with a densic pan and shallow water table. Paddy Water Environ. 12, 263-274.

Herrero, J., Ba, A.A., Aragues, R., 2003. Soil salinity and its distribution determined by soil sampling and electromagnetic techniques. Soil Use Manage. 19 (2), 119-126.

Herrero, J., Nethisinghe, A., Hudnall, W.H., Pérez-Coveta, O., 2011. Electromagnetic induction as a basis for soil salinity monitoring within a Mediterranean irrigation district. J. Hydrol. 405, 427-438.

Hezarjaribi, A., Sourell, H., 2007. Feasibility study of monitoring the total available water content using non-invasive electromagnetic induction-based and electrode-based soil electrical conductivity measurements. Irrig. Drain. 56, 53-65.

Hillel, D., 2000. Salinity Management for Sustainabile Irrigation. The World Bank, Washington, DC.

Hirschfield, T., 1985. Salinity determination using NIRA. Appl. Spectrosc. 39, 740-741.

Hopkins, D.G., Richardson, J.L., 1999. Detecting a salinity plume in an unconfined sandy aquifer and assessing secondary soil salinization using electromagnetic induction techniques, North Dakota, USA. Hydrgeol. J. 7, 380-392. 
Horler, D.N.H., Dockray, M., Barber, J., 1983. The red edge of plant leaf reflectance. Int. J. Remote Sens. 4, 273-288.

Horney, R.D., Taylor, B., Munk, D.S., Roberts, B.A., Lesch, S.M., Plant, R.E., 2005. Development of practical site-specific management methods for reclaiming salt-affected soil. Comput. Electron. Agric. 46 (1-3), 379-397.

Houssain, M.B., Lamb, D.W., Lockwood, P.V., Frazier, P., 2010. EM38 for volumetric soil water content estimation in the root-zone of deep vertisol soils. Comput. Electron. Agric. 74, 100-109.

Howari, F.M., 2003. The use of remote sensing data to extract information from agricultural land with emphasis on soil salinity. Aust. J. Soil. Res. 41, 1243-1253. https://doi.org/ 10.1071/SR03033.

Howari, F.M., Goodell, P.C., Miyamoto, S., 2002. Spectral properties of salt crustsw formed on saline soils. J. Environ. Qual. 31, 1453-1461.

Huang, S., Liu, Q., Li, X., 2005a. Spectral analysis of soil salinity using the Grey System Theory. In: IGARSS '05, Proceedings of the International Geoscience and Remote Sensing Symposium. Seoul, Korea, July 24-29, 2005. IEEE, Piscataway, NJ, pp. 4455-4457. https://doi.org/10.1109/IGARSS.2005.1525909.

Huang, S., Liu, Q., Li, X., 2005b. Spectral model of soil salinity in Xinjiang of China. In: IGARSS '05, Proceedings of the International Geoscience and Remote Sensing Symposium. Seoul, Korea, July 24-29, 2005. IEEE, Piscataway, NJ, pp. 4458-4460. https://doi.org/10.1109/IGARSS.2005.1525910.

Huang, J., Davies, G.B., Bowd, D., Monteiro Santos, F.A., Triantafilis, J., 2014a. Spatial prediction of the exchangeable sodium percentage at multiple depths using electromagnetic inversion modelling. Soil Use Manage. 30 (2), 241-250.

Huang, J., Nhan, T., Wong, V.N.L., Johnston, S.G., Lark, R.M., Triantafilis, J., 2014b. Digital soil mapping of a coastal acid sulfate soil landscape. Soil Res. 52, 327-339.

Huang, J., Wong, V.N.L., Triantafilis, J., 2014c. Mapping soil salinity and pH across an estuarine and alluvial plain using electromagnetic and digital elevation model data. Soil Use Manage. 30, 394-402.

Huang, J., Lark, R.M., Robinson, D.A., Lebron, I., Keith, A.M., Rawlins, B., Tye, A., Kura, O., Raines, M., Triantafilis, J., 2014d. Scope to predict soil properties at within-fieeld scale from small samples using proximally sensed g-ray spectrometer and EM induction data. Geoderma 232-234, 69-80.

Huang, J., Barrett-Lennard, E.G., Kilminster, T., Sinnott, A., Triantafilis, J., 2015a. An error budget for mapping field-scale soil salinity at various depths using different sources of ancillary data. Soil Sci. Soc. Am. J. 79, 1717-1728.

Huang, J., Mokhtari, A., Cohen, D., Monteiro Santos, F., Triantafilis, J., 2015b. Modelling soil salinity across a gilgai landscape by inversion of EM38 and EM31 data. Eur. J. Soil Sci. 66, 951-960.

Huang, J., Subasinghe, R., Malik, R., Triantafilis, J., 2015c. Salinity hazard and risk mapping of point source salinization using proximally sensed electromagnetic instruments. Comput. Electron. Agric. 113, 213-224.

Huang, J., Scudiero, E., Clary, W., Corwin, D.L., Triantafilis, J., 2015d. Time-lapse monitoring of soil water content using electromagnetic conductivity imaging. Soil Use Manage. 33 (2), 191-204. https://doi.org/10.1111/sum.12261.

Huang, J., Taghizadeh-Mehrjardi, R., Minasny, B., Triantafilis, J., 2015e. Modeling soil salinity along a hillslope in Iran by inversion of EM38 data. Soil Sci. Soc. Am. J. 79, 1142-1153. https://doi.org/10.2136/sssaj2014.11.0447.

Huang, J., Zare, E., Malik, R.S., Triantafilis, J., 2015f. An error budget for soil salinity mapping using different ancillary data. Soil Res. 53, 561-575. https://doi.org/10.1071/ SR15043. 
Huang, J., Monteiro Santos, F.A., Triantafilis, J., 2016. Mapping soil water dynamics and a moving wetting front by spatiotemporal inversion of electromagnetic induction data. Water Resour. Res. 52, 9131-9145. https://doi.org/10.1002/2016WR019330.

Huang, J., Kilminster, T., Barrett-Lennard, E.G., Triantafilis, J., 2017a. Characterization of field-scale dryland salinity with depth by quasi-3d inversion of DUALEM-1 data. Soil Use Manage. 33, 205-215.

Huang, J., Koganti, T., Monteiro Santos, F.A., Triantafilis, J., 2017b. Mapping soil salinity and a fresh-water intrusion in three-dimensions using a quasi-3d joint-inversion of DUALEM-421S and EM34 data. Sci. Total Environ. 577, 395-404.

Huang, J., McBratney, A.B., Minasny, B., Triantafilis, J., 2017c. 3D soil water nowcasting using electromagnetic conductivity imaging and the ensemble Kalman filter. J. Hydrol. $549,62-78$.

Huang, J., McBratney, A.B., Minasny, B., Triantafilis, J., 2017d. Monitoring and modelling soil water dynamics using electromagnetic conductivity imaging and the ensemble Kalman filter. Geoderma 285, 76-93.

Huang, J., Pedrera-Parrilla, A., Vanderlinden, K., Taguas, E.V., Gómez, J.A., Triantafilis, J., 2017e. Potential to map depth-specific soil organic matter content across an olive grove using quasi-2d and quasi-3d inversion of DUALEM-21 data. Catena 152, 207-217.

Huete, A.R., 1988. A soil-adjusted vegetation index (SAVI). Remote Sens. Environ. 25 (3), 295-309.

Huete, A.R., Didan, K., Miura, T., Rodriguez, E.P., Gao, X., Ferreira, L.G., 2002. Overview of the radiometric and biophysical performance of the MODIS vegetation indices. Remote Sens. Environ. 83, 195-213.

Hunt, G.R., 1980. Electromagnetic radiation: the communications link in remote sensing. In: Siegal, B.S., Gillespie, A.R. (Eds.), Remote Sensing in Geology. Wiley, New York, NY, pp. 5-45.

Huth, N.I., Poulton, P.L., 2007. An electromagnetic induction method for monitoring variation in soil moisture in agroforestry systems. Aust. J. Soil. Res. 45, 63-72.

Inman, D.J., Freeland, R.S., Yoder, R.E., Ammons, J.T., Leonard, L.L., 2001. Evaluating GPR and EMI for morphological studies of loessial soil. Soil Sci. 166, 622-630.

Inman, D.J., Freeland, R.S., Ammons, J.T., Yoder, R.E., 2002. Soil investigations using electromagnetic induction and ground-penetrating radar in southwest Tennessee. Soil Sci. Soc. Am. J. 66, 206-211.

Inman, D., Khosla, R., Reich, R., Westfall, D.G., 2008. Normalized difference vegetation index and soil color-based management zones in irrigated maize. Agron. J. 100 (1), 60-66.

Islam, M.M., Meerschman, E., Saey, T., De Smedt, P., Van De Vijver, E., Van Meirvenne, M., 2012. Comparing apparent electrical conductivity measurements on a paddy field under flooded and drained conditions. Precis. Agric. 13, 384-392.

Islam, M.M., Meerschman, E., Saey, T., De Smedt, P., Van De Vijver, E., Delefortrie, S., Van Meirvenne, M., 2014a. Characterizing compaction variability with an electromagnetic induction sensor in a puddled paddy rice field. Soil Sci. Soc. Am. J. 78, 579-588.

Islam, M.M., Saey, T., De Smedt, P., Van De Vijver, E., Delefortrie, S., Van Meirvenne, M., 2014b. Modeling within field variation of the compaction layer in a paddy rice field using a proximal soil sensing system. Soil Use Manage. 30, 99-108.

Ivits, E., Cherelet, M., Tóth, T., Lewińska, K.E., Tóth, G., 2013. Characterization of productivity limitation of salt-affected lands in different climate regions of Europe using remote sensing derived productivity indicators. Land Degrad. Dev. 24, 438-454. https://doi.org/10.1002/ldr.1140.

Ivushkin, K., Bartholomeus, H., Bregt, A.K., Pulatov, A., 2017. Satellite thermography for soil salinity assessment of cropped areas in Uzbekistan. Land Degrad. Dev. 28, 870-877. https://doi.org/10.1002/ldr.2670. 
Jadoon, K.Z., Moghadas, D., Jadoon, A., Missimer, T.M., Al-Mashharawi, S.K., McCabe, M.F., 2015. Estimation of soil salinity in a drip irrigation system by using joint inversion of multicoil electromagnetic induction measurements. Water Resour. Res. 51, 3490-3504. https://doi.org/10.1002/2014WR016245.

Jadoon, K.Z., Altaf, M.U., McCabe, M.F., Hoteit, I., Muhammad, N., Moghadas, D., Weihermüller, L., 2017. Inferring soil salinity in a drip irrigation system from multiconfiguration EMI measuremeents using adaptive Markov chain Monte Carlo. Hydrol. Earth Syst. Sci. 21, 5375-5383.

James, I.T., Waine, T.W., Bradley, R.I., Taylor, J.C., Godwin, R.J., 2003. Determination of soil type boundaries using electromagnetic induction scanning techniques. Biosyst. Eng. 86, 421-430.

Jardani, A., Revil, A., Santos, F., Fauchard, C., Dupont, J.P., 2007. Detection of preferential infiltration patthways in sinkholes using joint inversion of self-potential and EM-34 conductivity data. Geophys. Prospect. 55, 1-12.

Jayawickreme, D.H., Van Dam, R.L., Hyndman, D.W., 2008. Subsurface imaging of vegetation, climate, and root-zone moisture interactions. Geophys. Res. Lett. 35 L18404https://doi.org/10.1029/2008GL034690.

Jayawickreme, D.H., Santoni, C.S., Kim, J.H., Jobbagy, E.G., Jackson, R.B., 2011. Changes in hydrology and salinity accompanying a century of agricultural conversion in Argentina. Ecol. Appl. 21, 2367-2379.

Jaynes, D.B., 1996. Mapping the areal distribution of soil parameters with geophysical techniques. In: Corwin, D.L., Loague, K. (Eds.), Applications of GIS to the Modeling of Non-point Source Pollutants in the Vadose Zone. Soil Science Society of America, Madison, WI, pp. 205-216. SSSA Special Publication No. 48.

Jaynes, D.B., Colvin, T.S., Ambuel, J., 1993. Soil type and crop yield determinations from ground conductivity surveys. In: ASAE Paper No. 933552, 1993 ASAE Winter Meetings, 14-17 Dec. 1993, Chicago, IL. ASAE, St. Joseph, MI.

Jaynes, D.B., Colvin, T.S., Ambuel, J., 1995a. Yield mapping by electromagnetic induction. In: Robert, P.C., Rust, R.H., Larson, W.E. (Eds.), Site-Specific Management for Agricultural Systems. ASA-CSSA-SSSA, Madison, WI, pp. 383-394.

Jaynes, D.B., Novak, J.M., Moorman, T.B., Cambardella, C.A., 1995b. Estimating herbicide partition coefficients from electromagnetic induction measurements. J. Environ. Qual. 24, 36-41.

Jensen, J.R., 2000. Remote Sensing of the Environment: An Earth Resource Perspective. Prentice Hall, Upper Saddle River, NJ.

Jiang, P., Anderson, S.H., Kitchen, N.R., Sadler, E.J., Sudduth, K.A., 2007a. Landscape and conservation management effects on hydraulic properties of a claypan-soil toposequence. Soil Sci. Soc. Am. J. 71, 803-811.

Jiang, P., Anderson, S.H., Kitchen, N.R., Sudduth, K.A., Sadler, E.J., 2007b. Estimating plant-available water capacity for claypan landscapes using apparent electrical conductivity. Soil Sci. Soc. Am. J. 71, 1902-1908.

Jin, X.M., Vekerdy, Z., Zhang, Y.K., Liu, J.T., 2012. Soil salt content and its relationship with crops and groundwater depth in the Yinchuan Plain (China) using remote sensing. Arid Land Res. Manag. 26, 227-235. https://doi.org/10.1080/15324982.2012.681339.

Johnson, C.K., Doran, J.W., Duke, H.R., Wienhold, B.J., Eskridge, K.M., Shanahan, J.F., 2001. Field-scale electrical conductivity mapping for delineating soil condition. Soil Sci. Soc. Am. J. 65, 1829-1837.

Johnson, C.K., Eigenberg, R.A., Doran, J.W., Wienhold, B.J., Eghball, B., Woodbury, B.L., 2005a. Status of soil electrical conductivity studies by central state researchers. Trans. ASAE 48, 979-989. 
Johnson, C.K., Eskridge, K.M., Corwin, D.L., 2005b. Apparent soil electrical conductivity: applications for designing and evaluating field-scale experiments. Comput. Electron. Agric. 46, 181-202.

Johnston, M.A., Savage, M.J., Moolman, J.H., du Pleiss, H.M., 1997. Evaluation of calibration methods for interpreting soil salinity from electromagnetic induction measurements. Soil Sci. Soc. Am. J. 61, 1627-1633.

Judkins, G., Myint, S., 2012. Spatial variation of soil salinity in the Mexicali Valley, Mexico: application of a practical method for agricultural monitoring. Environ. Manag. 50, 478-489. https://doi.org/10.1007/s00267-012-9889-3.

Jung, W.K., Kitchen, N.R., Sudduth, K.A., Kremer, R.J., Motavalli, P.P., 2005. Relationship of apparent soil electrical conductivity to claypan soil properties. Soil Sci. Soc. Am. J. 69, 883-892.

Jung, W.K., Kitchen, N.R., Sudduth, K.A., Anderson, S.H., 2006. Spatial characteristtics of claypan soil properties in an agricultural field. Soil Sci. Soc. Am. J. 70, 1387-1397. https://doi.org/10.2136/sssaj2005.0273.

Jurinak, J.J., Suarez, D.L., 1996. The chemistry of salt-affected soils and waters. In: Tanji, K.K. (Ed.), Agricultural Salinity Assessment and Management, first ed. ASCE, New York, NY, pp. 42-63.

Kachanoski, R.G., Van-Wesenbeeck, I.J., Gregorich, E.G., 1988. Estimating spatial variations of soil water content using noncontacting electromagnetic inductive methods. Can. J. Soil Sci. 68 (4), 715-722.

Kachanoski, R.G., Van-Wesenbeeck, I.J., de Jong, E., 1990. Field scale patterns of soil water storage from non-contacting measurements of bulk electrical conductivity. Can. J. Soil Sci. 70 (3), 537-542.

Kaffka, S.R., Lesch, S.M., Bali, K.M., Corwin, D.L., 2005. Site-specific management in saltaffected sugar beet fields using electromagnetic induction. Comput. Electron. Agric. 46 (1-3), 329-350.

Kalinski, R.J., Kelly, W.E., 1993. Estimating water content of soils from electrical resistivity. Geotech. Test. J. 16, 323-329.

Kaman, H., Cetin, M., Kirda, C., 2011. Monitoring and assessing of changes in soil and groundwater salinity of Yemisli Irrigation District of Turkey using low quality irrigation water. Sci. Res. Essay 6, 1388-1396.

Karnieli, A., Kaufman, Y.J., Remer, L., Wald, A., 2001. AFRI-aerosol free vegetation index. Remote Sens. Environ. 77, 10-21.

Kaufman, Y.J., Tanré, D., 1992. Atmoshericalloy resistant vegetation index (ARVI) for EOS-MODIS. IEEE Trans. Geosci. Remote Sens. 30, 261-270.

Kean, W.F., Jennings Walker, M., Layson, H.R., 1987. Monitoring moisture migration in the vadose zone with resistivity. Ground Water 25, 562-571.

Keller, G.V., 1994. Rock and mineral properties. In: Nabighian, M.N. (Ed.), Electromagnetic Methods in Applied Geophysics: Theory. In: Investigations in Geophysics 3, Vol. 1. Society of Exploration Geophysicists, Tulsa, OK, pp. 13-52.

Kelley, J., Higgins, C.W., Pahlow, M., Noller, J., 2017. Mapping soil texture by electromagnetic induction: a case for regional data coordination. Soil Sci. Soc. Am. J. 81, 923-931. https://doi.org/10.2136/sssaj2016.12.0432.

Kelly, B.F., Acworth, R.I., Greve, A.K., 2011. Better placement of soil moisture point measurements guided by 2D resistivity tomography for improved irrigation scheduling. Soil Res. 49, 504-512.

Khakural, B.R., Robert, P.C., Hugins, D.R., 1998. Use of non-contacting electromagnetic inductive method for estimating soil moisture across a landscape. Commun. Soil Sci. Plant Anal. 29, 2055-2065. 
Khan, N.M., Rastoskuev, V.V., Shalina, E., Sato, Y., 2001. Mapping salt-affected soil using remote sensing indicators: a simple approach with the use of GIS Idrissi. In: 22nd Asian Conference on Remote Sensing. 5-9 Nov. 2001, Singapore.

Khan, N.M., Rastoskuev, V.V., Sato, Y., Shiozawa, S., 2005. Assesssment of hydrosaline land degradation by using a simple approach of remote sensing indicators. Agric. Water Manag. 77 (1), 96-109.

Khan, F.S., Zaman, Q.U., Chang, Y.K., Farooque, A.A., Schumann, A.W., Madani, A., 2016. Estimation of rootzone depth above a gravel layer (in wild blueberry fields) using electromagnetic induction method. Precis. Agric. 17, 155-167.

Kibria, G., Hossain, M., 2012. Investigation of geotechnical parameters affecting electrical resistivity of compacted clays. J. Geotech. Geoenviron. Eng. 138 (12), 1520-1529.

Kidd, D., Malone, B., McBratney, A., Minasny, B., Webb, M., 2015. Operational sampling challenges to digital soil mapping in Tasmania, Australia. Geoderma Reg. 4, 1-10.

Kimble, J.M., Doolittle, J., Taylor, R., Windhorn, R., Gerken, J., 2001. The use of EMI and electrical instruments for estimating soil properties to help in mapping. In: Proceedings of the 2001 AGU Fall Meeting Abstract, San Francisco, CA, USA, 10-14 Dec. 2001.

Kinal, J., Stoneman, G.L., Williams, M.R., 2006. Calibrating and using EM31 electromagnetic induction meter to estimate and map soil salinity in the jarrah and karri forests of south-western Australia. For. Ecol. Manage. 233, 78-84.

Kitchen, N.R., Sudduth, K.A., Drummond, S.T., 1996. Mapping of sand deposition from 1993 Midwest floods with electromagnetic induction measurements. J. Soil Water Conserv. 51 (4), 336-340.

Kitchen, N., Sudduth, K., Drummond, S., 1999. Soil electrical conductivity as a crop productivity measure for claypan soils. J. Prod. Agric. 12, 607-617.

Kitchen, N.R., Drummond, S.T., Lund, E.D., Sudduth, K.A., Buchleiter, G.W., 2003. Soil electrical conductivity and topography related to yield for three contrasting soil-crop systems. Agron. J. 95, 483-495.

Klassen, S.P., Villa, J., Adamchuk, V., Serraj, R., 2014. Soil mapping for improved phenotyping of drought resistance in lowland rice fields. Field Crop. Res. 167, 112-118.

Klein, D.J., Sill, W.R., 1982. Electrical properties of artificial clay-bearing sandstones. Geophysics 47, 1593-1601.

Knotters, M., Brus, D.J., Voshaar, J.H.O., 1995. A comparison of kriging, co-kriging and kriging combined with regression for spatial interpolation of horizon depth with censored observations. Geoderma 67, 227-246.

Kobayashi, C., Lau, I., Wheaton, B., Cater, D., Bourke, L., Asada, N., Kashimura, O., Ong, C., Cudahy, T., 2013. Estimating soil salinity using hyperspectral data in the Western Australian wheat belt. In: IGARSS '13, Proceedings of the International Geoscience and Remote Sensing Symposium. Melbourne, Australia, 21-26 July 2013. IEEE, Piscataway, NJ, pp. 4325-4328. https://doi.org/10.1109/IGARSS.2013.6723791.

Koestel, J., Kemna, A., Javaux, M., Binley, A., Vereecken, H., 2008. Quantitative imaging of solute transport in an unsaturated and undisturbed soil monolith with 3-D ERT and TDR. Water Resour. Res. 44 W12411https://doi.org/10.1029/2007WR006755.

Korsaeth, A., 2005. Soil apparent electrical conductivity $\left(\mathrm{EC}_{\mathrm{a}}\right)$ as a means of monitoring changes in soil inorganic $\mathrm{N}$ on heterogeneous morainic soils in SE Norway during two growing seasons. Nutr. Cycl. Agroecosyst. 72, 213-227.

Koszinski, S., Gerke, H.H., Hierold, W., Sommer, M., 2013. Geophysical-based modeling of a kettle hole catchment of the morainic soil landscape. Vadose Zone J. 12 (4), vzj2013.02.0044. https://doi.org/10.2136/vzj2013.02.0044.

Koszinski, S., Miller, B.A., Hierold, W., Haelbich, H., Sommer, M., 2015. Spatial modeling of organic carbon in degraded peatland soils of northeast Germany. Soil Sci. Soc. Am. J. 79, 1496-1508. https://doi.org/10.2136/sssaj2015.01.0019. 
Krabbenborg, A.J., Biewinga, D.T., 1988. Meting van het geleidingsvermogen als hulp bij de bodenkartering; een onderzoek naar de praktische bruikbaarheid van de Geionics EM38. Cultuurtechnisch Tijdschrift 27 (6), 377-387.

Kravchenko, A.N., Bollero, G.A., Omonode, R.A., Bullock, D.G., 2002. Quantitative mapping of soil drainage classes using topographical data and soil electrical conductivity. Soil Sci. Soc. Am. J. 66, 235-243.

Krum, J.M., Flitcroft, I., Gerber, P., Carrow, R.N., 2011. Performance of a mobile salinity monitoring device developed for turfgrass situations. Agron. J. 103 (1), 23-31.

Kuang, B., Mahmood, H.S., Quraishi, M.Z., Hoogmoed, W.B., Mouazen, A.M., van Henten, E.J., 2012. Sensing soil properties in the laboratory, in situ, and on-line: a review. Adv. Agron. 114, 155-223. https://doi.org/10.1016/B978-0-12-394275-3.00003-1.

Kühn, J., Brenning, A., Wehrhan, M., Koszinski, S., Sommer, M., 2009. Interpretation of electrical conductivity patterns by soil properties and geological maps for precision agriculture. Precis. Agric. 10, 490-507.

Kumar, A., Lee, W.S., Ehsani, M.R., Albrigo, L.G., Yang, C., Mangan, R.L., 2012. Citrus greening disease detection using aerial hyperspectral and multispectral imaging techniques. J. Appl. Remote Sens. 6 (1), 063542. https://doi.org/10.1117/1.JRS.6.063542.

Kweon, G., Lund, E., Maxton, C., 2013. Soil organic matter and cation-exchange capacity sensing with on-the-go electrical conductivity and optical sensors. Geoderma 199, 80-89. https://doi.org/10.1016/j.geoderma.2012.11.001.

Lal, R., Iivari, T., Kimble, J.M., 2004. Soil Degradation in the United States: Extent, Severity, and Trends. CRC Press, Boca Raton, FL.

Landrum, C., Castrignanò, A., Mueller, T., Zourarakis, D., Zhu, J., De Benedetto, D., 2015. An approach for delineating homogeneous within-field zones using proximal sensing and multivariate geostatistics. Agric. Water Manag. 147, 144-153.

Lardo, E., Coll, P., Le Cadre, E., Palese, A.M., Villenave, C., Xiloyannis, C., Celano, G., 2012. Electromagnetic induction (EMI) measurements as a proxy of earthworm presence in Southern French vineyards. Appl. Soil Ecol. 61, 76-84.

Lasne, Y., Paillou, P.H., Ruffie, G., Serradilla, C., Demontoux, F., Freeman, A., Far, T., McDonald, K., Chapman, B., 2008. Effect of salinity on the dielectric properties of geological materials: implication for soil moisture detection by means of radar remote sensing. IEEE Trans. Geosci. Remote Sens. 46, 1674-1688.

Lesch, S.M., 2005. Sensor-directed response surface sampling designs for characterizing spatial variation in soil properties. Comput. Electron. Agric. 46 (1-3), 153-179. https://doi. org/10.1016/j.compag.2004.11.004.

Lesch, S.M., 2012. Statistical models for the prediction of field-scale and spatial salinity patterns from soil conductivity survey data. In: Wallender, W.W., Tanji, K.K. (Eds.), Agricultural Salinity Assessment and Management. ASCE, Reston, VA, pp. 461-482.

Lesch, S.M., Corwin, D.L., 2003. Using the dual-pathway parallel conductance model to determine how different soil properties influence conductivity survey data. Agron. J. 95, 365-379.

Lesch, S.M., Corwin, D.L., 2008. Prediction of spatial soil property information from ancillary sensor data using ordinary linear regression: model derivations, residual assumptions and model validation tests. Geoderma 148, 130-140.

Lesch, S.M., Rhoades, J.D., Lund, L.J., Corwin, D.L., 1992. Mapping soil salinity using calibrated electromagnetic measurements. Soil Sci. Soc. Am. J. 56 (2), 540-548.

Lesch, S.M., Rhoades, J.D., Corwin, D.L., 1993. Statistical modeling and prediction methodologies for large scale spatial soil salinity characterization. In: A Case Study Using Calibrated Electromagnetic Measurements with the Broadview Water District. U.S. Salinity Laboratory, Riverside, CA Technical Report \#131. Available online http:// citeseerx.ist.psu.edu/viewdoc/download;jsessionid=744E7797134200EEF3B3FE9178 F4D86F?doi=10.1.1.30.1289\&rep=rep1\&type=pdf accessed Feb. 13, 2018 https:// pdfs.semanticscholar.org/d741/83bae61378577de128283ea0139f9f0a73dc.pdf (accessed Feb. 13, 2018). 
Lesch, S.M., Strauss, D.J., Rhoades, J.D., 1995a. Spatial prediction of soil salinity using electromagnetic induction techniques: 1 . Statistical prediction models: a comparison of multiple linear regression and cokriging. Water Resour. Res. 31, 373-386.

Lesch, S.M., Strauss, D.J., Rhoades, J.D., 1995b. Spatial prediction of soil salinity using electromagnetic induction techniques: 2. An efficient spatial sampling algorithm suitable for multiple linear regression model identification and estimation. Water Resour. Res. 31, 387-398.

Lesch, S.M., Herrero, J., Rhoades, J.D., 1998. Monitoring for temporal changes in soil salinity using electromagnetic induction techniques. Soil Sci. Soc. Am. J. 62, 232-242.

Lesch, S.M., Rhoades, J.D., Corwin, D.L., 2000. ESAP-95 Version 2.10R: User Manual and Tutorial Guide, Research Rpt. 146. USDA-ARS. U.S. Salinity Laboratory, Riverside, CA.

Lesch, S.M., Corwin, D.L., Robinson, D.A., 2005. Apparent soil electrical conductivity mapping as an agricultural management tool in arid zone soils. Comp. Electron. Agric. 46, 351-378.

Li, X.M., Yang, J.S., Liu, M.X., Liu, G.M., Yu, M., 2012. Spatio-temporal changes in soil salinity in arid areas of South Xinjiang using electromagnetic induction. J. Integr. Agric. 11, 1365-1376.

Li, J., Pu, L., Zhu, M., Dai, X., Xu, Y., Chen, X., Zhang, L., Zhang, R., 2015. Monitoring soil salt content using $\mathrm{HJ}-1 \mathrm{~A}$ hyperspectral data: a case study of coastal areas in Rudong County Eastern China. Chin. Geogr. Sci. 25, 213-223. https://doi.org/10.1007/ s11769-014-0693-2.

Li, H.Y., Shi, Z., Webster, R., Triantafilis, J., 2013a. Mapping the three-dimensional variation of soil salinity in a rice-paddy soil. Geoderma 195-196, 31-41.

Li, H.Y., Wu, C.F., Li, F.H., Shi, Z., 2013b. Three-dimensional variation of electrical conductivity in a paddy rice soil based on the disjunctive kriging method. Res. J. Appl. Sci. Eng.Technol. 6, 1486-1489.

Li, H., Lee, W.S., Wang, K., Ehsani, R., Yang, C., 2014. Extended spectral angle mapping (ESAM) for citrus greening disease detection using airborne hyperspectral imaging. Comput. Electron. Agric. 15 (2), 162-183.

Liao, K.-h., Zhu, Q., Doolittle, J., 2014. Temporal stability of apparent soil electrical conductivity measured by electromagnetic induction techniques. J. Mountain Sci. 11 (1), 98-109. https://doi.org/10.1007/s11629-012-2630-0.

Ließ, M., 2015. Sampling for regression-based digital soil mapping: closing the gap between statistical desires and operational applicability. Spat. Stat. 13, 106-122.

Lillesand, T.M., Kiefer, R.W., Chipman, J.W., 2004. Remote Sensing and Image Interpretation, fifth ed. John Wiley and Sons, New York, USA.

Liu, H.Q., Huete, A., 1995. A feedback based modification of the NDVI to minimize canopy background and atmospheric noise. IEEE Trans. Geosci. Remote Sens. 33 (2), 457-465.

Liu, J., Pattey, E., Nolin, M.C., Miller, J.R., Ka, O., 2008. Mapping within-field soil drainage using remote sensing, DEM and apparent soil electrical conductivity. Geoderma 143, 261-272. https://doi.org/10.1016/j.geoderma.2007.11.011.

Liu, G., Li, J., Zhang, X., Wang, X., Lv, Z., Yang, J., Shao, H., Yu, S., 2016. GIS-mapping spatial distribution of soil salinity for eco-storing the Yellow River Delta in combination with elecgttromagnetic induction. Ecol. Eng. 94, 306-314.

Lobell, D.B., 2010. Remote sensing of soil degradation: introduction. J. Environ. Qual. 39, 1-4.

Lobell, D.B., Ortiz-Monasterio, J.I., Gurrola, F.C., Valenzuela, L., 2007. Identification of saline soils with multiyear remote sensing of crop yields. Soil Sci. Soc. Am. J. 71 (3), 777-783.

Lobell, D.B., Lesch, S.M., Corwin, D.L., Ulmer, M.G., Anderson, K.A., Potts, D.J., Doolittle, J.A., Matos, M.R., Baltes, M.J., 2010. Regional-scale assessment of soil salinity in the Red River Valley using multi-year MODIS EVI and NDVI. J. Environ. Qual. $39,35-41$. 
Loke, M.H., Chambers, J.E., Rucker, D.F., Kuras, O., Wilkinson, P.B., 2013. Recent developments in the direct-current geoelectrical imaging method. J. Appl. Geophys. 95, 135-156.

López-Bruna, D., Herrero, J., 1996. The behavior of the electromagnetic sensor and its calibration for soil salinity. Agronomie 16, 95-105.

López-Lozano, R., Casterad, M.A., Herrero, J., 2010. Site-specific management units in a commercial maize plot delineated using very high resolution remote sensing and soil properties mapping. Comput. Electron. Agric. 73, 219-229.

Lu, N., Zhang, Z., Gao, Y., 2005. Recognition and mapping of soil salinization in arid environment with hyperspectral data. In: IGARSS '05, Proceedings of the International Geoscience and Remote Sensing Symposium. Seoul, Korea, July 24-29, 2005. IEEE, Piscataway, NJ, pp. 4520-4523. https://doi.org/10.1109/IGARSS.2005.1525926.

Lu, C., Zhou, Z., Zhu, Q., Lai, X., Liao, K., 2017. Using residual analysis of electromagnetic induction data interpretation to improve the prediction of soil properties. Catena 149, 176-184.

Lück, E., Gebbers, R., Ruehlmann, J., Spangenberg, U., 2009. Electrical conductivity mapping for precision farming. Near Surf. Geophys. 7 (1), 15-25.

Lück, E., Ruehlmann, J., Kirchmann, H., 2011. Properties of soils from the Swedish longterm fertility experiments: VI. Mapping soil electrical conductivity with different geophysical methods. Acta Agric. Scand. Sect. B Soil Plant Sci. 61, 438-447.

Lueck, E., Ruehlmann, J., 2013. Resistivity mapping with GEOPHILUS ELECTRICUSinformation about lateral and vertical soil heterogeneity. Geoderma 199, 2-11. https:// doi.org/10.1016/j.geoderma.2012.11.009.

Lukas, V., Neudert, L., Kren, J., 2009. Mapping of soil conditions in precision agriculture. Acta Agrophys. 13 (2), 393-405.

Lund, E.D., Chrissty, C.D., Drummond, P.E., 1999. Applying soil electrical conductivity to precision agriculture. In: Robert, P.C., Rust, R.H., Larson, W.E. (Eds.), Proceedings of the Fourth International Conference on Precision Agriculture. St. Paul, MN, July 19-22, 1998. ASA-CSSA-SSSA, Madison, WI, pp. 1089-1100.

Maas, E.V., 1996. Crop salt tolerance. In: Tanji, K.K. (Ed.), Agricultural Salinity Assessment and Management, first ed. ASCE, New York, NY, pp. 262-304.

Maas, E.V., Hoffman, G., 1977. Crop salt tolerance-current assessment. J. Irrig. Drain. Div. Am. Soc. Civ. Eng. 103, 115-134.

MacDonald, S.L., Staid, M., Staid, M., Cooper, M.L., 2016. Remote hyperspectral imaging of grapevine leafroll-associated virus 3 in cabernet sauvignon vineyards. Comput. Electron. Agric. 130, 109-117. https://doi.org/10.1016/j.compag.2016.10.003.

Madani, A.A., 2005. SSoil salinity detection and monitoring using Landsat data: a case study from Siwa Oasis, Egypt. GIsci. Remote Sens. 42 (2), 171-181. https://doi.org/ 10.2747/1548-1603.42.2.171.

Mahmood, H.S., Hoogmoed, W.B., van Henten, E.J., 2012. Sensor data fusion to predict multiple soil properties. Precis. Agric. 13, 628-645.

Major, D., Baret, F., Guyot, G., 1990. A ratio vegetation index adjusted for soil brightness. Int. J. Remote Sens. 11 (5), 727-740.

Malins, D., Metternicht, G., 2006. Assessing the spatial extent of dryland salinity through fuzzy modeling. Ecol. Model. 193, 387-411.

Mallants, D., Vanclooster, M., Toride, N., Vanderborght, J., van Genuchten, M.T., Feyen, J., 1996. Comparison of three methods to calibrate TDR for monitoring solute movement in undisturbed soil. Soil Sci. Soc. Am. J. 60, 747-754.

Mallet, F., Carrière, S.D., Chalikakis, K., Marc, V., 2018. Assessing soil water content spatiotemporal variability at the hillslope scale in a headwater catchment using a multi variable interpolation model based on EMI surveys (Draix, South Alps, France). Environ. Earth Sci. 77, 507. https://doi.org/10.1007/s12665-018-7687-9. 
Malo, D.D., Lee, D.K., Lee, J.U.H., Christopherson, S.M., Cole, C.M., Kleinjan, J.L., Carlson, C.G., Clay, D.E., Chnag, J., Reese, C.L., et al., 2000. Soil moisture, bulk density, soil temperature, and soil sensor (Veris $3100^{\circledR}$ and Geonics EM-38 ${ }^{\circledR}$ ) Moody County site. Annual Report Soil PR00-41 South Dakota State University, Brookings, SD.

Mandal, A.K., 2016. Mapping and characterization of salt-affected and water logged soils in the Gangetic plain of central Haryana (India) for reclamation and management. Cogent. Geosci. 2, 1213689. https://doi.org/10.1080/23312041.2016.1213689.

Mandal, A.K., Sharma, R.C., 2011. Delineation and characterization of waterlogged salt affected soils in IGNP using remote sensing and GIS. J. Indian Soc. Remote Sens. 39 (1), 39-50. https://doi.org/10.1007/s12524-010-0051-5.

Mankin, K.R., Karthikeyan, R., 2002. Field assessment of saline seep remediation using electromagnetic induction. Trans. ASAE 45 (1), 99-107.

Mankin, K.R., Ewing, K.L., Schrock, M.D., Kluitenberg, G.J., 1997. Field measurement and mapping of soil salinity in saline seeps. In: ASAE Paper No. 973145, 1997 ASAE Winter Meetings, Dec. 1997, Chicago, IL. ASAE, St. Joseph, MI.

Martínez, G., Vanderlinden, K., Ordóñez, R., Muriel, J.L., 2009. Can apparent electrical conductivity improve the spatial characterization of soil organic carabon? Vadose Zone J. 8 (3), 586-593. https://doi.org/10.2136/vzj2008.0123.

Martínez, G., Vanderlinden, K., Giráldez, J.V., Espejo, A.J., Muriel, J.L., 2010. Field-scale soil moisture pattern mapping using electromagnetic induction. Vadose Zone J. 9, 871-881. https://doi.org/10.2136/vzj2009.0160.

Martínez, G., Huang, J., Vanderlinden, K., Giráldez, J.V., Triantafilis, J., 2018. Pottential to predict depth-specific soil-water content beneath an olive tree using electromagnetic conductivity imaging. Soil Use Manage. 34, 236-248. https://doi.org/10.1111/sum.12411.

Martini, E., Werban, U., Zacharias, S., Pohle, M., Dietrich, P., Wollschläger, U., 2017. Repeated electromagnetic induction measurements for mapping soil moisture at the field scale: validation with data from a wireless soil moisture monitoring network. Hydrol. Earth Syst. Sci. 21, 495-513. https://doi.org/10.5194/hess-2016-93.

Mashimbye, Z.E., Cho, M.A., Nell, J.P., de Clercq, W.P., van Niekerk, A., Turner, D.P., 2012. Model-based integrated methods for quantitative estimation of soil salinity from hyperspectral remote sensing data: a case study of selected South African soils. Pedosphere 22 (5), 640-649.

Masoud, A.A., 2014. Predicting salt abundance in slightly saline soils from Landsat ETM+ imagery using spectral mixture analysis and soil spectrometry. Geoderma 217-218, 45-56. https://doi.org/10.1016/j.geoderma.2013.10.027.

Massoud, F.I., 1981. Salt Affected Soils at a Global Scale and Concepts for Control. FAO Land and Water Development Division, Technical Paper: Food and Agriculture Organization of the United Nations, FAO, Rome, Italy, p. 21.

Massuel, S., Favreau, G., Descloitres, M., Le Troquer, Y., Albouy, Y., Cappelaere, B., 2006. Deep infiltration through a sandy alluvial fan in semiarid Niger inferred from electrical conductivity survey, vadose zone chemistry and hydrological modelling. Catena 67, 105-118.

McBratney, A.B., Bishop, T.F.A., Teliatnikov, I.S., 2000. Two soil profile reconstruction techniques. Geoderma 97, 209-221.

McBratney, A.B., Minasny, B., Whelan, B.M., 2005. Obtaining 'useful' high resolution soil data from proximally-sensed elecetrrical conductivity/resistivity (PSEC/R) surveys. Precis. Agric. 5, 503-510.

McBride, R.A., Gordon, A.M., Shrive, S.C., 1990. Estimating forest soil quality from terrain measurements of apparent electrical conductivity. Soil Sci. Soc. Am. J. 54, 290-293.

McCarter, W.J., Desmazes, P., 1997. Soil characterization using electrical measurements. Géotechnique 47 (1), 179-183. 
McCutcheon, M.C., Farahani, H.J., Stednick, J.D., Buchleiter, G.W., Green, T.R., 2006. Effect of soil water on apparent soil electrical conductivity and texture relattionships in a dryland field. Biosyst. Eng. 94 (1), 19-32.

McKenzie, R.C., 2000. Salinity: mapping and determining crop tolerance with an electromagnetic induction meter (Canada). In: Vlotman, W.F. (Ed.), EM38 Workshop, pp. 57-68. New Delhi, India, 4 Feb. 2000. Available online, http://www2.alterra. wur.nl/Internet/webdocs/ilri-publicaties/special_reports/Srep13/Srep13-h6.pdf accessed Sept. 13, 2018.

McKenzie, R.C., Chomistek, W., Clark, N.F., 1989. Conversion of electromagnetic inductance readings to saturated paste extract values in soils for different temperature, texture, and moisture conditions. Can. J. Soil Sci. 69, 25-32.

McKenzie, R.C., Matherss, H.M., Woods, S.A., 1993. Salinity and Crop Tolerance of Ornamental Trees and Shrubs. Alberta Special Crops and Horicultural Research Center, Brooks, AB, Canada.

McKenzie, R.C., George, R.J., Woods, S.A., Cannon, M.E., Bennet, D.L., 1997. Use of electromagnetic-induction meter (EM38) as a tool in managing salinization. Hydrgeol. J. 5 (1), 37-50.

McLeod, M.K., Slavich, P.G., Irhas, Y., Moore, N., Rachman, A., Ali, N., Iskandar, T., Hunt, C., Caniago, C., 2010. Soil salinity in Aceh after the December 2004 Indian Ocean tsunami. Agric. Water Manag. 97, 605-613.

McNeill, J.D., 1980. Electromagnetic Terrain Conductivity Measurement at Low Induction Numbers. Tech. Note TN-6, Geonics Limited, Ontario, Canada.

McNeill, J.D., 1986. Rapid, Accurate Mapping of Soil Salinity Using Electromagnetic Ground Conductivity Meters. Tech. Note TN-18, Geonics Limited, Ontario, Canada.

McNeill, J.D., 1992. Rapid, accurate mapping of soil salinity by electromagnetic ground conductivity meters. In: Topp, G.C., Reynolds, W.D., Green, R.E. (Eds.), Advances in Measurement of Soil Physical Properties: Bringing Theory Into Practice. Soil Science Society of America, Madison, WI, pp. 209-229. SSSA Special Publication No. 30 .

McNeill, J.D., 1996. Why doesn't Geonics Limited build a Multi-frequency EM31 or EM38? Technical Note TN-30, Geonics Ltd., Mississauga, Ontario.

Melendez-Pastor, I., Navarro-Pedreño, J., Koch, M., Goméz, I., 2010. Applying imaging spectroscopy techniques to map saline soils with ASTER images. Geoderma 158, 55-65. https://doi.org/10.1016/j.geoderma.2010.02.015.

Mertens, F.M., Pätzold, S., Welp, G., 2008. Spatial heterogeneity of soil properties and its mapping with apparent electrical conductivity. J. Plant Nutr. Soil Sci. 171, 146-154.

Merzlyak, M.N., Gitelson, A.A., Chivkunova, O.B., Rakitin, V.Y., 1999. Non-destructive optical detection of pigment changes during leaf senescence and fruit ripening. Physiol. Plant. 106, 135-141.

Mester, A., van der Kruk, J., Zimmermann, E., Vereecken, H., 2011. Quantitative two-layer conductivity inversion of multi-configuration electromagnetic induction instruments. Vadose Zone J. 10, 1319-1330. https://doi.org/10.2136/vzj2011.0035.

Metternicht, G.I., 1997. Fuzzy supervised classification of JERS-1 SAR data for soil salinity studies. In: Proceedings of IEEE International Geoscience and Remote Sensing. Symposium. Singapore, Singapore, Aug. 3-8, 1997. IEEE, Piscataway, NJ, pp. 338-340. https://doi.org/10.1109/IGARSS.1997.615879.

Metternicht, G.I., 1998. Fuzzy classification of JERS-1 SAR data: an evaluation of its performance for soil salinity mapping. Ecol. Model. 111, 61-74.

Metternicht, G.I., 2001. Assessing temporal and spatial changes of salinity using fuzzy logic, remote sensing and GIS. Foundations of an expert system. Ecol. Model. 144, 163-179. 
Metternicht, G.I., 2003. Categorical fuzziness: a comparison between crisp and fuzzy class boundary modelliong for mapping salt-affected soils using Landsat TM data and a classification based on anion ratios. Ecol. Model. 168, 371-389.

Metternicht, G.I., Zinck, J.A., 1997. Spatial discrimination of salt- and sodium-affected soil surfaces. Int. J. Remote Sens. 18, 2571-2586. https://doi.org/10.1080/014311697217486.

Metternicht, G.I., Zinck, J.A., 2003. Remote sensing of soil salinity: potentials and constraints. Remote Sens. Environ. 85, 1-20.

Metternicht, G.I., Zinck, J.A., 2009. Remote Sensing of Soil Salinization. CRC Press, Boca Raton, FL.

Mhaimeed, A.S., Wu, W., Al-Shafie, W.M., Ziadat, F., Al-Musawi, H.H., Saliem, K.A., 2013. Use remote sensing to map soil salinity in the Musaib area in Central Iraq. Int. J. Geosci. Geomatics 1 (2), 34-41.

Miao, Y., Mulla, D.J., Robert, P.C., 2018. An integrated approach to site-specific management zone delineation. Front. Agric. Sci. Eng. 5 (4), 432-441.

Minasny, B., McBratney, A.B., 2006. A conditioned Latin hypercube method for sampling in the presence of ancillary information. Comput. Geosci. 32, 1378-1388.

Minasny, B., McBratney, A.B., Walvoor, D.J., 2007. The variance quadtree algorithm: use for spatial sampling design. Comput. Geosci. 33, 383-392.

Misra, R.K., Padhi, J., 2014. Assessing field-scale soil water distribution with electromagnetic induction method. J. Hydrol. 516, 200-209.

Moffett, K.B., Robinson, D.A., Gorelick, S.M., 2010. Relationship of salt marsh vegetation zonation to spatial patterns in soil moisture, salinity, and topography. Ecosystems 13, 1287-1302.

Moghadas, D., Taghizadeh-Mehrjardi, R., Triantafilis, J., 2016. Probabilistic inversion of EM38 data for 3D soil mapping in central Iran. Geoderma Reg. 7, 230-238.

Moghadas, D., Jadoon, K.Z., McCabe, M.F., 2017. Spatiotemporal monitoring of soil water ccontent profiles in an irrigated field using probabilistic inversion of time-lapse EMI data. Adv. Water Resour. 110, 238-248.

Monteiro Santos, F.A., 2004. 1-D laterally constrained inversion of EM34 profiling data. J. Appl. Geophys. 56, 123-134.

Monteiro Santos, F.A., Triantafilis, J., Bruzgulis, K.E., Roe, J.A.E., 2010. Inversion of multiconfiguration electromagnetic (DUALEM-421) profiling data using a one-dimensional laterally constrained algorithm. Vadose Zone J. 9, 117-125.

Moral, F.J., Rebollo, F.J., 2017. Characterization off soil fertility using the Rasch model. J. Soil Sci. Plant Nutr. 17 (2), 486-498.

Morari, F., Castrignanò, A., Pagliarin, C., 2009. Application of multivariate geostatistics in delineating management zones within a gravelly vineyard using geo-electrical sensors. Comput. Electron. Agric. 68, 97-107.

Moreira, L.C.J., Teixeira, A.D.S., Galvão, L.S., 2014. Laboratory salinization of Brazilian alluvial soils and the spectral effects of gypsum. Remote Sens. (Basel) 6, 2647-2663. https://doi.org/10.3390/rs6042647.

Moreira, L.C.J., Teixeira, A.D.S., Galvão, L.S., 2015. Potential of multispectral and hyperspectral data to detect saline-exposed soils in Brazil. GIsci. Remote Sens. 52 (4), 416-436. https://doi.org/10.1080/15481603.2015.1040227.

Morgan, C.L.S., Norman, J.M., Wolkowski, R.P., Lowery, B., Morgan, G.D., Schuler, R., 2000. Two approaches to mapping plant available water: EM-38 measurements and inverse yield modeling. In: Roberts, P.C., Rust, R.H., Larson, W.E. (Eds.), Proceedings of the 5th International Conference on Precision Agriculture (CD-ROM), Minneapolis, MN, 16-19 July 2000. ASA-CSSA-SSSA, Madison, WI, pp. 1-13.

Morshed, M.M., Islam, M.T., Jamil, R., 2016. Soil salinity detection from satellite image analysis: an integrated approach of salinity indices and field data. Environ. Monit. Assess. 188, 119. https://doi.org/10.1007/s10661-015-5045-x. 
Morway, E.D., Gates, T.K., 2012. Regional assessment of soil watr salinity across an intensively irrigated river valley. J. Irrig. Drain. Eng. 138 (5), 393-405.

Mougenot, B., Pouget, M., Epema, G., 1993. Remote sensing of salt affected soils. Remote Sens. Rev. 7, 241-259.

Moysey, S.M.J., Liu, Z., 2012. Can the onset of macropore flow be detected using electrical resistivity measurements? Soil Sci. Soc. Am. J. 76 (1), 10-17.

Mulder, V.L., de Bruin, S., Schaepman, M.E., Mayr, T.R., 2011. The use of remote sensing in soil and terrain mapping—a review. Geoderma 162, 1-19. https://doi.org/10.1016/j. geoderma.2010.12.018.

Mulla, D.J., 2013. Twenty years of remote sensing in precision agriculture: key advances and remaining knowledge gaps. Biosyst. Eng. 114 (4), 358-371.

Naderi-Boldaji, M., Sharifi, A., Alimardani, R., Hemmat, A., Keyhani, A., Loonstra, E.H., Weisskopf, P., Stettler, M., Keller, T., 2013. Use of a triple-sensor fusion system for on-the-go measurement of soil compaction. Soil Tillage Res. 128, 44-53.

Naderi-Boldaji, M., Sharifi, A., Hemmat, A., Alimardani, R., Keller, T., 2014. Feasibility study on the potential of electrical conductivity sensor Veris ${ }^{\circledR} 3100$ for field mapping of topsoil strength. Biosyst. Eng. 126, 1-11.

Nagra, G., Burkett, D., Huaang, J., Ward, C., Triantafilis, J., 2017. Field level digital mapping of soil mineralogy using proximal and remote-sensed data. Soil Use Manage. 33, 425-436.

Narjary, B., Jangra, P., Abhishek, R., Kumar, N., Raju, R., Thimappa, K., Meena, R.L., Kumar, S., Kumar, P., Chichmatalpure, A.R., Kamra, S.K., 2017. Quantitative assessment of soil salinity using electromagnetic induction technique and geostatistical approach. J. Soil Salinity Water Qual. 9 (2), 156-166.

Naumann, J.C., Anderson, J.E., Young, D.R., 2008. Linking physiological responses, chlorophyll fluorescence and hyperspectral imagery to detect salinity stress using the physiological reflectance index in the coastal shrub, Myrica cerifera. Remote Sens. Environ. 112, 3865-3875.

Nawar, S., Buddenbaum, H., Hill, J., Kozaj, J., 2014. Modeling and mapping of soil salinity with reflectance spectroscopy and Landsat data using two quantitative methods (PLSR and MARS). Remote Sens. (Basel) 6, 10813. https://doi.org/10.3390/ rs61110813.

Nawar, S., Buddenbaum, H., Hill, J., 2015. Digital mapping of soil properties using multivariate statistical analysis and ASTER data in an arid region. Remote Sens. (Basel) 7, 1181-1205. https://doi.org/10.3390/rs70201181.

Nearing, G.S., Tuller, M., Jones, S.B., Heinse, R., Meding, M.S., 2013. Electromagnetic induction for mapping textural contrasts of mine tailing deposits. J. Appl. Geophys. 89, 11-20.

Neely, H.L., Morgan, C.L.S., Hallmark, C.T., McInnes, K.J., Molling, C.C., 2016. Apparent electrical conductivity response to spatially variable vertisol properties. Geoderma 263, 168-175.

Nehmdahl, H., Greve, M.H., 2001. Using soil electrical conductivity measurements for delineating management zone on highly variable soils in Denmark. In: Proceedings of the 3rd European Conference on Precision Agriculture, Montpellier, France, 18-20 June 2001, pp. 461-466.

Nelson, M.A., Bishop, T.F.A., Triantafilis, J., Odeh, I.O.A., 2011. An error budget for different sources of error in digital soil mapping. Eur. J. Soil Sci. 62, 417-430.

Nettleton, W.D., Bushue, L., Doolittle, J.A., Wndres, T.J., Indorante, S.J., 1994. Sodium affected soil identification in south-central Illinois by electromagnetic induction. Soil Sci. Soc. Am. J. 58, 1190-1193.

Nield, S.J., Boettinger, J.L., Ramsey, R.D., 2007. Digitally mapping gypsic and natric soil areas using Landsat ETM data. Soil Sci. Soc. Am. J. 71, 245-252. https://doi.org/ 10.2136/sssaj2006-0049. 
Nielsen, D.R., Biggar, J.W., Erh, K.T., 1973. Spatial variability of field-measured soil-water properties. Hilgardia 42 (7), 215-259. https://doi.org/10.3733/hilg.v42n07p215.

Nijland, W., van der Meijde, M., Addink, E.A., de Jong, S.M., 2010. Detection of soil moisture and vegetation water abstraction in a Mediterranean natural area using electrical resistivity tomography. Catena 81, 209-216. https://doi.org/10.1016/j.catena.2010.03.005.

Nobes, D.C., Armstrong, M.J., Close, M.E., 2000. Delineation of a landfill leachate plume and flow channels in coastal sands near Christchurch, New Zealand, using a shallow electromagnetic survey method. Hydrgeol. J. 8 (3), 328-336.

Noborio, K., 2001. Measurement of soil water content and electrical conductivity by time domain reflectometry: a review. Comp. Electron. Agric. 36, 113-132.

Nocco, M.A., Ruark, M.D., Kucharik, C.J., 2019. Apparent electrical conductivity predicts physical properties of coarse soils. Geoderma 335, 1-11https://doi.org/10/1016/j. geoderma.2018.07.047.

Nogués, J., Robinson, D.A., Herrero, J., 2006. Incorporating electromagnetic induction methods into regional soil salinity survey of irrigation districts. Soil Sci. Soc. Am. J. 70, 2075-2085.

Norman, C.P., 1989. Kyvalley [Victoria] EM38 Salinity Survey. Research Report SeriesDepartment of Agriculture and Rural Affairs, Victoria. Available onlinehttp://agris.fao. org/agris-search/search.do?recordID=AU9430080. accessed Feb. 12, 2018.

Northcote, K.H., Skene, J.K.M., 1972. Australian Soils with Saline and Sodic Properties. CSIRO Australian Soil Publication No. 27. 62 ppCSIRO, East Melbourne, Victoria, Australia.

Noureddine, K., Eddine, M.D., El Kader, D.A., 2014. New index for salinity assessment applied on saline context area (case of the Lower Chéliff Plain). Int. J. Sci.: Basic Appl. Res. 18 (2), 401-404.

Nouri, H., Borujeni, S.C., Alaghmand, S., Anderson, S.J., Sutton, P.C., Parvazian, S., Beecham, S., 2018. Soil salinity mapping of urban greenery using remote sensing and proximal sensing techniques; the case of Veale Gardens within the Adelaide Parklands. Sustainability 10, 2826. https://doi.org/10.3390/su10082826.

Nyquist, J.E., Blair, M.S., 1991. Geophysical tracking and data logging system: description and case history. Geophysics 56 (7), 1114-1121.

Odeh, I.O.A., Onus, A., 2008. Spatial analysis of soil salinity and soil structural stability in a semiarid region of New South Wales, Australia. Environ. Manag. 42, 265-278. https:// doi.org/10.1007/s00267-008-9100-z.

Odeh, I.O.A., Todd, A.J., Triantafilis, J., McBratney, A.B., 1998. Status and trends of soil salinity at different scales: the case for the irrigated cotton growing region of eastern Australia. Nutr. Cycl. Agroecosyst. 50, 99-107.

Oh, S.H., Kwon, B.D., 2001. Geostatistical approach to bayesian inversion of geophysical data: Markov chain Monte Carlo method. Earth Planets Space 53 (8), 777-791.

Oskoee, R.S., 2017. Surface soil salinity detection and mapping, using hyperspectral satellite data of hyperion EO-1. Saussurea 7 (1), 32-44.

Oster, J.D., Letey, J., Vaughan, P., Wu, L., Qadir, M., 2012. Comparison of transient state models that include salinity and matric stress effects on plant yield. Agric. Water Manag. 103, 167-175. https://doi.org/10.1016/j.agwat.2011.11.011.

Padhi, J., Misra, R.K., 2011. Sensitivity of EM38 in determining soil water distribution in an irrigated wheat field. Soil Tillage Res. 117, 93-102.

Paine, J.G., 2003. Determining salinization extent, identifying salinity sources, and estimating chloride mass using surface, borehole, an airborne electromagnetic induction methods. Water Resour. Res. 39 (3), 3-1-3-10.

Pan, L., Adamchuk, V.I., Prasher, S., Gebbers, R., Taylor, R.S., Dabas, M., 2014. Vertical soil profiling using a galvanic contact resisitivity scanning approach. Sensors 14, 13243-13255. https://doi.org/10.3390/s140713243. 
Panissod, C., Michel, D., Hesse, A., Joivet, A., Tabbagh, J., Tabbagh, A., 1998. Recent developments in shallow depth electrical and electrostatic prospecting using mobile arrays. Geophysics 63 (5), 1542-1550.

Pedrera-Parrilla, A., Brevik, E.C., Van De Vijver, E., Espejo, A.J., Taguas, E.V., Giráldez, J.V., Martos, S., Vanderlinden, K., 2015. Effects of different topsoil properties on apparent electrical conductivity under varying soil water contents. Estudios en la Zona No Saturada 12, 25-32.

Pedrera-Parrilla, A., Van De Vijer, E., Van Meirvenne, M., Espejo-Pérez, A.J., Giráldez, J.V., Vanderlinden, K., 2016. Apparent electrical conductivity measurements in an olive orchard under wet and dry soil conditions: significance for clay and soil water content mapping. Precis. Agric. 17, 531-545. https://doi.org/10.1007/s11119-016-9435-z.

Pedrera-Parrilla, A., Pachepsky, Y.A., Taguas, E.V., Martos-Rosillo, S., Giráldez, J.V., Vanderlinden, K., 2017. Concurrent temporal stability of the apparent electrical conductivity and soil water content. J. Hydrol. 544, 319-326.

Peng, J., Biswas, A., Jiang, Q., Zhao, R., Hu, J., Hu, B., Shi, Z., 2019. Estimating soil salinity from remote sensing and terrain data in southern Xinjiang Province, China. Geoderma 337, 1309-1319. https://doi.org/10.1016/j.geoderma.2018.08.006.

Penuelas, J., Baret, F., Filella, I., 1995. Semiempirical indexes to assess carotenoids chlorophyll-a ratio from spectral reflectance. Photosynthetica 31, 221-230.

Peralta, N.R., Costa, J.L., 2013. Delineation of management zones with ssoil apparent electrical conductivity to improve nutrient management. Comput. Electron. Agric. 99, 218-226.

Peralta, N.R., Cicore, P.L., Marino, M.A., Marrques da Silva, J.R., Costa, J.L., 2015. Use of geophysical survey as a predator of the edaphic properties variability in soils used for livestock production. Spanish J. Agric. Res. 13 (4), e1103. https://doi.org/10.5424/sjar/ $2015134-8032$.

Piikki, K., Söderström, M., Stenverg, B., 2013. Sensor data fusion for topsoil clay mapping. Geoderma 199, 106-116.

Platonov, A., Noble, A., Kuziev, R., 2012. Soil salinity mapping using multi-temporal satellite images in agricultural fields of Syrdarya Province of Uzbekistan. In: Shahid, S.S., Abdelfattah, M.A., Taha, F.K. (Eds.), Developments in Soil Salinity AssessmentInnovative Thinking and Use of Marginal Soil and Water Resources in Irrigated Agriculture. Springer, Dordrecht, pp. 87-98. https://doi.org/10.1007/978-94-0075684-7.

Pognant, D., Canone, D., Previati, M., Ferraris, S., 2013. Using EM equipment to verify the presence of seepage losses in irrigation canals. Procedia Environ. Sci. 19, 836-845. https://doi.org/10.1016/j.proenv.2013.06.093.

Pozdnyakov, A.I., Eliseev, P.I., Pozdnyakov, L.A., 2015. Electrophysical approach to assessing some cultivation and fertility elecments of light soils in the humid zone. Eurasian Soil Sci. 48 (7), 726-734.

Qadir, M., Quillerou, E., Nangia, V., Murtaza, G., Singh, M., Thomas, R.J., Dreschsel, P., Noble, A.D., 2014. Economics of salt-induced land degradation and restoration. Natural Resour. Forum 38, 282-295.

Qu, Y.H., Duan, X.L., Gao, H.Y., Chen, A.P., An, Y.Q., Song, J.L., Zhou, H.M., He, T., 2009. Quantitative retrieval of soil salinity using hyperspectral data in the region of Inner Mongolia Hetao Irrigation District. Spectrosc. Spectr. Anal. 29 (5), 1362-1366. https:// doi.org/10.3964/j.issn.1000-0593(2009)05-1362-05.

Rahimian, M.H., Hasheminejhad, Y., 2011. Calibration of electromagnetic induction device (EM38) for soil salinity assessment. Iran. J. Soil Res. 24, 243-252.

Rallo, G., Provenzano, G., Castellini, M., Sirera, A.P., 2018. Application of EMI and FDR senssors to assess the fraction of transpirable soil water over an olive grove. Water 10, 168. https://doi.org/10.3390/w10020168. 
Rampant, P., Abuzar, M., 2004. Geophysical tools and digital elevation models: tools for understanding crop yield and soil variability. In: Proceedings of the SuperSoil 20043rd Australian New Zealand Soils Conference, Sydney, Australia, 5-9 Dec. 2004.

Ranjan, R.S., Karthigesu, T., Bulley, N.R., 1995. Evaluation of an Electromagnetic Method for Detecting Lateral Seepage Around Manure Storage Lagoons. ASAE Paper No. 952440, ASAE, St. Joseph, MI.

Rao, G.T., Gurunadha Rao, V.V.S., Padalu, G., Dhakate, R., Subramanya Sarma, V., 2014. Application of electrical resistivity tomography methods for delineation of groundwater contamination and potential zones. Arabian J. Geosci. 7 (4), 1373-1384.

Reece, C.F., 1998. Simple method for determining cable length resistance in time domain reflectometry systems. Soil Sci. Soc. Am. J. 62, 314-317.

Reedy, R.C., Scanlon, B.R., 2003. Soil water content monitoring using electromagnetic induction. J. Geotech. Geoenviron. Eng. 129, 1028-1039.

Rekha, P.N., Gangadharan, R., Pillai, S.M., Ramanathan, G., Panigrahi, A., 2012. Hyperspectral image processing to detect the soil salinity in coastal watershed. In: IEEEFourth International Conference on Advanced Computing. Anna University, Chennai, India. 13-15 Dec. 2012.

Rengasamy, P., 2006. World salinization with emphasis on Australia. J. Exp. Bot. 57 (5), 1017-1023.

Revil, A., Cathles, L.M., Losh, S., Nunn, J.A., 1998. Electrical conductivity in shaly sands with geophysical applications. J. Geophys. Res. 103 (B10), 23925-23936.

Revil, A., Karaoulis, M., Johnson, T., Kemna, A., 2012. Review: some low-frequency electrical methods for subsurface characterization and monitoring in hydrogeology. Hydrgeol. J. 20, 617-658.

Rezaei, M., Saey, T., Seuntjens, P., Joris, I., Boënne, W., Van Meirvenne, M., Cornelis, W., 2016. Predicting saturated hydraulic conductivity in a sandy grassland using proximally sensed apparent electrical conductivity. J. Appl. Geophys. 126, 35-41. https://doi.org/ 10.1016/j.jappgeo.2016.01.010.

Rhoades, J.D., 1981. Determining leaching fraction from field measurements of soil electrical conductivity. Agric. Water Manag. 3, 205-215.

Rhoades, J.D., 1992. Instrumental field methods of salinity appraisal. In: Topp, G.C., Reynolds, W.D., Green, R.E. (Eds.), Advances in Measurement of Soil Physical Properties: Bring Theory into Practice. Soil Science Society of America, Madison, WI, pp. 231-248. SSSA Special Publication No. 30.

Rhoades, J.D., 1993. Electrical conductivity methods for measuring and mapping soil salinity. In: Sparks, D.L. (Ed.), Advances in Agronomy. In: vol. 49. Academic Press, San Diego, CA, pp. 201-251.

Rhoades, J.D., 1996. Salinity: Electrical conductivity and total dissolved solids. In: Sparks, D.L. (Ed.), Methods of Soil Analysis: Part 3-Chemical Methods. In: SSSA Book Series No. 5 Soil Science Society of America, Madison, WI, pp. 417-435.

Rhoades, J.D., Corwin, D.L., 1981. Determining soil electrical conductivity-depth relations using an inductive electromagnetic soil conductivity meter. Soil Sci. Soc. Am. J. 45 (2), 255-260.

Rhoades, J.D., Corwin, D.L., 1990. Soil electrical conductivity: effects of soil properties and application to soil salinity appraisal. Commun. Soil Sci. Plant Anal. 21 (11 and 12), 837-860.

Rhoades, J.D., Halvorson, A.D., 1977. Electrical Conductivity Methods for Detecting and Delineating Saline Seeps and Measuring Salinity in Northern Great Plains Soils, ARS W-42. USDA-ARS Western Region, Berkeley, CA. 45 pp.

Rhoades, J.D., Ingvalson, R.D., 1971. Determining salinity in field soils with soil resistance measurements. Soil Sci. Soc. Am. Proc. 35, 54-60. 
Rhoades, J.D., Loveday, J., 1990. Salinity in irrigated agriculture. In: Stewart, B.A., Nielsen, D.R. (Eds.), Irrigation of Agricultural Crops. In: Agron. Monogr. No. 30, Soil Science Society of America, Madison, WI, pp. 1089-1142.

Rhoades, J.D., van Schilfgaarde, J., 1976. An electrical conductivity probe for determining soil salinity. Soil Sci. Soc. Am. J. 40, 647-650.

Rhoades, J.D., Raats, P.A.C., Prather, R.J., 1976. Effects of liquid-phase electrical conductivity, water content and surface conductivity on bulk soil electrical conductivity. Soil Sci. Soc. Am. J. 40, 651-655.

Rhoades, J.D., Manteghi, N.A., Shouse, P.J., Alves, W.J., 1989a. Estimating soil salinity from saturated soil-paste electrical conductivity. Soil Sci. Soc. Am. J. 53 (2), 428-433.

Rhoades, J.D., Manteghi, N.A., Shouse, P.J., Alves, W.J., 1989b. Soil electrical conductivity and soil salinity: new formulations and calibrations. Soil Sci. Soc. Am. J. 53 (2), 433-439.

Rhoades, J.D., Shouse, P.J., Alves, W.J., Manteghi, N.M., Lesch, S.M., 1990a. Determining soil salinity from soil electrical conductivity using different models and estimates. Soil Sci. Soc. Am. J. 54, 46-54.

Rhoades, J.D., Corwin, D.L., Lesch, S.M., 1990b. Effect of soil ECa-depth profile patterns on electromagnetic induction measurements. Research Report No. 125. USDA-ARS. U.S. Salinity Laboratory, Riverside, CA.

Rhoades, J.D., Lesch, S.M., LeMert, R.D., Alves, W.J., 1997. Assessing irrigation/drainage/ salinity management using spatially referenced salinity measurements. Agric. Water Manag. 35, 147-165.

Rhoades, J.D., Chanduvi, F., Lesch, S., 1999a. Soil Salinity Assessment: Methods and Interpretation of Electrical Conductivity Measurements, FAO Irrigation and Drainage Paper \#57. Food and Agriculture Organization of the United Nations, Rome, Italy.

Rhoades, J.D., Corwin, D.L., Lesch, S.M., 1999b. Geospatial measurements of soil electrical conductivity to assess soil salinity and diffuse salt loading from irrigation. In: Corwin, D.L., Loague, K., Ellsworth, T.R. (Eds.), Assessment of Non-Point Source Pollution in the Vadose Zone. In: Geophysical Monograph, 108, American Geophysical Union, Washington, DC, pp. 197-215.

Richardson, A.J., Wiegand, C.L., 1977. Distinguishing vegetation from soil background information. Eng. Remote Sens. 43, 1541-1542.

Robinet, J., von Hebel, C., Govers, G., van der Kruk, J., Minella, J.P.G., Schlesner, A., Ameijeiras-Mariño, Y., Vanderborght, J., 2018. Spatial variability of soil water content and soil electrical conductivity across scales derived from electromagnetic induction and time domain reflectometry. Geoderma 314, 160-174.

Robinson, D.A., Abdu, H., Jones, S.B., Seyfried, M., Lebron, I., Knight, R., 2008. Ecogeophysical imaging of watershed-scale soil pattern links with plant community spatial patterns. Vadose Zone J. 7, 1132-1138.

Robinson, D.A., Lebron, I., Kocar, B., Phan, K., Sampson, M., Crook, N., Fendorf, S., 2009. Time-lapse geophysical imaging of soil moisture dynamics in tropical deltaic soils: an aid to interpreting hydrological and geochemical processes. Water Resour. Res. 45, W00D32. https://doi.org/10.1029/2008WR006984.

Robinson, D.A., Lebron, I., Querejeta, J.I., 2010. Determining soil-tree-grass relationships in a California oak savanna using eco-geophysics. Vadose Zone J. 9, 528-536.

Robinson, D.A., Abdu, H., Lebron, I., Jones, S.B., 2012. Imaging of hill-slope soil moisture wetting patterns in a semi-arid oak savanna catchment using time-lapse electromagnetic induction. J. Hydrol. 416, 39-49.

Rodrigues Jr., F.A., Bramley, R.G.V., Gobbett, D.L., 2015. Proximal soil sensing for precision agriculture: simultaneous use of electromagnetic induction and gamma radiometrics in contrasting soils. Geoderma 243-244, 183-195. https://doi.org/10.1016/ j.geoderma.2015.01.004. 
Rodríguez, R.A., Leiva, F.R., Gomez, M.I., 2015. Homogeneous zones for site-specific management in maize using electromagnetic induction sensor at the Bogota Sabana. Revista U.D.C.A Actualidad \& Divulgación Científica 18 (2), 373-383.

Rodríguez-Pérez, J.R., Plant, R.E., Lambert, J.J., Smart, D.R., 2011. Using apparent soil electrical conductivity $\left(\mathrm{EC}_{\mathrm{a}}\right)$ to characterize vineyard soils of high clay content. Precis. Agric. 12, 775-794.

Rossi, R., Amato, M., Bitella, G., Biochicchio, R., Ferreira Gomes, J.J., Lovelli, S., et al., 2010. Electrical resistivity tomography as a non-destructive method for mapping root biomass in an orchard. Eur. J. Soil Sci. 62, 206-215.

Rossi, R., Amato, M., Pollice, A., Bitella, G., Gomes, J.J., Bochicchio, R., Baronti, S., 2013. Electrical resistivity tomography to detect the effects of tillage in a soil with a variable rock fragment content. Eur. J. Soil Sci. 64, 239-248. https://doi.org/10.1111/ ejss. 12024.

Rouse, J., Haas, R., Schell, J., Deering, D., 1973. Monitoring vegetation systems in the Great Plains with ERTS. In: Third ERTS Symposium. NASA SP-351, pp. 309-317.

Rouse, J.W., Haas, R.H., Schell, J.A., Deering, D.W., Harlan, J.C., 1974. Monitoring the Vernal Advancement or Retrogradation of Natural Vegetation. NASA/GSFC, Type III, Final Report. Greenbelt, MD, p. 371.

Rudolph, S., van der Kruk, J., von Hebel, C., Ali, M., Herbst, M., Montzka, C., Pätzold, S., Robinson, D.A., Vereecken, H., Weihermüller, L., 2015. Linking satellite derived LAI patterns with subsoil heterogeneity using large-scale ground-based electromagnetic inductiton measurements. Geoderma 241-242, 262-271. https://doi.org/10.1016/ j.geoderma.2014.11.015.

Saey, T., Simpson, D., Vitharana, U.W.A., Vermeersch, H., Vermang, J., Van Meirvenne, M., 2008. Reconstructing the paleotopography beneath the loess cover with the aid of an electromagnetic induction sensor. Catena 74, 58-64.

Saey, T., Van Meirvenne, M., Vermeersch, H., Ameloot, N., Cockx, L., 2009a. A pedotransfer function to evaluate the soil profile textural heterogeneity using proximally sensed apparent electrical conductivity. Geoderma 150, 389-395.

Saey, T., Simpson, D., Vermeersch, H., Cockx, L., Van Meirvenne, M., 2009b. Comparing the EM38DD and DUALEM-21S sensors for depth-to-clay mapping. Soil Sci. Soc. Am. J. 73 (1), 7-12.

Saey, T., Van Meirvenne, M., De Smedt, P., Cockx, L., Meerschman, E., Islam, M.M., Meeuws, F., 2011. Mapping depth-to-clay using fitted multiple depth response curves of a proximal EMI sensor. Geoderma 162, 151-158.

Saey, T., De Smedt, P., Islam, M.M., Meerschman, E., Van De Vijer, E., Lehouck, A., Van Meirvenne, M., 2012a. Depth slicing of multi-receiver EMI measurements to enhance the delineation of contrasting subsoil features. Geoderma 189-190, 514-521.

Saey, T., Islam, M.M., De Smedt, P., Meerschman, E., Van Der Vijver, E., Lehouck, A., Van Meirvenne, M., 2012b. Using a multi-receiver survey of apparent soil electrical conductivity to reconstruct a Holocene tidal channel in a polder area. Catena 95, 104-111.

Saey, T., De Smedt, P., Delefortrie, S., Van De Vijver, E., Van Meirvenne, M., 2015. Comparing one- and two-dimensional EMI conductivity inverse modeling procedures for characterizing a two-layered soil. Geoderma 241-242, 12-23.

Salama, R.B., Bartle, G., Farrington, P., Wilson, V., 1994. Basin geomorphological controls on the mechanism of recharge and discharge and its effect on salt storage and mobilization-comparative study using geophysical surveys. J. Hydrol. 155, 1-26.

Samake, O., Smaling, E.M.A., Kropff, M.J., Stomph, T.J., Kodio, A., 2005. Effects of cultivation practices on spatial variation of soil fertility and millet yields in the Sahel of Mali. Agric. Ecosyst. Environ. 109, 335-345. 
Scanlon, B.R., Paine, J.G., Goldsmith, R.S., 1999. Evaluation of electromagnetic induction as a reconnaissance technique to characterize unsaturated flow in an arid setting. Ground Water 37 (2), 296-304.

Schmidhalter, U.A., Zintel, A., Neudecker, E., 2001. Calibration of electromagnetic induction measurements to survey the spatial variability of soils. In: Proceedings of the 3rd European Conference on Precision Agriculture, Montpellier, France, 18-20 June 2001, pp. 479-484.

Schumann, A., Zaman, Q., 2003. Mapping water table depth by electromagnetic induction. Appl. Eng. Agric. 19, 675-688.

Schwartz, B.F., Schreiber, M.E., Yan, T., 2008. Quantifying field-scale soil moisture using electrical resistivity imaging. J. Hydrol. 362, 234-246.

Scudiero, E., Deiana, R., Teatini, P., Cassiani, G., Morari, F., 2011. Constrained optimization of spatial sampling in salt contaminated coastal farrmland using EMI and continuous simulated annealing. Procedia Environ. Sci. 7, 234-239.

Scudiero, E., Teatini, P., Corwin, D.L., Delana, R., Berti, A., Morari, F., 2013. Delineation of site-specific management units in a saline region of Venice Lagoon, Italy using soil reflectance and apparent soil electrical conductivity. Comput. Electron. Agric. 99, 54-64.

Scudiero, E., Skaggs, T.H., Corwin, D.L., 2014a. Regional scale soil salinity evaluation using Landsat 7, Western San Joaquin Valley, California, USA. Geoderma Reg. 2-3, 82-90.

Scudiero, E., Teatini, P., Corwin, D.L., Ferro, N.D., Simonetti, G., Morari, F., 2014b. Spatiotemporal response of maize yield to edaphic and meteorological conditions in a saline farmland. Agron. J. 106, 2163-2174. https://doi.org/10.2134/agronj14.0102.

Scudiero, E., Skaggs, T.H., Corwin, D.L., 2015. Regional-scale soil salinity assessment using Landsat ETM + canopy reflectance. Remote Sens. Environ. 169, 335-343. https://doi. org/10.1016/j.rse.2015.08.026.

Scudiero, E., Lesch, S.M., Corwin, D.L., 2016a. Validation of sensor-directed spatial simulated annealing soil sampling strategy. J. Environ. Qual. 45, 1226-1233. https://doi.org/ 10.2134/jeq2015.09.0458.

Scudiero, E., Corwin, D.L., Anderson, R.G., Skaggs, T.H., 2016b. Moving forward on mapping and monitoring soil salinity at the regional-scale with remote sensing. Front. Environ. Sci. 4, 1-5. https://doi.org/10.3389/fenvs.2016.00065.

Scudiero, E., Corwin, D.L., Anderson, R.G., Yemoto, K., Clafry, W., Wang, Z.L., Skaggs, T.H., 2017. Remote sensing is a valuable tool for mapping soil salinity in agricultural lands. Calif. Agric. 71 (2), 1-8. https://doi.org/10.3733/ca.2017a0009.

Séger, M., Cousin, I., Frison, A., Boizard, H., Ricard, G., 2009. Characterization of the structural heterogeneity of the soil tilled layer by using in situ 2D and 3D electrical resistivity measurements. Soil Tillage Res. 103, 387-398.

Segundo, A.K.R., Martins, J.H., Monteiro, P.M.B., de Oliveira, R.A., Freitas, G.M., 2015. A novel low-cost instrumentation system for measuring the water content and apparent electrical conductivity of soils. Sensors 15, 25546-25563. https://doi.org/10.3390/ s151025546.

Seladji, S., Cosenza, P., Tabbagh, A., Ranger, J., Richard, G., 2010. The effect of compaction on soil electrical resistivity: a laboratory investigation. Eur. J. Soil Sci. 61, 1043-1055.

Serrano, J.M., Peca, J.O., Marques da Silva, J.R., Shaidian, S., 2010. Mapping soil and pasture variability with an electromagnetic induction sensor. Comput. Electron. Agric. 73, 7-16.

Serrano, J.M., Shahidian, S., Marques da Silva, J.R., 2012. Apparent electrical cconductivity in dry versus wet soil conditions in a shallow soil. Precis. Agric. 14 (1), 99-114. https:// doi.org/10.1007/s11119-012-9281-6.

Serrano, J.M., Shahidian, S., Marques da Silva, J.R., 2013. Small scale soil variation and its effect on pasture yield in southern Portugal. Geoderma 195-196, 173-183. https://doi. org/10.1016/j.geoderma.2012.12.001. 
Serrano, J.M., Shahidian, S., Marques da Silva, J.R., 2014. Spatial and temporal patterns of apparent electrical conductivity: DUALEM vs. Veris sensors for monitoring soil properties. Sensors 14, 10024-10041. https://doi.org/10.3390/s140610024.

Shainberg, I., Rhoades, J.D., Prather, R.J., 1980. Effect of exchangeable sodium percentage, cation exchange capacity, and soil solution concentration on soil electrical conductivity. Soil Sci. Soc. Am. J. 44, 469-473.

Shamsi, S.R.F., Zare, S., Abtahi, S.A., 2013. Soil; salinity characteristics using moderate resolution imaging spectroradiometer (MODIS) images and statistical analysis. Arch. Agron. Soil Sci. 59 (4), 471-489. https://doi.org/10.1080/03650340.2011.646996.

Shanahan, P.W., Binley, A., Whalley, W.R., Watts, C.W., 2015. The use of electromagnetic induction to monitor changes in soil moisture profiles beneath different wheat genotypes. Soil Sci. Soc. Am. J. 79, 459-466. https://doi.org/10.2136/sssaj2014.09.0360.

Shaner, D.L., Khosla, R., Brodahl, M.K., Buchleiter, G.W., Farahani, H.J., 2008a. How well does zone sampling based on soil electrical conductivity maps represent soil variability? Agron. J. 100 (5), 1472-1480.

Shaner, D.L., Farahani, H.J., Buchleiter, G.W., 2008b. Predicting and mapping herbicidesoil partition coefficients for EPTC, metribuzin, and metolachlor on three Colorado fields. Weed Sci. 56, 133-139.

Shao, Y., Hu, Q., Guo, H., Lu, Y., Dong, Q., Chunming, H., 2003. Effect of dielectric properties of moist salinized soils on backscattering coefficients extracted from RADARSAT image. IEEE Trans. Geosci. Remote Sens. 41 (8), 1879-1888. https:// doi.org/10.1109/TGRS.2003.813499.

Shatar, T.M., McBratney, A.B., 2004. Boundary-line analysis of field-scale yield response to soil properties. J. Agric. Sci. 142 (5), 553-560.

Sheets, K.R., Hendrickx, J.M.H., 1995. Non-invasive soil water content measurement using electromagnetic induction. Water Resour. Res. 31, 2401-2409.

Sheets, K.R., Taylor, J.P., Hendrickx, J.M.H., 1994. Rapid salinity mapping by electromagnetic induction for determining riparian restoration potential. Restor. Ecol. 2, 242-246.

Sherlock, M.D., McDonnell, J.J., 2003. A new tool for hillslope hydrologists: spatially distributed groundwater level and soil water content measured using electromagnetic induction. Hydrol. Process. 17, 1965-1977.

Shoshany, M., Goldshleger, N., Chudnovsky, A., 2013. Monitoring of agricultural soil degradation by remote-sensing methods: a review. Int. J. Remote Sens. 34 (17), 6152-6181. https://doi.org/10.1080/01431161.2013.793872.

Shrestha, R.P., 2006. Relating soil electrical conductivity to remote sensing and other soil properties for assessing soil salinity in Northeast Thailand. Land Degrad. Dev. 17, 677-689. https://doi.org/10.1002/ldr.752.

Shrestha, D.P., Margate, D.E., van der Meer, F., Anh, H.V., 2005. Analysis and classification of hyperspectral data for mapping land degradation: an application in southern Spain. Int. J. Appl. Earth Obs. Geoinf. 7, 85-96. http://da.doi.org/10.1016/j.jag. 2005.01.001.

Sidike, A., Zhao, S., Wen, Y., 2014. Estimating soil salinity in Pingluo County of China using QuickBird data and soil reflectance spectra. Int. J. Appl. Earth Obs. Geoinf. 26, 156-175. https://doi.org/10.1016/j.jag.2013.06.002.

Singh, G., Bundela, D.S., Sethi, M., Lal, K., Kamra, S.K., 2010. Remote sensing and geographic information system for appraisal of salt-affected soils in Indi. J. Environ. Qual. 39, 5-15. https://doi.org/10.2134/jeq2009.0032.

Siqueira, G.M., Dafonte, J.D., Lema, J.B., Armesto, M.V., Silva, E.F.F., 2014. Using soil apparent electrical conductivity to optimize sampling of soil penetration resistance and to improve the estimations of spatial patterns of soil compaction. ScientificWorldJournal 2014, Article ID 269480. https://doi.org/10.1155/2014/269480. 
Siri-Prieto, G., Reeves, D.W., Shaw, J.N., Mitchell, C.C., 2006. World's oldest cotton experiment: relathionships between soil chemical and physical properties and apparent electrical conductivity. Commun. Soil Sci. Plant Anal. 37, 767-786.

Sivanpillai, R., Claypool, D.A., Siloju, R., 2012. Relating AEROCam-derived NDVI to apparent soil electrical conductivity $\left(\mathrm{EC}_{\mathrm{a}}\right)$ for corn fields in Wyoming, USA. Remote Sens. Lett. 3 (1), 49-56. https://doi.org/10.1080/01431161.2010.533296.

Slavich, P.G., 1990. Determining $\mathrm{EC}_{\mathrm{a}}$-depth profiles from electromagnetic induction measurements. Aust. J. Soil. Res. 28, 443-452.

Slavich, P.G., Petterson, G.H., 1990. Estimating average rootzone salinity from electromagnetic induction (EM-38) measurements. Aust. J. Soil. Res. 28, 453-463.

Slavich, P.G., Yang, J., 1990. Estimation of field-scale leaching rates from chloride mass balance and electromagnetic induction measurements. Irrig. Sci. 11, 7-14.

Smith-Rose, R.L., 1933. The electrical properties of soil for alternating currents at radio frequencies. Proc. R. Soc. London 140, 359-377.

Soliman, A.S., Farshad, A., Sporry, R.J., Shrestha, D.P., 2004. Predicting salinization in its earaly stage, using electromagnetic data and geostatistical techniques. In: Proceedings of the 25th Asian Conference on Remote Sensing, Chiang Mai, Thailand, 22-26 Nov. 2004.

Sommer, M., Wehrhan, M., Zipprich, M., Weller, U., zu Castell, W., Ehrich, S., Tandler, B., Selige, T., 2003. Hierarchical data fusion for mapping soil units at field scale. Geoderma 112, 179-196.

Sørenson, K., 1996. Pulled array continuous profiling. First Break 14 (3), 85-90.

Spaans, E.J.A., Baker, J.M., 1993. Simple baluns in parallel probes for time domain reflectometry. Soil Sci. Soc. Am. J. 57, 668-673.

Squires, V.R., Glenn, E.P., 2009. Salination, desertification, and soil erosion. In: Squires, V.R. (Ed.), The Role of Food, Agriculture, Forestry and Fisheries in Human Nutrition. In: Encyclopedia of Life Support Systems, vol. III. EOLSS Publishers, Oxford, UK, pp. 102-123.

Sreenivas, K., Venkataratnam, L., Rao, P.V.N., 1995. Dielectric properties of salt-affected soils. Int. J. Remote Sens. 16, 641-649.

SriRanjan, R., Karthigesu, T., 1995. Evaluation of an Electromagnetic Method for Detecting Lateral Seepage Around Manuare Storage Lagoons. ASAE Paper No. 952440, ASAE, St. Joseph, MI.

Stadler, A., Rudolph, S., Kupisch, M., Langensiepen, M., van der Kruk, J., Ewert, F., 2015. Quantifying the effects of soil variability on crop growth using apparent soil electrical conductivity measurements. Eur. J. Agron. 64, 8-20.

Stepień, M., Samborski, S., Gozdowski, D., Dobers, E.S., Chormański, J., Szatylowicz, J., 2015. Assessment of soil texture class on agricultural fields using $\mathrm{EC}_{\mathrm{a}}$, amber NDVI, and topographic properties. J. Plant Nutr. Soil Sci. 178 (3), 523-536. https://doi.org/ 10.1002/jpln.201400570.

Strachan, I.B., Pattey, E., Boisvert, J.B., 2002. Impact of nitrogen and environmental conditions on corn as detected by hyperspectral reflectance. Remote Sens. Environ. 80, 213-224.

Stroh, J.C., Archer, S., Doolittle, J.A., Wilding, L., 2001. Detection of edaphic discontinuities with ground penetrating radar and electromagnetic induction. Landsc. Ecol. 16, 377-390.

Sudduth, K.A., Kitchen, N.R., 1993. Electromagnetic induction sensing of claypan depth. In: ASAE Paper No. 931531, 1993 ASAE Winter Meetings, 12-17 Dec. 1993, Chicago, IL. ASAE, St, Joseph, MI.

Sudduth, K.A., Kitchen, N.R., Drummond, S.T., 1999. Soil conductivity sensing on claypan soils: comparison of electromagnetic induction and direct methods. In: Robert, P.C., Rust, R.H., Larson, W.E. (Eds.), Proceedings of the Fourth International Conference on Precision Agriculture. ASA-CSSA-SSSA, Madison, WI, pp. 979-990. St. Paul, MN, July 19-22, 1998. 
Sudduth, K.A., Kitchen, N.R., Bollero, G.A., Bullock, D.G., Wiebold, W.J., 2003. Comparison of electromagnetic induction and direct sensing of soil electrical conductivity. Agon. J. 95, 472-482. https://doi.org/10.2134/agronj2003.0472.

Sudduth, K.A., Kitchen, N.R., Wiebold, W.J., Batchelor, W.D., Bollero, G.A., Bullock, D.G., Clay, D.E., Palm, H.L., Pierce, F.J., Schuler, R.T., Thelen, K.D., 2005. Relating apparent electrical conductivity to soil properties across the north-central USA. Comput. Electron. Agric. 46, 263-283.

Sudduth, K.A., Kitchen, N.R., Myers, D.B., Drummond, S.T., 2010. Mapping depth to argillic soil horizons using apparent electrical conductivity. J. Environ. Eng. Geophys. $15,135-146$.

Sudduth, K.A., Myers, D.B., Kitchen, N.R., Drummond, S.T., 2013. Modeling soil electrical conductivity-depth relationships with data from proximal and penetrating $\mathrm{EC}_{\mathrm{a}}$ sensors. Geoderma 199, 12-21.

Sun, Y., Druecker, H., Hartung, E., Hueging, H., Cheng, Q., Zeng, Q., Sheng, W., Lin, J., Roller, O., Paetzoid, S., Schulze Lammers, P., 2011a. Map-based investigation of soil physical conditions and crop yield using diverse sensor techniques. Soil Tillage Res. 112 (2), 149-158.

Sun, Y., Caixia, C., Lin, J., Cheng, Q., Meng, F., Li, D., 2011b. A case study of EM38 for characterizing topsoil thickness in a reclaimed field. J. Chin. Inst. Eng. 34 (6), 843-847.

Sun, Y., Cheng, Q., Lin, J., Schellberg, J., Lammers, P.S., 2013. Investigating soil physical properties and yield response in a grassland field using a dual-sensor penetrometer and EM38. J. Plant Nutr. Soil Sci. 176, 209-216.

Szabolcs, I., 1989. Salt-Affected Soils. CRC Press, Boca Raton, FL.

Szabolcs, I., 1992. Salinization of soils and water and its relation to desertification. Desertification Control Bull. 21, 32-37.

Taghizadeh-Mehrjardi, R., Minasny, B., Sarmadian, F., Malone, B.P., 2014. Digital mapping of soil salinity in Ardakan Region, Central Iran. Geoderma 213, 15-28. https:// doi.org/10.1016/j.geoderma.2013.07.020.

Tanji, K.K., 1996. Nature and extent of agricultural salinity. In: Tanji, K.K. (Ed.), Agricultural Salinity Assessment and Management, first ed. ASCE, New York, NY, pp. 1-17.

Tanji, K.K., 2002. Salinity in the soil environment. In: Lauchli, A., Luttge, U. (Eds.), Salinity: Environment-Plants-Molecules. Kluwer Academic Publishers, The Netherlands, pp. 21-51.

Taylor, G., Dehaan, R., 2000. Salinity mapping with hyperspectral imagery. In: Taylor, G. (Ed.), 14th Internatiojnal Conference, Applied Geologic Remote Sensing. Springer, The Netherlands, pp. 512-519.

Taylor, G.R., Bennett, B.A., Mah, A.H., Hewson, R.D., 1994. Spectral properties of salinised land and implications for interpretation of 24 channel imaging spectrometry. In: Proc. First International Remote Sensing Conference and Exhibition, Strasbourg, France. vol. 3, pp. 504-513.

Taylor, G.R., Mah, A.H., Kruse, F.A., Kierein-Young, K.S., Hewson, R.D., Bennett, B.A., 1995. The extraction of dielectric properties of saline soils from AIRSAR and SIR-C imagery. In: Milne, A.K. (Ed.), Proceedings of the International Workshop on Radar Image Processing and Applications. University of NSW, Sydney, Australia.

Taylor, G.R., Mah, A.H., Kruse, F.A., Kierein-Young, K.S., Hewson, R.D., Bennett, B.A., 1996. Characterization of saline soils using airborne radar imagery. Remote Sens. Environ. 57 (3), 127-142.

Teggi, S., Costanzini, S., Despini, F., Chiodi, P., Immordino, F., 2012. SPOT5 imagery for soil salinity assessment in Iraq. In: Civco, D.L., Ehlers, M., Habib, S., Maltese, A., Messinger, D., Michel, U., Nikolakopoulos, K.G., Schulz, K. (Eds.), Earth Resources and Environmental Remote Sensing/GIS Appllications III. In: Proc. SPIE, vol. 8538. The International Society for Optical Engineering, pp. 85380V-1-85380V-12. https://doi.org/10.1117/12.974498. 
Telford, W.M., Gledart, L.P., Sheriff, R.E., 1990. Applied Geophysics, second ed. Cambridge University Press, Cambridge, UK.

Terrón, J.M., Marques da Silva, J.R., Moral, F.J., García-Ferrer, A., 2011. Soil apparent electrical conductivity and geographically weighted regression for mapping soil. Precis. Agric. 12, 750-761.

Thiessen, J., Rousselle, G., Simon, F.X., Tabbagh, A., 2011. Slingram EMI prospection: are vertical oriented devices a suitable solution in archaeological and pedological prospection? J. Appl. Geophys. 75, 731-737.

Thomas, M., Fitzpatrick, R.W., Heinson, G.S., 2009. Distribution and causes of intricate saline-sodic soil patterns in an upland South Australian hillslope. Aust. J. Soil. Res. 47, 328-339.

Thorhaug, A., Richardson, A.D., Berlyn, G.P., 2006. Spectral reflectance of Thalassia tesudinum (Hydrocharitaceae) seagrass: low salinity effects. Am. J. Bot. 93, 110-117.

Tilley, D.R., Ahmed, M., Son, J.H., Badrinarayanan, H., 2007. Hyperspectral reflectance response of freshwater macrophytes to salinity in a brackish subtropical marsh. J. Environ. Qual. 36, 780-789.

Topp, G.C., Davis, J.L., 1981. Detecting infiltration of water through the soil cracks by time-domain reflectometry. Geoderma 26, 13-23.

Topp, G.C., Davis, J.L., Annan, A.P., 1980. Electromagnetic determination of soil water content: measurement in coaxial transmission lines. Water Resour. Res. $16,574-582$.

Topp, G.C., Davis, J.L., Annan, A.P., 1982. Electromagnetic determination of soil water content using TDR: I. Applications to wetting fronts and steep gradients. Soil Sci. Soc. Am. J. 46, 672-678.

Toth, T., Csillag, F., Biehl, L.L., Michéli, E., 1991. Characterization of semivegetated salt-affected soils by means of field remote sensing. Remote Sens. Environ. 37, 167-180.

Travelletti, J., Sailhac, P., Malet, J.-P., Grandjean, G., Ponton, J., 2012. Hydrological response of weathered clay-shale slopes: water infiltration monitoring with time-lapse electrical resistivity tomography. Hydrol. Process. 26, 2106-2119. https://doi.org/ 10.1002/hyp.7983.

Triantafilis, J., Buchanan, S.M., 2009. Identifying common near-surface and subsurface stratigraphic units using EM34 signal data and fuzzy k-means analysis in the Darling River Valley. Aust. J. Earth Sci. 56, 535-556.

Triantafilis, J., Buchanan, S.M., 2010. Mapping the spatial distribution of subsurface saline material in the Darling River Valley. J. Appl. Geophys. 70, 144-160.

Triantafilis, J., Lesch, S.M., 2005. Mapping clay content variation using electromagnetic induction techniques. Comput. Electron. Agric. 46 (1-3), 203-237.

Triantafilis, J., Monteiro Santos, F.A., 2010a. Resolving the spatial distribution of the true electrical conductivity with depth using EM38 and EM31 signal data and a laterally constrained inverse model. Aust. J. Soil. Res. 48, 434-446. https://doi.org/10.1071/ SR09149.

Triantafilis, J., Monteiro Santos, F.A., 2010b. 2-Dimensional soil and vadose-zone representation using an EM38 and EM34 and a laterally constrained inversion model. Aust. J. Soil. Res. 47, 809-820.

Triantafilis, J., Monteiro Santos, F.A., 2013. Electromagnetic conductivity imaging (EMCI) of soil using a DUALEM-421 and inversion modelling software (EM4Soil). Geoderma 211-212, 28-38. https://doi.org/10.1016/j.geoderma.2013.06.001.

Triantafilis, J., Laslett, G.M., McBratney, A.B., 2000. Calibrating an electromagnetic induction instrument to measure salinity in soil under irrigated cotton. Soil Sci. Soc. Am. J. 64, 1009-1017.

Triantafilis, J., Odeh, I.O.A., McBratney, A.B., 2001a. Five geostatistical models to predict soil salinity from electromagnetic induction data across irrigated cotton. Soil Sci. Soc. Am. J. 65, 869-878. 
Triantafilis, J., Huckel, A.I., Odeh, I.O.A., 2001b. Comparison of statistical prediction methods for estimating field-scale clay content using different combinations of ancillary variables. Soil Sci. 166 (6), 415-427.

Triantafilis, J., Ahmed, M.F., Odeh, I.O.A., 2002. Application of a mobile electromagnetic sensing system (MESS) to assess cause and management of soil salinization in an irrigated cotton-growing field. Soil Use Manage. 18 (4), 330-339.

Triantafilis, J., Huckel, A.I., Odeh, I.O.A., 2003. Field-scale assessment of deep drainage risk. Irrig. Sci. 21, 183-192.

Triantafilis, J., Odeh, I.O.A., Jarmen, A.L., Short, M.G., Kokkoris, E., 2004. Estimating and mapping deep drainage risk at the district level in the lower Gwydir and Macquarie Valleys, Australia. Aust. J. Exp. Agric. 44, 893-912.

Triantafilis, J., Lesch, S.M., La Lau, K., Buchanan, S.M., 2009. Field level digital soil mapping of cation exchange capacity using electromagnetic induction and a hierarchical spatial regression model. Aust. J. Soil. Res. 47, 651-663.

Triantafilis, J., Roe, J.A.E., Monteiro Santos, F.A., 2011. Detecting a leachate plume in an aeolian sand landscape using DUALEM-421 induction probe to measure electrical conductivity followed by inversion modelling. Soil Use Manage. 27, 357-366.

Tripatthi, N.K., Brijesh, K.R., Dwivedi, P., 1997. Spatial modeling of soil alkalinity in GIS environment using IRS data. Geospat. World. Available online https://www. geospatialworld.net/article/spatial-modelling-of-soil-alkalinity-in-gis-environment-usingirs-data/. Accessed 16 July 2018 [Accessed 16 July 2018].

Tromp-van Meerveld, H.J., McDonnell, J.J., 2009. Assessment of multi-frequency electromagnetic induction for determining soil moisture patterns at the hillslope scale. J. Hydrol. 368 (1-4), 56-67.

Tucker, C.J., 1979. Red and photographic infrared linear combinations for monitoring vegetation. Remote Sens. Environ. 8 (2), 127-150.

Tucker-Kulesza, S., Sassenrath, G.F., Tran, T., Koehn, W., Erickson, L., 2017. Site-specific erodibility in claypan soils: dependence of subsoil characteristics. Appl. Eng. Agric. 33 (5), 705-718.

Tycholiz, C., Ferguson, I.J., Sherriff, B.L., Cordeiro, M., Sri Ranjan, R., Pérez-Flores, M.A., 2016. Geophysical delineation of acidity and salinity in the Central Manitoba gold mine tailings pile, Manitoba, Canada. J. Appl. Geophys. 131, 29-40.

Tye, A.M., Kessler, H., Ambrose, K., Williams, J.D.O., Tragheim, D., Scheib, A., Raines, M., Kuras, O., 2011. Using integrated near-surface geophysical surveys to aid mapping and interpretation of geology in an alluvial landscape within a 3D soil-geology framework. Near Surf. Geophys. 9 (1), 15-31. https://doi.org/10.3997/1873-0604.2010038.

U.S. Salinity Laboratory Staff, 1954. USDA Handbook No. In: 60-Diagnosis and Improvement of Saline and Alkali Soils. U.S. Government Printing Office, Washington, DC.

University of California-Davis, 2009. The Economic Impacts of Central Valley Salinity. Final Report to the State Water Resources Control Board. Available online at https://www. waterboards.ca.gov/rwqcb5/water_issues/salinity/library_reports_programs/econ_rpt_ final.pdf. (verified 7 Sept. 2018).

Urdanoz, V., Aragüés, R., 2011. Pre- and post-irrigation mapping of soil salinity with electromagnetic induction techniques and relationships with drainage water salinity. Soil Sci. Soc. Am. J. 75, 207-215.

Urdanoz, V., Aragüés, R., 2012. Comparison of Geonics EM38 and Dualem 1S electromagnetic induction sensors for the measurement of salinity and other soil properties. Soil Use Manage. 28, 108-112.

Urdanoz, V., Amezketa, E., Clavería, I., Ochoa, V., Aragüés, R., 2008. Mobile and georeferenced electromagnetic sensors and applications for salinity assessment. Span. J. Agric. Res. 6 (3), 469-478. 
Uribeetxebarria, A., Arnó, J., Escolà, A., Martínez-Casasnovas, J.A., 2018. Apparent electrical conductivity and multivariate analysis of soil properties to assess soil constraints in orchards affected by previous parceling. Geoderma 319, 185-193. https://doi.org/ 10.1016/j.geoderma.2018.01.008.

Valente, D.S.M., De Queiroz, D.M., Pinto, F.A.C., Santos, F.L., Santos, N.T., 2014. Spatial variability of apparent electrical conductivity and soil properties in a coffee production field. Eng. Agric. Jaboticabal 34 (6), 1224-1233.

van der Lelij, A., 1983. Use of an Electromagnetic Induction Instrument (Type EM38) for Mapping of Soil Salinity: Internal Report Research Branch. Water Resources Commission, NSW, Australia.

Van Groenigen, J.W., Siderius, W., Stein, A., 1999. Constrained optimisation of soil sampling for minimisation of the kriging variance. Geoderma 87, 239-259.

Van Groenigen, J.W., Pieters, G., Stein, A., 2000. Optimizing spatial sampling for multivariate contamination in urban areas. Environmetrics 11, 227-244.

Varvel, G.E., Schlemmer, M.R., Schepers, J.S., 1999. Relationship between spectral data from an aerial image and soil organic matter and phosphorus levels. Prec. Agric. 1 (3), 291-300.

Vaughan, P.J., Lesch, S.M., Corwin, D.L., Cone, D.G., 1995. Water content effect on soil salinity prediction: a geostatistical study using cokriging. Soil Sci. Soc. Am. J. 59, 1146-1156.

Verma, K.S., Saxena, R.K., Barthwal, A.K., Deshmukh, S.N., 1994. Remote sensing techniques for mapping salt affected soils. Int. J. Remote Sens. 15 (9), 1901-1914. https:// doi. org/10.1080/01431169408954215.

Vervoort, R.W., Annen, Y.L., 2006. Paleochannels in Northern New South Wales: inversion of electromagnetic induction data to infer hydrologically relevant stratigraphy. Aust. J. Soil. Res. 44, 35-45.

Viezzoli, A., Tosi, L., Teatini, P., Silvestri, S., 2010. Surface water-groundwater exchange in transitional coastal environments by sirborne electromagnetics: the Venice Lagoon example. Geophys. Res. Lett. 37 L01402https://doi.org/10.1029/2009GL041572.

Viscarra Rossel, R., Lobsey, C., 2016. Scoping Review of Proximal Soil Sensors for Grain Growing. CSIRO, Australia.

Viscarra Rossel, R.A., Adamchuk, V.I., Sudduth, K.A., McKenzie, N.J., Lobsey, C., 2011. Proximal soil sensing: an effective approach for soil measurements in space and time. Adv. Agron. 113, 243-291.

Visconti, F., Miguel de Paz, J., 2016. Electrical conductivity measurements in agriculture: the assessment of soil salinity. In: Cocco, L. (Ed.), New Trends and Developments in Metrology. IntechOpen, pp. 99-126. https://doi.org/10.5772/59388. Open access: available at https://www.intechopen.com/books/new-trends-and-developments-inmetrologyaccessed 20 June 2018.

Vitharana, U.W.A., Meirvenne, M., Cockx, L., Bourgeois, J., 2006. Identifying potential management zones in a layered soil using several sources of ancillary information. Soil Use Manage. 22, 405-413.

Vitharana, U.W.A., Saey, T., Cockx, L., Simpson, D., Vermeersch, H., Van Meirvenne, M., 2008. Upgrading a $1 / 20,000$ soil map with an apparent electrical conductivity survey. Geoderma 148, 107-112.

Vogelmann, J.E., Rock, B.N., Moss, D.M., 1993. Red edge spectral measurements from sugar maple leaves. Int. J. Remote Sens. 14, 1563-1575.

von Hebel, C., Rudolph, S., Mester, A., Huisman, J.A., Kumbhar, P., Vereecken, H., van der Kruk, J., 2014. Three-dimensional imaging of subsurface structural patterns using quantitative large-scale multiconfiguration electromagnetic induction data. Water Resour. Res. 50, 2732-2748. https://doi.org/10.1002/2013WR014864. 
Waine, T.W., Blackmore, B.S., Godwin, R.J., 2000. Mapping available water content and estimating soil textural classs using electro-magnetic induction. In: Proceedings of EurAgEng 2000, Paper No. 00-SW-44.

Walter, J., Lück, E., Bauriegel, A., Richter, C., Zeitz, J., 2015. Multi-scale analysis of electrical conductivity of peatlands for the assessment of peat properties. Eur. J. Soil Sci. 66, 639-650. https://doi.org/10.1111/ejss.12251.

Walter, J., Lück, E., Bauriegel, A., Facklam, M., Zeitz, J., 2018. Seasonal dynamics of soil salinity in peatlands: a geophysical approach. Geoderma 310, 1-11. https://doi.org/ 10.1016/j.geoderma.2017.08.022.

Wang, D., Wilson, C., Shannon, M.C., 2002. Interpretation of salinity and irrigation effects on soybean canopy reflectance in visible and near-infrared spectrum domain. Int. J. Remote Sens. 23 (5), 811-824.

Wang, Q., Li, P., Chen, X., 2012. Modeling salinity effects on soil reflectance under various moisture conditions and its inverse application: a laboratory experiment. Geoderma 170, 103-111. https://doi.org/10.1016/j.geoderma.2011.10.015.

Wang, J., Li, Z., Qin, X., Yang, X., Gao, Z., Qin, Q., 2014. Hyperspectral predicting model of soil salinity in Tianjin costal area using partial least square regression. In: Proceedings of IEEE International Geoscience Remote Sensing Symposium, Quebec City, QC, Canada, July 13-18, 2014. IEEE, Piscataway, NJ, pp. 3251-3254. https://doi.org/10.1109/ IGARSS.2014.6947172.

Watson, H.D., Neely, H.L., Morgan, C.L.S., McInnes, K.J., Molling, C.C., 2017. Identifying subsoil vafriation associated with gilgai using electromagnetic induction. Geoderma 295, 34-40.

Weaver, T., Hulugalle, N., Ghadiri, H., 2013. Estimating drainage under cotton with chloride mass balance and an EM38. Commun. Soil Sci. Plant Anal. 44, 1700-1707. https:// doi.org/10.1080/00103624.2013.783059.

Webb, R.A., 1972. Use of boundary line in the analysis of biological data. J. Hortic. Sci. 47, 309-319.

Wei, J.-B., Xiao, D.-N., Zeng, H., Fu, Y.-K., 2008. Spatial variability of soil properties in relation to land use and topography in a typical small watershed of the black soil region, northeastern China. Environ. Geol. 53, 1663-1672.

Welle, P.D., Mauter, M.S., 2017. High-resolution model for estimating the economic and policy implications of agricultural soil salinization in California. Environ. Res. Lett. 12, Article ID, 094010. https://doi.org/10.1088/1748-9326/aa848c.

Weller, U., Zipprich, M., Sommer, M., Zu Castell, W., Wehrhan, M., 2007. Mapping clay content across boundaries at the landscapescale with electromagnetic induction. Soil Sci. Soc. Am. J. 71 (6), 1740-1747. https://doi.org/10.2136/sssaj2006.0177.

Weng, Y., Gong, P., Zhu, Z.L., 2008a. Soil salt content estimation in the Yellow River Delta with satellite hyperspectral data. Can. J. Remote Sens. 34 (3), 259-270.

Weng, Y., Gong, P., Zhu, Z.L., 2008b. Reflectance spectroscopy for the assessment of soil salt ccontent in soils of the Yellow River Delta of China. Int. J. Remote Sens. 29 (19), 5511-5531. https://doi.org/10.1080/01431160801930248.

Weng, Y.L., Gong, P., Zhu, Z.L., 2010. A spectral index for estimating soil salinity in the Yellow River Delta Region of China using EO-1 Hyperion data. Pedosphere 20 (3), 378-388.

Wenner, F., 1915. A method of measuring Earth resistivity. U.S. Dept. Com. Bureau of Standards Sci. Paper No. 258, NIST, Gaithersburg, MD.

Werban, U., Kuka, K., Merbach, I., 2009. Correlation of electrical resistivity, electrical conductivity and soil parameters at a long-term fertilization experiment. Near Surf. Geophys. 7, 5-14.

West, L.J., Stewart, D.I., Binley, A.M., Shaw, B., 1999. Resistivity imaging of soil during electrokinetic transport. Eng. Geol. 53 (2), 205-215. https://doi.org/10.1016/S00137952(99)00034-4. 
Whiteley, R.J., 1994. Environmental geophysics: challenges and perspectives. Explor. Geophys. 25, 189-196.

Whitney, K., Scudiero, E., El-Askary, H.M., Skaggs, T.H., Allali, M., Corwin, D.L., 2018. Validating the use of MODIS time series for salinity assessment over agricultural soils in California, USA. Ecol. Indic. 93, 889-898. https://doi.org/10.1016/j. ecolind.2018.05.069.

Wiegand, C.L., Everitt, J.H., Richardson, A.J., 1992. Comparison of multispectral video and SPOT-1 HRV observations for cotton affected by soil salinity. Int. J. Remote Sens. $13,1511-1525$.

Wiegand, C.L., Rhoades, J.D., Escobar, D.E., Everitt, J.H., 1994. Photographic and videographic observations for determining and mapping the response of cotton to soil-salinity. Remote Sens. Environ. 49, 212-223.

Wiegand, C.L., Anderson, G., Lingle, S., Escobar, D., 1996. Soil salinity effects on crop growth and yield-illustration of an analysis and mapping methodology for sugarcane. J. Plant Physiol. 148, 418-424.

Williams, B.G., Baker, G.C., 1982. An electromagnetic induction technique for reconnaissance surveys of soil salinity hazards. Aust. J. Soil. Res. 20, 107-118.

Williams, B.G., Braunach, M., 1984. The detection of subsurface salinity within the northern slopes region of Victoria, Australia. In: French, R.H. (Ed.), Salinity in Watercourses and Reservoirs: Proceedings of the 1983 International Symposium on State-of-the-Art Control of Salinity, Salt Lake City, UT, 13-15 July 1983. Butterworth Publishers, Stoneham, MA, pp. 515-524.

Williams, B.G., Fidler, F.T., 1983. The use of electromagnetic induction for locating subsurface saline material. In: Relation of Groundwater and Quality. IAHS Publication No. 146, pp. 189-196. Proceedings of the Hamburg Symposium, August, 1983.

Williams, B.G., Hoey, D., 1987. The use of electromagnetic induction to detect the spatial variability of the salt and clay contents of soils. Aust. J. Soil. Res. 25, 21-27.

Wilson, R.C., Freeland, R.S., Wilkerson, J.B., Yoder, R.E., 2002. Imaging the lateral migration of subsurface moisture using electromagnetic induction. In: ASAE Paper No. 023070. 2002 ASAE Annual International Meeting, 28-31 July 2002, Chicago, IL. ASAE, St. Joseph, MI.

Wilson, R.C., Freeland, R.S., Wilkerson, J.B., Yoder, R.E., 2003. Inferring subsurface morphology from transient soil moisture patterns using electrical conductivity. Trans. ASAE 46, 1435-1441.

Wittler, J.M., Cardon, G.E., Gates, T.K., Cooper, C.A., Sutherland, P.L., 2006. Calibration of electromagnetic induction for regional assessment of soil water salinity in an irrigated valley. J. Irrig. Drain. Eng. 132, 436-444. ASCE.

Wold, S., Sjostrom, M., Eriksson, L., 2001. PLS-regression: a basic tool of chemometrics. Chemom. Intel. Lab. Syst. 58 (2), 109-130. https://doi.org/10.1016/S0169-7439(01) 00155-1.

Wollenhaupt, N.C., Richardson, J.L., Foss, J.E., Doll, E.C., 1986. A rapid method for estimating weighted soil salinity from apparent soil electrical conductivity measured with an aboveground electromagnetic induction meter. Can. J. Soil Sci. 66, 315-321.

Wong, M.T.F., Asseng, S., 2006. Determining the causes of spatial and temporal variability of wheat yields at sub-field scale using a new method of upscaling a crop model. Plant Soil 283, 203-215.

Wong, M.T.F., Asseng, S., Robertson, M.J., Oliver, Y., 2008. Mapping subsoil acidity and shallow soil across a field with information from yield maps, geophysical sensing and the grower. Precis. Agric. 9, 3-15.

World Meteorological Organization, 1997. Comprehensive Assessment of the Freshwater Resources of the World. WMO and Stockholm Environment Institutes, Stockholm, Sweden. 
Wraith, J.M., 2002. Solute content and concentration-indirect measurement of solute concentration - time domain reflectometry. In: Dane, J.H., Topp, G.C. (Eds.), Methods of Soil Analysis. In: Part 4-Physical Methods Soil Science Society of America, Madison, WI, pp. 1289-1297.

Wu, W., 2014. The generalized difference vegetation index (GDVI) for dryland characterization. Remote Sens. (Basel) 6, 1211-1233. https://doi.org/10.3390/rs6021211.

Wu, C.-C., Margulis, S.A., 2011. Real-time soil moisture and salinity profile estimation using assimilation of embedded sensor datastreams. Vadose Zone J. 12 (1). vzj2011.0176https://doi.org/10.2136/vzj2011.0176.

Wu, J., Vincent, B., Yang, J., Bouarfa, S., Vidal, A., 2008. Remote sensing monitoring of changes in soil salinity: a case study in Inner Mongolia, China. Sensors 8, 7035-7049. https://doi.org/10.3390/s8117035.

Wu, W., Al-Shafie, W.M., Mhaimeed, A.S., Ziadat, F., Nangia, V., Payne, W.B., 2014a. Soil salinity mapping by multiscale remote sensing in Mesopotamia, Iraq. IEEE J. Sel. Top Appl.Obs. Remote Sens. 7 (11), 4442-4452. https://doi.org/10.1109/ JSTARS.2014.2360411.

Wu, W., Mhaimeed, A.S., Al-Shafie, W.M., Ziadat, F., Dhehibi, B., Nangia, V., De Pauw, E., 2014b. Mapping soil salinity changes using remote sensing in Central Iraq. Geoderma Reg. 2-3, 21-31.

Wunderlich, T., Petersen, H., al Hagrey, S.A., Rabbel, W., 2013. Pedophysical models for resistivity and permittivity of partially water-saturated soils. Vadose Zone J. 12https:// doi.org/10.2136/vzj2013.01.0023.

Xu, C., Zeng, W., Huang, J., Wu, J., van Leeuwen, W.J., 2016. Prediction of soil moisture content and soil salt concentration from hyperspectral laboratory and field data. Remote Sens. (Basel) 8, 42. https://doi.org/10.3990/rs8010042.

Xue, J., Su, B., 2017. Significant remote sensing vegetation indices: a review of developments and applications. J. Sensors 2017, Article ID, 1353691, 17 pp. https:// doi.org/10.1155/2017/1353691.

Yahiaoui, I., Douaoui, A., Zhang, Q., Ziane, A., 2015. Soil salinity prediction in the Lower Cheliff plain (Algeria) based on remote sensing and topographic feature analysis. J. Arid. Land 7, 794-805. https://doi.org/10.1007/s40333-015-0053-9.

Yan, L., Zhou, S., Wu, C., Feng, L., Li, H., 2007. Optimised spatial sampling scheme for soil electriclal conductivity based on variance quad-tree (VQT) method. Agric. Sci. China 6, 1463-1471.

Yang, C., Everitt, J.H., 2002. Relationships between yield monitor data and airborne multidate multispectral digital imagery for grain sorghum. Prec. Agric. 3 (4), 373-388.

Yang, C., Everitt, J.H., Bradford, J.M., 2007. Airborne hyperspectral imagery and linear spectral unmixing for mapping variation in crop yield. Prec. Agric. 8 (6), 279-296.

Yang, L., Huang, C., Liu, G., Liu, J., Zhu, A.X., 2015. Mapping soil salinity using a similarity-based prediction approach: a case study in Huanghe River Delta, China. Chin. Geogr. Sci. 25 (3), 283-294. https://doi.org/10.1007/s11769-015-0740-7.

Yang, C., Odvody, G.N., Thomasson, J.A., Isakeit, T., Nichols, R.L., 2016. Change detection of cotton root rot infection over 10-year intervals using airborne multispectral imagery. Comput. Electron. Agric. 123, 154-162.

Yao, R., Yang, J., 2010. Quantitative evaluation of soil salinity and its spatial distribution using electromagnetic induction method. Agric. Water Manag. 97, 1961-1970. https://doi.org/10.1016/j.agwat.2010.02.001.

Yao, R.J., Yang, J.S., Liu, G.M., 2007. Calibration of soil elecgtromagnetic conductivity in inverted salinity profiles with an integration method. Pedosphere 17, 246-256.

Yao, Y., Wei, N., Chen, Y., He, Y., Tang, P., 2010. Soil moisture monitoring using hyperspectral remote sensing technology. In: Proceedings of the 2010 Second IITA 
International Conference on Geoscience and Remote Sensing (IITA-GRS), Qingdao, China, 28-31 August 2010, pp. 373-376.

Yao, R.J., Yang, J.S., Zhao, X., Chen, X., Han, J., Li, X., Liu, M., Shao, H., 2012. A new soil sampling design in coastal saline region using EM38 and VQT method. Clean: Soil Air Water 40 (9), 972-979.

Yao, R.J., Yang, J.S., Gao, P., Shao, H.B., Liu, G.M., Yu, S.P., 2014. Comparison of statistical prediction methods for characterizing the spatial variability of apparent electrical conductivity in coastal salt-affected farmland. Environ. Earth Sci. 71, 233-243.

Yao, R.J., Yang, J.S., Wu, D.H., Xie, W.P., Cui, S.Y., Wang, X.P., Yu, S.P., Zhang, X., 2015. Determining soil salinity and plant biomass response for a farmed coastal cropland using the electromagnetic induction method. Comput. Electron. Agric. 119, 241-253.

Yao, R.J., Yang, J.S., Wu, D.H., Xie, W.P., Gao, P., Jin, W.H., 2016a. Digital mapping of soil salinity and crop yield across a coastal agricultural landscape using repeated electromagnetic induction (EMI) surveys. PLoS One 11 (5). e0153377https://doi.org/ 10.1371/journal.pone.0153377.

Yao, R.J., Yang, J.S., Wu, D.H., Xie, W.P., Gao, P., Wang, X.P., 2016b. Geostatisticaal monitorirng of soil salinity for precision management using proximally sensed electromagnetic induction (EMI) method. Environ. Earth Sci. 75, 1362. https://doi.org/ 10.1007/s12665-016-6179-z.

Yemefack, M., Rossiter, D.G., Njomgang, R., 2005. Multi-scale characterization of soil variability within an agricultural landscape mosaic system in southern Cameroon. Geoderma 125, 117-143.

Yu, R., Liu, T., Xu, Y., Zhu, C., Zhang, Q., Qu, Z., Liu, X., Li, C., 2010. Analysis of salinization dynamics by remote sensing in Hetao Irrigation District of North China. Agric. Water Manag. 97, 1952-1960. https://doi.org/10.1016/j.agwat.2010.03.009.

Zalasiewicz, J.A., Mathers, S.J., Cornwell, J.D., 1985. The application of ground conductivity measurements to geological mapping. Q. J. Eng. Geol. 18, 139-148.

Zarco-Tejada, P.J., Ustin, S.L., Whiting, M.L., 2005. Temporal and spatatial relationships between within-field yield variability in cotton and high-spatiaal hyperspectral remote sensing imagery. Agron. J. 97 (3), 641-653.

Zare, E., Huang, J., Santos, F., Triantafilis, J., 2015. Mapping salinity in three dimensions using a DUALEM-421 and electromagnetic inversion software. Soil Sci. Soc. Am. J. 79, 1729-1740.

Zewdu, S., Suryabhagavan, K.V., Balakrishman, M., 2017. Geo-spatial approach for soil salinity mapping in Sego Irrigation Farm, South Ethiopia. J. Saudi Soc. Agric. Sci. $16,16-24$.

Zhang, T.T., Zeng, S.L., Gao, Y., Ouyang, Z.T., Li, B., Fang, C.M., Zhao, B., 2011. Using hyperspectral vegetation indices as a proxy to monitor soil salinity. Ecol. Indic. 11, 1552-1562.

Zhang, T.T., Qi, J.G., Gao, Y., Ouyang, Z.T., Zeng, S.L., Zhao, B., 2015. Detecting soil salinity with MODIS time series VI data. Ecol. Indic. 52, 480-489.

Zheng, Z., Zhang, F., Ma, F., Chai, X., Zhu, Z., Shi, J., Zhang, S., 2009. Spatiotemporal changes in soil salinity in a drip-irrigated field. Geoderma 149, 243-248.

Zhu, Q., Lin, H., Doolittle, J., 2010a. Repeated electromagnetic induction surveys for determining subsurface hydrologic dynamics in an agricultural landscape. Soil Sci. Soc. Am. J. 74, 1750-1762.

Zhu, Q., Lin, H., Doolittle, J., 2010b. Repeated electromagnetic induction surveys for improved soil mapping in an agricultural landscape. Soil Sci. Soc. Am. J. 74, 1763-1774.

Zhu, Q., Lin, H., Doolittle, J., 2013. Functional soil mapping for site-specific soil moisture and crop yield management. Geoderma 200-201, 45-54. 


\section{Further reading}

Aldakheel, Y.Y., Elprince, A., Al-Hosaini, A., 2005. Mapping of salt-affected soils of irrigated lands in arid regions using remote sensing and GIS. In: Proceedings of 2nd International Conference on Recent Advances in Space Technologies (RAST 2005), Istanbul, Turkey, 9-11 June 2005, pp. 467-472.

Corwin, D.L., 2015. Use of advanced information technologies for water conservation on salt-affected soils. In: Mueller, T.G., Sassenrath, G.F. (Eds.), GIS Applications in Agriculture. In: Conservation Planning, vol. 4. Taylor and Francis Group, Boca Raton, FL, pp. 119-150. Chapter 8.

Corwin, D.L., Lesch, S.M., Lobell, D.B., 2012. Chapter 10: Laboratory and field measurements. In: Wallender, W.W., Tanji, K.K. (Eds.), Agricultural Salinity Assessment and Management, second ed. In: ASCE Manuals and Reports on Engineering Practice No. 71 ASCE, New York, NY, pp. 295-341.

Francés, A.P., Lubczynski, M.W., 2011. Topsoil thickness prediction at the catchment scale by integration of invasive sampling, surface geophysics, remote sensing and statistical modeling. J. Hydrol. 405, 31-47.

Guo, Y., Huang, J., Shi, Z., Li, H., 2015. Mapping spatial variability of soil salinity in a coastal paddy field based on electromagnetic sensors. PLoS One 10 (5). e0127996https://doi. org/10.1371/journal.pone.0127996.

Scudiero, E., Skaggs, T.H., Corwin, D.L., 2016c. Comparative regional-scale soil salinity assessment with near-ground apparent electrical conductivity and remote sensing canopy reflectance. Ecol. Indic. 70, 276-284. https://doi.org/10.1016/j.ecolind.2016.06.015. 